INFORME

\title{
Las enfermedades poco frecuentes en los medios Informe Abril - Junio 2014 Observatorio sobre enfermedades raras FEDER (OBSER)
}

\author{
Rare diseases in the media \\ Report April-June 2014 \\ Observatory for Rare Diseases FEDER (OBSER)
}

\section{Coordinadores}

Josep Solves Almela

Antonio Miguel Bañón Hernández

\begin{abstract}
Autores
Àngels Àlvarez Villa, Juan Manuel Arcos Urrutia, Antonio Miguel Bañón Hernández, Carolina Figueras Solanilla, Paz Orero García, Samantha Requena Romero, Inmaculada Rius Sanchis, Sebastián Sánchez Castillo
\end{abstract}

\section{Resumen}

Se presenta el análisis de los resultados del tratamiento que los medios españoles hicieron de las llamadas enfermedades raras durante los meses de abril, mayo y junio del año 2014. Este informe tiene el mismo objetivo general que tenía el primer informe de los tres meses anteriores: comprender cómo presentan estas patologías los medios españoles y, correlativamente, cómo evoluciona esta representación de los medios. En este informe se intenta comparar los datos de aquel primer trimestre con los del ahora objeto de estudio.

Palabras clave: enfermedades raras, medios, España, 2014

\begin{abstract}
This report presents the analysis of how Spanish mass media dealt with the so-called rare deseases during the months of April, May and June of 2014. The report has the same general objective of the first one for the previous three months: understand how rare diseases are presented in the Spanish media and, correspondingly, how that media representation evolves. In this report, the data of the first trimester is compared to the second one.
\end{abstract}

Keywords: rare diseases, media, Spain, 2014

Josep Solves Almela, Universidad Cardenal Herrera, jsolves@uch.ceu.es

Antonio Miguel Bañón Hernández, Universidad de Almería, amhernan@ual.es

Recibido: marzo 2015 / Aceptado: septiembre 2015

\section{Contenidos}

Solves Almela, J. y Bañón Hernández, A.M. (coords.) (2015). Las enfermedades poco frecuentes en los medios. Textos en Proceso 1, pp. 90-236. DOI 10.17710/tep.2015.1.1.5sol 
1. Introducción 93

(POR ANTONIO MIGUEL BAÑÓN HERNÁNDEZ JOSEP SOLVES ALMELA).................................93

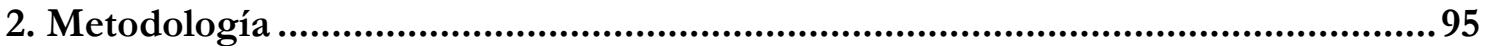

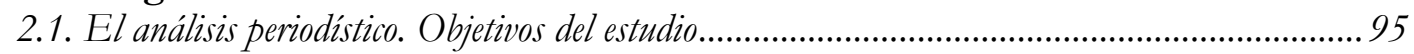

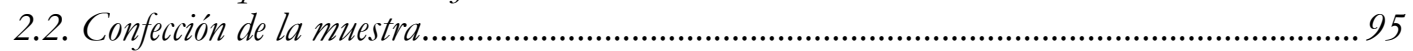

2.3. Unidades de análisis...................................................................................................96

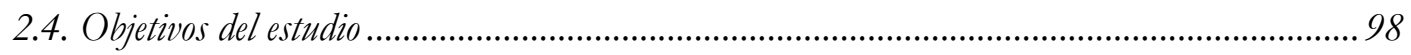

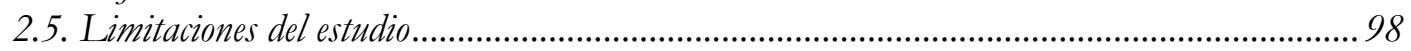

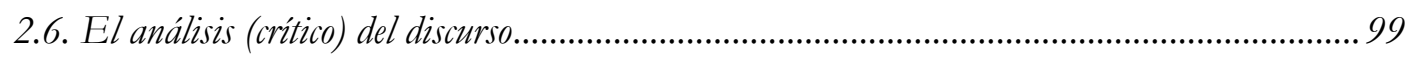

3. Primera parte. Las enfermedades raras en la prensa........................................... 103

(POR INMACULADA RIUS SANCHIS Y PAZ ORERO GARCÍA, UNIVERSIDAD CEU CARDENAL

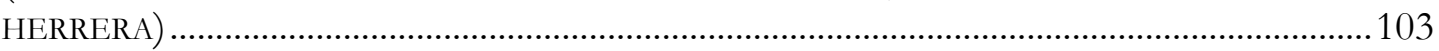

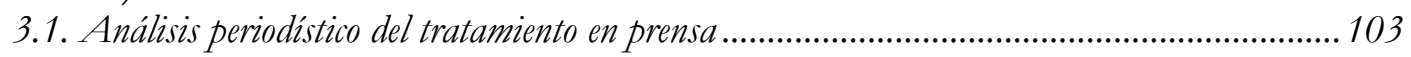

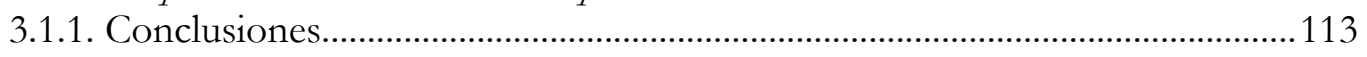

3.2. Análisis del discurso de la prensa española sobre las EPF en abril .................115

(POR ANTONIO M. BAÑÓN HERNÁNDEZ, UNIVERSIDAD DE ALMERÍA, CYSOC)...................115

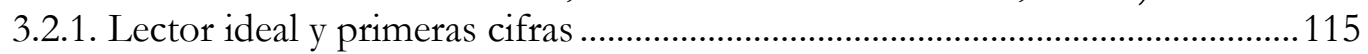

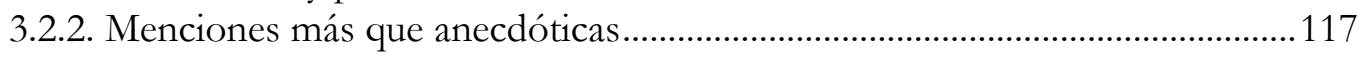

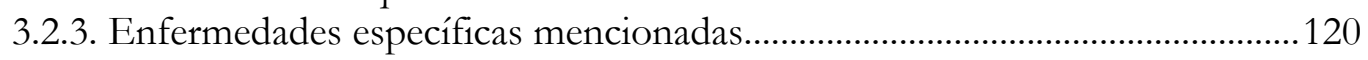

3.2.4. Bloques temáticos y temas principales tratados ...............................................121

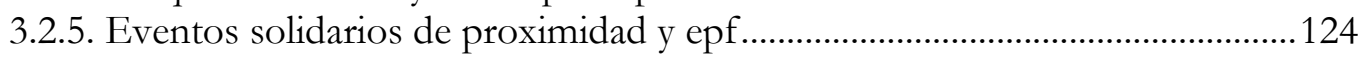

3.2.6. ¿Ser una sociedad que desarrolla actos solidarios a favor de las personas con

EPF significa ser una sociedad necesariamente comprometida con ellas y

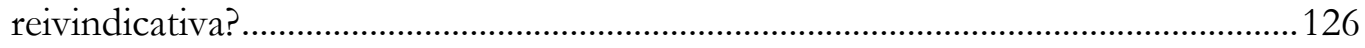

3.2.7. Temas derivados de los eventos de proximidad ................................................... 128

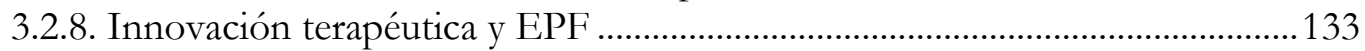

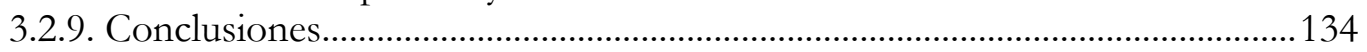

3.3. Análisis del discurso de la prensa española sobre las epf en mayo .................. 136

(POR SAMANTHA REQUENA ROMERO, UNIVERSIDAD DE ALMERÍA) ...................................136

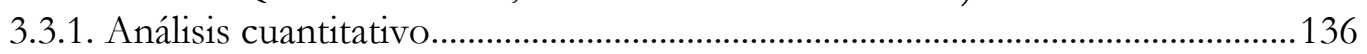

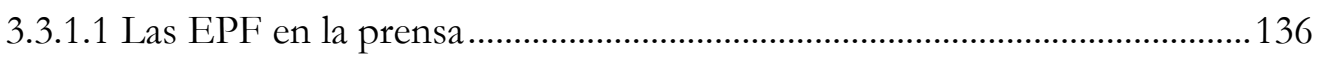

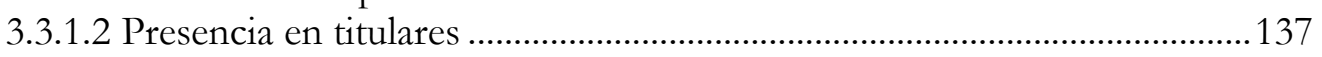

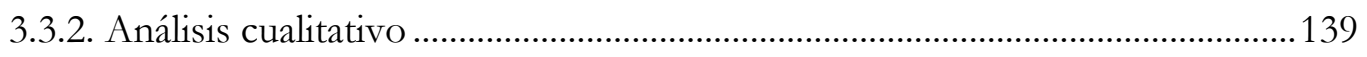

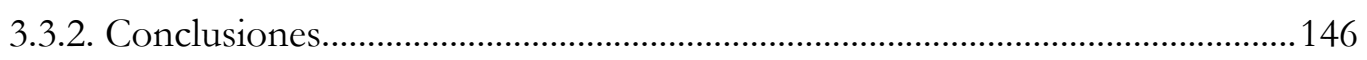

3.4 Análisis del discurso de la prensa española sobre las EPF en junio ................. 146

(POR JUAN MANUEL ARCOS URRUTIA, UNIVERSIDAD DE ALMERÍA, CYSOC) .........................146

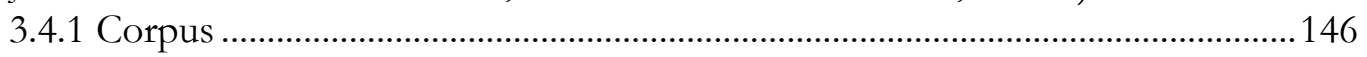

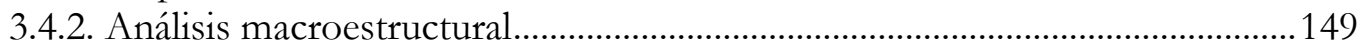

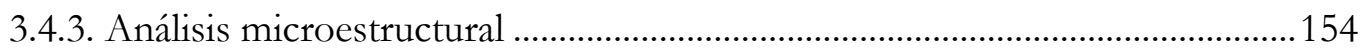

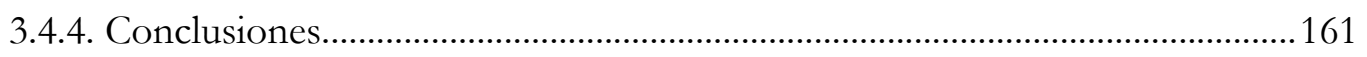

3.5. Análisis multimodal (segundo trimestre 2014) ............................................... 163

(POR CAROLINA FIGUERAS, UNIVERSITAT DE BARCELONA) ..............................................163

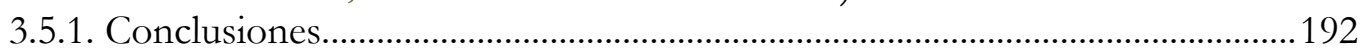

4. Segunda parte. Las enfermedades raras en la salud........................................... 193

(POR ÀNGELS ÁLVAREZ VILLA, UNIVERSIDAD CEU CARDENAL HERRERA)..........................193 


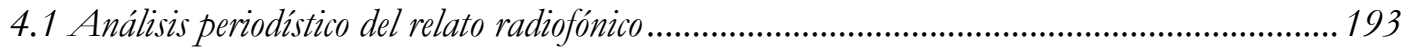

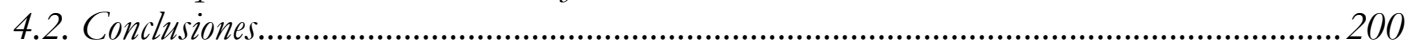

4.2 Análisis del discurso radiofónico sobre las EPF en el mes de mayo................. 201

(POR SAMANTHA REQUENA ROMERO, UNIVERSIDAD DE ALMERÍA) …...............................201

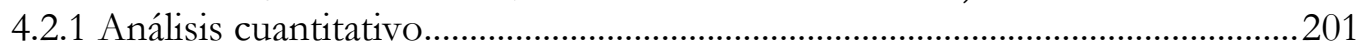

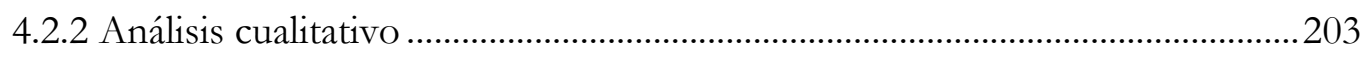

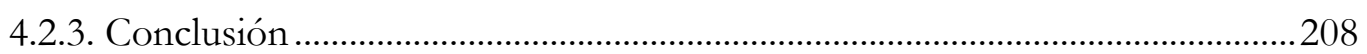

5. Tercera parte. Las enfermedades raras en la televisión ..................................... 208

(POR SEBASTIÁN SÁNCHEZ CASTILLO, UNIVERSITAT DE VALÈNCIA) .....................................208

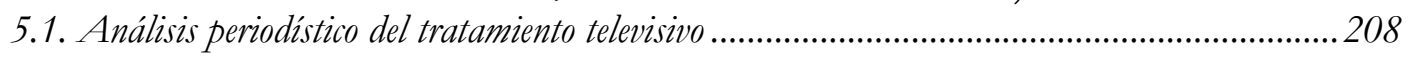

5.1.1. Canal de televisión y localización de las noticias ..................................................209

5.1.2. Medios públicos o privados ................................................................................2210

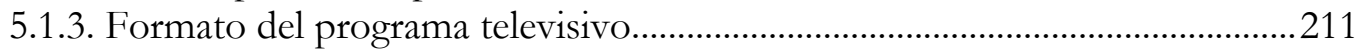

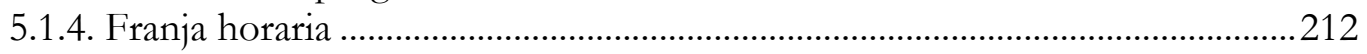

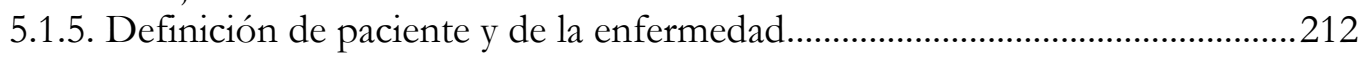

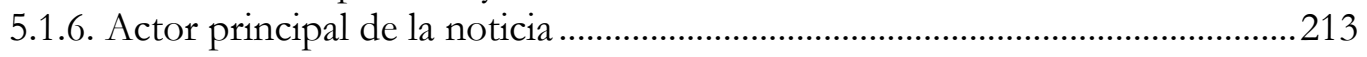

5.1.7 ¿Qué enfermedades se han visibilizado? ..............................................................213

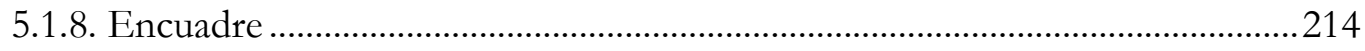

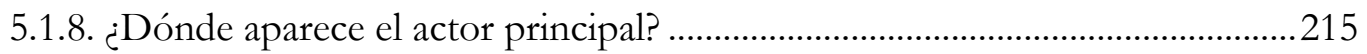

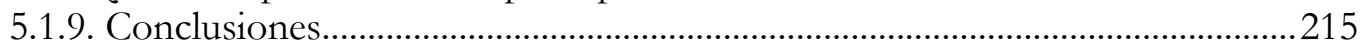

5.2. El discurso de la televisión sobre las EPF en el mes de mayo .......................... 216

(POR SAMANTHA REQUENA ROMERO, UNIVERSIDAD DE ALMERÍA) ...................................216

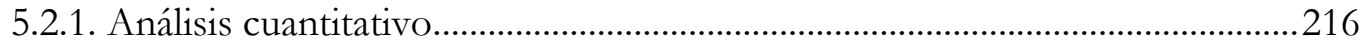

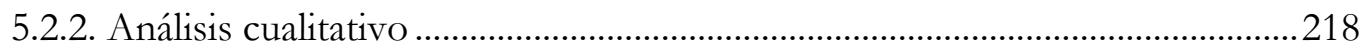

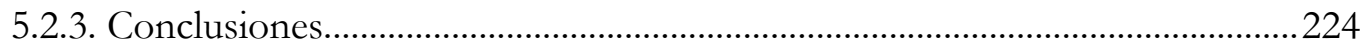

5.3. El discurso de la televisión sobre las EPF. Análisis de un ejemplo de junio de

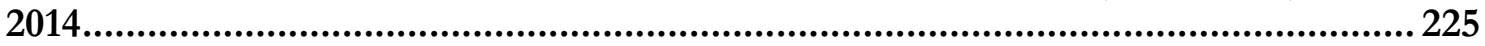

(POR JUAN MANUEL ARCOS URRUTIA, UNIVERSIDAD DE ALMERÍA, CYSOC) ……………....225

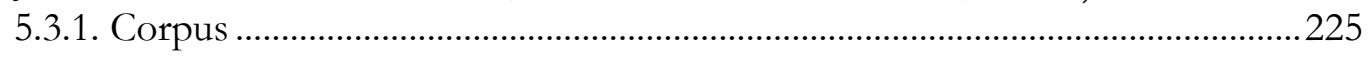

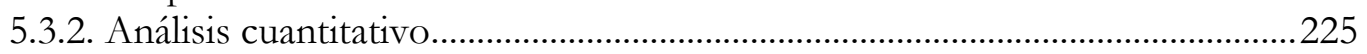

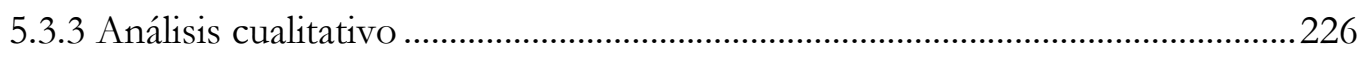

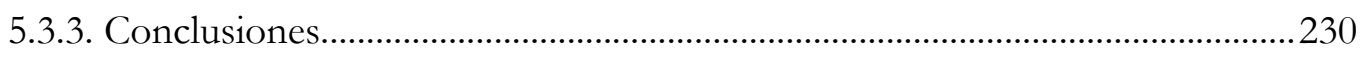

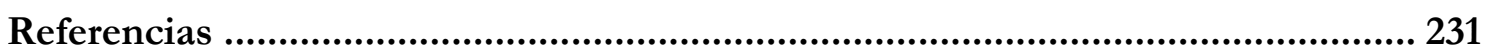




\section{Introducción}

\section{(Por Antonio Miguel Bañón Hernández.Josep Solves Almela)}

En este segundo informe de 2014 presentamos el análisis de los resultados del tratamiento que los medios españoles hicieron de las llamadas enfermedades raras durante los meses de abril, mayo y junio de este año. Con el mismo objetivo general que tenía el primer informe, el que analizaba los tres primeros meses del año: comprender cómo presentan estas patologías los medios españoles y, correlativamente, cómo evoluciona esta imagen que los medios construyen y difunden. Por eso, en general el estudio que ahora presentamos intenta comparar los datos de aquel primer trimestre con los del ahora objeto de estudio.

Hemos incorporado algunas - muy pocas- modificaciones en la ficha que utilizamos para realizar el análisis periodístico y, sobre todo, hemos cambiado el enfoque en la realización y la presentación de los capítulos que constituyen este segundo informe.

En nuestro análisis de los tres primeros meses del año dividimos el informe en dos grandes partes: un análisis cuantitativo que, partiendo de un análisis de contenido, tenía como objetivo comprender el comportamiento de los medios como "instancia profesional", es decir, sus rutinas productivas, reflejadas en datos como los géneros utilizados para informar sobre estas patologías, la firma o no de las piezas, los temas o los protagonistas y fuentes; y un análisis del discurso, que indagaba en "lo oculto bajo lo que se dice", lo que se esconde tras las palabras y frases, y que es realmente lo importante. El primer tipo de análisis lo llevó a cabo básicamente el Grupo de Investigación sobre Discapacidad y Comunicación (GIDYC) de la Universidad CEU Cardenal Herrera y el segundo el grupo ECCO (Estudios Críticos sobre la comunicación) de la Universidad de Almería y la profesora Carolina Figueras, de la Universitat de Barcelona.

En este segundo informe mantenemos estas dos aproximaciones, y sobre todo sus potencialidades, pero se presentan de forma más engarzada o entrelazada, de manera que ya no existe una clara separación entre las metodologías cuantitativas y las cualitativas, sino más bien una aproximación mixta al objeto que no renuncie a las ventajas o posibilidades de ningún método o técnica.

Por eso, en este caso, el informe se divide en tres grandes partes que coinciden con los tres grandes me-dios o soportes analizados (la prensa, la radio y la televisión) y se incluyen en cada una de ellas análisis desde diversas metodologías -cuantitativas unas, cualitativas otras-, con la intención de presentar una visión más comprensiva del objeto. 
Persisten, eso sí, dos grandes enfoques, que provienen de la especialización de los investigadores que han contribuido al informe. En primer lugar, cada medio se analiza desde la perspectiva ya mencionada de la producción de la noticia, es decir, se parte de un análisis de contenido para deducir de él los valores noticia subyacentes a la información: analizamos la presencia o ausencia de las enfermedades raras, pero intentamos sobre todo comprender la importancia que los periodistas otorgan a los acontecimientos que producen estas patologías para comprender la lógica profesional subyacente. Por eso nos centramos en la firma, los géneros o los enfoques. Como ya dijimos en el primer informe de 2014, no se trata tanto de constatar el número de noticias o el tamaño de las piezas, como de indagar en la "importancia" que los profesionales del periodismo -y sus medios- otorgan a las enfermedades de baja prevalencia. A esta aproximación la llamaremos de forma tentativa "análisis periodístico".

En segundo lugar, cada gran soporte -prensa, radio y televisión- se analizan en su “discurso", en lo que dicen a veces sin decirlo, en lo que se deduce por parte del lector, oyente o espectador de lo que los medios dicen, conscientemente o no. Y también en lo que "no se dice", tan importante a veces, o más, como lo que se expresa. Es decir, se les aplica un "análisis crítico del discurso". Y todo ello sin una drástica separación entre lo "cuantitativo" o cuantificable y lo propiamente "cualitativo".

Por eso cada gran parte del informe reúne aproximaciones diversas que aprovechan los distintos recursos de la investigación social para alcanzar el objetivo prioritario: comprender cómo los medios españoles construyen y difunden la imagen de las enfermedades poco frecuentes y de las personas que las tienen.

La primera parte del informe, pues, incluye en primer lugar un análisis periodístico del tratamiento que la prensa española hizo de las patologías minoritarias durante los meses de abril, mayo y junio de 2014 realizado por Inmaculada Rius y Paz Orero, de la Universidad CEU Cardenal Herrera; y a continuación, Antonio Bañón, Samantha Requena y Juan Manuel Arcos, de la Universidad de Almería, realizan tres capítulos en los que se aplica un exhaustivo análisis del discurso de esta misma prensa en los meses de abril, mayo y junio, respectivamente. Esta parte se concluye con un estupendo "análisis multimodal” realizado como ocurriera en nuestro primer informe del año- por Carolina Figueras, de la Universitat de Barcelona, en el que se aplica el análisis del discurso a las "imágenes" publicadas por la prensa española para ilustrar sus informaciones durante este período. 
En la segunda parte, dedicada a la radio, Àngels Álvarez, de la Universidad CEU Cardenal Herrera, se encarga de realizar el análisis periodístico, al tiempo que Samantha Requena realiza el análisis crítico del discurso en las ondas, circunscrito, eso sí, al mes de mayo, que se utiliza en este caso como muestra tipo.

Finalmente, en la tercera parte, Sebastián Sánchez, de la Universitat de València, realiza un análisis periodístico del tratamiento televisivo de las enfermedades poco frecuentes, Samantha Requena realiza el análisis del discurso de este medio durante el mes de mayo y Juan Manuel Arcos aplica este mismo tipo de metodología a un caso concreto producido en el mes de junio: la carrera popular a favor de las enfermedades raras organizada en Almería el 8 de junio del 2014.

\section{Metodología}

\subsection{El análisis periodístico. Objetivos del estudio}

Como en el caso del primer informe del 2014, el objetivo principal de nuestro estudio es partir de un análisis cuantitativo para valorar, no tanto la presencia de las enfermedades raras en los medios españoles, es decir, el número total de noticias, el espacio que ocupan, etc., sino la calidad de dicha información para intentar medir el valor que los medios están otorgando a este tipo de noticias. Por eso, como se verá, nuestro análisis periodístico gira en torno a los datos sobre el género informativo, es decir, el formato que el medio ha decidido dedicarle a la información, firma de las piezas o si estas van acompañadas o no de fotografías. Porque todos ellos son indicadores del interés que los periodistas creen ver en la información que están transformando en noticia.

\subsection{Confección de la muestra}

En el caso de la prensa, para esta aproximación periodística, al igual que hicimos para el análisis del primer trimestre, hemos seleccionado una muestra de las informaciones publicadas por la prensa española sobre enfermedades de baja prevalencia.

El vaciado de prensa nos ofrecía un total de 1.008 noticias en este segundo trimestre. En el mes de abril, se publicaron 255 piezas, es decir, una media de 8 noticias por día, con un único acontecimiento destacado: el 22 de ese mes aparecen 22 piezas a propósito de la candidatura a las elecciones europeas de la Agrupación de Electores Discapacitados y de Enfermedades Raras (DER). En el mes de mayo se publican 430 piezas, una media de 14 noticias por día. El número se explica por dos hechos: 1) se cumplen diez años de Letizia como princesa de Asturias, y por eso la mayor parte de las informaciones corresponden al 
13 de mayo (25 piezas), pero el asunto colea hasta el día 23. 2) Resultado electoral de la agrupación DER en las europeas: días 26 (30 piezas) y 27 de mayo (21 piezas).

En el mes de junio se publican 323 piezas. La causa: Letizia se convierte en reina de España. Hay múltiples perfiles biográficos en los cuales se cita su compromiso con las patologías minoritarias. Las informaciones son un goteo del 3 al 20 de junio. Destacan los días 3 (36 piezas), 19 (14 piezas) y 20 (27 piezas).

Para la confección de la muestra de las informaciones que se analizarán en este segundo informe de 2014 hemos seguido los criterios que utilizamos en nuestro informe del primer trimestre: confeccionar una muestra de 4 semanas, que reúna un número suficiente de piezas para observar adecuadamente las grandes tendencias en los elementos del tratamiento informativo que nos interesan, así como los acontecimientos más relevantes del período analizado.

Teniendo esto en cuenta, la muestra para este segundo informe se concretó del siguiente modo: escogimos para el mes de abril la semana del 21 al 27, que era la $4^{\text {a }}$; para el mes de mayo, la semana del 12 al 18, que era la $3^{\text {a }}$, y la semana del 26 al 31, que era la $5^{\mathrm{a}}$; y para el mes de junio la semana del 2 al 8 , que era la $2^{\text {a }}$. De este modo, formábamos un mes entero de muestra, representado por semanas de todos los períodos del mes construido, al tiempo que garantizábamos la observación de la prensa ante los acontecimientos más relevantes del trimestre. La muestra, además, era casi idéntica en número de días a la que utilizamos para el primer semestre.

\subsection{Unidades de análisis}

Como en nuestro primer informe de 2014, para la confección de la muestra se ha utilizado el clipping, es decir, la reunión de noticias sobre enfermedades raras confeccionado para FEDER por la empresa Accceso Group. O sea, las piezas periodísticas que incluyen en su texto la expresión "enfermedad/es rara/s" o expresiones sinónimas. Hemos considerado unidad de análisis todo texto encabezado por un titular, excepto aquellos textos que forman parte de otra pieza y suponen el desarrollo de algún aspecto de la misma, es decir, los "despieces".

Teniendo en cuenta los criterios para la muestra, en total, se han codificado para este trimestre 252 piezas. De ellas, 4 aparecían en portada, (La Verdad de Cartagena 26/04/2014; Diario de Almería 14/05/2014; y Diari de Terrassa 31/05/2014 y 07/06/2014); y 1 era portada de la sección de deportes (Diario de Almería 08/06/2014). 
En nuestro anterior informe seleccionamos para la muestra únicamente aquellas piezas textuales que incluían estas patologías como tema principal y se descartaron aquellas en las que se hacía mención a ellas de forma tangencial, es decir: menciones en las páginas de cultura o en la programación de televisión, en apartados como "suben y bajan", o en las que se mencionan estas patologías sin tratar la pieza en absoluto sobre ellas. En esta ocasión hemos descartado también estas piezas que podemos denominar "referencias tangenciales", pero las hemos contabilizado aparte porque consideramos, como explicaremos después, que tienen su importancia: son un claro síntoma de que las patologías de baja prevalencia se han convertido para los periodistas en una cuestión a tener en cuenta cuando se habla de "otras cosas" que, en principio, no tienen que ver con ellas directamente.

En esta situación de "referencia tangencial" hemos contabilizado un total de 89 piezas. La distribución concreta es: 30 de temas varios (a veces se cuelan textos en los que se indica que de lo que se habla "NO es una enfermedad rara"), 23 referidas al análisis electoral de las europeas en las que la mención a las ER se reduce a la infografía o tabla con los porcentajes de votos obtenidos por cada partido (los textos sobre la candidatura y resultados sí que están analizados) y 36 se refieren a la princesa/reina Letizia. Hemos descartado los perfiles biográficos con una extensión de dos o más páginas en los que la referencia a su vinculación con las ER ni siquiera ocupaba una frase. Aquellas noticias o reportajes en los que la mención es más robusta sí se han incluido en el análisis.

Respecto a la denominación de la enfermedad, optamos por agruparlas en dos grandes categorías: las noticias que remiten al ámbito semántico de lo extraño o raro (enfermedad rara) y aquellas que remiten más bien a la baja prevalencia (enfermedad minoritaria). La inmensa mayoría de las piezas se han ajustado a una u otra opción o a ambas. Sólo hay 7 casos en los que la enfermedad se denomina de manera concreta y no se utiliza ninguna de esas dos expresiones o similares. $\mathrm{Y}$ destacamos otros 5 casos en los que, a pesar de haber catalogado la pieza en uno de los grupos mencionados, como "rara" o "minoritaria", se la denomina también como "mal". Son: Viva Cádiz 22/04/2014 ("dicho mal"); Ideal de Granada 27/04/2014 ("la cura de este mal"); 3) Pronto 07/06/2014 ("los niños afectados por males atípicos"); Deia 04/06/2014 ("contra el mal"); y Diario de noticias de Álava 04/06/2014 ("una cura a estos males").

Las tablas de análisis que utilizamos en nuestro informe del primer trimestre de 2014 se han ajustado bastante bien a lo que se publica. Sin embargo, hemos hecho algunas 
modificaciones para ajustarlas mejor a nuestras necesidades de análisis, una vez testadas en aquel primer estudio.

Así pues, cada una de estas unidades de análisis ha sido codificada atendiendo a las fichas que se detallan en las tablas 1 a 3 de esta introducción y los datos se han tratado posteriormente con los programas informáticos Microsoft Excel y SPSS.

Para este tipo de análisis, en el caso de las piezas de radio y televisión hemos incluido todas las referencias, sin excepción, como también hiciéramos en el primer informe. De manera que el análisis de los medios audiovisuales se basa en el universo de las noticias que estos medios emitieron en España durante los tres meses observados y no en una muestra.

\subsection{Objetivos del estudio}

Como también ocurría en el anterior informe, el objetivo principal de nuestro estudio es partir de un análisis cuantitativo para valorar, no tanto la presencia de las enfermedades raras en los medios españoles, es decir, el número total de noticias, el espacio que ocupan, etc., sino la calidad de dicha información para intentar medir el valor que los medios están otorgando a este tipo de noticias.

Por eso, como se verá, nuestro estudio gira en torno a los datos sobre el género informativo, es decir, el formato que el medio ha decidido dedicarle a la información, firma de las piezas o si estas van acompañadas o no de fotografías. Porque todos ellos son indicadores del interés que los periodistas creen ver en la información que están transformando en noticia.

\subsection{Limitaciones del estudio}

En nuestro estudio no pueden ser computadas las fuentes que no se citan en los textos, por más que sospechemos que se trata de reproducciones o copias de teletipos de agencia o por mucho que se note que tras la información hay personas o asociaciones e instituciones concretas.

Un total de 46 registros no contienen sección. De esas 46 noticias, 43 ya venían de origen en el vaciado de prensa con "sección: otros", mientras que las otras 3 corresponden a la contraportada, que no la teníamos incluida en el libro de códigos. Estos detalles se tendrán en cuenta en el próximo informe. 


\subsection{El Análisis (Crítico) del Discurso}

Nuestro análisis cualitativo está basado preferentemente en la aproximación conocida como Análisis (Crítico) del Discurso, que busca conocer la construcción simbólica de quienes participan en debates sobre asuntos socialmente relevantes. Uno de esos asuntos, naturalmente, es la salud. Y, dentro de ella, las enfermedades poco frecuentes y las personas y grupos vinculados de alguna manera a ellas. En este análisis valoraremos mensajes unimodales (escritos u orales) y también multimodales (audiovisuales, por un lado, y de interrelación de palabra escrita e imagen fija, por otro).

El proceso de análisis es complejo y se refleja en tres tipos de estructura: a) la macroestructura (temas globales y temas específicos); b) la microestructura (procesos retóricoargumentativos y categorías gramaticales); y c) la superestructura (factores contextuales y esquemas de género). La conjunción de todas ellas conforma la base de aproximaciones teórico-metodológicas que han resultado muy útiles para el análisis (crítico) del discurso. Naturalmente, no son estructuras independientes entre sí. Al contrario. En todo caso, su consideración autónoma facilita el análisis.

Por un lado, al analizar la microestructura textual, es básico aludir a las estructuras estilísticas. En este sentido, destaca el papel relevante que desempeña el concepto de elección de unas unidades o categorías fónicas, gráficas, léxico-semánticas o morfo-sintácticas en lugar de otras. En efecto, continuamente elegimos unas variantes estilísticas y rechazamos otras opciones posibles. Y cada elección de una variante determinada tiene una función. Opciones, variantes y funciones van asociadas a determinados contextos, a determinadas situaciones y también a ciertos tipos textuales. Por otro lado, no sólo la producción implica la selección de variantes; también quién recibe el mensaje tiene diversas opciones interpretativas.

El tipo de estilo utilizado está directamente relacionado con las reglas y con las estrategias discursivas. Las variantes estilísticas y las estrategias discursivas han de ser analizadas a partir de un determinado género comunicativo. En nuestro caso, la pieza informativa de prensa, radio o televisión. Los periodistas no pueden suprimir fácilmente sus creencias y actitudes hacia las personas y hacia las acciones sobre las que informan. Aparecen, de hecho, reflejadas en el texto de muchas maneras: selección de temas, elaboración de los mismos, jerarquías de relevancia, uso de categorías esquemáticas y palabras elegidas para describir los hechos.

La pieza informativa tiene, como otros muchos tipos de discurso, una organización esquemática y su aprendizaje forma parte del proceso de socialización. En el caso de la 
prensa, la parte más relevante de esta organización esquemática es el titular y, a continuación, el encabezamiento, que normalmente se distingue por un tipo especial de letra.

El Análisis Crítico del Discurso ha sabido aprovechar la rentabilidad que para el análisis textual tiene la combinación de las perspectivas cuantitativas y cualitativas.

Los medios de comunicación tienen una doble función: la primera es presentar los discursos y las acciones de los distintos actores sociales que participan en el debate público sobre un tema. La segunda es representarse a sí mismos (de forma explícita o implícita) al hablar sobre esos actores y sobre sus acciones. Ambas miradas son de interés para nuestro análisis discursivo.

En relación a la cantidad de piezas analizadas con esta metodología, se han incluido en el estudio todas las publicadas o emitidas por los medios españoles, según el antes mencionado clipping de FEDER, en cada período de análisis, sin descartar ninguna.

Tabla 1. Ficha de prensa

\begin{tabular}{|c|c|}
\hline 1. Medio & Nombre del medio \\
\hline 2. Fecha & $\mathrm{dd} / \mathrm{mm} / \mathrm{aaaa}$ \\
\hline 3. Sección & $\begin{array}{l}\text { 1= Sociedad; } 2=\text { Sanidad/investigación; } 3=\text { Sucesos; } 4=\text { Regio- } \\
\text { nal/local; } 5=\text { Nacional/España/Política; } 6=\text { Internacional; } \\
7=\text { Opinión; } 8=\text { Economía; } 9=\text { Suplemento; } 10=\text { Cultura, depor- } \\
\text { tes/espectáculos }\end{array}$ \\
\hline 4. Réplica de Pieza & $\begin{array}{l}0=\text { Ninguna; } 1=\text { Una réplica; } 2=\text { Dos réplicas; } 3=\text { Tres réplicas; } \\
4=4+\end{array}$ \\
\hline 5. Género & $\begin{array}{l}1=\text { Breve; } 2=\text { Noticia } ; 3=\text { Reportaje; } 4=\text { Entrevista } ; 5=\text { Opinión; } \\
6=\text { Editorial }\end{array}$ \\
\hline 6. Firma del texto & $\begin{array}{l}1=\text { Agencia; } 2=\text { Firma del autor; } 3=\text { Firma del medio; } 4=\text { No } \\
\text { consta }\end{array}$ \\
\hline 7. Apoyo gráfico & $0=\mathrm{No} ; 1=\mathrm{Sí}$ \\
\hline 8. $\mathrm{N}^{\circ}$ fotos o gráficos & $0=$ Ninguno $; 1=1 ; 2=2 ; 3=3 \mathrm{o}+$ \\
\hline 9. Aparece afectado en foto & $0=\mathrm{No} ; 1=\mathrm{Sí}$ \\
\hline $\begin{array}{l}\text { 10. Categorías temáticas explícitas } \\
\text { (investigación Científica/descubrimiento; } \\
\text { Cuestiones económicas; reivindicación y/o } \\
\text { inversión; Actos sociales/eventos; Historia } \\
\text { de vida; Decisiones políticas; Educación; } \\
\text { Medicamentos huérfanos; Sin diagnóstico) } \\
\end{array}$ & $0=\mathrm{No} ; 1=\mathrm{Sí}$ \\
\hline 11. Encuadres & $\begin{array}{l}\text { 1= Como realidad social (interés humano, solidaridad, historias } \\
\text { de vida, etc.); } 2=\text { Como enfermedad especializada (cuestión } \\
\text { técnica o clínica, cuestiones de investigación, etc.); } 3=\text { Como } \\
\text { conflicto político }\end{array}$ \\
\hline 12. Localización noticia & $\begin{array}{l}\text { 1=Andalucía; } 2=\text { Aragón; } 3=\text { Canarias; } 4=\text { Castilla y León; } 5=\text { Cas- } \\
\text { tilla la Mancha; } 6=\text { Cataluña; } 7=\text { Comunidad de Madrid; } 8=\text { Co- } \\
\text { munidad Foral de Navarra; } 9=\text { Comunidad Valenciana; } 10=\text { Can- } \\
\text { tabria; } 11=\text { Extremadura; } 12=\text { Galicia; } 13=\text { Islas Baleares ; 14=La } \\
\text { Rioja; 15=País Vasco; 16=Principado de Asturias; 17=Región de } \\
\text { Murcia; 18=Ceuta; 19=Melilla; 20=Otros países; 21=Sin locali- } \\
\text { zar; 22=España }\end{array}$ \\
\hline & $0=\mathrm{No} ; 1=\mathrm{Sí}$ \\
\hline
\end{tabular}




\begin{tabular}{|l|l|}
\hline $\begin{array}{l}\text { 13. Fuentes (Institucionales; Asociaciones } \\
\text { y/o Fundaciones; Médicos/Personal sani- } \\
\text { tario; Investigadores/científicos; Afectados } \\
\text { y/o familiares; Publicaciones científicas) }\end{array}$ & \\
\hline $\begin{array}{l}\text { 14. Actor principal (Institucional; Médi- } \\
\text { cos/personal sanitario; Científicos/Investi- } \\
\text { gadores; Pacientes; Familiares; Personajes }\end{array}$ & $0=$ No; $1=$ Sí \\
Famosos; Asociaciones; Voluntarios; FE- & \\
$\begin{array}{l}\text { DER; Niño/a) NOTA: NO SEÑALAR } \\
\text { MÁS DE 2 }\end{array}$ & \\
\hline $\begin{array}{l}\text { 15. Denominación del paciente (En- } \\
\text { fermo/a; Paciente; Afectado/a; Niño/a } \\
\text { Dependiente; Discapacitado/a; Otras de- } \\
\text { nominaciones; No se nombra al sujeto) }\end{array}$ & $0=$ No; $1=$ Sí \\
\hline $\begin{array}{l}\text { 16. Definición de la Enfermedad (Enfer- } \\
\text { medad Rara; Enfermedad Minoritaria; En- } \\
\text { fermedad Extraña; Patología; Síndrome; }\end{array}$ & $0=$ No; $1=$ Sí \\
Trastorno; Enfermedad; Ninguna Defini- \\
ción)
\end{tabular}

Tabla 2. Ficha de radio

\begin{tabular}{|c|c|}
\hline Medio & Nombre del medio \\
\hline 1. Nombre del programa & \\
\hline 2. Género & $\begin{array}{l}\text { 1=Boletín horario; } 2=\text { Diario Hablado; } 3=\text { Magazín generalista; 4=Magazín es- } \\
\text { pecializado; } 5=\text { Otro }\end{array}$ \\
\hline $\begin{array}{l}\text { 3. Franja horaria de la emi- } \\
\text { sión }\end{array}$ & 1=Mañana $; 2=$ Mediodía $; 3=$ Tarde $; 4=$ Noche $; 5=$ Madrugada \\
\hline 4. Ámbito de difusión & 1=Local; 2=Autonómico; 3=Estatal \\
\hline 5. Día de emisión & 1=Entre semana; $2=$ Fin de semana \\
\hline 6. Tipología de la emisora & $1=$ Pública; $2=$ Privada \\
\hline 2. Fecha & $\mathrm{dd} / \mathrm{mm} / \mathrm{aaaa}$ \\
\hline 3. Género & $\begin{array}{l}\text { 1= Noticia; } 2=\text { Organización de la polémica (debate, tertulia, mesa redonda, } \\
\text { coloquio); } 3=\text { Reportaje; } 4=\text { Entrevista; } 5=\text { Opinión (comentario, crónica, crí- } \\
\text { tica); } 6=\text { Editorial; } 7=\text { Informe }\end{array}$ \\
\hline $\begin{array}{l}\text { 4. Firma del texto: locución } \\
\text { del texto }\end{array}$ & $1=$ Aparece nombre del locutor $; 2=$ No consta \\
\hline 5. Apoyo sonoro & $0=\mathrm{No} ; 1=\mathrm{Sí}$ \\
\hline -Corte de voz & $0=\mathrm{No} ; 1=\mathrm{Sí}$ \\
\hline -Sonido ambiente (efectos) & $0=$ No; $1=$ Sí \\
\hline -Música & $0=$ No; $1=$ Sí \\
\hline 6. $\mathrm{N}^{\circ}$ cortes de voz & $0=$ Ninguno $; 1=1 ; 2=2 ; 3=3 \mathrm{o}+$ \\
\hline $\begin{array}{l}\text { 7. Aparece afectado en } \\
\text { corte de voz o declaración }\end{array}$ & $0=\mathrm{No} ; 1=\mathrm{Sí}$ \\
\hline $\begin{array}{l}\text {-Identidad del protagonista } \\
\text { del corte }\end{array}$ & $\begin{array}{l}\text { 1= Institucionales; } 2=\text { Asociaciones y/o Fundaciones; } 3=\text { Médicos/ Personal } \\
\text { sanitario; } 4=\text { Investigadores/científicos; } 5=\text { Afectados y/o familiares; } 6=\mathrm{Pu}- \\
\text { blicaciones científicas }\end{array}$ \\
\hline \multirow[b]{2}{*}{$\begin{array}{l}\text { 8. Categorías temáticas ex- } \\
\text { plícitas }\end{array}$} & $0=\mathrm{No} ; 1=$ Sí \\
\hline & $\begin{array}{l}\text { 1= Investigación científica/descubrimiento; } 2=\text { Cuestiones económicas reivin- } \\
\text { dicación y/o inversión; } 3=\text { Actos sociales } / \text { eventos; } 4=\text { Historia de vida; } 5= \\
\text { Decisiones políticas; } 6=\text { Educación; } 7=\text { Medicamentos huérfanos; } 8=\operatorname{Sin} \\
\text { diagnóstico }\end{array}$ \\
\hline 9. Encuadres & $\begin{array}{l}\text { 1= Como realidad social (interés humano, solidaridad, historias de vida, etc.); } \\
2=\text { Como enfermedad especializada (cuestión técnica o clínica, cuestiones } \\
\text { de investigación, etc.); } 3=\text { Como conflicto político }\end{array}$ \\
\hline
\end{tabular}




\begin{tabular}{|c|c|}
\hline 10. Localización noticia & $\begin{array}{l}\text { 1=Andalucía; } 2=\text { Aragón; } 3=\text { Canarias; } 4=\text { Castilla y León; } 5=\text { Castilla la Man- } \\
\text { cha; } 6=\text { Cataluña; } 7=\text { Madrid; } 8=\text { Navarra; } 9=\text { C. Valenciana; } 10=\text { Cantabria; } \\
\text { 11=Extremadura; } 12=\text { Galicia; } 13=\text { Islas Baleares; 14=La Rioja; 15=País Vasco; } \\
\text { 16=Asturias; } 17=\text { Región de Murcia; 18=Ceuta; 19=Melilla; 20=Otros países; } \\
\text { 21=Sin localizar; 22=España }\end{array}$ \\
\hline \multirow[b]{2}{*}{ 11. Fuentes } & $0=\mathrm{No} ; 1=\mathrm{Sí}$ \\
\hline & $\begin{array}{l}\text { 1= Institucionales; } 2=\text { Asociaciones y/o Fundaciones; } 3=\text { Médicos } / \text { Personal } \\
\text { sanitario; } 4=\text { Investigadores/científicos; } 5=\text { Afectados y/o familiares; } 6=\mathrm{Pu}- \\
\text { blicaciones científicas }\end{array}$ \\
\hline \multirow[b]{2}{*}{ 12. Actor principal } & $0=\mathrm{No} ; 1=\mathrm{Sí}$ \\
\hline & $\begin{array}{l}\text { 1= Político; } 2=\text { Médicos o personal sanitario; } 3=\text { Científicos y/o investigado- } \\
\text { res; } 4=\text { Pacientes; } 5=\text { Familiares; } 6=\text { Personajes públicos (todos los famosos); } \\
7=\text { Asociaciones; } 8=\text { Voluntarios; } 9=\text { FEDER }\end{array}$ \\
\hline \multirow{2}{*}{$\begin{array}{l}\text { 13. Denominación del pa- } \\
\text { ciente }\end{array}$} & $0=$ No; $1=$ Sí \\
\hline & $\begin{array}{l}1=\text { Enfermo } / \mathrm{a} ; 2=\text { Paciente; } 3=\text { Afectado } / \mathrm{a} ; 4=\text { Niño } / \mathrm{a} ; 5=\text { Dependiente; } 6= \\
\text { Discapacitado } / \mathrm{a} ; 7=\text { Otras denominaciones; } 8=\text { No se nombra al sujeto }\end{array}$ \\
\hline \multirow[b]{2}{*}{$\begin{array}{l}\text { 14. Definición de la Enfer- } \\
\text { medad }\end{array}$} & $0=\mathrm{No} ; 1=\mathrm{Sí}$ \\
\hline & $\begin{array}{l}\text { 1= Enfermedad Rara; } 2=\text { Enfermedad Minoritaria; } 3=\text { Enfermedad Extraña; } \\
4=\text { Patología; } 5=\text { Síndrome; } 6=\text { Trastorno; } 7=\text { Enfermedad; } 8=\text { Ninguna De- } \\
\text { finición }\end{array}$ \\
\hline
\end{tabular}

Tabla 3. Códigos y variables para TELEVISIÓN

\begin{tabular}{|c|c|}
\hline 1. Fecha & $\mathrm{dd} / \mathrm{mm} / \mathrm{aaaa}$ \\
\hline 2. Canal & $\begin{array}{l}\text { Antena 3; BTV; Canal 9; Canal Sur; Cuatro; ETB; ETB2; Intereconomía; } \\
\text { La 2; La Sexta; Tele 5; Telemadrid; TV Bilbao; TV3; TVE1; TVG; Otras; }\end{array}$ \\
\hline $\begin{array}{l}\text { 3. Localización de la } \\
\text { noticia }\end{array}$ & $\begin{array}{l}\text { 1=Andalucía; } 2=\text { Aragón; } 3=\text { Canarias; } 4=\text { Castilla y León; } 5=\text { Castilla la } \\
\text { Mancha; } 6=\text { Cataluña; } 7=\text { Madrid; } 8=\text { Navarra; } 9=\text { C. Valenciana; } \\
\text { 10=Cantabria; } 11=\text { Extremadura; } 12=\text { Galicia; } 13=\text { Islas Baleares; } 14=\mathrm{La} \\
\text { Rioja; } 15=\text { País Vasco; } 16=\text { Asturias; } 17=\text { Región de Murcia; } 18=\text { Ceuta; } \\
\text { 19=Melilla; 20=Otros países; } 21=\text { Sin localizar; 22=España }\end{array}$ \\
\hline 4. Carácter del canal & 1=Pública; $2=$ Privada \\
\hline 5. Formato & 1. Informativo; 2. Magazine; 3. Divulgativo \\
\hline 6. Horario & 1. Matinal; 2. Mediodía; 3. Tarde/noche \\
\hline 7. Definición del paciente & $\begin{array}{l}1=\text { Enfermo } / \mathrm{a} ; 2=\text { Paciente } 3=\text { Afectado } / \mathrm{a} ; 4=\mathrm{Niño} / \mathrm{a} ; 5=\text { Dependiente; } \\
6=\text { Discapacitado } / \mathrm{a} ; 7=\text { Otras denominaciones; } 8=\text { No se nombra al } \\
\text { sujeto }\end{array}$ \\
\hline 8. Actor principal & $\begin{array}{l}\text { 1= Político; } 2=\text { Médicos o personal sanitario; } 3=\text { Científicos y } / o \\
\text { investigadores; } 4=\text { Pacientes; } 5=\text { Familiares; } 6=\text { Personajes públicos (todos } \\
\text { los famosos); } 7=\text { Asociaciones; } 8=\text { Voluntarios; } 9=\text { FEDER; } 10=\text { Niño } / \mathrm{a}\end{array}$ \\
\hline $\begin{array}{l}\text { 9. Definición de la } \\
\text { enfermedad }\end{array}$ & $\begin{array}{l}0=\text { No se indica; } 1=\text { Enfermedad Minoritaria; } 2=\text { Enfermedad Rara; } \\
3=\text { Extraña enfermedad; } 4=\text { Patología; } 5=\text { Síndrome; } 6=\text { Trastorno; } \\
7=\text { Enfermedad }\end{array}$ \\
\hline 10. Encuadres & $\begin{array}{l}\text { 1= Como realidad social (interés humano, solidaridad, historias de vida, } \\
\text { etc.); } 2=\text { Como enfermedad especializada (cuestión técnica o clínica, } \\
\text { cuestiones de investigación, etc.); } 3=\text { Como conflicto político }\end{array}$ \\
\hline $\begin{array}{l}\text { 11. Lugar de aparición de } \\
\text { personaje principal }\end{array}$ & $\begin{array}{l}1=\text { Centros de salud y/o rehabilitación; } 2=\text { Centros educativos; } 3=\text { En la } \\
\text { calle; } 4=\text { Hogar familiar; } 5=\text { Instalaciones de ocio y/o deporte; } 6=\text { Otros }\end{array}$ \\
\hline $\begin{array}{l}\text { 12. Duración vídeo: en } \\
\text { segundos }\end{array}$ & \\
\hline
\end{tabular}




\section{Primera Parte. Las enfermedades raras en la prensa}

\subsection{Análisis periodístico del tratamiento en prensa}

(Por Inmaculada Rius Sanchis y Paz Orero Garcia, Universidad CEU Cardenal Herrera)

En este apartado se dan a conocer los resultados cuantitativos de la cobertura informativa que la prensa española realizó acerca de las Enfermedades Minoritarias, en el segundo trimestre del año. Dado el volumen que la totalidad de la muestra ofrecía, se escogieron para el presente estudio, como se indicaba en la Introducción, semanas representativas de cada uno de los tres meses. De esta forma, en abril fueron analizados los días del 21 al 27, es decir, la cuarta semana. Para el mes de mayo, se han analizado dos semanas: la del 12 al 18, que fue la $3^{\text {a }}$, y la del 26 al 31, que fue la $5^{\mathrm{a}}$; y para el mes de junio la semana del 2 al 8, que fue la segunda del mes. La muestra, pues, reunía 27 días. En este período, un total de 95 cabeceras publicaron, en conjunto, 252 piezas relativas a estas enfermedades. A continuación presentamos los resultados distribuidos por tablas.

La primera conclusión que se extrae hace referencia a la prensa española que más apuesta por informar sobre las Enfermedades Poco Frecuentes (tabla 1), siendo la prensa local/regional mayoritaria - una vez más-, frente a los periódicos generalistas, algunos de los cuales como $A B C$, La Vanguardia, $A S$ en este trimestre no publican información alguna. Por lo que respecta a los diarios El Mundo y 20 Minutos computaban sus resultados agrupados entre la edición nacional y algunas de carácter local. Los tres primeros puestos los ocupan: Diario de Noticias (11 piezas informativas), Correo Farmacéutico (9) y La Opinión de Murcia (9), desbancando de sus puestos a los rotativos que en el trimestre anterior habían sido los tres primeros (ABC, Diario de Burgos y La Tribuna de Albacete en esta ocasión, con 0, 6 y 3 inserciones).

La novedad del diario Deia, entrando por vez primera en el cuadro de registro en nuestro primer informe de este año, se mantiene para los asentamientos de abril-junio, ahora con 7 inserciones. Si comparamos los datos del presente trimestre con el anterior observamos dos datos:

En primer lugar, aunque en ambos casos trabajamos sobre muestras, y no sobre el total de las piezas localizadas, es de destacar la bajada en el número de inserciones, es decir, en el número de noticias publicadas sobre Enfermedades de Baja Prevalencia, cae de 495 a 252. Es decir, un $50 \% 9 \%$. Ello se debe sin duda a las actividades informativas de relevancia mediática que tuvieron lugar entre los meses de enero a marzo: Día Mundial de las Enfermedades Raras, sesión del Senado con la asistencia de la por entonces Princesa Letizia 
y la entrega de Premios FEDER; y la febril actividad en torno a dichas fechas de todas las asociaciones, incluida la Federación que las aglutina. A ello hemos de sumar la resaca navideña y el telemaratón organizado por FEDER, ASEM y Fundación Isabel Gemio.

Y en segundo lugar, del mismo modo que registramos "bajas" en el listado de diarios que el trimestre anterior facilitaron informaciones sobre el tema y ahora no; también aparecen nuevas cabeceras en el registro: 20 Minutos, Viva Cádiz, Mujer Hoy; Motociclismo; La Rioja; Granada Hoy, El Punt Avuí, El Día y Diari de Terrasa. Aunque la suma de las noticias que se aporta es, en conjunto, tan sólo de 17 piezas informativas.

Por lo que respecta al tratamiento informativo (tabla 2), constatamos, una vez más, la preponderancia de las fuentes institucionales, a cierta distancia de las asociaciones y fundaciones. El breve trecho que las separaba en el trimestre anterior (tan sólo 8 piezas informativas), en la presente ocasión ha aumentado a 15.

En relación con las categorías temáticas (en especial los actos y eventos, tabla 3), los afectados y sus familias vuelven a ser la tercera fuente a la que acuden los informadores. Le siguen, de lejos, los especialistas (investigadores y científicos); los médicos y el personal sanitario. De nuevo las publicaciones científicas son una fuente muy poco utilizada por los periodistas. Destaca el hecho de que FEDER baje su estatus de fuente destacada a la penúltima posición.

Las categorías temáticas, por su parte, siguen centradas sobre todo en actos y eventos; la reivindicación económica preocupa sobremanera a quienes se convierten en la segunda y tercera fuente informativa (asociaciones y afectados), algo que ya vimos se constataba de igual forma en el análisis del trimestre anterior. Como novedad del estudio de los meses de abril a junio podemos aportar el descenso notable de las historias de vida y los medicamentos huérfanos. Por otra parte, toman posiciones la investigación, y las informaciones en las que el tema protagonista es facilitar datos de todo tipo: número de personas con estas enfermedades en nuestro país o fuera de él, etc. 
Tabla 1. Piezas por cabeceras

\begin{tabular}{|c|c|c|}
\hline & Frecuencia & Porcentaje \\
\hline$\overline{\text { DIARIO DE NOTICIAS }}$ & 11 & 4,36 \\
\hline LA OPINIÓN DE MURCIA & 9 & 3,57 \\
\hline CORREO FARMACÉUTICO & 9 & 3,57 \\
\hline LA VERDAD DE CARTAGENA & 7 & 2,77 \\
\hline DIARIO PALENTINO & 7 & 2,77 \\
\hline DEIA & 7 & 2,77 \\
\hline EL CORREO ESPAÑOL & 7 & 2,77 \\
\hline EL SEMANARIO DE DIARIO MÉDICO & 6 & 2,38 \\
\hline DIARI DE TARRASSA & 6 & 2,38 \\
\hline DIARIO DE BURGOS & 6 & 2,38 \\
\hline DIARIO DE ALMERÍA & 6 & 2,38 \\
\hline CÓRDOBA & 5 & 1,98 \\
\hline LEVANTE & 5 & 1,98 \\
\hline DIARIO MÉDICO & 5 & 1,98 \\
\hline LA OPINIÓN DE A CORUÑA & 5 & 1,98 \\
\hline FARO DE VIGO & 5 & 1,98 \\
\hline EL MUNDO & 5 & 1,98 \\
\hline LA GACETA REGIONAL DE SALAMANCA & 4 & 1,58 \\
\hline EL NORTE DE CASTILLA & 4 & 1,58 \\
\hline LA OPINIÓN-EL CORREO DE ZAMORA & 4 & 1,58 \\
\hline IDEAL DE GRANADA & 4 & 1,58 \\
\hline GACETA MÉDICA & 4 & 1,58 \\
\hline 20 MINUTOS & 3 & 1,19 \\
\hline DIARIO DE ÁVILA & 3 & 1,19 \\
\hline LA NUEVA ESPAÑA & 3 & 1,19 \\
\hline IDEAL DE JAÉN & 3 & 1,19 \\
\hline LA RAZÓN & 3 & 1,19 \\
\hline HERALDO DE ARAGÓN & 3 & 1,19 \\
\hline DIARIO DE NOTICIAS DE ÁLAVA & 3 & 1,19 \\
\hline DIARIO DE NAVARRA & 3 & 1,19 \\
\hline LA REGIÓN & 3 & 1,19 \\
\hline LA TRIBUNA DE ALBACETE & 3 & 1,19 \\
\hline LA TRIBUNA DE CIUDAD REAL & 3 & 1,19 \\
\hline IDEAL DE ALMERÍA & 3 & 1,19 \\
\hline LA TRIBUNA DE TOLEDO & 3 & 1,19 \\
\hline EL PERIÓDICO DE EXTREMADURA & 2 & 0,79 \\
\hline HUELVA INFORMACIÓN & 2 & 0,79 \\
\hline DIARIO DE PONTEVEDRA & 2 & 0,79 \\
\hline LAS PROVINCIAS & 2 & 0,79 \\
\hline INFORMACIÓN & 2 & 0,79 \\
\hline LA VOZ DE GALICIA & 2 & 0,79 \\
\hline LA VERDAD DE MURCIA & 2 & 0,79 \\
\hline MÁLAGA HOY & 2 & 0,79 \\
\hline DIARIO DE LEÓN & 2 & 0,79 \\
\hline DIARIO DE MALLORCA & 2 & 0,79 \\
\hline ATLÁNTICO DIARIO & 2 & 0,79 \\
\hline EL DIARIO MONTAÑÉS & 2 & 0,79 \\
\hline EUROPA SUR & 2 & 0,79 \\
\hline EL CORREO DE ANDALUCÍA & 2 & 0,79 \\
\hline EL ADELANTADO DE SEGOVIA & 2 & 0,79 \\
\hline PRONTO & 2 & 0,79 \\
\hline LANZA & 2 & 0,79 \\
\hline
\end{tabular}

Solves Almela, J. y Bañón Hernández, A.M. (coords.) (2015). Las enfermedades poco frecuentes en los medios. Textos en Proceso 1, pp. 90-236. DOI 10.17710/tep.2015.1.1.5sol 
"CINCO DÍAS

EL PAIS

EL DÍA DE CÓRDOBA

EL GLOBAL

EL DIARIO VASCO

EL PROGRESO

HOY DE EXTREMADURA

CANARIAS 7

EL FARO DE MELILLA

ÚLTIMA HORA

LA VOZ DE AVILÉS

DIARIO DE AVISOS

DIARIO DE JEREZ

EL PERIÓDICO DE CATALUNYA

DIEZ MINUTOS

DIARIO DE TERUEL

LA VOZ DE ALMERÍA

LA OPINIÓN DE MÁLAGA

DIARIO DE CADIZ

LA TRIBUNA DE CUENCA

EL ECONOMISTA

EL FARO DE CEUTA

SUPER DEPORTE

HOY CORAZÓN

EL IDEAL GALLEGO

SUPERTELE

TELEPROGRAMA

SUR

EL COMERCIO

HERALDO DE SORIA

DIARIO DE SEVILLA

EL CORREO GALLEGO

NOTICIAS DE GUIPUZKOA

VIVA CÁDIZ

MUJER HOY

MOTOCICLISMO

LA RIOJA

GRANADA HOY

EL PUNT AVUÍ

EL DÍA

Total

Tabla 2. Fuentes

\begin{tabular}{|c|c|c|}
\hline & Frecuencia & Porcentaje \\
\hline Institucionales & 72 & 34,78 \\
\hline Asociación/Fundación & 57 & 27,53 \\
\hline Afectados & 43 & 20,77 \\
\hline Investigadores/Científicos & 16 & 7,72 \\
\hline FEDER & 12 & 5,79 \\
\hline
\end{tabular}

0,79

0,79

0,79

0,79

0,79

0,79

0,79

0,39

0,39

0,39

0,39

0,39

0,39

0,39

0,39

0,39

0,39

0,39

0,39

0,39

0,39

0,39

0,39

0,39

0,39

0,39

0,39

0,39

0,39

0,39

0,39

0,39

0,39

0,39

0,39

0,39

0,39

0,39

0,39

0,39

100,0 


\begin{tabular}{l|cc} 
- Publicaciones Científicas & 7 & 3,38 \\
\hline Total & 207 & 100,0 \\
\hline
\end{tabular}

Tabla 3. Categorías temáticas

\begin{tabular}{l|cc}
\hline \multicolumn{1}{c}{} & Frecuencia & Porcentaje \\
\hline Actos/Eventos & 128 & 26,61 \\
Reivindicación Económica/Inversión & 116 & 24,11 \\
Investigación & 82 & 17,04 \\
Decisiones Políticas & 66 & 13,72 \\
Historia de Vida & 38 & 7,90 \\
Cifras & 24 & 4,98 \\
Medicamentos Huérfanos & 21 & 4,36 \\
Sin Diagnóstico & 6 & 1,24 \\
\hline Total & 481 & 100,0 \\
\hline
\end{tabular}

Respecto de la investigación y las historias de vida, que observamos en tercero y quinto lugar, respectivamente son categorías temáticas habituales para los periodistas cuando desean informar sobre las Enfermedades de Baja Prevalencia, pero, en el trimestre que nos ocupa, observamos una disminución lógica de las historias de vida, pasada la celebración del Día Mundial de las ER.

En estrecha relación con la fuente principal, encontramos a los actores más destacados por los periodistas en sus informaciones sobre Enfermedades Poco Frecuentes (tabla 4). De tal forma que tanto las asociaciones como las instituciones repiten el primer y segundo puesto, invirtiéndolo respecto de la Tabla 2. Las asociaciones son protagonistas incuestionables de las piezas informativas, por encima incluso de los niños, quienes mantienen el mismo grado de interés que en el trimestre anterior. Por su parte, FEDER desciende en este ítem de análisis un 28,23\% respecto de los meses enero-marzo, y lo mismo le ocurre a los famosos, que bajan un 21,62\%. Todo ello justificado, como ya hemos argumentado anteriormente, por los períodos de estudio acometidos y el calendario de actividades diseñado, saliendo obviamente favorecido el primer trimestre del año.

Los pacientes y familiares ocupan el tercer puesto reservando el cuarto y quinto lugar como actores principales de la información a los niños/as y los investigadores, respectivamente. Obvia la explicación de este dato, tratándose, de los verdaderos protagonistas en el ámbito de las Enfermedades Minoritarias.

La denominación que los periodistas escogen para nombrar a las personas con una Patología de Baja Prevalencia es variada (tabla 5). La más recurrente en esta ocasión ya no es afectado/a, sino niño/a. Seguimos observando un valor mayor en "Otras denominaciones"; ello es debido a que a menudo se les menciona: por su nombre, por el rango familiar (hijo/a, 
madre/padre, etc.), como persona/s, como españoles (cuando se facilitan datos globales), etc. Este ítem, junto con el de "Sin Denominación”, destaca numéricamente por esta razón.

Tabla 4. Actor principal

\begin{tabular}{l|cc}
\hline \multicolumn{1}{c}{} & Frecuencia & Porcentaje \\
\hline Asociación/Fundación & 103 & 24,34 \\
Institución & 90 & 21,27 \\
Pacientes/Familiares & 70 & 16,54 \\
Niños & 62 & 14,65 \\
Investigadores & 31 & 7,32 \\
FEDER & 24 & 5,67 \\
Famoso & 24 & 5,67 \\
Médicos & 19 & 4,49 \\
Total & 423 & 100,0 \\
\hline
\end{tabular}

Tabla 5. Denominación de la persona con ER

\begin{tabular}{l|cc}
\hline \multicolumn{2}{c}{ Frecuencia } & Porcentaje \\
\hline Otras Denominaciones & 252 & 48,74 \\
Sin Denominación & 73 & 14,11 \\
Niño/a & 72 & 13,92 \\
Afectado/a & 44 & 8,51 \\
Paciente & 43 & 8,31 \\
Enfermo/a & 31 & 5,99 \\
Dependiente & 1 & 0,19 \\
Discapacitado/a & 1 & 0,19 \\
Total & 517 & 100,0 \\
\hline
\end{tabular}

Una vez más, observamos en ello la pretensión del periodista de evitar nombrarlos al contar el caso, priorizando el aportar informaciones diversas sin poner el punto de atención en la sustantivación del protagonista. También podemos concluir que se ha instalado una forma de nombrarlos que se aleje del ámbito médico. Con todo, resulta muy difícil omitir completamente la denominación de los sujetos de una pieza informativa, recurriendo así al tratamiento que las propias fuentes facilitan: "afectado/a", "enfermo/a", "paciente”. Queda constancia, asimismo, por segundo trimestre consecutivo, del dato residual de las denominaciones: "dependiente" y "discapacitado/a".

En cuanto al modo en que se designa en la prensa la enfermedad (tabla 6), el término de mayor asentamiento es Enfermedad Rara. En el presente trimestre nos propusimos observar el grado de incidencia periodística de la denominación Enfermedad Rara, respecto de las que desde las asociaciones y la federación que las aglutina -FEDER- se desea introducir: Enfermedad Poco Frecuente y Enfermedad Minoritaria. Los datos no dejan duda al respecto, y la separación entre ambos grupos, a favor del primero, sigue siendo la que se impone en los medios de comunicación y, de estos, hacia la sociedad. Añadiremos a lo dicho que en 7 
ocasiones se denominaba a las distintas enfermedades por su nombre concreto y no con los genéricos a los que aludíamos. En otros 5 casos además de las acepciones genéricas también se las denominaba "mal": "dicho mal" (Viva Cádir, 22 de abril); "la cura de este mal" (Ideal de Granada, 27 de abril); "los niños afectados por males atípicos” (Pronto, 7 de junio); “contra el mal" (Deia, 4 de abril), y "una cura a estos males" (Diario de Noticias de Álava, 4 de abril).

Tabla 6. Denominación de la enfermedad

\begin{tabular}{l|cc}
\hline & Frecuencia & Porcentaje \\
\hline Enfermedad Rara & 241 & 89,59 \\
Enfermedad Minoritaria & 28 & 10,40 \\
Total & 269 & 100,0 \\
\hline
\end{tabular}

La importancia que los periodistas otorgan a una información está en relación directa con el género informativo que se escoge para darla a conocer al público (tabla 7). Los cinco géneros que mostramos a continuación, están ordenados de menos a más importancia, siendo el "breve" la unidad mínima de significación informativa, mientras que la "opinión" supone la implicación directa del medio de comunicación en el tema que trata, la intención de generar un liderazgo sobre ello entre la opinión pública, por lo que, además, se destacará en las primeras planas de la cabecera en cuestión.

Tabla 7. Género de la pieza

\begin{tabular}{l|cc}
\hline \multicolumn{1}{c}{} & Frecuencia & Porcentaje \\
\hline Noticia & 126 & 52,71 \\
Breve & 51 & 21,33 \\
Reportaje & 38 & 15,89 \\
Entrevista & 13 & 5,43 \\
Opinión & 11 & 4,60 \\
\hline Total & 239 & 100,0 \\
\hline
\end{tabular}

En este sentido, el "editorial” sería el género de máxima relevancia. Se observa que no aparece en nuestra tabla, puesto que ningún medio dedicó un editorial a las Enfermedades Minoritarias en la muestra analizada.

Para el período del presente análisis, la noticia sigue superando al breve y la opinión se aleja de la cifra de los reportajes. Los tres géneros que denotan más relevancia para los periodistas (opinión, entrevista y reportaje) alcanzan un porcentaje del 25,94\%. Otros géneros que hemos medido pero que alcanzan una cifra poco relevante son: foto noticia (10 inserciones) y sube-baja (3).

De igual forma, un segundo criterio del valor informativo que el medio le otorga al acontecimiento es que la pieza vaya firmada, lo que vemos que ocurre en un 59,52\% de las veces (tabla 8). 
Tabla 8. Firma de la pieza

\begin{tabular}{l|cc}
\hline \multicolumn{1}{c}{ Frecuencia } & Porcentaje \\
\hline Firma de Autor & 150 & 59,52 \\
No Consta & 50 & 19,84 \\
Firma del Medio & 27 & 10,71 \\
Agencia de noticias & 25 & 9,92 \\
Total & 252 & 100,0 \\
\hline
\end{tabular}

El tercer elemento periodístico de relevancia es acompañar a las piezas informativas de imágenes que la completen, o la hagan destacar (tablas 9-11). Más de la mitad de las piezas informativas llevan imágenes, repitiéndose la tendencia que ya observáramos para el trimestre anterior.

Tabla 9. Apoyo gráfico

\begin{tabular}{l|cc}
\hline & Frecuencia & Porcentaje \\
\hline SÍ & 173 & 68,65 \\
NO & 79 & 31,34 \\
\hline Total & 252 & 100,0 \\
\hline
\end{tabular}

Tabla 10. Número de fotos/gráficos

\begin{tabular}{l|cc}
\hline \multicolumn{1}{c}{ Frecuencia } & Porcentaje \\
\hline 1 & 126 & 50 \\
Ninguna & 79 & 31,34 \\
2 & 28 & 11,11 \\
3 ó + & 19 & 7,53 \\
\hline Total & 252 & 100,0 \\
\hline
\end{tabular}

Tabla 11. ¿Aparece afectado en la foto?

\begin{tabular}{l|cc}
\hline & Frecuencia & Porcentaje \\
\hline NO & 198 & 78,57 \\
SI & 54 & 21,42 \\
\hline Total & 252 & 100,0 \\
\hline
\end{tabular}

Otro indicador de la importancia periodística otorgada es que la información aparezca en portada. En nuestro estudio, las Enfermedades Poco Frecuentes ocupan espacio de primera plana en 4 ocasiones (1,58\% del total). La prevalencia sigue siendo baja, -y una tendencia observada en todos nuestros estudios-. Continúa llamando la atención teniendo en cuenta el número elevado de diarios analizados (95). Los diarios que abordaron las Enfermedades Minoritarias en sus primeras planas fueron: La Verdad de Cartagena (26 de abril); el Diario de Almería (14 de mayo) y el Diari de Tarrasa (el 31 de mayo y el 7 de junio).

Lo mismo ocurre con el uso de la contraportada, que para el trimestre del actual estudio, fue casi el mismo número que de portadas: 3 (1,19\%). 
Desciende, asimismo, la cantidad de fotos en una misma pieza informativa, pero el porcentaje de fotos publicadas $(68,64 \%)$ sigue superando al de aquellas informaciones que se distribuyen sin imagen (31,34\%), aunque los afectados no son en un porcentaje alto sus protagonistas.

Medimos asimismo el enfoque que los periodistas otorgan a las informaciones (tabla 12), asignándolo a tres encuadres principales: como realidad social (la noticia se enfoca como de interés humano, solidaridad, a través de historias de vida, etc.); como enfermedad especializada (el enfoque es más bien que se trata de una cuestión técnica o clínica, de investigación, etc.) y como conflicto político (la noticia es el resultado de acontecimientos relacionados con una confrontación de intereses, voluntades o derechos). En consonancia a la cantidad de actos y eventos del presente trimestre (tabla 3), la correlación con los encuadres es lógica.

De nuevo el encuadre desde el punto de vista de la realidad social vuelve a ser el mayoritario, aunque lógicamente haya descendido respecto del trimestre anterior. En esta ocasión lo destacado no es tanto estos valores, sino los consignados para el tratamiento como enfermedad especializada y como conflicto político, ya que el número de noticias es mucho menor que las registradas en el período enero-marzo, pero los valores de estos dos encuadres no sólo son muy parejos a los de entonces, sino que en el caso del conflicto político es ligeramente superior. Ahora 85 y 50 inserciones, respectivamente; y en el trimestre anterior 89 y 46.

Tabla 12. Encuadres

\begin{tabular}{l|cc}
\hline & Frecuencia & Porcentaje \\
\hline Como realidad social & 117 & 46,42 \\
Como enfermedad & & 33,73 \\
especializada & 85 & 19,84 \\
Como conflicto político & 50 & 100,0 \\
\hline Total & 252 & \\
\hline
\end{tabular}

Si la prensa local, como vimos, fue quien más interés puso en informar sobre las cuestiones de interés periodístico de las Enfermedades Poco Frecuentes, la sección a destacar fue, en su lógica correlación, la de "Regional/Local" (tabla 13). Por lo que respecta a "Sociedad", cae considerablemente, como observamos en la tabla correspondiente, a favor de la investigación que ocupa su lugar. Las secciones donde las Enfermedades Minoritarias aparecen menos son las de opinión, cultura, economía y comunicación. 
Tabla 13. SECCIÓN

\begin{tabular}{l|cc}
\hline & Frecuencia & Porcentaje \\
\hline Regional/Local & 114 & 45,23 \\
Sanidad/Investigación & 46 & 18,25 \\
Deportes & 23 & 9,12 \\
Nacional/España/Política & 14 & 5,55 \\
Suplemento & 14 & 5,55 \\
Sociedad & 11 & 4,36 \\
Cultura & 11 & 4,36 \\
Opinión & 9 & 3,57 \\
Economía & 5 & 1,98 \\
Comunicación & 5 & 1,98 \\
\hline Total & 252 & 100,0 \\
\hline
\end{tabular}

En último término, mostramos por comunidades autónomas las más destacadas en nuestra observación (tabla 14). Es decir el ámbito de localización del suceso relatado en las piezas informativas. La acepción "España" sigue siendo la primera, por segundo trimestre consecutivo, pese a que la localización de las noticias sea regional, y su mayor cobertura informativa también. Los siguientes primeros puestos difieren respecto del registro que realizamos en los meses anteriores. Para el presente análisis, entre abril y junio Madrid deja de estar en cabeza (de 41 piezas pasa a registrar solo 5) y cede su sitio a Castilla y León, Andalucía y el País Vasco.

Para finalizar debemos constatar que 89 piezas informativas fueron descartadas por resultar tangenciales a las Enfermedades Poco Frecuentes. De éstas, 30 hacían referencia a temas diversos llegándose a indicar, en alguna ocasión, de forma explícita que "no es una Enfermedad Rara”. Otras 23 trataban el análisis electoral de los comicios europeos. En ellas la mención a las EM se reducía a la infografía o a una tabla, con los porcentajes de votos obtenidos por cada partido. En estos casos, los textos sobre candidaturas y resultados sí se analizaban. Respecto de las otras 36 piezas informativas (hasta completar las 89 que hemos mencionado), eran en relación a la princesa Letizia. Sólo en los casos en los que los perfiles biográficos, eran de un texto superior a dos o más páginas, ocupando las EM en ellos ni siquiera una frase, se tomó la decisión de descartarlos.

Tabla 14. Localización de la información

\begin{tabular}{l|cc}
\hline & Frecuencia & Porcentaje \\
\hline España & 71 & 28,17 \\
Castilla y León & 29 & 11,50 \\
Andalucía & 26 & 10,31 \\
País Vasco & 20 & 7,93 \\
Galicia & 18 & 7,14 \\
Región de Murcia & 15 & 5,95
\end{tabular}




\begin{tabular}{l|cc} 
Comunidad Foral de & & 5,15 \\
Navarra & 13 & 3,17 \\
Comunidad Valenciana & 8 & 3,17 \\
Castilla La Mancha & 8 & 3,17 \\
Otros países & 8 & 1,98 \\
Madrid & 5 & 1,98 \\
Cataluña & 5 & 1,98 \\
Principado de Asturias & 5 & 1,98 \\
Sin localizar & 5 & 1,58 \\
Extremadura & 4 & 1.19 \\
Canarias & 3 & 1,19 \\
Islas Baleares & 3 & 0,79 \\
Cantabria & 2 & 0,79 \\
Aragón & 2 & 0,39 \\
Melilla & 1 & 0,39 \\
La Rioja & 1 & 0 \\
Ceuta & 0 & 100,0 \\
\hline Total & 252 & \\
\hline
\end{tabular}

\subsubsection{Conclusiones}

1. La primera conclusión que se extrae hace referencia a la prensa española que más apuesta por informar sobre las Enfermedades Poco Frecuentes (tabla 1), siendo la prensa local/regional mayoritaria -una vez más-, frente a los periódicos generalistas, algunos de los cuales como $A B C, L a$ Vanguardia o $A S$ en este trimestre no publican información alguna.

2. Los tres primeros puestos los ocupan: Diario de Noticias (11 piezas informativas), Correo Farmacéntico (9) y La Opinión de Murcia (9), desbancando de sus puestos a los rotativos que en el trimestre anterior habían sido los tres primeros $(A B C$, Diario de Burgos y La Tribuna de Albacete en esta ocasión, con 0; 6 y 3 inserciones).

3. Bajada en el número de inserciones, es decir, en el número de noticias publicadas sobre Enfermedades de Baja Prevalencia, cae de 495 a 252. Es decir, un 50’9\%.

4. Aparecen nuevas cabeceras en el registro: 20 Minutos, Viva Cádiæz Mujer Hoy; Motociclismo; La Rioja; Granada Hoy, El Punt Avuí, El Día y Diari de Tarrasa. Aunque la suma de las noticias que se aporta es, en conjunto, tan sólo de 17 piezas informativas.

5. Preponderancia de las fuentes institucionales, a cierta distancia de las asociaciones y fundaciones. El breve trecho que las separaba en el trimestre anterior (tan sólo 8 piezas informativas), en la presente ocasión ha aumentado a 15.

6. En relación con las categorías temáticas (en especial los actos y eventos, tabla 3), los afectados y sus familias vuelven a ser la tercera fuente a la que acuden los 
informadores. Le siguen, de lejos, los especialistas (investigadores y científicos); los médicos y el personal sanitario. De nuevo las publicaciones científicas son una fuente muy poco utilizada por los periodistas. Destaca el hecho de que FEDER baje su estatus de fuente destacada a la penúltima posición.

7. Las categorías temáticas siguen centradas en actos y eventos. La reivindicación económica preocupa sobremanera a quienes se convierten en la segunda y tercera fuente informativa (asociaciones y afectados), algo que ya vimos en el análisis del trimestre anterior. Como novedad podemos aportar el descenso notable de las historias de vida y los medicamentos huérfanos. Por otra parte, toma posiciones la investigación, y las informaciones en las que el tema protagonista es facilitar datos de todo tipo: número de personas con estas enfermedades en nuestro país o fuera de él, por ejemplo.

8. En estrecha relación con la fuente principal, encontramos a los actores: tanto las asociaciones como las instituciones, repiten el primer y segundo puesto. Las asociaciones son protagonistas incuestionables de las piezas informativas, por encima incluso de los niños, quienes mantienen el mismo grado de interés que en el trimestre anterior. Por su parte, FEDER desciende en este ítem de análisis un 28,23\% respecto de los meses enero-marzo, y lo mismo le ocurre a los famosos, que bajan un 21,62\%.

9. La denominación que los periodistas escogen para nombrar a las personas con una Patología Poco Frecuente, es variada. La más recurrente en esta ocasión ya no es afectado/a, sino niño/a. Seguimos observando un valor mayor en "Otras denominaciones"; ello es debido a que a menudo se les menciona: por su nombre, por el rango familiar (hijo/a, madre/padre, etc.), como persona/s, como españoles (cuando se facilitan datos globales), etc. Este ítem, junto con el de "Sin Denominación”, destaca numéricamente por esta razón.

10. En cuanto al modo en que se designa en la prensa la enfermedad, el término de mayor asentamiento es Enfermedad Rara (89,59\%).

11. La noticia (52,71\%) sigue superando al breve $(21,33 \%)$ y la opinión se aleja de la cifra de los reportajes. Los tres géneros que denotan más relevancia para los periodistas (opinión, entrevista y reportaje) alcanzan juntos un porcentaje del 25,94\%.

12. Piezas firmadas: un 59,52 \% Con apoyo fotográfico: $68,65 \%$, de al menos una fotografía (50\%). Sin acompañamiento gráfico: 31,34\%. Sección destacada: 
regional/local (42,23\%). Las secciones donde las Enfermedades Minoritarias aparecen menos son las de opinión, cultura, economía y comunicación.

13. La realidad social vuelve a ser el encuadre noticioso mayoritario, aunque lógicamente haya descendido respecto del trimestre anterior. En el periodo abril-junio lo destacado no son tanto estos valores, sino los consignados para el tratamiento como enfermedad especializada y como conflicto político, ya que el número de noticias es mucho menor que las registradas en el período enero-marzo, pero los valores de estos dos encuadres no sólo son muy parejos a los de entonces, sino que en el caso del conflicto político es ligeramente superior. Ahora 85 y 50 inserciones, respectivamente; y en el trimestre anterior 89 y 46.

14. Respecto del ámbito de localización del suceso relatado en las piezas informativas, "España" sigue siendo la primera, por segundo trimestre consecutivo, pese a que la localización de las noticias sea regional, y su mayor cobertura informativa también. Los siguientes primeros puestos difieren respecto del registro que realizamos en los meses anteriores. Para el presente análisis, Madrid deja de estar en cabeza (de 41 piezas pasa a registrar solo 5) y cede su sitio a Castilla y León (29 piezas), Andalucía (26) y el País Vasco (20).

15. Para finalizar debemos constatar que 89 piezas informativas fueron descartadas por resultar tangenciales a las Enfermedades Minoritarias. De éstas, 30 hacían referencia a temas diversos llegándose a indicar, en alguna ocasión, de forma explícita que "no es una Enfermedad Rara”. Otras 23 trataban el análisis electoral de los comicios europeos. En ellas la mención a las EM se reducía a la infografía o a una tabla, con los porcentajes de votos obtenidos por cada partido. En estos casos, los textos sobre candidaturas y resultados sí se analizaban. Respecto de las otras 36 piezas informativas (hasta completar las 89 que hemos mencionado), eran en relación a la princesa Letizia. Sólo en los casos en los que los perfiles biográficos, eran de un texto superior a dos o más páginas, ocupando las EM en ellos ni siquiera una frase, se tomó la decisión de descartarlos.

\subsection{Análisis del discurso de la prensa española sobre las EPF en abril} (Por Antonio M. Bañón Hernández, Universidad de Almería, CySOC)

\subsubsection{Lector ideal y primeras cifras}


Imaginemos un lector ideal que consulta 95 periódicos diariamente durante un mes. Un lector que podríamos llamar, por poner un nombre poco frecuente, Juan ¿Qué imagen tendría esa persona, Juan, de las enfermedades poco frecuentes tras un mes de lectura diaria de todos esos periódicos? He seleccionado el mes de abril de 2014, un mes en el que ya ha pasado, supuestamente, la campaña mundial que todos los meses de febrero se realiza para apoyar a las personas que tienen una EPF y cuyo recorrido abarca también varias semanas de marzo. ¿Qué información aparece, por lo tanto, después de estas semanas tan intensas?

Lo primero que podríamos decir es que las EPF tienen una presencia constante en nuestros medios de comunicación, sobre todo en la prensa. La lucha por encontrar un espacio se está ganando. En nuestro corpus de abril de 2014 encontramos, en prensa no digital, 255 noticias. Están distribuidas en 95 publicaciones periódicas nacionales y regionales, aunque el impacto sin duda es muy superior en los diarios de tirada regional (Tabla 1).

Tabla 1. Piezas informativas por publicación en abril

\begin{tabular}{|c|c|}
\hline \multicolumn{2}{|c|}{10 piezas informativas } \\
\hline Diario de Burgos & \\
\hline \multicolumn{2}{|c|}{9 piezas informativas } \\
\hline Diario Médico + Semanario DM & \\
\hline \multicolumn{2}{|c|}{8 piezas informativas } \\
\hline Correo Farmacéutico & El Comercio \\
\hline \multicolumn{2}{|c|}{7 piezas informativas } \\
\hline La Región & \\
\hline \multicolumn{2}{|c|}{6 piezas informativas } \\
\hline La Opinión-El Correo de Zamora & El Global \\
\hline Gaceta Médica & La Voz de Avilés \\
\hline Levante & Diario de Noticias \\
\hline Faro de Vigo & La Verdad \\
\hline \multicolumn{2}{|c|}{5 piezas informativas } \\
\hline Diario de Almería & Diario de Pontevedra \\
\hline El Progreso & Atlántico Diario \\
\hline \multicolumn{2}{|c|}{4 piezas informativas } \\
\hline La Nueva España & Diario de León \\
\hline La Opinión de Murcia & Diario de Mallorca \\
\hline \multicolumn{2}{|c|}{3 piezas informativas } \\
\hline El Correo Gallego & El Día de Córdoba \\
\hline El Faro de Melilla & El Mundo (Valencia) \\
\hline Córdoba & Diario de Ávila \\
\hline Diario Palentino & Sur \\
\hline La Opinión de Málaga & Las Provincias \\
\hline 20 Minutos & Diario de Navarra \\
\hline Dinero y Salud & El Mundo (Innovadores) \\
\hline La Opinión de A Coruña & Ideal de Granada \\
\hline Málaga Hoy & El Correo Español \\
\hline Canarias 7 & La Tribuna de Albacete \\
\hline El Faro de Ceuta & La Razón (A tu Salud)+La Razón \\
\hline \multicolumn{2}{|c|}{2 piezas informativas } \\
\hline Súper Deporte & El Norte de Castilla \\
\hline La Gaceta Regional de Salamanca & Hoy de Extremadura \\
\hline
\end{tabular}




\begin{tabular}{|l|l|}
\hline Lanza & El Periódico de Extremadura \\
\hline Información (Alicante) & La Voz de Galicia \\
\hline Ideal de Jaén & Expansión \\
\hline El Diario Montañés & El País (Nacional + Medicina) \\
\hline Cinco Días & \\
\hline \multicolumn{2}{|c|}{ 1 pieza informativa } \\
\hline La Rioja & Excelente \\
\hline Diario de Avisos & Huelva Información \\
\hline Nueva Alcarria & La Tribuna de Ciudad Real \\
\hline Mediterráneo & La Tribuna de Cuenca \\
\hline Viva Cádiz & La Tribuna de Toledo \\
\hline Diari de Terrassa & Diario de Cádiz \\
\hline Europa Sur & Diario de Jerez \\
\hline Granada Hoy & Diario de Sevilla \\
\hline Noticias de Gipuzkoa & Heraldo de Aragón \\
\hline El Mundo-El Día de Baleares & Mujer Hoy \\
\hline El Mundo (Andalucía) & El Diario Vasco \\
\hline Pronto & ABC (Castilla y León) \\
\hline El Correo de Andalucía & ABC (Nacional) \\
\hline Mundo Deportivo & ABC (Valencia) \\
\hline El País (País Vasco) & Ideal de Almería \\
\hline El País (Valencia) & El Periódico de Catalunya \\
\hline Alerta de Cantabria & Ser Padres \\
\hline Farmaventas & Deia \\
\hline Diario de Teruel & \\
\hline &
\end{tabular}

Como se observa, el Diario de Burgos tiene una presencia sobresaliente en este corpus. La ubicación del CREER (Centro de Referencia Estatal de Atención a Personas con Enfermedades Raras y sus Familias) en esa ciudad explica esa primera posición, con 10 piezas informativas en las que se trata de EPF. Los contenidos sanitarios propios de Diario Médico (y su Semanario), Gaceta Médica y Correo Farmacéutico hacen que la posibilidad de que aparezcan informaciones sobre EPF sea mayor, y, por eso, ocupan esas posiciones preferentes. La presencia del diario asturiano El Comercio en la cuarta posición, con 8 piezas informativas, se debe, sobre todo, a la aparición de un debate específico en torno al desarrollo del Registro de Enfermedades Raras y la reacción en contra de la ASENCRO (Asociación de Usuarios de la Sanidad del Principado), con el posterior apoyo del partido Foro Asturias. Se decía que había problemas importantes de protección de datos. Esto explica también la posición destacada de La Voz de Avilés.

\subsubsection{Menciones más que anecdóticas}

Hay piezas informativas en las que el tema principal no es 'las enfermedades raras'. Éstas pueden aparecer de forma tangencial, pero su presencia incluso en estos casos puede tener, unas veces para bien y otras para mal, un valor más que anecdótico. Pongamos algunos ejemplos. 
La noticia titulada "MIR, Médicos de calidad a precio de saldo en Navarra" (Diario de Noticias, 07.04.14). Hay distintos testimonios en los que los médicos hablan de sus perspectivas de futuro o de sus anhelos. Entre ellos, aparece un joven estudiante de $5^{\circ}$ de medicina (22 años), Francisco Nava, que, en este contexto, dice lo siguiente: 'Me gustaría ver avances en el estudio de las enfermedades raras. Ahora mismo en Bilbao hay una familia que recoge fondos para la investigación porque no hay presupuesto y se merecen esa posibilidad'. Es un joven médico que indica el grado de inserción del tema de las EPF en el discurso (valga la palabra) profesional.

Otro ejemplo. El Boletín Oficial del Estado del 29 de abril de 2014 publicaba el listado de candidaturas que se presentaban a la Elección de Diputados al Parlamento Europeo celebradas el 25 de mayo de 2014. Aparecían 39 candidaturas, en este orden: Iniciativa Feminista.

1. Partido Socialista Obrero Español (PSOE).

2. Partido Popular (P.P.).

3. Coalición por Europa (CEU).

4. Foro de Ciudadanos (FAC).

5. Unión, Progreso y Democracia (UPyD).

6. Partido Animalista contra el Maltrato Animal (PACMA).

7. L'Esquerra pel Dret a Decidir (EPDD).

8. Ciudadanos-Partido de la Ciudadanía.

9. Impulso Social.

10. Agrupación de Electores Recortes Cero.

11. Primavera Europea.

12. Extremadura Unida.

13. Partido Humanista.

14. VOX.

15. Partido de la Libertad Individual.

16. Falange Española de las J.O.N.S.

17. Partido Comunista de los Pueblos de España.

18. Partido X, Partido del Futuro.

19. Agrupación de Electores D.E.R. (Discapacitados y Enfermedades Raras).

20. Salamanca-Zamora-León (PREPAL).

21. Izquierda Unida-Iniciativa per Catalunya Verds-Asamblea de Izquierdas-Federación Los Verdes.

22. Los Pueblos Deciden (LPD).

23. Extremeños por Europa-Coalición Electoral.

24. Partido Andalucista.

25. Movimiento Corriente Roja (MCR).

26. Escaños en Blanco.

27. Por la República, Por la Ruptura con la Unión Europea (RRUE).

28. Podemos. 
29. Alternativa Republicana (ALTER).

30. Partida da Terra (PT).

31. Solidaridad y Autogestión Internacionalista (SAIn).

32. La España en Marcha (LEM).

33. Confederación Pirata (PIRATAS).

34. Democracia Nacional (DN).

35. Proyecto Europa.

36. Movimientos de Renovación Democrática Ciudadana (RED).

37. Movimiento Social Republicano (M.S.R.).

38. Ciudadanos Libres Unidos (CILUS).

La mención específica de la prensa a la Agrupación DER implica una elección entre 39 candidaturas y hay que otorgar el mérito que merece a la propia agrupación y también a los periodistas que se interesaron de forma concreta por ella. He aquí un fragmento del Diario de Almería el 22 de abril de 2014: "Entre las nuevas candidaturas figuran las de VOX, Recortes Cero y Podemos, así como la Agrupación de Electores de Discapacitados y Enfermedades Raras (DER), que encabeza un joven de 25 años con distrofia muscular degenerativa" (Diario de Almería. 22.04.14). El impacto de esta candidatura, en términos parecidos, aparece en Málaga Hoy (03.04.14), La Opinión de Málaga (20.04.14) o Sur (20.04.14). Hay informaciones más completas de DER, del cabeza de lista Eduard Carreras y de Samuel, otro de los jóvenes promotores que falleció, en 20 Minutos Andalucía (24.04.14). Del valor aparentemente marginal puede pasarse al nuclear, como demuestra la noticia del diario Córdoba titulada "Hacer más visible en Europa la diferencia" (28.04.14). Más claro es aún ese paso en el periódico Málaga Hoy: "El partido de las enfermedades raras pide propuestas para su programa" (30.04.14). Obsérvese, además, que, entre discapacidad y ER, el periódico elige ER. Muy significativo también.

Las EPF también son citadas como temas preferentes de las becas concedidas por la Fundación Ramón Areces. Y se hace, indicando que esos proyectos seleccionados se mencionan “entre muchos otros'. Las EPF además han entrado a formar parte de lo que llamaría el "grupo de tres": cáncer, diabetes y enfermedades raras. Haber entrado en ese grupo es importante desde el punto de vista de los medios de comunicación. En el diario Ideal (16 de abril), leemos:

Se trata del primer organismo autonómico en España que tendrá capacidad plena para dar luz verde a estos proyectos, que ya investigan en Andalucía soluciones al cáncer, la diabetes y enfermedades raras.

La aparición aparentemente incidental de las EPF en las piezas informativas puede estar asociada también con cuestiones negativas, por supuesto. De hecho, en el mes de abril de 
2014, estas enfermedades aparecen relacionadas con informaciones sobre una agresión sexual y sobre violencia hacia un niño en el contexto familiar. El primer caso corresponde a un hombre que dijo no recordar el ataque que realizó a una mujer en Rianxo por padecer el síndrome de Kleine-Levin, también conocido como el síndrome de la Bella Durmiente. El segundo se refiere a un bebé de Ourense que llegó a urgencias con fracturas. Los investigadores judiciales, antes de tomar una decisión, pidieron que el servicio de Pediatría valorase si sufría osteogénesis imperfecta. Esta información se publicó el 25 de abril en Faro de Vigo y días antes en El Correo Gallego. El día 29 el Faro publicaba el siguiente titular: "La pediatra descarta una enfermedad rara del bebé de Ourense y atribuye las lesiones a malos tratos".

\subsubsection{Enfermedades especificas mencionadas}

Además de las frecuentes referencias a las 'enfermedades raras', 'poco frecuentes' o 'minoritarias', también encontramos, lógicamente, menciones a patologías específicas ¿Cuáles son estas enfermedades cuyo nombre observó nuestro lector ideal, Juan, en este mes de abril de 2014? Las siguientes 54:

- Distrofia muscular degenerativa (en 21 piezas).

- Síndrome de Sanfilippo (en 9 piezas), fibrosis quística (9).

- Sarcoidosis (8).

- Distrofia muscular de Duchenne (6), osteogénesis imperfecta (6).

- Esclerosis lateral amiotrófica (5), atrofia muscular espinal (5), síndrome 4p o síndrome de Wolf-Hirschorn (5).

- Citrulinemia (4), hemofilia (4), retinosis pigmentaria (4), angioedema hereditario (4).

- Distrofia muscular de Steinert (3).

- Ataxia (2), síndrome de Arnold Chiari (2), síndrome de Brugada (2), síndrome de Hippel-Lindau (2), síndrome de Kleine-Levin (2), síndrome de Lowe (2), calcifilaxis (2), esclerosis múltiple (2), fenilcetonuria (2), sarcoma de tejidos blandos (2), síndrome de Williams (2), síndrome de Wolfram (2), trisomia parcial 9 (2).

- Ataxia de Friedreich (1), ataxia telangiectasia (1), distonía (1), distonía idiopática muscular (1), distrofia miotónica (1), distrofia muscular (1), Pelizaeus-Merzbacher (1), gangliosidosis (1), hipogenesia del cuerpo calloso (1), hipoxia cerebral (1), inmunodeficiencia primaria (1), leucemia linfática crónica (1), leucoencefalopatía megalencefática (1), lupus (1), miastenia (1), miopatía hipertrófica (1), miopatía 
mitocondrial infantil (1), epidermólisis bullosa (1), síndrome de Cach (1), síndrome de Depleción de ADN mitocondrial (1), síndrome de Donohue (1), síndrome de maullido de Gato (1), síndrome de Parsonage-Turner (1), síndrome de PhelanMcDermid (1), síndrome de Rett (1), síndrome hemolítico urémico atípico (1), anemia de Fanconi (1), amiloidosis transtirretina (en 1), y siringomelia (1).

El mero hecho de aparecer en la prensa es un éxito, desde el punto de vista de la visibilización. Siempre se recuerda que hablamos de unas 7.000 patologías poco frecuentes como cifra más o menos redonda de referencia.

Ahora bien, hemos de conocer también si se está consiguiendo una información cualitativamente adecuada, con datos pertinentes y relevantes y sin prejuicios ni estereotipos. Los ciudadanos saben que hace falta dinero para investigar en EPF o para atender necesidades de recursos específicos, especialmente de los niños. ¿Pero saben lo que son las EPF? ¿Saben si son genéticas en su mayoría o conocen la cifra de prevalencia a partir de la cual se considera una enfermedad rara? ¿Podrían los ciudadanos españoles, nuestros vecinos, decirnos el nombre de cinco enfermedades poco frecuentes? ¿De cuatro? ¿De tres? ¿De una?

\subsubsection{Bloques temáticos y temas principales tratados}

Los bloques y los temas principales tratados en el mes de abril de 2014 son los siguientes:

Politica sanitaria

- Candidatura DER a las elecciones europeas.

- Las ER en el Plan de Salud de la Comunidad de Cantabria.

- Los resultados de los ensayos en Europa deberán publicarse.

- La Junta de Castilla y León destina 36 millones a medicamentos 'huérfanos'.

- Dudas sobre el Registro de Patologías Raras en Asturias por parte de ASENCRO.

- El Tripartit pide revertir la sanidad privada en Valencia.

- Plan de alertas para pacientes con angioedema.

- Creación de Comité para autorizar investigaciones con pre-embriones en Andalucía.

- Las Comunidades Autónomas y el acceso equitativo a las innovaciones terapéuticas.

- El síndrome de Wolfram y la unidad de Huércal-Overa.

Cursos, Congresos y Jornadas

- Congreso de Esclerosis Lateral Amiotrófica (ELA).

- Jornadas sobre Retinosis pigmentaria. 
- Congreso de Hemofilia.

- Encuentro del Síndrome de Maullido de Gato.

- Encuentro de la Asociación Nacional de Arnold Chiari.

- Jornadas sobre Coagulopatías y enfermedades raras en Jaén.

Investigación

- Empresas biotecnológicas que buscan tratamientos para las ER.

- El presidente de El Corte Inglés menciona las becas de la fundación a EPF.

- Implante de un corazón mecánico como alternativa al trasplante.

- La terapia génica como modelo útil.

- Zeltia se dispara en bolsa por la llegada de Yondelis al mercado japonés.

- Los enfermos de fibrosis quística piden mejor acceso a nuevos fármacos.

- Descubren factor genético de la Distonía del músico.

- Avance en la regulación de una encefalopatía.

- ASEBIO y el ISCIII se unen para fomentar la investigación en EPF.

Dinero y ER

- Actividades solidarias para recaudar dinero.

- El precio de los fármacos.

- Consultoría Omakase, especializada en la gestión sanitaria.

- La influencia de la crisis en la calidad de vida de las personas.

- Empresas que rentabilizan la investigación en ER (Oryzon).

Formación y educación

- Curso en el CREER sobre autocuidados y calidad de vida.

- Iniciativas del CREER en contextos escolares.

- Formación de los médicos de primaria en enfermedades neuromusculares.

- Eco en Almería del Congreso Escolar Internacional.

- Los MIR y la mención a las EPF.

Violencia y EPF

- Agresión sexual y EPF.

- Malos tratos infantiles y sospechas de EPF (en Ourense).

Discapacidad y EPF

- Entrevista a Luis Cayo, Presidente del CERMI. 
- Elecciones en el CERMI de Melilla.

Visibilidad

- Entrevistas y reportajes a afectados.

- Día Internacional sobre el Autismo.

- Día Internacional del síndrome de Wolf.

- Día Internacional de la hemofilia.

FEDER

- Convenio de colaboración entre IMELSA y FEDER.

- FEDER como destinataria de la recaudación de eventos solidarios.

- Presidente de FEDER en la inauguración de las Jornadas de la Asociación de Afectados de Retina de la Región de Murcia.

- Tesorero de FEDER presenta un libro en Mallorca.

- FEDER aparece como fuente periodística en algunas noticias.

- Acuerdo entre FEDER y Celgene.

- Delegada de FEDER en Madrid habla sobre EPF y educación.

- Presentación del proyecto de FEDER 'Educar en enfermedades raras, una materia de todos' apoyado por Genzyme.

- Presencia de la Delegada de FEDER en Andalucía en un reportaje sobre Wolfram.

- Presidente de FEDER en el Día Internacional del síndrome de Wolf-Hirschhorn.

- FEDER se solidariza con la Federación de Fibrosis Quística para pedir acceso a nuevos tratamientos.

- FEDER como entidad que premia el trabajo de los profesionales de los medios de comunicación (concretamente, A tu salud, de La Razón).

- La Subdirectora de FEDER en los encuentros Salud 2000.

- FEDER y campaña 'Paciente únicos'.

De todos estos temas, nos detendremos, siguiendo, en parte, los parámetros utilizados para la investigación cuantitativa de este Informe, en dos marcos determinados: los eventos solidarios de proximidad, y la investigación y la innovación terapéutica. 


\subsubsection{Eventos solidarios de proximidad y EPF}

Las informaciones de prensa sobre EPF están en la actualidad frecuentemente asociadas a eventos solidarios de proximidad. En abril de 2014, hallamos iniciativas, en efecto, procedentes de muy diversos ámbitos.

En el deportivo, encontramos informaciones sobre la implicación del C.D. Mirándes (con Stop Sanfilippo), del C.D. Osasuna (con la investigación en ataxia de Friedreich) y del Valencia C.F, a través de sus jugadores internacionales Paco Alcácer y Juan Bernat (con un hombre con una EPF sin determinar, al que dieron una camiseta firmada para que pudiese realizar una rifa). Nuestro lector ideal, Juan, también encuentra en este corpus del mes de abril la organización de carreras y marchas atléticas en Derio, en Mojácar, en Zamora, en Ceuta, en los montes Torozos (entre Valladolid y Palencia), o en la Casa de Campo de Madrid, esta última organizada por el medallista olímpico Fermín Cacho. Los beneficiarios de estas iniciativas fueron la asociación Gure Señeak, de nuevo Stop Sanfilippo, los afectados por Distrofia muscular de Duchenne o -según se dice-“"un niño de 4 años que padece una enfermedad rara" (La Razón. 26.04.14).

También el mundo del ciclismo mostró su solidaridad con la prueba de 380 kilómetros de montaña, la prueba ciclista de apoyo a D'Genes o la ciclomarcha por las enfermedades raras metabólicas de El Tiemblo (Ávila). De igual forma, hallamos iniciativas procedentes del Rugby (se realizó una rifa en la Final de la Copa del Rey con las camisetas de los dos equipos firmadas) o del Golf (el Club de Golf Escorpión de Bétera acogió la tercera edición del torneo benéfico a favor de la Alianza de familias con enfermos afectados por el síndrome de Von Hippel Lindau).

En el ámbito de la cultura y de la moda, encontramos propuestas de festivales de música solidarios, como el realizado en A Guarda (a beneficio de Martiño, "un niño que sufre una de las llamadas "enfermedades raras"” (Atlántico. 08.04.14); o el festival benéfico Abejarock, que el año pasado colaboró con la plataforma Unidos por Adrián (un niño de Ciudad Rodrigo con una enfermedad poco frecuente), y que este año, en su sexta edición, destinará los beneficios a investigar el síndrome de Cach, una enfermedad rara que afecta al pequeño Alejandro, de Santibáñez de Béjar.

Por la prensa, nuestro lector ideal también conocerá las Galas solidarias de la Casa de la Cultura de Cehegín (organizada por la Asociación Arnold Chiari y D’Genes) y de Cádiz (para apoyar a Stop Sanfilippo). 
También con exposiciones, como la titulada "Menos raras" (en Barcelona) o la denominada "Pintaluces" (fotografías expuestas en Badajoz por Enrique Vidarte en solidaridad, según se indica, con la Federación Extremeña de Enfermedades Raras, El Periódico de Extremadura. 09.04.14).

La Agrupación de Fallas de Centro se unió en un proyecto solidario para ayudar a Sofía, una niña de ocho años que sufre miopatía mitocondrial infantil.

Víctor Ullate se implicó a través de su escuela de Danza en el movimiento 'Todos somos raros. Todos somos únicos'.

Dos escritoras, María Serralba y Encarni Arcoya, realizaron dos libros (una novela y una serie de relatos cortos) destinados a recaudar dinero para Emilio Biota, un niño ilicitano con hipoxia cerebral, y para Idaira, una niña malagueña con atrofia muscular espinal. El actor Martiño Rivas protagonizó un vídeo para ayudar y promocionar la labor que lleva a cabo la Federación Galega de Enfermedades Raras e Crónicas.

En este mes de abril, algunas cofradías y hermandades también muestran su solidaridad con las EPF. Por ejemplo, la Hermandad Penitencial de Nuestra Señora de Begoña.

Empresas que no tienen relación con el ámbito sanitario ni con las EPF lideran pequeñas (pero significativas) iniciativas: Pub 'Torero' de Ceuta, o Chocolates Maruja de Ceuta, la Terraza Isla del Mar de Tenerife, Telepizza o Bodegas Murviedro aparecen mencionados en las piezas informativas de abril de 2014. También aparecen otras más relacionadas con el ámbito sanitario, como Novovisión o Fraternidad Muprespa. Y, finalmente, vinculadas a las enfermedades poco frecuentes encontramos a Genzyme y su colaboración con el proyecto educativo de FEDER, a Celgene y su firma de un convenio con la Federación. Igualmente, a ASEBIO, que firma un convenio con el Instituto de Salud Carlos III para fomentar la investigación en enfermedades poco frecuentes.

De igual forma, los centros educativos (desde enseñanza primaria hasta enseñanza universitaria) se implican en eventos solidarios. La Universidad de Murcia vende libros en beneficio de personas con enfermedades raras, el Colegio Marista Liceo Castilla de Burgos (por iniciativa del CREER) acogía sesiones de sensibilización, la Semana Cultural del Colegio Miralvalle de Plasencia incluye la recogida de tapones y una marcha a favor de las enfermedades poco frecuentes, el Instituto Luis Carrillo de Sotomayor de Córdoba acoge la Feria Solidaria para recaudar dinero que fue destinado a Paula, una niña con una enfermedad rara, el Colegio San Agustín de Salamanca colabora con un niño salmantino que necesita un 
tratamiento, en el Colegio Salesianos de Cádiz se desarrolla una gala para luchar contra la enfermedad de Sanfilippo, etc.

Naturalmente, la lectura positiva de este tipo de eventos es clara: genera un mayor vínculo de las personas con EPF con su entorno, aumenta la visibilidad de estas patologías $\mathrm{y}$, por consiguiente, de los problemas derivados del hecho de tenerlas y, finalmente, proporciona fondos para la acción directa. Ante este tipo de eventos, lo adecuado es mostrar, como se hace, agradecimiento. Pero todo tiene varias lecturas cuando hablamos de EPF. Compartiendo ese agradecimiento, por supuesto, me gustaría hacer algunas reflexiones complementarias.

\subsection{6. ¿ ¿Ser una sociedad que desarrolla actos solidarios a favor de las personas con EPF significa ser una sociedad necesariamente comprometida con ellas y reivindicativa?}

El compromiso implica entender la causa, asignar responsabilidades y asumir las propuestas de mejora. Y este es un primer problema sobre el que habría que reflexionar al observar lo que los medios informan sobre EPF.

Focalizar sólo sobre el comportamiento solidario de un grupo, de un pueblo, de una ciudad, puede llevar a dos problemas: el primero consiste en que lo verdaderamente importante para el periódico o para el periodista sea trasladar la idea de que la sociedad tiene un corazón de oro, que somos solidarios. Pero, si ese es el planteamiento único, el riesgo es el de olvidar que lo más importante de la puesta en marcha de un acto solidario es conseguir ayudar a los destinatarios de ese acto; en nuestro caso, las personas con EPF y las asociaciones de personas con EPF.

Un ejemplo de que a veces lo importante de la solidaridad es para los medios reflejar el compromiso de quienes la practican, en lugar de destacar la situación de quienes tienen una patología minoritaria, es la noticia «Porriño recauda más de 300 kilos de tapones» (Atlántico. 02.04.14). Esta noticia lleva por subtitular el siguiente: "La meta es llegar a 36 toneladas y ayudar en tres nuevos casos”. Sabemos por Roma Tébar que el alcalde porriñés había afirmado que "el resultado era positivo, "pues en apenas cuatro meses hemos conseguido llegar a 300 kilos de tapones solidarios’. Además, también se nos informa de que la empresa de reciclaje paga 250 euros por cada tonelada de plástico. ¿Cuánto tiempo haría falta para llegar a esas 36 toneladas siguiendo ese ritmo que se considera 'positivo'? No reflexionar sobre esta circunstancia equivale a considerar como objetivo preferente la mera representación del hecho mismo de ser solidario. Porque las cuentas no salen. 
Claro que hay que llevar cuidado con parecer desagradecido. Cualquier ayuda es importante, por supuesto, y ésta es la reacción habitual de las personas con EPF. Ahora bien, puede ser que una acción solidaria no sea útil desde el punto de vista de la financiación. Si bien sí puede serlo desde el punto de vista de la sensibilización. Pero no se puede afirmar que algo ha sido un éxito recaudatorio, cuando no lo ha sido si partimos de los objetivos establecidos al comienzo del hecho solidario.

El segundo problema es el de olvidar que las Administraciones tienen también responsabilidades que asumir y no siempre lo hacen. Por lo que hemos observado, la mayor parte de noticias de este tipo apenas hacen referencia a este aspecto. Una consecuencia derivada de este modelo informativo es la promoción de un discurso basado preferentemente en la compasión, justo el tipo de discurso que más suelen rechazar los afectados, las familias y las asociaciones.

Pocas son las ocasiones en las que esta circunstancia se hace explícita en las informaciones de abril de 2014. Tres ejemplos:

1. Fernando García Figueroa: "Mientras el Ministerio de Sanidad, Servicios Sociales e Igualdad restringe sus presupuestos destinados a la investigación de este tipo de enfermedades. Una vez más, la sociedad civil, a través de sus aportaciones voluntarias, tendrá que hacer frente a una necesidad que corresponde al Estado" (El Periódico de Extremadura. 09.04.14).

2. "Óscar Padura y Leire Mitxelena, pese a saber que tal vez no beneficien directamente a sus hijos, tienen depositadas muchas esperanzas en el trabajo de Biomics. El primero apunta que 'esto es el mundo al revés, los enfermos y sus familias financiando la investigación, a la americana”' (El Diario Vasco. 23.04.14) [FQ]

3. Josean Villanueva, de la Asociación de Esclerosis Múltiple de Navarra, afirma: 'No podemos quedarnos quietos', aunque añade que eso no puede utilizarse nunca por parte de la Administración 'para hacer dejación de sus responsabilidades' (titular de Diario de Pamplona. 26.04.14).

Un elemento con gran valor añadido en el desarrollo de los eventos solidarios es el hecho de que se digan, por parte de los organizadores, y se reproduzcan, por parte de los medios, los objetivos por los que tales eventos tienen lugar y el destino del dinero recaudado. Hay tres modelos básicos desde el punto de vista informativo: a) se habla en general de investigación en EPF; b) se mencionan proyectos específicos; y c) se habla de personas concretas, normalmente niños o niñas, a cuya atención van destinados los dineros. He aquí algunos ejemplos:

El presidente de FEDER, Juan Carrión, que ha anunciado que lo recaudado irá destinado al servicio de información y orientación a las familias de la Federación” (La Verdad. 02.04.14). 
"La recaudación obtenida con la inscripción de los participantes en la carrera, una vez descontados los gastos, será destinada a sufragar las revisiones médicas de los enfermos" (Ideal. 03.04.14).

"Toda la recaudación que se consiga irá destinada íntegramente a la investigación que desarrolla el equipo biomédico de las doctoras Mercedes Serrano y Belén Pérez de la unidad 703 del Ciberer, del Hospital materno infantil San Juan de Dios de Barcelona. Este centro es pionero en el estudio de enfermedades poco frecuentes de tipo metabólico, como el síndrome de Lowe, el síndrome de CDG y el grupo de enfermedades neurodegenerativas por acumulación cerebral de hierro (NBIA)" (El Norte de Castilla. 23.04.14).

"El Centro Cultural de A Guarda acogerá mañana a las 20 horas un festival benéfico a favor de Martiño, de 7 años de edad, y que padece una enfermedad rara degenerativa" (Faro de Vigo. 03.04.14).

Como ya hemos dicho en otras ocasiones, la información sobre el porqué se pide la colaboración económica en eventos solidarios debe ser prioritaria, y las asociaciones, cuando son ellas las organizadoras, tendrían que ser muy cuidadosas en este punto siempre. Eso fortalecería su imagen.

\subsubsection{Temas derivados de los eventos de proximidad}

De los eventos de proximidad se deriva un par de temas asociados que merece la pena mencionar. El primero es el que se refiere a la fusión entre enfermedad poco frecuente y elevado coste. He aquí un fragmento de la noticia en la que se informa sobre la implicación de las Fallas en las EPF:

Fallas unidas contra las enfermedades raras" (Las Provincias. 24.04.14): "La Agrupación de Fallas de Centro se han unido en un proyecto solidario para ayudar a Sofía, una niña de ocho años que sufre miopatía mitocondrial infantil, una enfermedad rara y cuyo tratamiento es de coste muy elevado.

Hemos encontrado un ejemplo muy claro de esta asociación en una entrevista a Federico Mayor Zaragoza aparecida en el diario El País el 26 de abril de 2014. La entrevistadora es la periodista Silvia Carpallo. Dice Mayor Zaragoza:

"R. (...) Lo que deben hacer es fomentar la investigación, y no estar sólo pendientes de aquello que parece que va a tener gran impacto económico".

Ante lo que reacciona la periodista de esta forma:

"P. ¿Se refiere a la investigación en enfermedades raras?".

La réplica del entrevistado, finalmente, es la siguiente: 
"R. Exacto, y es aquí donde cabe el pacto con la Administración. La industria sabe que en determinados casos no va a tener beneficios económicos, pero sí el beneficio supremo de que algunos pacientes podrán mejorar la calidad de vida (...). La política sanitaria debería velar porque estos grupos de pacientes sean atendidos. Si en algún campo no deben aplicarse nunca las estadísticas es en salud".

La reacción de Silvia Carpallo es muy significativa porque demuestra lo asumida que puede estar ya la idea de que impacto socio-sanitario alto equivale a enfermedades poco frecuentes. De hecho, en este mes de abril también se informa del nacimiento de una consultora que, según leemos en El Correo Farmacéutico (21.04.14), “estará especializada en situaciones de 'alto impacto sociosanitario', focalizando su actividad en ámbitos como la oncología, las enfermedades raras, la terapia avanzada y los pacientes crónicos”. ¿Qué quiere decir “de alto impacto sociosanitario’? ¿Qué tiene una gran influencia sobre la calidad de vida de las personas afectadas? En realidad, es una fórmula eufemística, como tantas otras utilizadas en el lenguaje político-administrativo, para hacer referencia al poderoso caballero don dinero. De hecho, un medio de información económica es mucho más claro al hacer referencia a esta consultora:

Ofrece un asesoramiento en situaciones complejas y costosas para la sanidad pública, como la oncología, las enfermedades raras y la gestión de los pacientes crónicos. Expansión (15.04.14).

Esta asociación llega incluso a los pacientes mismos. Igual que las personas con enfermedades raras pueden ser representadas o denominadas, por una especie de metonimia, como personas raras, cuando hablamos de enfermedades costosas podemos desembocar en la idea de 'pacientes costosos':

Son pacientes que sufren problemas severos y que, por la falta de tratamiento, son muy costosos para el sistema (Expansión, 03.04.14).

El Editorial de El Semanario de Diario Médico del 14 de abril se titula "El precio de los fármacos y el coste de la vida". Naturalmente, las enfermedades raras y muy raras son mencionadas:

El debate estalla cíclicamente cada vez que surge un fármaco o una familia de fármacos de probada eficacia y, por lo general, precio elevado. Ocurrió con los antirretrovirales contra el $\mathrm{VIH}$, con algunos oncológicos y con muchos de los medicamentos para enfermedades huérfanos o muy raras.

Y también cuando se habla de enfermedades concretas, como la amiloidosis transtirretina o la hemofilia: 
En el mercado mundial solo existe un tratamiento farmacológico para la fase inicial de una de las formas de la amiloidosis transtirretina, la variante polineuropática. Su coste es muy elevado y solo tiene aprobación para Europa" / "Los únicos tratamientos existentes son un fármaco descubierto en EEUU con un precio de 140000 euros al año y el trasplante de hígado, solo adecuado para un pequeño grupo poblacional y a un coste sociosanitario muy elevado" (El Periódico de Catalunya. 16.04.14).

"José Antonio Ruiz [presidente de la Asociación Orensana de Hemofilia] insiste en la importancia de seguir los tratamientos médicos, 'que sólo se suministran en farmacia hospitalaria, y que además tienen un elevado coste aunque, al menos de momento, entran en los pagados por la Seguridad Social”' (La Región. 17.04.14)

El marcador temporal 'de momento' es un indicador muy significativo del componente emotivo que tiene este debate para los afectados y que está basado en el miedo a perder tratamientos o servicios de atención sanitaria.

Este tipo de planteamientos tiene una interpretación añadida sobre la que merece la pena reflexionar: la solución (médica) se convierte en el problema (económico). La situación es especialmente grave si tenemos en cuenta que hablamos de un porcentaje muy bajo de tratamientos existentes para los afectados por enfermedades raras. A esa conversión de la solución en problema alude precisamente Emili Esteve en un debate diseñado y difundido por El Global el 28 de abril de 2014. Un debate en el que también estuvo presente, por cierto, la actual directora de FEDER, Alba Ancochea.

Probablemente, las asociaciones de pacientes tienen que insistir más en esta idea, y aliviar, en cambio, la asociación entre costoso y poco frecuentes, mediante contraargumentos y antiargumentos que permitan mostrar también la importancia de la reutilización de tratamientos ya existentes o la transversalidad de la investigación, por ejemplo, un tema que sí tiene cierto protagonismo en el mes de abril:

"Su investigación es vital para la cura del cáncer y una multitud de enfermedades raras que apenas tienen tratamiento" (Diario de León. 08.04.14)

"Esa es la especialidad de esta compañía [Biotech] ubicada en el Parc Cientific de Barcelona, la reutilización de medicamentos para otras indicaciones" (El Periódico de Catalunya. 16.04.14)

"Cortés [profesor de la Universidad de Sevilla] afirma que las roturas de ADN tienen que 'repararse de forma exacta, ya que, de lo contrario, pueden generar problemas degenerativos o disparar procesos tumorales'. 'Pueden estar relacionados con patologías como la AT [ataxia telangiectasia] y quizás con otras enfermedades relacionadas" (El Correo Español. 18.04.14).

"La crema que cura las heridas de la radioterapia" (titular de portada del cuadernillo Innovadores de El Mundo. 21.04.14). "Este hallazgo ha sido fruto de la casualidad ya que los socios de la compañía buscaban medicamentos para enfermedades raras infantiles". 
"En el Hospital Universitario Central de Asturias (HUCA) acumulan una gran experiencia en operaciones de parkinson. Eso hizo posible [que] mi operación fuera un éxito" (La Nueva España. 27.04.14) [Distonía muscular].

"Aprovechando la experiencia ganada en estos campos hemos abordado otros estudios, como el de las mutaciones en cáncer de laringe o en enfermedades hereditarias, que en esencia se hacen de la misma forma: comparando el genoma del afectado con el de sus familiares. Y esta misma vía nos ha permitido descubrir el síndrome de Néstor y Guillermo (una enfermedad rara de envejecimiento acelerado) y la susceptibilidad al melanoma' [Dice Víctor Quesada, del Instituto Oncológico de la Universidad de Oviedo] / "Detrás de estas áreas de trabajo aparentemente opuestas está el concepto de transversalidad, que significa que hay tumores muy distintos pero que están relacionados genómicamente" (El Semanario de Diario Médico. 28.04.14).

De igual manera, habría que ir matizando la afirmación de que a las farmacéuticas no les resulta rentable trabajar en enfermedades poco frecuentes:

"No está mal hacer hincapié en que se trata de una enfermedad rara pues hay documentados alrededor de 70 casos en España y, como suele suceder con estas enfermedades minoritarias, no interesan a las empresas farmacéuticas, y su tratamiento queda sin investigar" (Viva Cádiz. 22.04.14) [síndrome de Sanfilippo].

"Muchos de los propios se realizan para tratamientos para enfermedades raras, que a la industria no le interesa" [ensayos clínicos] (Heraldo de Aragón. 27.04.14).

"Los huérfanos son medicamentos que no producen las grandes farmacéuticas porque afectan a pocos pacientes" (El Periódico de Catalunya. 16.04.14).

Ya que también encontramos informaciones en periódicos económicos en las que se habla de las EPF como 'nicho de mercado':

"Los fármacos de Minoryx contra las enfermedades raras" (Expansión. 03.04.14).

Titular: "La biotecnológica Oryzon vende a Roche dos fármacos por 15 millones" (Cinco Días. 08.04.14). "La molécula que lleva más avanzada la investigación es ORY1001, reconocida como fármaco huérfano (para el tratamiento de enfermedades raras) por la Agencia Europea del Medicamento en agosto de 2013 para el tratamiento de la leucemia mieloide aguda".

En el fondo, estamos asistiendo al debate sobre coste-beneficio en el ámbito sanitario. Un debate que, en ocasiones, se resuelve de forma un tanto gruesa, cuando los matices son tan importantes en estas cuestiones y más en el ámbito de las enfermedades minoritarias. Me salgo un momento del corpus de abril para hacer eco de la noticia de ElEconomista.es el 4 de septiembre de 2014 titulada "Sanidad impone el pago por resultados a los laboratorios: si el fármaco no cura, no cobran". El debate se intensificó con la financiación de un nuevo tratamiento para la hepatitis $\mathrm{C}$, pero sabemos que es un debate que también afecta de lleno a las EPF. Ahora bien, algo que parece evidente puede no serlo tanto: ¿`sólo se financiará lo 
que cure? ¿Qué significa 'curar'? ¿Y si el medicamento mejora el estado y la calidad de vida del paciente aunque no lo cure? ¿Y si la detiene? ¿Y si ralentiza su progreso? En nuestro corpus de abril de 2014, nuestro lector ideal, Juan, puede observar afirmaciones como las siguientes:

"Según los médicos esto le ayudará muchísimo y nos ayudará a que llegue a 2015, que será cuando llegue el fármaco para mantener a los niños" (La Opinión de Málaga. 29.04.14) [Se refiere al famoso caso de Idaira, con atrofia muscular espinal].

"Aunque su pronóstico no sea halagüeño, su caso está sirviendo de reclamo para trasladar a la sociedad la necesidad de investigar en esa patología rara y regalar así años de vida a los portadores de ese gen ruinoso que termina provocando la pérdida progresiva de la fuerza muscular" (Ideal de Granada. 27.04.14) [En relación también a Idaira].

"Las terapias contra la fibrosis quística permiten ganar en calidad de vida" (El Diario Vasco. 23.04.14).

Decíamos hace algunos minutos que la asociación entre EPF y gasto elevado era un asunto fácilmente derivable del tratamiento periodístico de los eventos solidarios de proximidad. Otra asociación es la de ese tipo de eventos y la política de proximidad. Directores de Organismos locales o regionales, Concejales o alcaldes de Almansa, de Porriño, de Pamplona, de Badajoz, de A Guarda, de Ontinyent, de Mojácar o de Guadalajara aparecen en las informaciones de abril de 2014 'acompañando', 'respaldando', o 'participando' en eventos solidarios. También aparecen como destinatarios del agradecimiento de las familias: es el caso del Ayuntamiento de Valencia de San Juan. No siempre hay una relación directa entre el hecho de decir que se apoya a un grupo o a una familia y el hecho mismo de apoyar. Es decir, entre el decir y el hacer. Ahora bien, en un caso, por ejemplo, sí hay una acción concreta: Prudencio Induráin, director del Instituto de Deporte y Juventud y de la Agencia Navarra para la Dependencia, no sólo apoyó una carrera organizada por una persona con discapacidad, sino que contribuyó económicamente para el desarrollo de la primera etapa.

Por cierto que la mirada amable por lo normal hacia la política local no siempre se mantiene en la representación discursiva que se hace de los responsables políticos a nivel regional, nacional o europeo:

"El Gobierno aún no ha aprobado la norma para pasar enfermos del sistema sanitario al de servicios sociales" (Canarias 7, 01.04.14).

"a pesar del drástico recorte de las ayudas a la dependencia" (Información. 16.04.14) [Habla el padre de una niña con síndrome 4p]. 
"Los enfermos de fibrosis quística piden que se incorporen nuevos fármacos" (Diario de Teruel. 23.04.14). "La Federación Española de Fibrosis Quística (FQ) denuncia en un comunicado, "el retraso" que se está produciendo en la llegada a España de los medicamentos más avanzados para el tratamiento de la enfermedad, debido a "las trabas" que está poniendo el Gobierno" / "Es evidente -apuntan los enfermos- que los recortes en las prestaciones sanitarias que se están produciendo en España, junto con la reducción de la inversión en investigación, están poniendo en peligro la calidad e incluso esperanza de vida de los niños y jóvenes con Fibrosis Quística".

"Si tú ves a Fran en la puerta del Ministerio diciendo que no le llega una hora de fisioterapia al mes, a ver qué político le dice que no cuando sabemos todo lo que sabemos" (La Voz de Galicia. 28.04.14).

"Mientras en Cataluña la subvenciona la sanidad pública, en Andalucía no" (La Opinión de Málaga. 30.04.14) [Idaira y la adquisición de una máquina para toser].

"Junto a una negociación equilibrada de los precios de los fármacos, las administraciones públicas tienen que elegir sus prioridades: salud, museos o carreteras. Y dentro de la salud, establecer con prudencia qué se financia" (Editorial del Semanario de Diario Médico. 14.04.14).

La Casa Real aparece mencionada en una ocasión y se hace destacando el apoyo de la entonces Princesa Letizia a la Asociación Española del Síndrome de Wolf-Hirschhorn (Información, 16.04.14). También es representada de forma positiva en este mes de abril la iniciativa europea según la cual las empresas farmacéuticas europeas habrían de informar obligatoriamente sobre sus ensayos para facilitar la cooperación transfronteriza. Es una iniciativa con clara repercusión en el ámbito de las EPF (Expansión, 03.04.14; Correo Farmacéutico, 07.04.14; El Global, 07.04.14).

\subsubsection{Innovación terapéutica y EPF}

El discurso periodístico sobre las EPF tiene un valor añadido: el de vincular estas patologías a lo innovador y a lo pionero. Ya decíamos anteriormente que las enfermedades raras se asocian a lo costoso. Sabemos que el hecho de ser el origen de nuevas propuestas terapéuticas está relacionado justamente con la alta inversión económica, por lo que este asunto hay que analizarlo a partir de ese marco. Por otra parte, el hecho de que haya una iniciativa pionera tiene una lectura positiva muy clara, pero también otra menos positiva: cuando no hay nada o cuando apenas hay nada, ser pionero es más sencillo. El punto de partida de muchas EPF en relación a la investigación es precisamente la ausencia de iniciativas. De cualquier forma, la innovación también conlleva prestigio en nuestra sociedad, por lo que los profesionales dedicados a estas patologías suelen ser considerados como profesionales prestigiosos. Los siguientes ejemplos expresan muy bien estas consideraciones: 
"La Fe implanta por primera vez en España un corazón mecánico alternativo al trasplante" (ABC. 05.05.14).

"Avance prometedor en la regulación de una tipología de encefalopatía" (Correo Farmacéutico. 07.04.14) / "permitirá implementar nuevas estrategias terapéuticas para los pacientes afectados". [leucoencefalopatía megalencefálica].

"La terapia génica, útil en modelo felino de la GM1" (titular de Diario Médico. 10.04.14). [gangliosidosis 1].

"Después de varios ingresos y complicadísimas pruebas, le detectaron un síndrome de Depleción de ADN mitocondrial, una enfermedad rara cuya única salida es el trasplante multiorgánico" (Pronto. 19.04.14).

"Andalucía tendrá el primer comité para autorizar investigaciones con preembriones" (Ideal. 16.04.14).

"Los enfermos de fibrosis quística piden que se incorporen nuevos fármacos" (Diario de Teruel. 23.04.14). "La Federación Española de Fibrosis Quística (FQ) denuncia en un comunicado, "el retraso" que se está produciendo en la llegada a España de los medicamentos más avanzados para el tratamiento de la enfermedad, debido a "las trabas" que está poniendo el Gobierno".

"Jornadas sobre coagulopatías y enfermermedades raras" (Ideal de Jaén. 26.04.14). [Organizado por la Asociación Andaluza de Hemofilia] "estas jornadas, que se estructurarán en tres bloques, que serán los de tratamiento de las coagulopatías, aspectos reproductivos y diagnósticos genéticos y una tercera parte sobre biotecnologías y terapias avanzadas".

"El conocimiento del genoma dará muchas alegrías al campo de las inmunodeficiencias" (La Verdad. 26.04.14) [Declaraciones de María Rocío Álvarez, directora del grupo de inmunotolerancia a trasplantes y enfermedades de base inmunológica del hospital Virgen de la Arrixaca].

“Confianza ciega en la innovación” (titular de Heraldo de Aragón. 27.04.14).

"Me explicó [el cirujano] con calma que la enfermedad no tiene cura y que la operación que iba a realizarme era un tratamiento experimental paliativo: una neuroestimulación profunda que consiste en la implantación en el cerebro de dos electrodos, y de un neuroestimulador en el abdomen (que es como llevar una pila de petaca"' (La Nueva España. 27.04.14) [Distonía muscular].

"Los investigadores del Instituto de Medicina Genómica de Valencia se han situado en primera línea mundial en el diagnóstico de enfermedades raras" (Levante. 29.04.14).

\subsubsection{Conclusiones}

1. Sigue apareciendo muy poca información, en general, sobre temas tan relevantes como, por ejemplo, los problemas específicos de los cuidadores (problemas de acceso al trabajo, problemas de pareja, problemas de comunicación en general, etc.) y la situación de los hermanos y hermanas de niños con EPF. 
2. FEDER tiene una presencia constante en la prensa durante el mes de abril de 2014, aunque no sea como fuente directa. Además, aborda temas diversos. La educación aparece como una cuestión prioritaria y también la participación en actividades de asociaciones. Destaca igualmente la firma de acuerdos y convenios.

3. Los eventos solidarios de proximidad ocupan el lugar más destacado desde el punto de vista temático. Es importante valorar en su justa medida y agradecer estas acciones. Hay ejemplos de implicación solidaria en el ámbito educativo, empresarial, social, cultural, artístico, religioso, deportivo, etc. Destaca el deportivo.

4. Focalizar sólo sobre el comportamiento solidario de un grupo, de un pueblo, de una ciudad, puede llevar a dos problemas: el primero consiste en que lo verdaderamente importante para el periódico o para el periodista sea trasladar la idea de que la sociedad tiene un corazón de oro, que somos solidarios. El segundo problema es el de olvidar que las Administraciones tienen también responsabilidades que asumir y no siempre lo hacen. Por lo que hemos observado, la mayor parte de noticias de este tipo apenas aluden a este aspecto.

5. Se siguen asociando las enfermedades poco frecuentes con problemas económicos debido al alto coste de sus cuidados y tratamientos. Este argumento está utilizado de forma razonable por las familias, pero también tiene un uso estratégico por parte de la Administración y, en ocasiones, los propios medios. Es necesario, en este último caso, potenciar la contraargumentación de este tipo de planteamientos aludiendo, por ejemplo, a la transversalidad evidente de las investigaciones en EPF. De igual forma, hay que entrar al fondo del debate sobre si un tratamiento sólo es asumible 'si cura'.

6. La representación de los políticos con responsabilidad local es amable y positiva, en general, frente a lo que sucede a nivel nacional y regional. La mención a la Casa Real es positiva y se mantiene así su vinculación a la causa de las EPF.

7. El discurso periodístico sobre las EPF tiene un valor añadido: el de vincular estas patologías a lo innovador y a lo pionero. Ya decíamos anteriormente que las enfermedades raras se asocian a lo costoso. Sabemos que el hecho de ser el origen de nuevas propuestas terapéuticas está relacionado justamente con la alta inversión económica, por lo que este asunto hay que analizarlo a partir de ese marco. Por otra parte, el hecho de que haya una iniciativa pionera tiene una lectura positiva muy clara, pero también otra menos positiva: cuando no hay nada o cuando apenas hay nada, ser pionero es más sencillo. 


\subsection{Análisis del discurso de la prensa española sobre las EPF en mayo}

(Por Samantha Requena Romero, Universidad de Almería)

\subsubsection{Análisis cuantitativo}

\subsubsection{Las EPF en la prensa}

El corpus de este mes está formado por 430 piezas informativas publicadas en 128 cabeceras distintas. Diario de Noticias es el periódico que más ha publicado sobre este tema con 15 noticias, sobre todo acerca de eventos solidarios por las EPF (ej. carrera Hiru Mendi Trail o jornadas gastronómicas), seguido por Diario de Burgos (14) con noticias sobre eventos solidarios y actividades del Centro de Referencia Estatal de Atención a Personas con Enfermedades Raras y sus Familias de Burgos (CREER); Diario de Navarra con noticias sobre actos de solidaridad y Heraldo de Aragón con distintos testimonios de afectados y varios impactos sobre cribado neonatal (10), El Semanario de Diario Médico (9); Córdoba, Diario Palentino, El Correo de Andalucía, El Diario Montañés, Ideal (Jaén), La Tribuna de Toledo y La Verdad de Cartagena (8).

Tabla 1. Cabeceras con más noticias sobre EPF en mayo

\begin{tabular}{|l|c|c|}
\hline \multicolumn{1}{|c|}{ CABECERA } & NOTICIAS & $\mathbf{\%}$ \\
\hline Diario de Noticias & 15 & 3,45 \\
\hline Diario de Burgos & 14 & 3,22 \\
\hline Diario de Navarra & 10 & 2,30 \\
\hline Heraldo de Aragón & 10 & 2,30 \\
\hline Semanario de Diario Médico & 9 & 2,07 \\
\hline Córdoba & 8 & 1,84 \\
\hline Diario Palentino & 8 & 1,84 \\
\hline El Correo de Andalucía & 8 & 1,84 \\
\hline El Diario Montañés & 8 & 1,84 \\
\hline Ideal (Jaén) & 8 & 1,84 \\
\hline La Tribuna de Toledo & 8 & 1,84 \\
\hline La Verdad de Cartagena & 8 & 1,84 \\
\hline Diario de Ávila & 7 & 1,61 \\
\hline El Norte de Castilla (Salamanca) & 7 & 1,61 \\
\hline Ideal (Granada) & 7 & 1,61 \\
\hline La Opinión de Murcia & 7 & 1,61 \\
\hline Levante & 7 & 1,61 \\
\hline Diari de Terrassa & 6 & 1,38 \\
\hline Diario de Teruel & 6 & 1,38 \\
\hline Diario Médico & 6 & 1,38 \\
\hline
\end{tabular}

En la tabla 1 presentamos las 20 cabeceras con más noticias publicadas sobre enfermedades raras. 


\subsubsection{Presencia en titulares}

Uno de nuestros intereses es saber si ciertos temas clave para nuestra investigación como son: la Federación Española de Enfermedades Raras (FEDER), la educación y las EPF; la investigación en EPF o las personas sin diagnóstico han sido titular de alguna noticia durante el mes de mayo. Para ello hemos buscado en el documento en el que se compilan todas las noticias publicadas por días los siguientes términos: "FEDER”, “educ", “esc." “inv”, “diag”. En los resultados de la búsqueda de "inv” también nos aparecía la palabra "inversión” que hemos considerado importante y por ello la hemos incluido en nuestro análisis. Por lo que se refiere a la búsqueda de "diag", debido a que las personas sin diagnóstico no ocupan en ningún momento el titular de la noticia, hemos creído oportuno observar en cuántas ocasiones la problemática de la consecución de un diagnóstico sí cubre los titulares. Los resultados han sido los siguientes:

Tabla 2. Presencia de temas clave en titulares en mayo

\begin{tabular}{|c|c|c|c|}
\hline Término & Titular & Medio & Fecha \\
\hline FEDER & $\begin{array}{l}\text { La Federación Española de Enfermedades Raras pide } \\
\text { un Plan Integral canario }\end{array}$ & Canarias 7 & 23 mayo \\
\hline \multirow[t]{3}{*}{ Educación } & $\begin{array}{l}\text { Doña Letizia anima a los escolares a conocer las } \\
\text { enfermedades raras }\end{array}$ & ABC, Diario de Teruel & 1 mayo \\
\hline & Educación para la salud: nunca será suficiente & $\begin{array}{l}\text { El Semanario Diario } \\
\text { Médico }\end{array}$ & 5 mayo \\
\hline & ¿La escuela ha de enseñarlo todo? & La Vanguardia & 10 mayo \\
\hline \multirow[t]{7}{*}{ Investigación } & $\begin{array}{l}\text { En investigación todas las jornadas de trabajo son } \\
\text { maratonianas }\end{array}$ & Gaceta Médica & 5 mayo \\
\hline & $\begin{array}{l}\text { TVE recauda dos millones de euros para investigar en } \\
\text { enfermedades raras }\end{array}$ & $\mathrm{ABC}$ & 8 mayo \\
\hline & $\begin{array}{l}\text { Partido de enfermedades raras dará el dinero por los } \\
\text { votos a investigación }\end{array}$ & Diario de Noticias & 13 mayo \\
\hline & $\begin{array}{l}\text { La asociación española contra el cáncer alerta de la } \\
\text { escasa investigación en tumores infantiles ¿ la directora } \\
\text { general de la fundación cientifica de la Asociación } \\
\text { Española contra el Cáncer }\end{array}$ & Diario de Burgos & 26 mayo \\
\hline & $\begin{array}{l}\text { La Asociación Española Contra el Cáncer alerta de la } \\
\text { escasa investigación }\end{array}$ & $\begin{array}{l}\text { El Correo de Andalucía, } \\
\text { La Tribuna de Albacete, } \\
\text { La Tribuna de Ciudad } \\
\text { Real, La Tribuna de } \\
\text { Toledo, El Adelantado } \\
\text { de Segovia, Diario } \\
\text { Palentino, Diario de } \\
\text { Burgos, Diario de Ávila }\end{array}$ & 26 mayo \\
\hline & $\begin{array}{l}\text { La AECC alerta de la escasa investigación en tumores } \\
\text { infantiles }\end{array}$ & Faro de Vigo & 26 mayo \\
\hline & $\begin{array}{l}\text { La asociación contra el cáncer lamenta la falta de } \\
\text { investigación en tumores infantiles }\end{array}$ & $\begin{array}{l}\text { La Opinión de A } \\
\text { Coruña }\end{array}$ & 26 mayo \\
\hline Invertir & Inveready Biotech II tendrá 17 millones para invertir & Expansión Cataluña & 14 mayo \\
\hline \multirow[t]{2}{*}{$\begin{array}{l}\text { Sin } \\
\text { diagnóstico }\end{array}$} & $\begin{array}{l}\text { Sólo } 42 \text { diagnósticos fallidos desde que se aplica la } \\
\text { segunda opinión médica }\end{array}$ & El Correo de Andalucía & 6 mayo \\
\hline & $\begin{array}{l}\text { El diagnóstico del angioedema hereditario tarda hasta } \\
15 \text { años }\end{array}$ & Diario Médico & 16 mayo \\
\hline
\end{tabular}


Como podemos observar en esta tabla, FEDER tan sólo es titular de una noticia en un diario regional, Canarias 7, para la que pide un Plan Integral de enfermedades raras.

En cuanto a Educación y EPF, es la iniciativa de FEDER 'Las Enfermedades Raras van al cole con Federito' la que más repercusión tiene en los medios de comunicación por el apoyo de la S.A.R. la Princesa Letizia. Aunque en prensa ocupa un solo titular, en radio y en televisión sí cuenta con más impactos.

En investigación, el tema que más se repite es la alerta anunciada por la Asociación Española contra el Cáncer (AECC) sobre la poca investigación que existe en tumores infantiles, la gran mayoría considerados enfermedades raras. Son 9 veces las que ocupa el titular.

El tema del diagnóstico y de las personas que aun no tienen un diagnóstico concreto sigue siendo un tema clave. Sin embargo, sigue teniendo poca repercusión en los medios de comunicación. Es muy frecuente encontrárnosla en la mayoría de las reivindicaciones realizadas por afectados en particular (Diario Médico, 16 mayo) la necesidad de nuevos marcadores diagnósticos que ayuden a reducir el tiempo de espera.

En el corpus analizado hemos identificado más de 80 enfermedades poco frecuentes. Todas ellas han sido mencionadas al menos una vez. Son las siguientes: Alzhéimer infantil, Anemia aplásica, Anemia de Fanconi, Angioedema hereditario, Ataxia, Ataxia de Friedreich, Ataxia telangiectasia, Atrofia medular espinal, Atrofia muscular espinal, Cáncer infantil, Carcinoide gástrico, Cistinosis, Colitis ulcerosa, Coroideremia, Displasia local proximal, Disqueratosis congénita, Distrofia degenerativa, Distrofia muscular de Becker, Distrofia muscular de Duchenne, Distrofia muscular degenerativa, Enfermedad (mal) de Kawasaki, Enfermedad (mal) de Wilson, Enfermedad de Crohn, Enfermedad de Gaucher, Enfermedad de los huesos de cristal, Enfermedades mitocondriales, Enfermedad de sarcoidosis, Enfermedad de Von Hippel Lindau, Esclerodermia, Esclerosis múltiple, Espina bífida, Fémur corto congénito, Fibromialgia, Fibrosis pulmonar idiopática, Fibrosis quística, Hemofilia, Hemoglobinuria paroxística nocturna, HHTR, Hipertensión arterial pulmonar, Hipomelanosis, Histiocitosis, Ictiosis, Leucemia infantil, Leucemia mieloide aguda (LMA), Leucodistrofia metacromática, Linfangioleiomiomatosis, Lupus, MPS (Mucopolisacaridosis), MPS6, Narcolepsia, Neurofibromatosis, Neuropatía óptica hereditaria de Leber, Osteogénesis imperfecta, Osteoporosis, Piel de mariposa, Polineuropatía amiloidótica familiar, Porfiria, Retinosis pigmentaria, Sarcoma de Ewing, Síndrome antifosfolípido, Síndrome de Angelman, Síndrome de Dravet, Síndrome de fatiga crónica, Síndrome de 
Hunter, Síndrome de Löwe, Síndrome de Marfan, Síndrome de Menkes, Síndrome de Moebius, Síndrome PAPA, Síndrome de Pearson, Síndrome de Rett, Síndrome de Sanfilippo, Síndrome de Tay-Sachs, Síndrome de Tourette, Síndrome de West, Síndrome de Williams, Síndrome de Wiskott-Aldrich, Síndrome de Wolf-Hirschhorn, Síndrome Hiper IgE, Síndrome X-frágil (SXF), Telangiectasia hemorrágica hereditaria, Trastorno de NiemannPick tipo C. Como podemos observar, en los medios no sólo se emplea el nombre científico de la enfermedad como puede ser 'osteogénesis imperfecta' sino que también hacen uso de la denominación que hace que la enfermedad parezca más cercana al entendimiento de la audiencia, y es por ello que se emplea la expresión 'huesos de cristal'.

La aparición de esta gran cantidad de enfermedades en la prensa durante el mes de mayo no hace sino corroborar la importancia que cada vez van teniendo este tipo de patologías para la sociedad española aunque también es cierto que tanta heterogeneidad y tal cantidad de nombres refuerzan la idea de la complicación a la hora de abordar todas y cada una de ellas (Bañón y Fornieles, 2011: 34).

\subsubsection{Análisis Cualitativo}

En este apartado vamos a analizar los temas que más presencia tienen en el corpus estudiado así como los recursos retórico-discursivos empleados para tratar dichos temas. Es por ello que haremos referencia al uso de nombres propios, de omisión de información, de recursividad léxica, de repetición, etc. Los temas o asuntos que más se tratan durante el mes de mayo son los siguientes:

- Presencia de la nueva agrupación política: DER (Agrupación de Discapacitados y Enfermedades Raras) (Hoy de Extremadura, 2 mayo; Ideal de Granada, 2 mayo; La Rioja, 2 mayo; El Diario Vasco, 25 mayo; Diari de Tarragona, 27 mayo; Córdoba, 26 mayo; Diario de Ávila, 26 mayo), etc.

- Eventos solidarios: recogida de tapones, carreras solidarias, etc. (Diario de Almería, 28 mayo; Diario de Noticias, 28 mayo; Diario del Altoaragón, 6 mayo; Europa Sur, 2 mayo), etc.

- Eventos informativos y reivindicativos: coincidiendo con la celebración del Día Mundial de determinadas patologías. La Osteogénesis Imperfecta el día 6 de mayo (La Tribuna de Toledo, 3 mayo); el Lupus el día 10 de mayo (El Correo Español, 6 mayo; Diario de Pontevedra, 7 mayo; Diario Médico, 9 mayo; Ideal de Jaén, 10 mayo; Correo Farmacéutico, 12 mayo); la Enfermedad Inflamatoria Intestinal el 27 de mayo 
(La Región, 27 mayo); la Esclerosis Múltiple el día 28 de mayo (Ideal Gallego, 25 mayo).

- Investigación:

- El estado de la investigación española en EPF

- Ensayos clínicos

- Nuevos Fármacos

Para comenzar nuestro análisis vamos a hacer referencia a la presencia de información ecoica cuando se ha publicado sobre el nuevo partido político a favor de la discapacidad y las enfermedades raras (DER). Es cierto que ha habido una alta difusión sobre este tema ya que en mayo, concretamente el 25, es cuando se celebraron las Elecciones Europeas. Es cierto que se han mencionado las 'enfermedades raras' en muchas ocasiones pero, como decíamos al principio de este fragmento, sólo aparecen cuando se desglosan las siglas de la agrupación política DER. Nosotros, los observadores, hemos echado en falta más información en los medios sobre qué propone DER, qué quiere conseguir, etc. ya que tan sólo hemos encontrado tres impactos: dos de ellos el 7 de mayo y otro el 13. Los diarios en los que han aparecido han sido: Diario de Pontevedra (DER), Málaga Hoy (Reclaman una Ley de Dependencia para toda la Unión Europea) y Diario de Noticias (Partido por de Enfermedades Raras dará el dinero por los votos a investigación). Por el contrario, sobre el tema de las elecciones en general se han publicado, por poner un ejemplo, el 2 de mayo, 12 impactos de los 24 publicados ese día sobre EPF. En total, hay 63 noticias sobre este mismo tema siendo el día que más se publica el 26 de mayo, un día después de las Elecciones Europeas con 15 impactos.

En cuanto a los eventos solidarios se siguen celebrando actos en los que todo lo recaudado va destinado a la causa de las enfermedades raras en general, como por ejemplo, el festival organizado por el Ayuntamiento de Hontoria del Pinar y la Asociación Costalago por Gaizka, un niño que padece el síndrome de Angelman y para quien va destinada toda la recaudación. Tras leer la noticia, surgen preguntas como ¿para qué? ¿qué necesita este niño? Y es información que no aparece en la nota informativa. No sabemos si es para investigación o para otras necesidades más personales que requiera el pequeño. Otro ejemplo es el de un partido de frontón en el que se donarán las camisetas para recaudar fondos para el síndrome Sanfilippo que afecta a cuatro niños de Bilbao (Deia, 3 mayo). No se da más información que esta y la definición de lo que es el síndrome Sanfilippo, pero nada conocemos de lo que harán con lo recaudado. Es por ello que la información sobre un evento solidario debería ser 
lo más completa posible para que así la participación pueda ser mayor. Un ejemplo de cómo aportar la máxima información sobre un acto solidario puede ser el siguiente: Goles para Aarón, afectado por el síndrome de Pearson (Heraldo de Aragón, 2 mayo). En este artículo se mencionan como 'posibles' conceptos para los que se recauda dinero: "futuros tratamientos o viajes a otros centros médicos”. El empleo del atenuador 'algo' en 'recaudar algo de fondos' deja entrever, o bien que el periodista no es muy optimista con la solidaridad de la gente, o simplemente da a entender que se puede participar sin tener que donar. Otro de los datos importantes que se deberían ofrecer cuando se informa sobre un evento solidario es, si se repite anualmente, la recaudación del año anterior. Sin embargo, no siempre es así. Por ejemplo, el día 2 de mayo Levante informa: El Torneo de Golfpara Alianza de Von Hippel Lindau llega a los 150 inscritos y se hace referencia a la de 2013 que se llegó a los 200 inscritos pero de recaudación no se dice nada.

Como hemos dicho en trabajos anteriores, un elemento que acerca la causa de las EPF al lector es el saber para quién se realiza un determinado evento solidario y eso se consigue a través del uso de los nombres propios (Bañón y Requena, 2014: 27). Durante el mes de mayo, esto también aparece. Son los casos de Gaizka (síndrome de Angelman, Diario de Burgos, 1 de mayo); Carla (enfermedad de West, La Gaceta Regional de Salamanca, 3 de mayo); Aarón (síndrome de Pearson, Heraldo de Aragón, 2 y 5 de mayo); Daniela (síndrome de Sanfilippo, Levante, 4 de mayo), Idaira (atrofia medular espinal, La Opinión de Málaga, 7 de mayo), Luz Rocío (HHT, La Opinión de Málaga, 9 de mayo), Alicia Cabello (síndrome de Dravet, Diari de Sabadell, 10 de mayo), Max y Aleix (Histiocitosis de células de Langerhans, Diari de Terrassa, 24 de mayo), Sergio (Tay-Sachs, Lanza, 30 de mayo), etc. En estos casos los participantes pueden "poner cara" a la causa por la que se pide solidaridad.

Pero los eventos solidarios ya no sólo se celebran para salvar vidas u ofrecer con lo recaudado una mejora en la calidad de vida del afectado sino que ahora también se recauda dinero para que "un niño pueda nacer sin la enfermedad que sus padres portan" (Ideal de Granada, 9 mayo). Es el caso de una familia de Huétor Tájar quienes tras haber perdido un bebé de dos meses afectado por acidemia propiónica quieren tener un bebé sano. La información que aparece en prensa no es lo completa que debiera ya que no especifica a través de qué método de fecundación o estudio genético se va a realizar. Tan sólo se dice "mediante un procedimiento que hace poco se ha llevado a cabo con éxito en una clínica" (Granada Hoy, 9 mayo). 
Por nuestra experiencia en el análisis de la presencia de las EPF en los medios de comunicación podemos decir que en todo corpus con el que hemos trabajado el testimonio de los afectados es un elemento fiable y recurrente. Además de aparecer en la promoción de eventos solidarios (Levante, 4 mayo) aparecen en eventos como la conmemoración del día Mundial de una determinada patología donde se informa además de reivindicar. El día 7 de mayo se publica en Diario de Pontevedra: "Más de 40.000 personas sufren lupus en España, la enfermedad invisible" y se hace referencia al testimonio de una paciente que dice "solo en un año debió acudir a cincuenta consultas, sin contar los análisis clínicos”. También se hace mención a las demandas de los pacientes: "los afectados por lupus piden una mayor implicación por parte de los médicos de Atención Primaria para el diagnóstico y seguimiento del lupus". En un apartado anterior decíamos que el día 10 de mayo se celebra el Día Mundial del lupus y es muy común encontrar noticias publicadas días antes y días después del mismo. Lo lógico sería que en la información encontrada "días después" se hiciera referencia a un seguimiento de las actividades celebradas el Día Mundial. Sin embargo, no encontramos en la información de los días 12 (Correo Farmacéutico, Lospacientes de lupus denuncian incomprensión socialy falta de apoyo) y 13 de mayo (La Vanguardia, ¿ Sabes lo que es el lupus?) mención alguna a las actividades llevadas a cabo durante el día 10. Tal vez se deba a una falta de coordinación entre las distintas entidades de cada Comunidad Autónoma.

Otro de los bloques temáticos relevantes es el de la investigación. En este apartado distinguiremos tres subtemas: el estado de la investigación española en EPF, los ensayos clínicos y la aprobación de nuevos fármacos.

Debido a que 2014 ha sido considerado "Año Español de la Biotecnología” (Dinero y Salud, 1 mayo), durante el mes de mayo se habla en muchas ocasiones de terapia génica, de nuevos centros de investigación (GENyO), de nuevos métodos diagnósticos (Gradiant) pero también de la parte menos positiva de la investigación como es el hecho de que se investiga poco en tumores infantiles. Sin embargo, si hay tres noticias que dibujan cómo está la investigación en España desde tres perspectivas totalmente distintas. Estas son: a) "En investigación todas las jornadas son maratonianas", entrevista a Manuel Posada, director del instituto de investigación en ER, ISCIII (Gaceta Médica, 5 mayo); b) “La ciencia española cae a nivel de 1998” (El Mundo, 30 mayo); y c) “Inveready Biotec II tendrá 17 millones para invertir" (Expansión, 14 mayo). Por un lado encontramos declaraciones como las de Manuel Posada que admite que hoy día en cuanto a investigación en ER "sí hay mucha ayuda y apoyo"; por otro lado, la investigadora Luisa María Botella reclama que "esta es sin duda la 
peor situación que hemos vivido"; y, en el último artículo se habla de que: "Con la aportación del CDTI, Inveready finaliza el periodo de constitución del fondo que dispone de un patrimonio de 17 millones de euros y que espera movilizar hasta 50 millones de euros para invertir en 20 empresas españolas del sector biosanitario". Se dice "hasta 50 millones de euros", lo que contrasta con "la peor situación" que exponía Botella o con la necesidad que tienen también otros proyectos de investigación para iniciarse y que deben "buscar mecenas" (Proyectos que buscan mecenas, El Diario Vasco, 14 mayo). Sería interesante analizar meses posteriores para saber si los medios se hacen eco de qué proyectos se inician con esta inversión y si la visión de los investigadores ha cambiado o no.

La Asociación Española Contra el Cáncer (AECC) también ha sido una de las grandes protagonistas en este bloque de investigación con más de 10 impactos. Su presidenta, Isabel Orbe, alerta de la escasa investigación en tumores infantiles y en su discurso aparece uno de los argumentos más repetidos en relación a las EPF y la investigación. Según Orbe, debido a que los tumores infantiles son considerados una enfermedad rara, "su análisis no es rentable". Argumento que se repite en otras noticias como: "sabemos que las enfermedades raras no son negocio" (Diario de Navarra, 9 mayo), "El lupus exigía inversiones demasiado fuertes para resultados inciertos" (El Correo Español, 6 mayo). Pero, en este caso podemos decir que en nuestro corpus hemos podido identificar menciones a uno de los contraargumentos más fuertes por el que se lucha en contra de lo anteriormente mencionado. El 31 de mayo, Diari de Terrassa publica "Queremos que sea un niño feliz" y en esta historia se hace referencia al hecho de que "con el dinero suficiente, habría cura en 5 años. Sería sobre todo para los que aún no han nacido". Es decir, actuar en un caso de una EPF, ayuda a los demás afectados. Esto también se ratifica en el artículo publicado por el mismo periódico cinco días antes "No sabían lo que tenía mi hijo". Fue gracias a que meses antes diagnosticaron a alguien con la misma enfermedad, por lo que estos padres pudieron recibir un diagnóstico muy rápido.

Estos mismos argumentos son asumidos por las propias farmacéuticas y empresas privadas de consultoría como Omakase. El consejero delegado de dicha consultoría llega a admitir en una entrevista a El Economista (15 mayo) que "los laboratorios deberán apostar por los contratos de pago por resultados para sus nuevos fármacos". Y, en este sentido se abriría el debate moral de para las EPF ¿qué se consideraría resultado que un medicamento frene la enfermedad, que la ralentice o que la cure? En este tema creemos que el abanico debería ser un poco más amplio y apelar a lo que se dice al final de la entrevista: "Hay que 
ser más solidario con lo que el sistema público puede ofrecer y tener una mentalidad de beneficio mutuo y no de beneficio propio"; nos quedamos con la idea de "beneficio compartido".

Los ensayos clínicos son los grandes desconocidos dentro del tema de la investigación. La mayor parte de la información que se ofrece generalmente sobre enfermedades poco frecuentes y ensayos clínicos tiene que ver con la recaudación de fondos de algún afectado en particular que desea participar en un ensayo clínico, pero pocos datos más se ofrecen. Sin embargo, esto ha ido cambiando y, por ejemplo, durante el mes de mayo observamos varios artículos sobre la regulación o aprobación de ensayos clínicos, pero la información no queda tampoco clara del todo. En El Semanario de Diario Médico (26 mayo) se constata que las EPF, sobre todo aquellas que aparecen en edades pediátricas, "quedan huérfanas y sin ensayos". Uno de los argumentos que se ofrecen en este artículo es que ni médicos ni investigadores pueden "elegir" sobre qué enfermedades realizar un ensayo clínico. Discovery Salud, por su parte, publica una noticia sobre la modificación de la legislación europea sobre ensayos clínicos y en la que se hace referencia a los afectados por una patología minoritaria. Según este artículo, esta modificación aprobada el 2 de abril por el Parlamento Europeo: "pretende ser una esperanza para los miles de personas que en Europa sufren alguna de las llamadas 'enfermedades raras' ya que facilita que los ensayos puedan realizarse simultáneamente en varios países”. Por tanto, si una persona afectada por síndrome de Sanfilippo lee estas dos noticias, ¿debería estar contento o descontento con la noticia? Pensamos que en un tema tan importante como son los avances en la ciencia y los ensayos clínicos, la información ha de ser lo más precisa posible ya que se está "jugando" con la esperanza, sobre todo, de los afectados. En este sentido vemos que el análisis desde el punto de vista lingüístico o microestructural es muy importante ya que un hecho o un acontecimiento singular para los medios, puede dejar de serlo para la sociedad por cómo se cuente.

El último tema al que vamos a referirnos en este análisis es el de "los nuevos fármacos". Si antes decíamos que los ensayos clínicos son muy importantes para las personas afectadas por una EPF, la aprobación de nuevos fármacos como tratamiento para una patología minoritaria lo es aún más. Durante el mes que hemos analizado se hace mención a la aprobación por parte de la Agencia Europea del Medicamento de 81 fármacos en 2013, 32 más que en 2012, y 12 de ellos destinados a enfermedades raras (El Global, 12 mayo). Lo cierto es que las cifras son esperanzadoras, sin embargo la información parece escasa. No sabemos qué medicamentos han sido aprobados ni para qué patologías han sido destinadas. 
Correo Farmacéutico (19 mayo) también publica una noticia sobre un preacuerdo entre la EMA y la FDA para la investigación de unos medicamentos como tratamiento de la enfermedad de Gaucher, aunque tampoco se especifica demasiado. No obstante, no sólo los "nuevos medicamentos" son noticia, también lo son la sustitución de medicamentos originales por genéricos y las consecuencias que esto está significando para pacientes "polimedicados". El Presidente de la Fundación contra la Hipertensión Pulmonar se queja de ello en una entrevista publicada en distintos medios (Diario de Ávila, Diario Palentino, 4 mayo). Según Enrique Carazo el sildenafilo ha sido sustituido por un genérico que no funciona tan bien en los pacientes con hipertensión pulmonar. Por otro lado, según la Gaceta de Salamanca, son los propios médicos quienes denuncian abandonos de tratamientos por no poder pagarlos (6 mayo). Algunas personas que tienen que tomar más de 5 medicamentos han dejado de hacerlo por no poder costear el tratamiento de su enfermedad. Llama la atención que en la propia noticia nos encontremos dos versiones distintas, la de la Asociación para la Defensa de la Sanidad Pública de Salamanca y la del Consejero de Sanidad de Castilla y León, Antonio Sáez Aguado. Según este último, solo se trataría de casos aislados. Como observamos, es el lector quien debe juzgar la noticia por sí solo ya que todas las versiones de las partes implicadas han quedado plasmadas en la noticia.

Para acabar con este análisis no podemos dejar de mencionar la aparición, aunque haya sido una sola vez en nuestro corpus de estudio, de un actor social muy importante vinculado a las EPF. Se habla de los pacientes, las familias, las asociaciones, los investigadores, los profesionales sanitarios... (Cruz y Requena, 2013: 212). Ahora también hablaremos del "paciente experto", que podríamos decir se encuentra entre el paciente y el profesional sanitario. De él se habla en términos de 'sostenibilidad' ya que gracias a personas como él (que saben gestionar su enfermedad, que mejoran la efectividad de los tratamientos y que reducen la frecuencia a consultas y urgencias) se reduce el gasto sanitario (Diario Médico, 13 mayo). Según Fidela Mirón, miembro de la junta directiva de FEDER, en EPF es un poco más complicado encajar al paciente experto. Sin embargo, nosotros pensamos que aquellas familias que conviven día a día con una persona afectada por una de estas patologías minoritarias, desde el mismo momento en que reciben el diagnóstico van convirtiéndose en expertos. 


\subsubsection{Conclusiones}

1. En comparación con otros meses (enero), el tema de la investigación es muy recurrente. $\mathrm{Al}$ igual que podemos decir que temas como la educación siguen sin tener demasiada presencia.

2. La celebración del Día Mundial de algún tipo de patología vuelve a ser objetivo de muchas asociaciones para informar a la sociedad sobre qué es, por ejemplo, el lupus. En muchas ocasiones hemos visto que hay gran tendencia a decir lo que NO son: narcolepsia "no es rara sino que está infradiagnosticada" (El Correo de Andalucía, 13 mayo); "el lupus es una enfermedad poco frecuente pero no es una enfermedad rara" (Diario Médico, 9 mayo); "la esclerodermia es una enfermedad degenerativa, crónica y que provoca discapacidad. No se contagia ni es hereditaria" (El Diario Montañés, 4 mayo).

3. La falta de especialización de algunos medios sigue estando presente cuando se repite información o cuando las expresiones o el tratamiento no es el adecuado, bien por el desconocimiento bien por el nulo tratamiento anterior de la información. Algunos ejemplos serían, cuando se describe la enfermedad de von Hippel-Lindau se dice que "es una enfermedad rara, familiar y hereditaria" (Súper Deporte, 3 mayo); cuando se hace referencia al proceso de peregrinaje por el que deben pasar las familias hasta conocer el diagnóstico se emplea el término "ir a caballo entre el hospital y la casa" o la expresión "problemas que arrastra hoy día” (La Opinión de Málaga, 9 mayo); o cuando escriben mal Histiocitosis de células de Langerhans (Langermans*) (Diari de Terrassa, 24 mayo).

\subsection{Análisis del discurso de la prensa española sobre las EPF en junio}

(Por Juan Manuel Arcos Urrutia, Universidad de Almería, CySOC)

\subsubsection{Corpus}

El corpus del mes de junio está formado por 347 piezas informativas publicadas en 107 cabeceras distintas. En la Tabla 1 mostramos un listado con aquellos diarios que informaron sobre las enfermedades poco frecuentes (EPF). Aparecen representadas la cabecera (CAB.), el número de noticias ( $\mathrm{N}^{\text {o }}$ NOTS.) y el porcentaje (\%) que le corresponde a cada uno de estos periódicos según su número y su relación con el total de noticias. En el Anexo final (Tabla 4), se indica a qué diario corresponde cada abreviatura presentada. 
Tabla 1. Número de noticias y porcentajes

\begin{tabular}{|c|c|c|}
\hline CABECERA & NOTICIAS. & $\%$ \\
\hline Correo Farmacéutico & 10 & 2,80 \\
\hline El Global & 10 & 2,80 \\
\hline Diario de Burgos & 9 & 2,52 \\
\hline Deia & 8 & 2,24 \\
\hline Diario de Almería & 8 & 2,24 \\
\hline Gaceta Médica & 8 & 2,24 \\
\hline Diario del Altoaragón & 7 & 1,96 \\
\hline Ideal (Almería) & 7 & 1,96 \\
\hline $\mathrm{ABC}$ & 6 & 1,68 \\
\hline Diario de Teruel & 6 & 1,68 \\
\hline El Diario Montañés & 6 & 1,68 \\
\hline El Mundo & 6 & 1,68 \\
\hline El Semanario de Diario Médico & 6 & 1,68 \\
\hline Heraldo de Aragón & 6 & 1,68 \\
\hline La Verdad de Cartagena & 6 & 1,68 \\
\hline Levante & 6 & 1,68 \\
\hline Diario de Noticias & 5 & 1,40 \\
\hline Diario Médico & 5 & 1,40 \\
\hline El Correo Gallego & 5 & 1,40 \\
\hline El Mundo (Cantabria) & 5 & 1,40 \\
\hline El Norte de Castilla (Salamanca) & 5 & 1,40 \\
\hline El Norte de Castilla & 5 & 1,40 \\
\hline La Nueva España & 5 & 1,40 \\
\hline Alerta de Cantabria & 4 & 1,12 \\
\hline Diario de Navarra & 4 & 1,12 \\
\hline Diario de Sevilla & 4 & 1,12 \\
\hline El Adelantado de Segovia & 4 & 1,12 \\
\hline Granada Hoy & 2 & 0,56 \\
\hline Heraldo de Soria & 2 & 0,56 \\
\hline Ideal (Granada) & 2 & 0,56 \\
\hline Diario de Ávila & 2 & 0,56 \\
\hline Diario de Cádiz & 2 & 0,56 \\
\hline Diario de León & 2 & 0,56 \\
\hline Diario de Teruel & 2 & 0,56 \\
\hline El Correo Español (Álava) & 2 & 0,56 \\
\hline La Tribuna de Ciudad Real & 2 & 0,56 \\
\hline El Día (Tenerife) & 2 & 0,56 \\
\hline El Economista & 2 & 0,56 \\
\hline El Faro de Melilla & 2 & 0,56 \\
\hline El Proceso & 2 & 0,56 \\
\hline El Periódico de Aragón & 2 & 0,56 \\
\hline La Verdad de Murcia & 2 & 0,56 \\
\hline La Voz de Almería & 2 & 0,56 \\
\hline Lanza & 2 & 0,56 \\
\hline Las Provincias & 2 & 0,56 \\
\hline Love & 2 & 0,56 \\
\hline Menorca Diario Insular & 2 & 0,56 \\
\hline Sport & 2 & 0,56 \\
\hline Última Hora & 2 & 0,56 \\
\hline 20 Minutos (Andalucía) & 1 & 0,28 \\
\hline ABC (Sevilla) & 1 & 0,28 \\
\hline ABC (Toledo) & 1 & 0,28 \\
\hline Anuncios & 1 & 0,28 \\
\hline Cinco Días & 1 & 0,28 \\
\hline
\end{tabular}




\begin{tabular}{|c|c|c|}
\hline El Comercio & 4 & 1,12 \\
\hline El Correo de Andalucía & 4 & 1,12 \\
\hline El Correo Español (Bizkaia) & 4 & 1,12 \\
\hline El Diario Vasco & 4 & 1,12 \\
\hline El Periódico de Extremadura & 4 & 1,12 \\
\hline La Razón & 4 & 1,12 \\
\hline La Voz de Avilés & 4 & 1,12 \\
\hline Super Deporte & 4 & 1,12 \\
\hline La Región & 3 & 0,84 \\
\hline La Rioja & 3 & 0,84 \\
\hline La Tribuna de Toledo & 3 & 0,84 \\
\hline La Vanguardia & 3 & 0,84 \\
\hline La Verdad de Alicante & 3 & 0,84 \\
\hline La Voz de Galicia & 3 & 0,84 \\
\hline Málaga Hoy & 3 & 0,84 \\
\hline La Opinión de Murcia & 3 & 0,84 \\
\hline La Opinión de Tenerife & 3 & 0,84 \\
\hline Diario de Jerez & 3 & 0,84 \\
\hline Diario de Pontevedra & 3 & 0,84 \\
\hline La Opinión de A Coruña & 3 & 0,84 \\
\hline Ideal (Jaén) & 2 & 0,56 \\
\hline La Opinión de Málaga & 2 & 0,56 \\
\hline La Tribuna de Albacete & 2 & 0,56 \\
\hline Atlántico Diario & 2 & 0,56 \\
\hline Canarias 7 & 2 & 0,56 \\
\hline Córdoba & 2 & 0,56 \\
\hline Europa Sur & 2 & 0,56 \\
\hline Diario de Avisos & 1 & 0,28 \\
\hline Diario de Mallorca & 1 & 0,28 \\
\hline Diario de Noticias (Álava) & 1 & 0,28 \\
\hline Dinero y Salud & 1 & 0,28 \\
\hline El Correo Español & 1 & 0,28 \\
\hline El Faro de Ceuta & 1 & 0,28 \\
\hline El Mundo (Sevilla) & 1 & 0,28 \\
\hline El Mundo-Diario de Valladolid & 1 & 0,28 \\
\hline El Mundo de tu Bebé & 1 & 0,28 \\
\hline El País (País Vasco) & 1 & 0,28 \\
\hline El Siglo de Europa & 1 & 0,28 \\
\hline Expansión & 1 & 0,28 \\
\hline Información (Alicante) & 1 & 0,28 \\
\hline La Mañana Diario de Ponent & 1 & 0,28 \\
\hline La Gaceta Regional de Salamanca & 1 & 0,28 \\
\hline La Opinión de Cartagena & 1 & 0,28 \\
\hline La Opinión-El Correo de Zamora & 1 & 0,28 \\
\hline La Provincia-Diario de Las Palmas & 1 & 0,28 \\
\hline La Tribuna de Cuenca & 1 & 0,28 \\
\hline La Voz de Cádiz & 1 & 0,28 \\
\hline Mujer Hoy & 1 & 0,28 \\
\hline Nueva Alcarria & 1 & 0,28 \\
\hline Pronto & 1 & 0,28 \\
\hline Sur & 1 & 0,28 \\
\hline Teleprograma & 1 & 0,28 \\
\hline Tiempo & 1 & 0,28 \\
\hline
\end{tabular}

En total son 107 cabeceras de periódicos nacionales, regionales y locales diferentes las que informaron sobre las EPF. Los medios que mayor número de noticias ofrecieron son 
dos diarios especializados: El Correo Farmacéutico y El Global, con 10 noticias cada uno. En el primero de ellos se informa, por ejemplo, de los avances médicos y de las nuevas medidas farmacéuticas adoptadas en alguna patología en concreto, como Gaucher, FPI o Duchenne. En el diario El Global, por su parte, aparecen representadas iniciativas de los laboratorios: Bayer alimenta con inversión su vocación innovadora, Celgene pisa fuerte en la generación de innovación o La Fundación Salud 2000 pro fármacos huérfanos y EE. RR., entre otras. Podemos destacar, además, la presencia de dos cabeceras de la provincia de Almería: Diario de Almería e Ideal, con 8 y 7 noticias, respectivamente. Esta difusión se debe a la celebración de la I Carrera solidaria por las enfermedades poco frecuentes que tuvo lugar en la capital almeriense el pasado 8 de junio. Esta carrera fue organizada por el Observatorio de las Enfermedades Raras de FEDER y por el AMPA del Colegio La Salle Virgen del Mar de Almería.

\subsubsection{Análisis macroestructural}

Los temas más relevantes que aparecen representados en las noticias de junio son los siguientes:

1. La Fundación Stop Sanfilippo consigue reunir un millón de euros para la investigación de esta patología.

2. Registro de EPF en Extremadura.

3. I Carrera solidaria EPF en Almería.

4. Sanidad impulsa la innovación en el ámbito de las EPF.

5. La I+D en patologías raras da notoriedad a Minoryx.

6. Galicia diagnosticó 39 patologías poco frecuentes de tipo metabólico en un año.

7. Diecisiete especialistas debaten en Navia sobre enfermedades raras.

8. El pequeño Juan Jiménez participará en un estudio mundial sobre su enfermedad.

9. Una bota de Xavi, rifada para ayudar a un niño con una EPF.

10. Varias familias con hijos que padecen EPF han sido estafadas por una mujer de Toledo.

11. Estudian en Salamanca una terapia innovadora contra la atrofia muscular infantil.

12. Autorización condicional de la EMA para una terapia en Duchenne.

13. Estudios de imagen para la detección en Gaucher de afectación ósea.

14. Shire Pharma, del lado de las asociaciones de pacientes.

15. La radiología, clave para la enfermedad de Gaucher. 
16. Isabel Gemio lucha contra las enfermedades raras.

17. Un tratamiento revolucionario para la atrofia muscular infantil.

18. Debra pide más recursos para los enfermos.

19. Farmacéuticas y biotecnológicas, a la caza de las enfermedades raras.

20. Pirfenidona, el último aliento para la FPI.

21. El proyecto 'Find' ayuda a los pediatras a identificar las enfermedades raras.

22. Reprochan los criterios exclusivos economicistas en medicamentos huérfanos.

23. Diez especialistas en porfiria analizan los avances de una enfermedad que sufren 2.000 personas.

24. La lucha de Pol contra el síndrome de Sanfilippo.

25. Dos expertos internacionales exploran al chico de Santa Lucía que sufre síndrome de Schimke.

Hay noticias en los que el principal protagonista es la propia patología o los afectados y sus familiares. En otras, los protagonistas son personas conocidas, Xavi o Isabel Gemio, que prestan su imagen y su lucha para apoyar la causa de las EPF. También encontramos temas en los que los protagonistas son las asociaciones de pacientes, profesionales sanitarios, políticos o empresas farmacéuticas, entre otros.

A continuación, en la Tabla 2 mostramos las EPF que se han mencionado al menos dos veces en las 347 noticias del corpus de junio. Nos hemos detenido en la frecuencia con la que aparece dicha patología, el porcentaje en relación al número total de noticias y en la cabecera en la que apareció esa enfermedad.

Tabla 2. Patologías mencionadas en junio

\begin{tabular}{|l|c|c|l|}
\hline Patología & $\begin{array}{c}\mathbf{N}^{\mathbf{0}} \\
\text { Menciones }\end{array}$ & $\mathbf{\%}$ & Medios \\
\hline $\begin{array}{l}\text { Atrofia muscular } \\
\text { espinal (AME) }\end{array}$ & 10 & 28,8 & $\begin{array}{l}\text { El Norte de Castilla (Salamanca) (4); Diario de } \\
\text { Teruel; La Opinión de Málaga; Diario Palentino } \\
\text { (2); El Mundo-Diario de Valladolid }\end{array}$ \\
\hline $\begin{array}{l}\text { Síndrome } \\
\text { (Enfermedad) de } \\
\text { Sanfilippo }\end{array}$ & 7 & 20,16 & $\begin{array}{l}\text { El Correo Español (Bizkaia); Diario de Teruel } \\
\text { (2); AD; El Correo Español (Álava); Expansión } \\
\text { (Cataluña); La Región }\end{array}$ \\
\hline $\begin{array}{l}\text { Esclerosis lateral } \\
\text { amiotrófica (ELA) }\end{array}$ & 6 & 17,28 & $\begin{array}{l}\text { Diario Médico; Nueva Alcarria; El Periódico de } \\
\text { Aragón; 20 Minutos (Andalucía); La Nueva } \\
\text { España; La Vanguardia }\end{array}$ \\
\hline $\begin{array}{l}\text { Mucopolisacaridosis } \\
\text { (MPS) }\end{array}$ & 6 & 17,28 & $\begin{array}{l}\text { El Global (2); Gaceta Médica (2); Diario de } \\
\text { Teruel; El Ideal Gallego }\end{array}$ \\
\hline $\begin{array}{l}\text { Distrofia muscular } \\
\text { (Enfermedad) de } \\
\text { Duchenne }\end{array}$ & 5 & 14,4 & $\begin{array}{l}\text { Correo Farmacéutico; Love; Sport; Diario de } \\
\text { Jerez; El Correo de Andalucía }\end{array}$ \\
\hline $\begin{array}{l}\text { Síndrome de Wolf- } \\
\text { Hirschhorn }\end{array}$ & 5 & 14,4 & $\begin{array}{l}\text { Diario de Pontevedra; El Ideal Gallego; El } \\
\text { Proceso; La Voz de Galicia; ABC (Toledo) }\end{array}$ \\
\hline
\end{tabular}




\begin{tabular}{|c|c|c|c|}
\hline $\begin{array}{l}\text { Síndrome de } \\
\text { Schimke// } \\
\text { Displasia Inmunósea } \\
\text { de Schimke }\end{array}$ & 4 & 11,52 & $\begin{array}{l}\text { La Verdad de Cartagena (3); La Opinión de } \\
\text { Cartagena }\end{array}$ \\
\hline $\begin{array}{l}\text { Enfermedad de } \\
\text { Gaucher }\end{array}$ & 4 & 11,52 & $\begin{array}{l}\text { Gaceta Médica; El Global; Heraldo de Aragón; } \\
\text { Correo Farmacéutico }\end{array}$ \\
\hline Fibrosis quística & 4 & 11,52 & $\begin{array}{l}\text { La Gaceta Regional de Salamanca; El Norte de } \\
\text { Castilla (Salamanca); Expansión (Cataluña); El } \\
\text { Diario Vasco }\end{array}$ \\
\hline Síndrome de Rett & 4 & 11,52 & $\begin{array}{l}\text { Información; Gaceta Médica; ABC (Toledo); La } \\
\text { Verdad de Alicante }\end{array}$ \\
\hline $\begin{array}{l}\text { Fémur corto } \\
\text { congénito }\end{array}$ & 3 & 8,64 & El Adelantado de Segovia (3) \\
\hline Porfiria & 3 & 8,64 & $\begin{array}{l}\text { Diario de Burgos; El Correo de Andalucía; } \\
\text { Correo Farmacéutico }\end{array}$ \\
\hline $\begin{array}{l}\text { Angioedema } \\
\text { hereditario }\end{array}$ & 2 & 5,76 & Gaceta Médica; El Global \\
\hline Distrofia muscular & 2 & 5,76 & El Día de Córdoba; Córdoba \\
\hline $\begin{array}{l}\text { Enfermedad } \\
\text { (Síndrome) de } \\
\text { Arnold Chiari }\end{array}$ & 2 & 5,76 & Diario de Burgos; La Nueva España \\
\hline $\begin{array}{l}\text { Enfermedad de } \\
\text { Fabry }\end{array}$ & 2 & 5,76 & El Mundo (Sevilla); Anuncios \\
\hline $\begin{array}{l}\text { Enfermedad de } \\
\text { Huntington }\end{array}$ & 2 & 5,76 & Diario de Burgos; El Correo Gallego \\
\hline $\begin{array}{l}\text { Enfermedad de los } \\
\text { huesos de cristal }\end{array}$ & 2 & 5,76 & El Mundo (Cantabria) (2) \\
\hline Espina bífida & 2 & 5,76 & La Opinión de Málaga; El Correo de Andalucía \\
\hline $\begin{array}{l}\text { Fibrodisplasia } \\
\text { osificante progresiva } \\
(\text { FOP })\end{array}$ & 2 & 5,76 & $\begin{array}{l}\text { Diario del Altoaragón; El Semanario de Diario } \\
\text { Médico }\end{array}$ \\
\hline Focomelia & 2 & 5,76 & Diario de Mallorca; Última Hora \\
\hline $\begin{array}{l}\text { Osteogénesis } \\
\text { imperfecta }\end{array}$ & 2 & 5,76 & El Mundo (Cantabria); El Diario Montañés \\
\hline Síndrome de Löwe & 2 & 5,76 & EL Mundo (Cantabria) (2) \\
\hline Síndrome de TAR & 2 & 5,76 & Diario de Mallorca; Última Hora \\
\hline Siringomielia & 2 & 5,76 & Diario de Burgos; La Nueva España \\
\hline
\end{tabular}

En el corpus aparecen un total de 98 enfermedades minoritarias representadas, de las cuales solamente 25 se nombran más de una vez. La Atrofia Muscular Infantil (por la repercusión de un estudio revolucionario en Salamanca) es la patología que más veces ha sido aludida. En total 10 veces. El segundo lugar lo ocupa la enfermedad de Sanfilippo con 7 menciones. Durante el mes de junio se han llevado a cabo varias campañas para recaudar fondos para esta patología, como por ejemplo, la rifa de una bota del jugador del F.C. Barcelona Xavi Hernández, así como la recaudación de un millón de euros que ha conseguido reunir la Fundación StopSanfilippo para la investigación de esta enfermedad. También tienen protagonismo otras patologías, como la ELA (Esclerosis Lateral Amiotrófica) que aparece representada 6 veces. Destacan, por ejemplo, los titulares en los que se hace mención a la propia patología: "La esclerosis amiotrófica afecta a más de 12 aragoneses al año" o 
"Guadalajara contabiliza 16 afectados por Esclerosis Lateral Amiotrófica". Es importante mencionar también la MPS como parte de las enfermedades que participarán en el Proyecto Find para ayudar a los pediatras a identificar enfermedades raras. El Síndrome de WolfHirschhorn aparece 5 veces en relación a una noticia muy desagradable: 'Estafados con rifas falsas los padres de una niña viguesa con una enfermedad rara'. Además de las patologías que se citan en la Tabla 2, aparecen mencionadas solo una vez (2,88\%, cada una). Estas enfermedades son las siguientes: Acidemia isovalérica, Aciduria glutámica tipo I, Adrenoleucodistrofia, Alzhéimer infantil, Atrofia del nervio óptico de Léber, Calcifilaxis, Cáncer de páncreas, Coroideremia, Craneosinostosis, Deficiencia de Acil CoA deshidrogenada de ácidos grasos, Deficiencia de anilisoripsina, Demencia de CreutzfeldtJakob, Distonía, Distrofia muscular de Becker, Distrofia muscular progresiva, Enfermedad de Lyme, Enfermedad de células falciformes, Enfermedad de cuerpos de Lewy, Enfermedad de Fahr, Enfermedad de Gerstmann-Sträussler, Enfermedad de jarabe de arce, Enfermedad de Kufor-Rakeb, Enfermedad de Marchiafava-Bignami, Enfermedad de Nasu-Hakola, Enfermedad de Niemann-Pick, Enfermedad de Pick, Enfermedad de piel de mariposa, Enfermedad de Von Willebrand, Enfermedad de Werning Hoffmann, Enfermedad de Whipple, Enfermedad de Behçet, Epidermolisis Ampollosa herditaria (EA), Epidermólisis Bullosa, Esclerodermia, Esclerosis, Esclerosis tuberosa con epilepsia secundaria, Fenilcetonuria, Fibrosis pulmonar idiopática (FPI), Gangliosidosis GM1, Gliomatosis cerebri, Glucogenosis tipo II, Hipertensión pulmonar compleja, Homocistinuria, Leucemia, Leucoencefalopatía megalencefálica, Linfangioleiomiomatosis (LAM), Mastocitosis, Miastenia (grave), Mielitis, Mieloma múltiple, Neuritis óptica, Neuroblastoma, Neurofibromatosis, Queratitis neurotrófica, Retinosis pigmentaria, Sarcoma, Sarna, Síndrome de Angelman, Síndrome de Donohue, Síndrome de Ehlers Danlos, Síndrome de Gilles de la Tourette, Síndrome de Kabuki, Síndrome de Marfan, Síndrome de Midas, Síndrome de Tourette, Síndrome de Von Hippel-Lindau, Síndrome de West, Síndrome de X Frágil, Telangiectasia hemorrágica hereditaria (HHT) y Trisomia 21. Como ya se ha dicho en este informe, el mero hecho de que estas patologías hayan aparecido, aunque solo sea en una ocasión, ya es un paso muy importante.

A continuación, en la Tabla 3, exponemos aquellas patologías que se nombran en los titulares, donde indicamos el número de menciones que ha tenido, el porcentaje respecto al número total de noticias del corpus general y las cabeceras en las que se ha publicado la noticia. 
Tabla 3. Patologías mencionadas en los titulares

\begin{tabular}{|l|c|c|l|}
\hline \multicolumn{1}{|c|}{ Patología } & $\begin{array}{c}\text { Menciones } \\
\text { en titulares }\end{array}$ & $\%$ & \multicolumn{1}{|c|}{ Medios } \\
\hline Atrofia muscular infantil & 2 & 5,76 & El Norte de Castilla (Salamanca) (2) \\
\hline Distrofia muscular de Duchenne & 2 & 5,76 & Correo Farmacéutico; Sport \\
\hline Enfermedad de Gaucher & 2 & 5,76 & $\begin{array}{l}\text { Heraldo de Aragón; Correo } \\
\text { Farmacéutico }\end{array}$ \\
\hline Esclerosis lateral amiotrófica & 2 & 5,76 & $\begin{array}{l}\text { El Periódico de Aragón; Nueva } \\
\text { Alcarria }\end{array}$ \\
\hline Fibrosis quística & 2 & 5,76 & $\begin{array}{l}\text { El Norte de Castilla (Salamanca); La } \\
\text { Gaceta Regional de Salamanca }\end{array}$ \\
\hline Síndrome de Rett & 2 & 5,76 & Información; Gaceta Médica \\
\hline Síndrome de Sanfilippo & 2 & 5,76 & El Correo Español (Bizkaia); DT \\
\hline Atrofia muscular espinal & 1 & 2,88 & Diario Palentino \\
\hline Distonía & 1 & 2,88 & El Periódico de Aragón \\
\hline Enfermedad de Huntington & 1 & 2,88 & Diario de Burgos \\
\hline Enfermedad de Werning Hoffmann & 1 & 2,88 & El Norte de Castilla (Salamanca) \\
\hline Fibrosis pulmonar idiopática (FPI) & 1 & 2,88 & Correo Farmacéutico \\
\hline Gliomatosis cerebri & 1 & 2,88 & Diario del Altoaragón \\
\hline Leucoencefalopatía megalencefálica & 1 & 2,88 & Gaceta Médica \\
\hline Mastocitosis & 1 & 2,88 & Diario Médico \\
\hline Miastenia (grave) & 1 & 2,88 & Levante \\
\hline Porfiria & 1 & 2,88 & Diario de Burgos \\
\hline Sarna & 1 & 2,88 & El Correo Gallego \\
\hline Síndrome de Arnold Chiari & 1 & 2,88 & Diario de Burgos \\
\hline Síndrome de (Gilles de la) Tourette & 1 & 2,88 & Lanza \\
\hline Síndrome de Schimke & 2,88 & La Verdad de Cartagena \\
\hline
\end{tabular}

En 28 ocasiones, como vemos en la Tabla 3, se ha mencionado alguna patología poco frecuente de las representadas en la Tabla 2 en los titulares, lo que significa un 8\%. Estas patologías aparecen representadas en los titulares, principalmente, cuando a) se trata de algún avance terapéutico, como son los casos de la Atrofia Muscular Infantil o la Distrofia Muscular de Duchenne; b) cuando se trata de casos particulares de avances con algún paciente, como es el caso de un joven afectado por el Síndrome de Schimke en el que dos expertos internacionales van a explorarlo; c) cuando se informa de alguna iniciativa informativa para dar a conocer ciertas patologías. Este es el caso de la porfiria, en la que en unas jornadas se han dado a conocer los avances para esta patología, o el encuentro en el CREER de Burgos sobre el síndrome de Huntington.

Los periódicos con más titulares son los siguientes: El Norte de Castilla, Correo Farmacéutico, El Periódico de Aragón, Diario de Burgos, Heraldo de Aragón y Gaceta Médica. Tenemos que advertir que hay un discurso ecoico (Bañón y Fornieles, 2011:20) en algunas de las menciones, ya que hay noticias y titulares que se repiten por tratarse de medios del mismo grupo editorial. Lo mismo sucede con noticias procedentes de agencias. 


\subsubsection{Análisis microestructural}

Las enfermedades raras se ven por un gran número de personas, entre ellas pacientes, familiares, sanitarios o farmacéuticos, como enfermedades caras, de difícil diagnóstico, de poca rentabilidad, desconocidas, etc. Aunque aparecen otros factores reflejados en las noticias de prensa del mes de junio de 2014.

Aunque poco a poco van apareciendo más noticias de ER en los medios, todavía queda mucho trabajo por hacer en materia de sensibilización y visibilidad para que la sociedad comprenda los problemas y las necesidades que estos pacientes y sus familias exigen a las administraciones del Estado. Aunque la situación diaria de estas personas es muy compleja, hay todavía un hilo de esperanza y encontramos titulares como el siguiente: "Un tratamiento revolucionario para la atrofia muscular infantil" (El Norte de Castilla, 29.06.14) o "Una esperanza para Juanito” (La Opinión de Cartagena, 24.06.14).

En la noticia del Diari de Terrasa "Pol vive una contrarreloj para salvarse" del 7 de junio, la madre de este niño que padece el Síndrome de Sanfilippo expone que 'hallar la cura era posible' y argumenta que el problema es 'financiar la investigación'. En su caso, 'estamos como locos por conseguir 4.000.000 de euros para hacer un ensayo clínico con humanos porque no podemos perder más tiempo con animales'. En esta declaración, los factores desesperación y rapidez van de la mano, como ocurre con otras muchas patologías poco frecuentes. La expresión 'estar como locos' conlleva una desesperación añadida al problema que padece la familia. Ya la expresión 'vive una contrarreloj para salvarse' nos indica, en este sentido, que hay que actuar muy rápido para salvar la vida a este pequeño.

Aunque las enfermedades poco frecuentes afectan por igual a niños, a adolescentes y a adultos, lo cierto es que hay un protagonismo claro de los primeros sobre los otros dos grupos. En este sentido, podemos decir, además, que las informaciones sobre enfermedades raras son informaciones en muchas ocasiones con nombre propio (de niña o de niño). Los nombres propios intensifican la sensación de proximidad y su componente emotivo. Durante el mes de junio hemos encontrado varios ejemplos:

\footnotetext{
“Una esperanza para Juanito” (La Opinión de Cartagena, 24.06.14).

"Pol vive una contrarreloj para salvarse" (Diari de Terrasa, 07.06.14).

“La esperanza de Nicolás y Víctor” (Diario de Burgos, 22.06.14).

“Cuenta atrás para ayudar a Lucas, Aitor, Arón y Pedro” (El Mundo-Cantabria, 10.06.14).
} 
En los titulares 1 y 3 los nombres de los niños vienen acompañados con la palabra 'esperanza', en el que se les transmite a los lectores que participen activamente ayudando y participando en las actividades para conseguir el objetivo previsto para cada causa solidaria prevista. Los factores tiempo y desesperación también están muy presentes en ambos titulares. Por su parte, los titulares 2 y 4 vienen acompañados por el valor metafórico del tiempo de nuevo, 'contrarreloj' y 'cuenta atrás' dando por sentado que hay que actuar muy rápido.

En relación al argumento que aparece siempre cuando se habla del coste del tratamiento de una patología rara, las familias, a veces, tienen que 'hipotecar' sus vidas para poder financiar los altísimos costes que tienen los tratamientos. Por ejemplo, el padre de una niña con síndrome de Ehlers Danlos comenta en la noticia "Que salga el sol muchos días" (22.06.14) la desesperación económica que acarrea esta situación. Indica que 'vivíamos muy bien, no nos podíamos quejar de dinero. Ahora nos hemos gastado todos los ahorros, nos ha ayudado la familia y todavía tenemos que recurrir a iniciativas de este tipo para poder hacer frente a los costes, porque todo esto es carísimo'. En esta declaración, el adverbio de tiempo "todavía" nos está indicando que el problema no ha acabado, es decir, aún les queda mucho camino por recorrer para poder encontrar una cura para la enfermedad de su hija.

También los pacientes o representantes de asociaciones demandan más dinero para financiar proyectos de investigación. Por ejemplo, Andrés Mayor, presidente de la asociación asturiana de retinosis, pide 'más investigación porque es lo que ellos más necesitan'. Además, las administraciones están trabajando para poder lograr una medicación menos gravosa, según se indica en esta misma noticia. En este sentido, Borja Rodríguez, trabajador social de la Salud Pública de Asturias, dice que el medicamento para una enfermedad puede costar entre 250.000 y 300.000 euros. De nuevo, el hecho de que aparezcan las cifras nos conduce a la idea de un precio muy elevado al que tienen que hacer frente las administraciones pública, tal y como aparece representado en las noticias.

Por otro lado, la observación de las descripciones en prensa de las EPF nos aporta datos de interés igualmente. Presentamos, a continuación, algunos ejemplos, basados principalmente en la descripción general o específica de la patología. A veces es complicado poder llegar a entender el contenido de la información por la utilización de una terminología $\tan$ especializada.

El Síndrome de Sanfilippo (o mucopolisacaridosis tipo III) es una enfermedad infantil degenerativa, genética y mortal. La enfermedad se comienza a manifestar de los 2 a los 5 
años de edad. La falta de una enzima en su organismo hace que su cuerpo no genere cadenas largas de moléculas de azúcar acumulándolas en los lisosomas (Diari de Terrassa, 07.06.14).

La enfermedad de Von Hippel-Lindau es una rara alteración genética que provoca que los afectados desarrollen tumores que pueden producir graves secuelas en órganos vitales provocando tetraplejia, ceguera... (Super Deporte, 10.06.14).

(...) leucoenfalopatía megalencefálica, una enfermedad rara y degenerativa de la mielina que provoca megalencefalia, deterioro de las funciones motoras, epilepsia y retraso mental y que, actualmente, carece de tratamiento efectivo (Gaceta Médica, 02.06.14).

El tema más positivo de la representación discursiva de las EPF es la investigación. El 90\% de estas enfermedades no tiene tratamiento, aunque tampoco podemos decir que no exista investigación en EPF; se está produciendo un importante avance. Es aquí donde siempre aparece un debate muy interesante, con dos tipos de discursos contradictorios. Aparece una valoración negativa, en el que se denuncia que no hay investigación, que los tratamientos son muy caros o que no se invierte lo suficiente. Por otro lado, se da una valoración positiva, puesto que es justamente en la investigación donde está la solución para paliar los problemas que sufren a diario las personas con una EPF y sus familias.

Los avances que se están realizando en genética, a partir de la terapia génica, o la implantación de nuevas empresas de componente biotecnológico en España están arrojando una pequeña luz para que en el futuro un número importante de estas patologías tenga ya un tratamiento que por lo menos reduzca la gravedad de su situación. La investigación en EPF está asociada con mucha frecuencia a valores positivos tales como la innovación, lo que les confiere un especial interés por parte de los medios de comunicación.

En el corpus de noticias de junio, hemos encontrado varios ejemplos de piezas informativas en las que se informa justamente de esta realidad: los avances en innovación y en biotecnología.

Bayer alimenta con inversión su vocación innovadora (El Global, 09.06.14).

Celgene pisa fuerte en la generación de innovación (El Global, 09.06.14).

La I+D en patologías raras da notoriedad de Minoryx (El Semanario de Diario Médico, 16.06.14).

La biotecnología se refugia en los medicamentos huérfanos (Expansión (Cataluña), 16.06.14).

La farmacéutica Dompé invierte 37 millones en biotecnología (El Economista, 19.06.14).

A lo largo de los últimos años, junto a las valoraciones positivas encontramos testimonios críticos. Algunas de las críticas surgen en el discurso de los propios pacientes y de las 
asociaciones que son los primeros en impulsar los proyectos y en colaborar activamente en las iniciativas que buscan recursos para la investigación. Estas iniciativas engloban, por ejemplo, recogidas de tapones, carreras solidarias o galas benéficas para recaudar dinero para ayudar a las personas con una EPF. Los medios de comunicación, como no podía ser de otra manera, se han hecho eco de estas actividades solidarias.

La noche de Gandía fue testigo de otra multitudinaria carrera (Superdeporte, 03.06.14).

Gala con mucha magia para ayudar a la pequeña Maialen (Deia, 08.06.14).

Más de mil almerienses corren hoy por una buena causa (Ideal de Almería, 08.06.14).

1.500 personas salen a correr por una buena causa (Ideal de Almería, 09.06.14).

Caballos y golf para la solidaridad (Diario de Avisos, 19.06.14).

Además de estas iniciativas solidarias, son importantes también los avances que se están llevando a cabo en la investigación médica. Hay iniciativas para intentar paliar la gravedad de varias enfermedades. Con esta noticia se abre una nueva ventana al panorama de las ER, ya que siempre son descritas como patologías muy caras o poco rentables. Pues bien, si se descubre que un fármaco en concreto puede ayudar a paliar los efectos de otras EPF sería un gran avance para este tipo de investigaciones.

Pirfenidona, el último aliento para la FPI (Correo Farmacéutico, 02.06.14).

Autorización condicional de la EMA para una terapia de Duchenne (Correo Farmacéutico 02.06.14).

Identificado un nuevo subtipo sistémico de mastocitosis (Diario Médico, 04.06.14).

Estudian un nuevo tratamiento para evitar la metastesis del cáncer de mama (ABC (Ed. Sevilla), 09.06.14).

Un tratamiento revolucionario para la atrofia muscular infantil (El Norte de Castilla (Edición de Salamanca), 29.06.14).

Pero también se destacan los avances tan importantes que se están produciendo a la hora de reducir el tiempo para comunicar el diagnóstico de ciertas EPF. El tiempo medio para tener un diagnóstico oscila entre los 5 y los 8 años.

Científicos canadienses descifran 146 enfermedades raras infantiles (Correo Farmacéutico, 09.06.14).

El proyecto 'Find' ayudará a los pediatras a identificar un grupo de enfermedades raras (El Ideal Gallego, 25.06.14). 
La prueba del talón detecta trece casos de enfermedades raras (Deia, 27.06.14).

Estudios de imagen para la detección en Gaucher de afección ósea (Correo Farmacéutico, 30.06.14).

Los avances en investigación, además, trascienden a lo médico y llegan, por ejemplo, también a la gestión sanitaria que tanto demandan los pacientes. Se trata de la creación de registros de ER en las distintas comunidades autónomas de España, como es el caso de Extremadura.

El registro de enfermedades raras de Extremadura detecta 18.000 casos (El Periódico de Extremadura, 06.06.14).

En relación con el discurso político en torno a las enfermedades poco frecuentes, Requena y Bañón (2011, 165-166) establecen dos momentos especialmente destacables. El primero hace referencia a la presencia o no de elementos que marcan los tiempos de acción de una forma definida o indefinida. En este sentido, aparecen algunos ejemplos en nuestro corpus de junio de 2014.

En la noticia "Amatou pide una unidad de referencia para abordar el síndrome de Tourette" del 30 de junio, Montserrat Reillo, la presidente de la Asociación CastellanoManchega de Pacientes con Síndrome de Tourette (Amatou), relató que hace un año solicitó al Servicio de Salud de Castilla La Mancha una unidad de referencia para esta patología, aunque por el momento todavía no ha recibido ninguna respuesta por parte de de la Administración sanitaria. En este punto hemos de decir que la Administración no adquiere, en cierto modo, un compromiso sobre actuaciones en torno a las EPF que vayan acompañadas de límites temporales muy poco definidos: 'aunque por el momento todavía no ha recibido ninguna respuesta de la Administración sanitaria'.

La segunda cuestión que plantean Requena y Bañón gira en torno a la simetría o asimetría entre el decir y el hacer de los políticos con responsabilidad directa o indirecta en el ámbito de la salud. Por lo que respecta a las noticias que hemos analizado tendremos que esperar un tiempo para cotejar si ese decir y ese hacer coindicen o, si por el contrario, se ha cumplido con lo prometido, como viene siendo lo habitual en este sentido.

Asimismo, ha adquirido protagonismo el discurso que desde los ayuntamientos se hacen. La mirada de la política municipal y las actividades que han desarrollado es más cercana a los problemas que los ciudadanos se encuentran y eso también puede manifestarse en el ámbito de las EPF. Tenemos un ejemplo en el que Isabel Paredes, delegada de Bienestar Social de Jerez destaca 'la labor de concienciación y sensibilización que juegan un papel fundamental en el tejido asociativo y de las administraciones'. Además apunta que 'desde lo 
público debemos estar cerca de los problemas de la ciudadanía y apoyar aquellas iniciativas que reducen en la mejora de calidad de vida'. Esos dos conceptos 'concienciación' y 'sensibilización' son muy importantes cuando se habla de enfermedades minoritarias, pero las asociaciones y los pacientes demandan otro tipo de iniciativas para paliar sus problemas. Piden más investigación, aunque los representantes políticos utilizan estos discursos mayoritariamente para hacer ver su implicación activa en estos problemas, hecho que solo se queda en una mera aproximación afectiva, algo que también es muy importante, pero que apenas se establece un compromiso real que se materialice en iniciativas concretas.

En relación a esta última reflexión, en nuestro corpus, aparece una noticia "Belén Do Campo, con los enfermos crónicos" del 13 de junio, en el que la delegada territorial de la Xunta de Galicia se reunió con una representante de la Federación Gallega de Enfermedades Raras y Crónicas para conocer de primera mano su labor. En esta noticia, aparecen en la foto que acompaña la pieza ambas mujeres dialogando sobre los problemas. Nos ha llamado la atención que la delegada está tomando nota de los problemas que le está transmitiendo. Esta iniciativa es muy interesante puesto que es lo que los pacientes llevan demandando durante muchos años, sentarse a trabajar con los responsables políticos.

Además, hemos identificado discursos muy relevantes presentados por los portavoces de las Comunidades Autónomas donde se establecen, por ejemplo, las iniciativas en materia de los registros de pacientes con ER o de iniciativas en general para mejorar las necesidades que demandan los colectivos de estas enfermedades. Durante el mes de junio, Extremadura ha puesto en marcha el registro y desde 2004 se han diagnosticado 15.000 casos afectados más tras revistar los protocolos, como se indica en la noticia 'El registro de enfermedades raras de Extremadura detecta 18.000 casos' (El Periódico de Extremadura, 06.06.14). El Consejero de Salud y Política Social, Luis Alfonso Hernández Carrón, subraya que el SES sigue trabajando 'de forma intensa' para mejorar la respuesta a las enfermedades minoritarias. El hecho de que utilice la expresión 'sigue trabajando de forma intensa' nos transmite la implicación total del consejero Carrón y de su cartera en la búsqueda de soluciones para estos enfermos desde hace muchos años.

En definitiva, cuando hablamos de discurso político sobre las ER hablamos, principalmente, de responsabilidad. Si lo que se dice es bueno, lo normal será aceptar, como bien indican Requena y Bañón (2011: 169), la responsabilidad de lo hecho. Por su parte, si lo que se dice no es bueno, la estrategia irá dirigida a ceder la responsabilidad o a extenderla. 
En los últimos meses se ha hablado mucho de los protocolos de actuación que las administraciones deben tener en cuenta para tratar el tema de las enfermedades poco frecuentes. Este hecho no está muy claro aún, puesto que la estrategia del Ministerio de Sanidad incide en la prevención, en los retrasos en el diagnóstico y en la atención primaria. La estrategia que nació en 2009 lleva años necesitando un impulso, algo que el Partido Popular trató de solucionarlo en febrero de 2014, aprobando una moción al respecto, pero sin mucho apoyo de la oposición. En este sentido, otro proceso que queremos destacar es de 'unanimidad', dado que es un tema muy sensible y todos los partidos políticos, independientemente de su color, deberían trabajar juntos y llegar a un consenso para paliar los problemas de las personas que sufren una EPF y sus familias.

En un tercer momento del análisis, nos pareció muy conveniente detenernos en la presencia de la Federación Española de Enfermedades Raras (FEDER) en las noticias de junio para comprobar la relevancia de su labor y de sus actividades, teniendo en cuenta los siguientes criterios:

- La aparición de FEDER en los titulares, los destacados o los subtitulares.

- Las menciones a FEDER.

- La referencia a FEDER como fuente de información.

- Imágenes de algún miembro de FEDER.

En cuanto al primer criterio, en el mes de junio, FEDER se cita solamente en tres noticias, pero en el subtitular. No tenemos noticias en las que FEDER se muestre en el titular de la pieza informativa. Aparece, por ejemplo, en una noticia sobre la organización de unas jornadas sobre EPF en Badajoz. En una segunda noticia, FEDER aparece en el subtítulo cuando se menciona que todo el dinero recaudado en la I Carrera solidaria por las EPF en Almería irá destinado a la Federación para financiar proyectos de investigación. Finalmente, en el destacado de la noticia "1.500 personas salen a correr por una buena causa" (Ideal de Almería, 09.06.14), se resalta que el dinero recaudado irá destinado a FEDER y a financiar proyectos de investigación. La aparición de FEDER en titulares, destacados o subtitulares es muy escasa. El dato es mucho mayor cuando FEDER es mencionado, como pasaremos a ver a continuación.

El segundo criterio hacía referencia a las menciones que FEDER había tenido durante el mes de junio. La Federación Española de Enfermedades Raras se menciona en 34 noticias. El porcentaje de noticias en relación al número total de piezas informativas del 
corpus es un 9,8\%. Este dato es muy relevante, dado el alto porcentaje de noticias en las que se menciona a la Federación.

Cuando hemos establecido el criterio de 'FEDER como fuente de información' nos referimos a todos aquellos ejemplos en los que la propia Federación es utilizada como fuente de información o cuando sus portavoces, ya sea su presidente (Juan Carrión), o cualquier otra persona de la Junta Directiva hablan en nombre de FEDER. En junio se ha hecho referencia a FEDER como fuente de información en 11 noticias.

El cuarto criterio a tener en cuenta en lo que respecta a la representación de FEDER en la prensa a partir de la aparición en imágenes de su presidente Juan Carrión o de cualquier otro miembro de la federación. Durante el mes de junio, vemos la presencia de Juan Carrión en 3 noticias. También aparecen representados otras personas de FEDER, como Antonio Bañón, director del Observatorio de Enfermedades Raras de FEDER, que viene representado 3 veces, por su activa participación en la organización de la I Carrera Solidaria celebrada en Almería el 8 de junio, o Justo Herranz o Rosario Fernández, miembros de FEDER, con una sola mención. Finalmente, en las fotografías que acompañan a las piezas informativas vemos a Juana María Sánchez, Delegada de FEDER en el País Vasco, y a Gema Esteban, Delegada de FEDER en Andalucía, mencionadas también en una ocasión.

\subsubsection{Conclusiones}

Exponemos a continuación las principales conclusiones de la representación discursiva de las enfermedades poco frecuentes durante el mes de junio de 2014 en los medios periodísticos españoles:

1. Las EPF constituyen un tema con presencia constante en los diarios españoles. Durante el mes de junio del presente año se han constatado 347 piezas informativas, repartidas en 107 cabeceras distintas de periódicos nacionales, regionales y locales que informaron sobre las EPF.

2. Los medios que mayor número de noticias ofrecieron son El Correo Farmacéutico y El Global, con 10 noticias cada uno.

3. En el corpus aparece un total de 98 enfermedades minoritarias representadas, de las cuales solamente 25 enfermedades se nombran más de una vez. La Atrofia Muscular Infantil es la patología que más veces ha sido aludida con un total de 10 impactos. El segundo lugar lo ocupa la enfermedad de Sanfilippo con 7. 
4. En toda la muestra en 28 ocasiones se ha mencionado alguna patología poco frecuente en los titulares, lo que significa un $8 \%$. Los periódicos con más titulares son los siguientes: El Norte de Castilla, Correo Farmacéutico, El Periódico de Aragón, Diario de Burgos, Heraldo de Aragón y Gaceta Médica.

5. Las enfermedades raras son vistas, por un gran número de personas, como enfermedades caras, de difícil diagnóstico, de poca rentabilidad, desconocidas, etc. Todos estos factores aparecen reflejados en las noticias de prensa del mes de junio de 2014.

6. El valor metafórico de tiempo y desesperación, a partir de expresiones como 'contrarreloj', 'estamos locos por conseguir' o 'cuenta atrás', están presentes en el desarrollo de las noticias.

7. Los avances que se están realizando en genética, a partir de la terapia génica, o la implantación de nuevas empresas de componente biotecnológico en España están arrojando una pequeña luz a los afectados por una EPF.

8. La investigación en EPF está asociada con mucha frecuencia a valores positivos tales como la innovación, lo que les confiere un especial interés por parte de los medios de comunicación.

9. La sociedad se implica de varias formas en las acciones solidarias para recaudar fondos para la investigación de las enfermedades poco frecuentes (carreras, caminatas, patinaje, galas de humor, partidos de fútbol).

10. En ocasiones aparece el nombre propio del niño o de la niña afectada en los titulares, intensificando la sensación de proximidad y su componente emotivo.

11. A veces, las descripciones de las EPF que aparecen en prensa son muy complicadas por la utilización de una terminología muy especializada.

12. Hemos identificado discursos muy relevantes presentados por los portavoces de las Comunidades Autónomas donde se establecen, por ejemplo, las iniciativas en materia de los registros de pacientes con ER o de iniciativas en general para mejorar las necesidades que demandan los colectivos de estas enfermedades.

13. La mirada de la política municipal y las actividades que han desarrollado es más cercana a los problemas de los ciudadanos con EPF.

14. Durante el mes de junio, La Federación Española de Enfermedades Raras (FEDER) se cita solamente en tres noticias, pero en el subtitular. No tenemos noticias en las que FEDER se muestre en el titular de la pieza informativa. 
15. FEDER aparece mencionado en 34 noticias distintas. El porcentaje de noticias en relación al número total de piezas informativas del corpus es un 9,8\%. Este dato es muy relevante, dado el alto porcentaje de noticias en las que se menciona a la Federación.

16. Durante el mes de junio se ha hecho referencia a FEDER como fuente de información en 11 piezas informativas distintas.

17. Juan Carrión, presidente de FEDER, y Antonio Bañón, director del Observatorio de las Enfermedades Raras de FEDER, aparecen representados en tres fotografías, respectivamente durante el mes de junio. Otros miembros de FEDER como Justo Herranz, Juana María Sánchez, Gema Esteban o Rosario Fernández vienen ilustrados solamente en una fotografía.

\subsection{Análisis multimodal (Segundo trimestre 2014)}

\section{(Por Carolina Figueras, Universitat de Barcelona)}

La representación que los medios de comunicación ofrecen de los individuos y sus acciones ejerce una influencia decisiva en la manera en que son percibidos por el gran público, en especial si la audiencia no tiene una experiencia personal directa con tales personas. Las consecuencias de esta construcción mediática pueden ser de gran calado para la vida de los protagonistas de la noticia, en particular en aquellos casos en los que los sujetos están exentos de poder y, a menudo, de representatividad (Catalano y Waugh, 2013). Las personas que sufren una enfermedad poco frecuente componen un colectivo especialmente vulnerable, por ser, por una parte, percibidos y retratados como diferentes al resto de la población; y, por otra, por requerir de unos medios asistenciales y de calidad de vida a los que la sociedad en conjunto debe sentirse comprometida y debe estar dispuesta a garantizar.

En sociología, las narrativas maestras constituyen fórmulas o guiones que usamos para contar historias. Las narrativas maestras dan forma a nuestras expectativas acerca de cómo funcionan las cosas en mundo y constriñen el modo de interpretar la realidad. De hecho, operan como marcos de conocimiento que legitiman ciertas ideologías e imponen límites a formas alternativas de pensar y de entender el mundo. Las narrativas maestras proporcionan patrones para explicar nuestras experiencias y narrar nuestras historias. La aceptación acrítica de una determinada narrativa maestra sobre la salud y la enfermedad, y su perpetuación a través de los medios de comunicación y otras estructuras que sustentan la cultura dominante de poder y posición (Tate, 1997), no hace más que reforzar el sistema de 
creencias que está en su base. Las narrativas maestras incluyen un buen número de estereotipos históricos en cuanto a género, clase social y etnicidad (Yosso, 2006, p. 9), y sirven para simplificar problemas sociales complejos, presentando personas y acontecimientos de forma unidimensional (Espino, 2008). Los medios de comunicación adoptan y perpetúan las narrativas maestras que modelan las ideas, las imágenes y los significados de la realidad social cotidiana (Erdmans, 1999, p. 341).

La aplicación de estos conceptos al tratamiento multimodal que reciben las enfermedades raras en la prensa escrita española revela determinados aspectos de la narrativa maestra con la que se explican estas patologías. Esta narrativa generalizada, divulgada y amplificada por los medios reduce y esquematiza una compleja problemática social, imponiendo un determinado marco interpretativo en el que pensar y entender estas enfermedades y a las personas que las sufren. Ese marco ideológico creado con y a través de la narrativa maestra va a influir decisivamente en cualquier curso de acción que se emprenda para ofrecer una mejor calidad y, a menudo, una esperanza de vida a los enfermos y a sus familias.

En una etapa de crisis económica como la que atraviesa España en los últimos años, la representación que la prensa está ofreciendo de las enfermedades raras y de las personas afectadas se inscribe en el marco ideológico de una narrativa maestra que plantea una redistribución de los roles asignados a los actores sociales involucrados. En esa nueva narrativa, surgida de la crisis económica, los actores sociales con protagonismo y capacidad de acción son, además de la persona enferma y su familia, la ciudadanía. Así, la responsabilidad de proporcionar los medios asistenciales para tratar a las personas afectadas y combatir la enfermedad se ha desplazado de los poderes públicos al ciudadano medio. La administración y los representantes políticos constituyen los grandes ausentes en ese nuevo discurso en el que el concepto de "estado del bienestar" se ha suplantado por los eufemismos "solidaridad", "compromiso" o incluso, en algún caso, "beneficencia". Ello queda patente en la práctica inexistencia de noticias, durante este segundo trimestre de 2014, en las que se proporcionen imágenes o declaraciones de los representantes de la administración y del gobierno, bien sea autonómico o nacional. Este vacío informativo resulta indicativo de la inhibición y falta de protagonismo de los poderes públicos como participantes en el debate social sobre las enfermedades raras. La labor de establecer compromisos y acuerdos de colaboración con la industria farmacéutica, la inversión en investigación para desarrollar nuevos tratamientos, o el diseño e implantación de programas de asistencia a enfermos y a 
sus cuidadores recaen ahora en las asociaciones de enfermos, como ilustra la siguiente noticia, extraída de El Global (7 de abril de 2014).

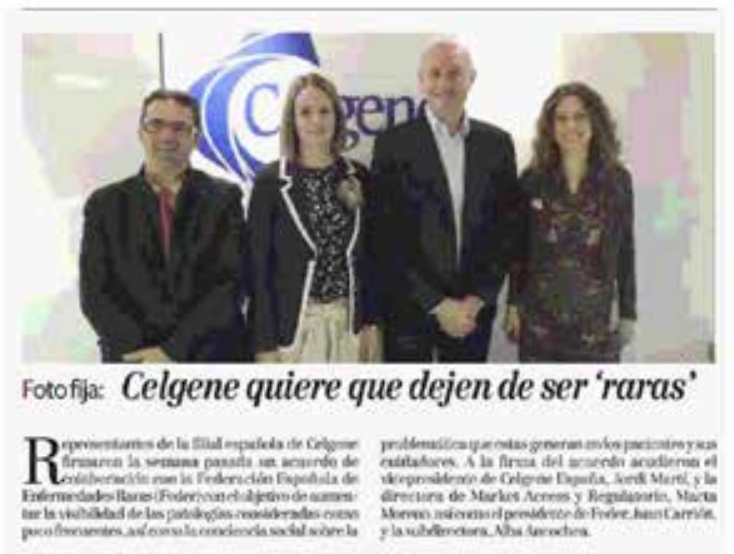

Figura 1. El Global (7 de abril de 2014)

El texto recoge el acuerdo de colaboración firmado entre FEDER y la filial española de Celgene, una compañía americana de biotecnología. En la imagen aparecen retratados los representantes de Celgene y el presidente de FEDER. La expresión de satisfacción reflejada en el rostro de los sujetos representados transmite optimismo y atestigua el éxito del acuerdo. A través del recurso retórico de la personificación ("Celgene quiere que dejen de ser raras"), se pretende humanizar la imagen de la industria farmacéutica ante el gran público. El sujeto omitido en "dejen de ser "raras" (la información sobreentendida) indica que la noticia va probablemente dirigida a quienes sufren una enfermedad rara y a sus familias. En cualquier caso, ningún representante de la administración estuvo presente en el acuerdo ni forma parte de la noticia.

Las escasas referencias al gobierno o a la administración en el corpus se producen siempre que se denuncia el caso particular de algún enfermo en situación de extrema necesidad, o cuando algún colectivo específico reclama más participación de los organismos de la administración. En cualquier caso, estas noticias son, sorprendentemente, escasas.

Como ejemplo del primer caso se presenta la siguiente noticia, publicada en 20 Minutos Andalucía el 26 de junio de 2014, que informa del drama de María Jesús, una "sevillana de 55 años que padece tres enfermedades 'raras y mortales", tal y como se la describe en el subtítulo de la noticia. Las tres imágenes que acompañan el artículo están tomadas en la cotidianidad de María Jesús, en el ámbito íntimo de su casa, para mostrar al espectador el alcance de su discapacidad. La primera imagen, de mayor tamaño, la muestra de cuerpo entero, reclinada en el sofá de su hogar, mirando directamente a la cama, en un 
acto de imagen con el que parece reclamar la ayuda del espectador. Esta actitud de reclamo aparece también en la representación que se ofrece de María Jesús en una de las dos imágenes de menor tamaño. La tercera imagen, tomada a una distancia más corta que las anteriores, retrata a María Jesús ocupada poniendo en orden unos documentos, lo que probablemente se usa para documentar su lucha continuada con la administración para recibir ayudas.

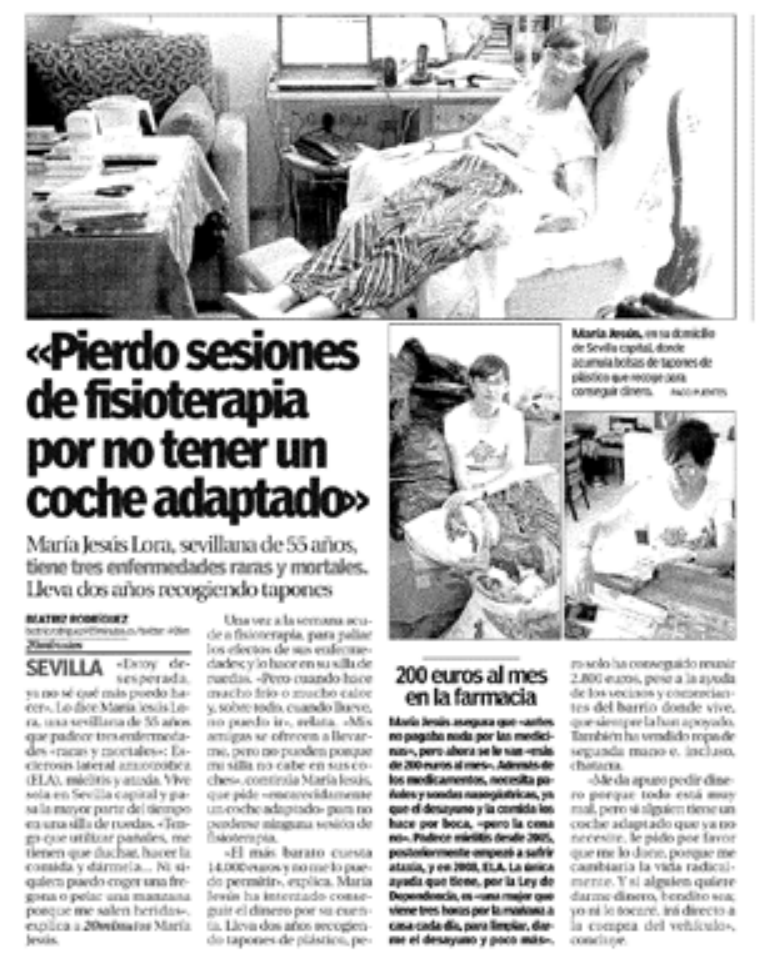

Figura 2. 20 Minutos Andalucía (26 de junio de 2014)

Tanto las imágenes como el texto de la noticia construyen a María Jesús como una persona dependiente, vulnerable y necesitada de asistencia, a la que el lector debe sentirse moralmente obligado a ayudar. La noticia, en efecto, recoge explícitamente la petición de María Jesús: un coche adaptado para llevar su silla de ruedas a las sesiones de fisioterapia. La petición se ejecuta de modo indirecto en el titular, cuando se citan literalmente las palabras de María Jesús: "Pierdo sesiones de fisioterapia por no tener un coche adaptado". Este tipo de representación, tan frecuente en la prensa escrita actual, parece formar parte ya de la narrativa periodística de las enfermedades raras, en la medida en que la administración va recortando el presupuesto dedicado a la atención y asistencia a estos pacientes.

Un discurso mucho más reivindicativo y combativo con respecto a los poderes públicos aparece construido en la siguiente noticia, procedente del diario La Nueva España (Occidente), y publicada el 25 de junio de 2014. En el titular se recoge la reclamación del colectivo de personas afectadas por patologías poco frecuentes para que se destinen más 
recursos financieros a la investigación. Resulta interesante destacar que en el titular no se especifica a quién se reclama tal contribución. Los poderes públicos no se mencionan ni se incorporan al discurso periodístico; solo se insiste y se focaliza en la necesidad de los enfermos. Las imágenes que acompañan al texto están en correspondencia con este discurso. La primera representa al público asistente a las jornadas celebradas en el hospital de Jarro, en Navia. Está tomada desde un ángulo oblicuo, lo que indica cierto distanciamiento con respecto a los personajes representados. El lector no se siente así parte del acto, sino que actúa como un simple espectador que lo contempla desde fuera. La segunda imagen reproduce a dos personas afectadas por retinosis pigmentaria. Ambas se ofrecen como objetos de contemplación. No interactúan con el espectador, puesto que están dirigiendo su atención hacia otra dirección, sin entrar en contacto directo con el observador. Parecen formar parte del público, porque están sentados en el espacio reservado para los asistentes al acto, pero tanto el comentario a pie de página que los clasifica como enfermos, como las sillas vacías a su alrededor, son índices discursivos de sus rasgos diferenciales con respecto al resto de participantes. El titular refuerza, asimismo, la singularidad, lo diferente, lo distintivo de las enfermedades raras: "Más dinero para lo poco común".

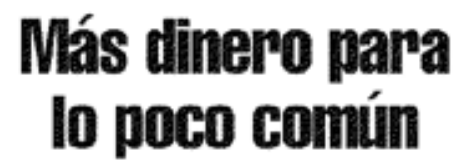

Los enfermos con patologías raras piden en Navia que se profundice en la investigación sobre sus casos

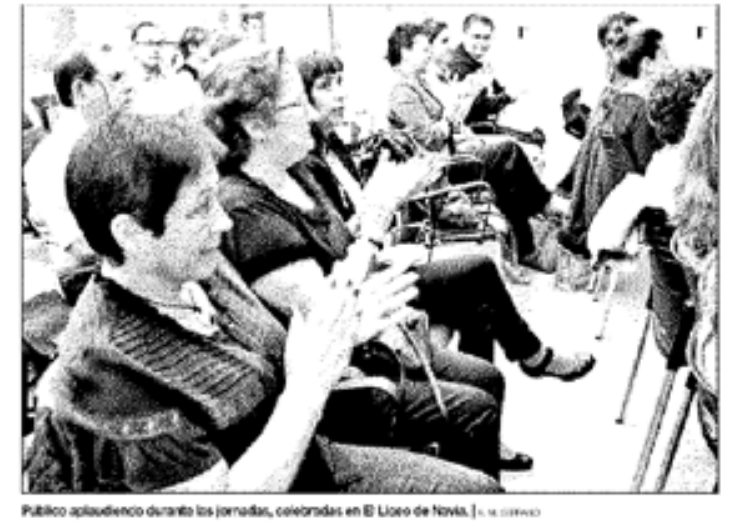

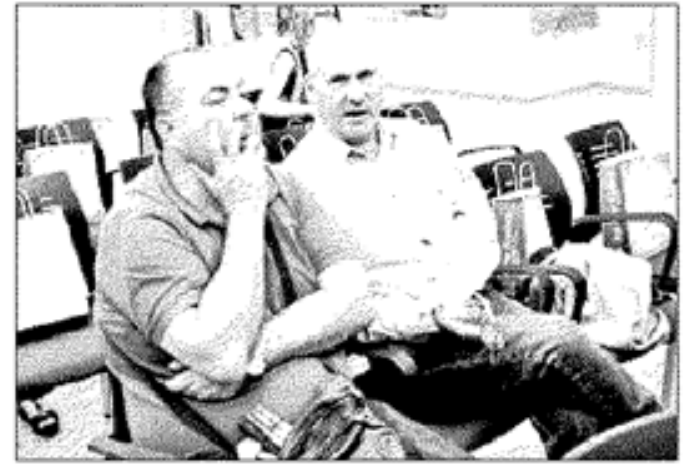

Andés Mayor y Sabino Vozzquez, antos con rotinosis pigmentaria. | $x$ u s.

Figura 3. La Nueva España (Occidente) (25 de junio de 2014) 
Otro tipo de noticias también de corte reivindicativo, aunque escasas, presentan un colectivo en lucha. En el siguiente ejemplo, el periódico se hace eco de una movilización para protestar contra los recortes en sanidad que afectan a las personas con enfermedades raras. La noticia apareció publicada en La Región el 27 de mayo de 2014.

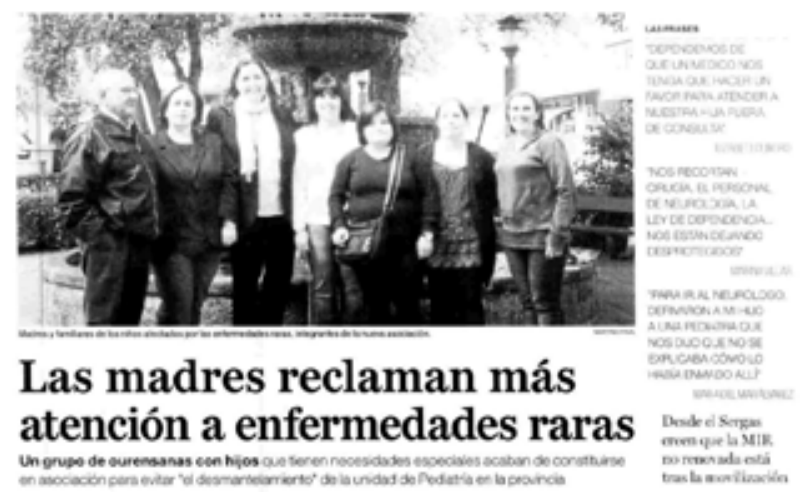

Figura 4. La Región (27 de mayo de 2014)

En el titular, la expresión referencial "las madres", sin mayor especificación, parece aludir a todo el colectivo de madres. Con esta estrategia se pretende dar una mayor dimensión a la reivindicación protagonizada por las familias de las personas que padecen una enfermedad poco frecuente. De hecho, el titular recurre a expresiones de denotación muy general y poco concreta, tales como "atención”. ¿En qué consiste, exactamente, esa atención que las madres reclaman? El titular, además, plantea que se trata de una atención "a enfermedades raras", y no directamente a los enfermos o a los familiares que los atienden. El resultado es un titular genérico, ambiguo, poco específico y escasamente informativo.

La fotografía que acompaña al texto capta a un grupo de personas que se describen, en el pie de la foto, como "madres y familiares de los niños afectados por las enfermedades raras". Se trata de una imagen de plano frontal, tomada a una distancia personal lejana (vemos a las personas retratadas desde la cintura hacia arriba). La actitud de los sujetos fotografiados es de requerimiento/afiliación: están mirando directamente al espectador, sonriendo, buscando el contacto visual y emocional con la audiencia. Se trata de una imagen de grupo, simbolizando el espíritu asociativo y reivindicativo del proyecto que comparten: impedir que se desmantele el equipo de pediatría de la provincia. Esta reclamación solo aparece claramente formulada en el subtítulo de la noticia.

En la narrativa maestra de las enfermedades raras construida y difundida en la prensa, varios actores aparecen representados, aunque, como se verá, recurriendo a determinados patrones convencionales o estereotipados. En orden de mayor a menor protagonismo y 
presencia en las noticias, aparecen los siguientes participantes: en primer lugar, los propios enfermos y sus familias, seguidos por los ciudadanos, y, por último, por los investigadores y personal sanitario. También es posible localizar algunas noticias, si bien poco numerosas, dedicadas a proyectos puntuales desarrollados por la industria farmacéutica; en esos casos, el representante de la compañía concede una entrevista a los medios.

En relación con las personas afectadas, en los medios se construye una diferente representación de los adultos y de los niños. Las historias que tienen a los niños como protagonistas son mayoritarias en las noticias de prensa. Las referidas a los adultos, aun siendo mucho menos numerosas, se ajustan a un patrón narrativo definido, en el que el protagonista suele ofrecerse al espectador como un ser único, diferente, y a menudo solitario. Así, en la siguiente noticia, aparecida el 1 de abril de 2014 en el diario Canarias 7, Conchi, una mujer canaria afectada por una enfermedad poco frecuente, aparece retratada en su casa, en su habitación (el ámbito más íntimo del hogar), junto al dispositivo que permite conectarla directamente con la Cruz Roja en caso de emergencia. Aunque mira directamente a la cámara, relajada y sonriendo, buscando establecer contacto directo con el espectador, los aparatos que debe usar para gestionar su enfermedad ocupan, como su figura, un lugar prominente en la imagen.

De hecho, la composición aparece dividida entre su figura, a la derecha del espectador, y el dispositivo electrónico del que depende, a la izquierda. Este dispositivo es, precisamente, lo que marca a Conchi como alguien diferente. En la primera parte del titular -“jamás me rindo”- se proyecta la metáfora conceptual LA ENFERMEDAD ES UNA LUCHA. Conchi se construye a sí misma aquí como alguien fuerte que tiene la voluntad de dominar y sobreponerse a su enfermedad. La segunda parte del titular, sin embargo, se encabeza con un "pero", e introduce un supuesto que contradice la representación inicial: "cada día soy más dependiente". Esta segunda parte conecta directamente con la imagen, y con el dispositivo que une a Conchi con los servicios de emergencia, documentando así su dependencia. A pesar de sentirse "dependiente", Conchi aparece retratada en completa soledad. En el cuerpo de la noticia se hace mención a los efectivos de la Cruz Roja, a familiares y a vecinos, pero en ningún caso se singulariza a nadie. Conchi resulta ser, por tanto, la única protagonista de la narrativa de su enfermedad. 


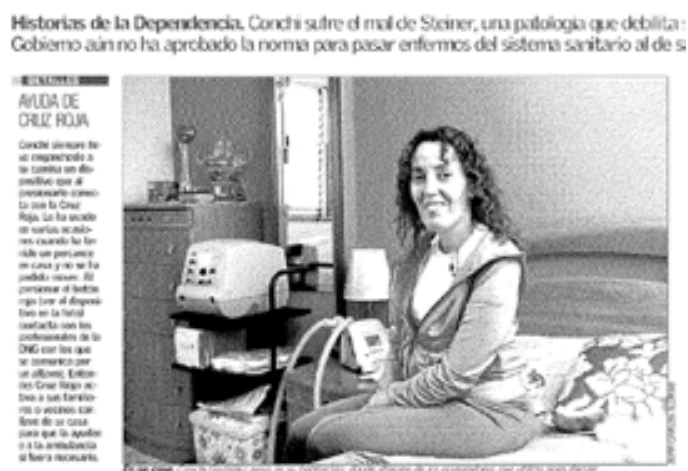

\section{«JAMÁS ME RINDO, PEROCADA DIA SOY MASDEPENDIENTE»}

Figura 5. Diario Canarias 7 (1 de abril de 2014)

Una representación similar de la persona adulta enferma se ofrece en la siguiente noticia, publicada en El Diario Montañés el 4 de mayo de 2014. La fotografía que ilustra el texto muestra a Valle, una mujer que padece esclerodermia. Es difícil reconocer el lugar en el que se ha tomado la imagen, aunque resulta llamativo que Valle aparezca detrás de una puerta que simula una reja. El simbolismo resulta evidente: Valle está prisionera de su enfermedad, que quizás la obliga a estar recluida en casa. La hipótesis de que la fotografía se ha tomado en su hogar adquiere fuerza cuando se considera que uno de los puntos centrales de interés de la imagen son sus manos, envueltas en un paño blanco. Las manos se mencionan en el cuerpo de la noticia como una de las extremidades hacia las que Valle llama la atención del periodista en relación con los estragos de la enfermedad. En cuanto a la postura, Valle está de pie, inmóvil frente al espectador, pero sin mirarle directamente. Su mirada está como perdida y no establece contacto directo con la cámara.

El titular contiene una cita literal de Valle, con la que se hace eco y se niega una metáfora común, que construye negativamente a los que sufren una enfermedad rara como seres diferentes. Valle, con una negación metalingüística, "No somos bichos raros", se distancia de esa opinión supuestamente generalizada y expresa su actitud de rechazo hacia el estereotipo. Al igual que Conchi, en la noticia analizada anteriormente, Valle es representada como alguien que, aun no siendo como los demás, se esfuerza constantemente por vivir con “normalidad”. Esta idea está expresada en el pie de foto que acompaña a la imagen de Valle: "ella ha seguido haciendo -más o menos- su vida y solo en determinados momentos cede ante su enfermedad". 


\section{"No somos bichos raros"}

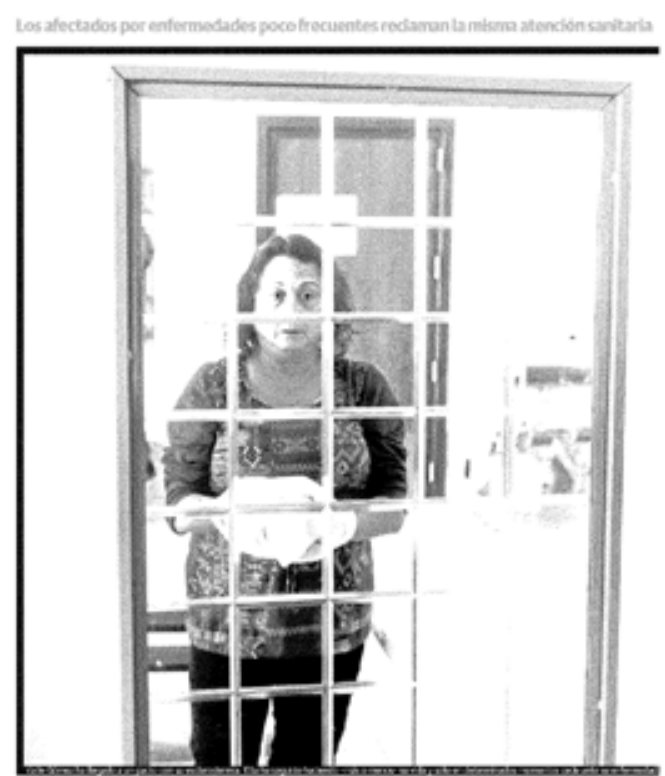

Figura 6. El Diario Montañés (4 de mayo de 2014)

De este análisis se desprende que, en la narrativa maestra de las enfermedades raras, los adultos se construyen visualmente con atributos que los señalan como distintos, aunque se les reconoce la voluntad, expresada verbalmente, de ser y de vivir como los demás. Con independencia de tales declaraciones, sin embargo, los medios acentúan la representación de los adultos con una enfermedad rara como ejemplares de una clase de individuos atípicos.

Los rasgos que identifican, definen, separan y aíslan a la persona enferma pueden ser capacidades que se presentan como sobresalientes porque superan las limitaciones que la enfermedad impone. Así ocurre, por ejemplo, con la noticia dedicada a Miguel Comeche (Última Hora, 12 de junio de 2014), autor de un libro titulado "Tocando el cielo con los dedos", en el que explica su experiencia con la enfermedad rara que padece. La imagen muestra a Miguel en un plano horizontal, a una distancia personal lejana. Miguel sonríe al espectador, y ofrece la portada de su libro, en la que se aprecia el dibujo de dos brazos con las palmas abiertas extendidos hacia el cielo, en clara referencia al título de su obra. Miguel establece un contacto directo con el espectador, mostrándole lo que lo convierte en único y singular: sus brazos anormalmente desarrollados y el libro, con título metafórico, en el que desafía la discapacidad con la que se nos presenta en la imagen. De nuevo, como sucedía con Conchi y con Valle, Miguel se retrata en los medios como un ser aislado, único y visiblemente distinguible por su enfermedad. 


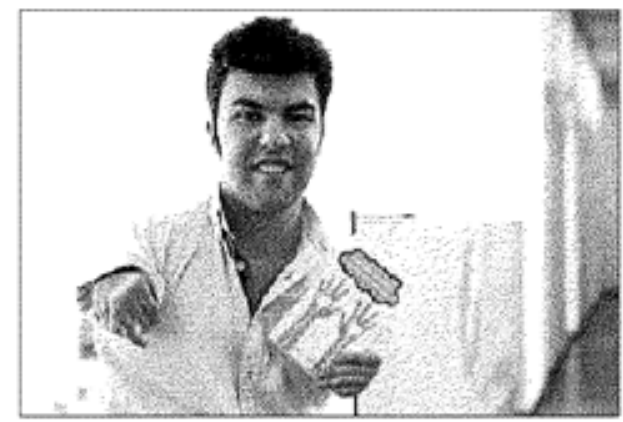

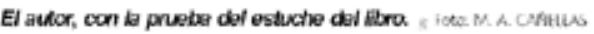

\section{Miguel Comeche, afectado por una enfermedad rara, prepara su libro 'Tocando el cielo con los dedos'}

Figura 7. Última Hora (12 de junio de 2014)

Como contrapunto a este tipo de representación en solitario, en algún caso se encuentran imágenes de personas afectadas por una enfermedad rara en las que captan momentos de su vida social. Un ejemplo lo encontramos en la siguiente noticia, publicada en el Diario de Almería el 22 de abril de 2014. El titular anuncia el fallecimiento de Jaime Jiménez, una persona muy querida que sufría distrofia muscular de Duchenne. La galería de imágenes que acompaña a la información impresa muestra a Jaime en diversos momentos de su vida pública, ya sea retratado con su familia (primera imagen), participando en una carrera para recaudar fondos (segunda imagen), o dando una charla (tercera imagen). En las dos primeras fotografías, la distancia con la que se representan los sujetos es pública: hay varias personas rodeando a Jaime, y hay espacio alrededor del grupo (vid. Kress y van Leeuwen, 2006). Con este tipo de representación se deja constancia de su intensa vida social. El titular, “Adiós a Jaime Jiménez Rodríguez”, opera como contrapunto a esas imágenes en las que Jaime aparece tan vitalmente activo.

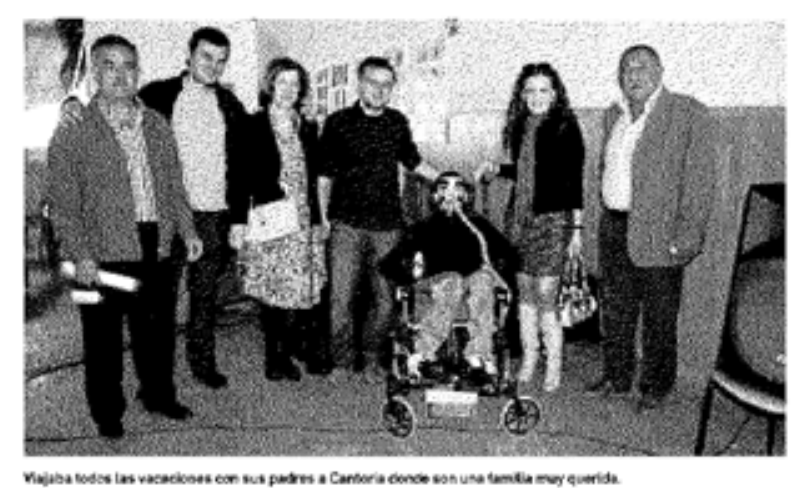




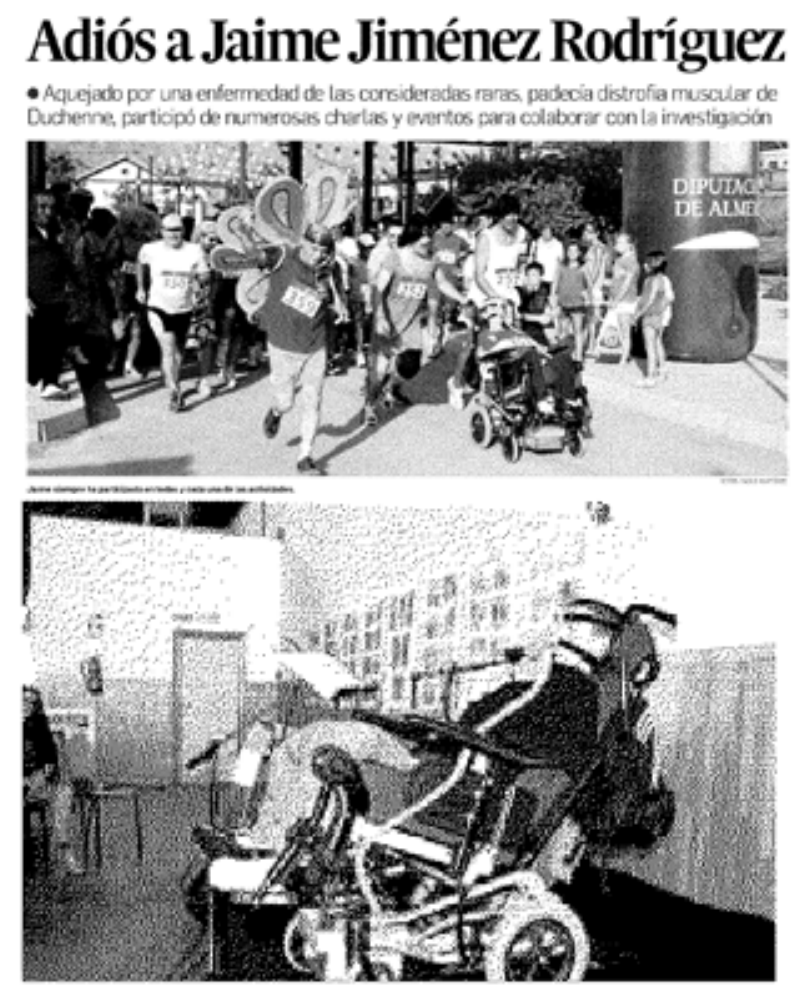

Ha sabido ganarse a los vecinos con su optimismo y ganas de vivir.

Figura 8. Diario de Almería (22 de abril de 2014)

En contraste con la representación del adulto, cuando los afectados son niños, los medios de comunicación recurren a una narrativa y a una representación discursiva de los protagonistas de la noticia un tanto distinta. En todas las noticias se plantea una situación extrema, tanto económica como de salud, y se solicita, directa o indirectamente, la contribución del público para paliar el sufrimiento del niño afectado y de su familia. En todos los casos se apela a la conciencia de la ciudadanía a través de un discurso emocional que busca la implicación afectiva de la audiencia. Las imágenes siempre amplifican esa narrativa en la que se recurre a las emociones. En general, se fotografía al niño que sufre la enfermedad rara y a su familia inmediata: padres y, a menudo, también hermanos. Este es el tipo de representación que encontramos en la siguiente noticia, publicada en La Región el 1 de octubre de 2014: 


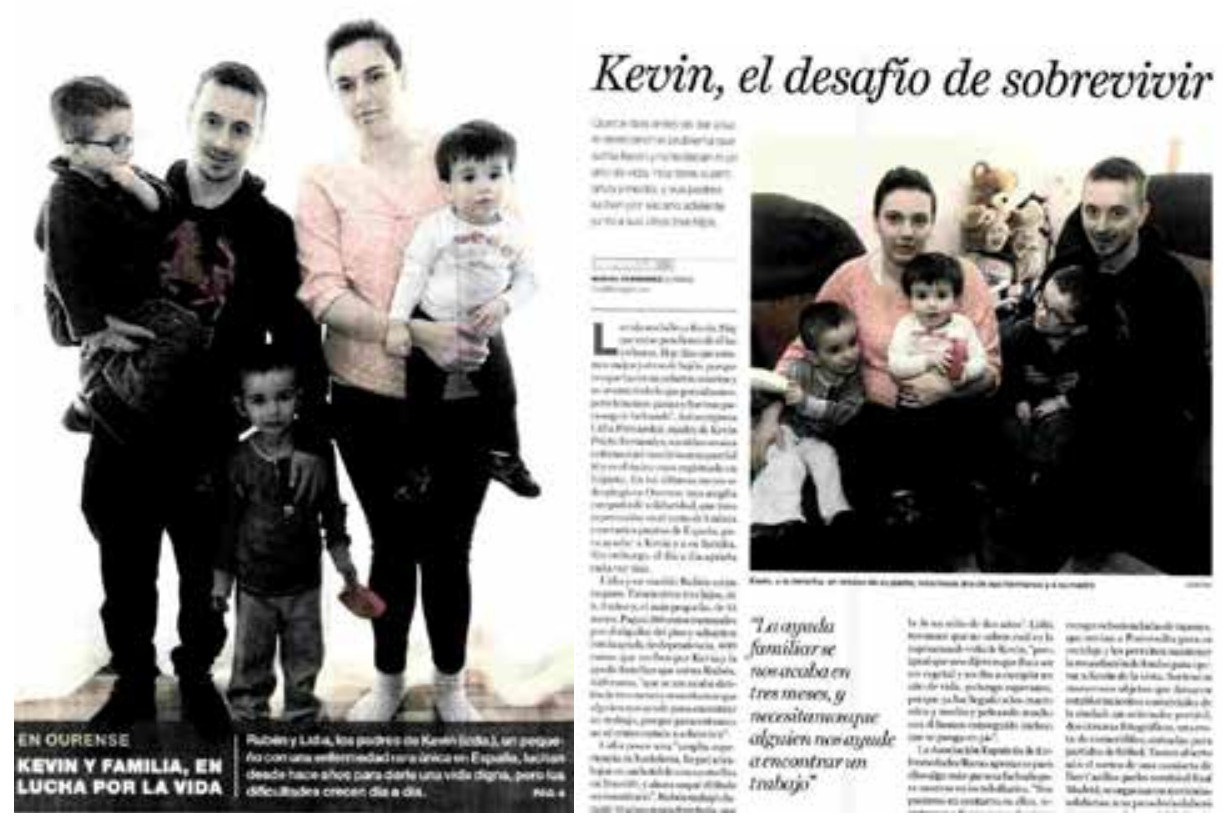

Figura 9. La Región el 1 de octubre de 2014

Ambas imágenes retratan a la familia al completo en el ámbito de su domicilio. En la primera imagen aparecen de cuerpo entero, a una distancia social lejana. En la segunda están sentados en el sofá de su casa. En ambas fotografías abrazan a sus tres hijos, en una clara expresión de amor y de protección, pero también de soledad ante el mundo. Las imágenes de los cinco miembros de la familia retratan simbólicamente el círculo de intimidad al que se relega la enfermedad. Esta representación visual también comunica la experiencia compartida de sufrir una enfermedad rara: la enfermedad no solo afecta a Kevin, sino a todos los miembros de la familia. De hecho, tanto en el titular como en los pies de foto se proyecta la metáfora conceptual LA VIDA CON UNA ENFERMEDAD RARA ES UNA BATALLA: "Kevin, el desafío de sobrevivir" (titular) y "Kevin y familia, en lucha por la vida". Con esta metáfora se articula una narrativa de las enfermedades raras explicadas como patologías de tal gravedad que, cuando afectan a los niños, el curso inexorable es la muerte, a menos que el ciudadano medio contribuya económicamente a la investigación y al tratamiento.

En esta narrativa periodística, la familia se construye discursivamente como un núcleo de resistencia ante la ineludible fatalidad de la enfermedad y como un círculo de protección ante el desamparo institucional. Así, en esta noticia se denuncia la situación de precariedad en la que se halla sumida la familia: los padres están desempleados y necesitan urgentemente recursos económicos para tratar a Kevin. Una vez más, la prensa reproduce la narrativa maestra de las enfermedades raras entendidas como una circunstancia personal adversa, de ámbito familiar y privado, que solo en casos de extrema necesidad, como este, 
apela a la solidaridad y compasión de la sociedad. Los poderes públicos no se representan en este discurso como los interlocutores válidos a los que solicitar asistencia.

Es, precisamente, la suspensión de la responsabilidad de la administración en invertir en investigación, proporcionar la adecuada asistencia sanitaria, y en garantizar las ayudas necesarias a la discapacidad lo que explica la proliferación de noticias como la siguiente, publicada en El Progreso el 8 de abril de 2014, en las que se informa del éxito de iniciativas populares con las que recaudar fondos para financiar tratamientos básicos:

\section{El niño Saúl Cancio podrá andar con el apoyo del banco de tapones de Lugo}

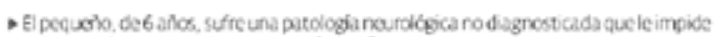
caminar. Eloinero de la inciativa servirá para financiar un andadcr cuegarantice su a utonomía

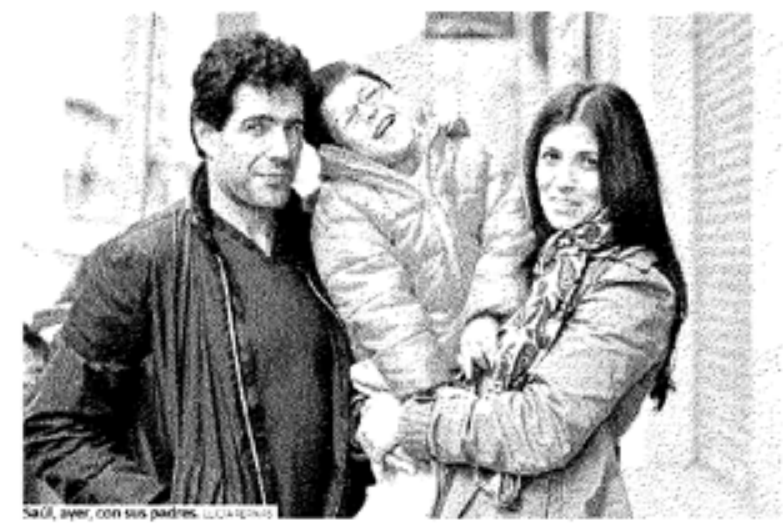

Figura 10. El Progreso el 8 de abril de 2014

Si el sistema sanitario público proporcionara los recursos para tratar adecuadamente las enfermedades raras, informaciones como esta probablemente no llegarían a los medios. Se convierten en noticia, pues, las actuaciones que debería ser competencia de oficio de la administración pública, y no son noticia las denuncias de la incompetencia e inhibición de los poderes públicos.

En el corpus analizado es muy frecuente encontrar el recurso a metáforas en los titulares de las noticias dedicadas a los niños, probablemente como una estrategia para simplificar la complejidad de la situación que afecta a las familias, y también para construir un mensaje poderoso que atraiga la atención del lector. En el siguiente artículo, publicado en el Diari de Terrassa el 7 de junio de 2014, se proyecta en el titular - "Pol vive una contrarreloj para salvarse"- la metáfora conceptual LA VIDA CON UNA ENFERMEDAD RARA ES UNA CARRERA, que está directamente vinculada a la metáfora LA VIDA CON UNA ENFERMEDAD RARA ES UNA BATALLA, a la que se ha recurrido en la noticia analizada previamente. Como en el caso anterior, con la metáfora se expresa con mayor 
intensidad el dramatismo de la situación: la inevitable muerte de Pol a menos que se recauden suficientes fondos para tratar su enfermedad.

\section{enfermedadesraras SANFILIPPO "Pol vive una contrarreloj para salvarse"

\author{
Los padres de Pol, un ezarense de 11 allos que padece el sindrome \\ de Sarfilippo, lievan seis af fos recaudando fondos a centrateioj \\ para salvar la vida de su hija roon nuevenowno
}

Figura 11. Titular del Diari de Terrassa (7 de junio de 2014)

La noticia incluye tres fotografías: una de Pol y su madre, sentados en el sofá de su residencia familiar, mirándose el uno al otro, en actitud relajada y compartiendo la lectura de unos libros. En la segunda aparece Pol sosteniendo un balón junto al futbolista Xavi Hernández. En la tercera se presenta al doctor que lo trata en el Hospital de Terrassa. Las tres fotografías configuran los tres aspectos principales de la vida de Pol con su enfermedad: la atención y el cuidado de sus padres, en el ámbito familiar; los reclamos a la solidaridad y apoyo de la ciudadanía, a través de la organización de eventos para reunir fondos que, a menudo, son apadrinados por personajes famosos; y su tratamiento médico, representado en la figura de su médico. A diferencia de lo que ocurre con las representaciones visuales de los adultos, en las imágenes de los niños aparecen otros personajes a través de los cuales la enfermedad es definida y explicada. Hay, por tanto, una polifonía de voces y una multiplicidad de protagonistas que explican la historia. Es una narrativa coral.
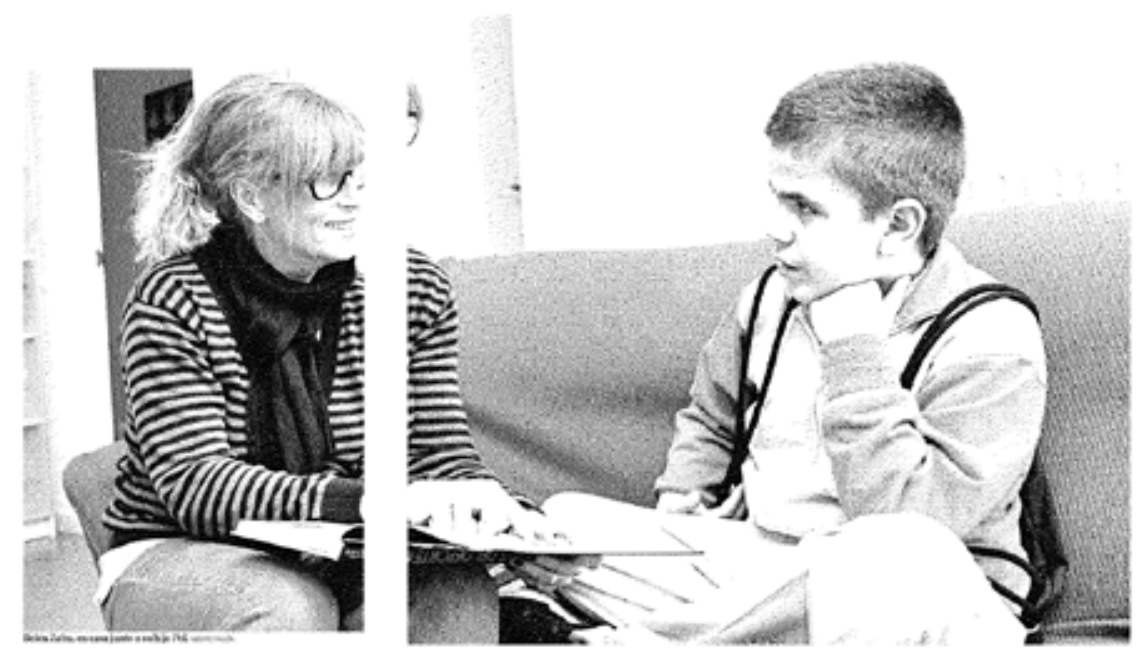


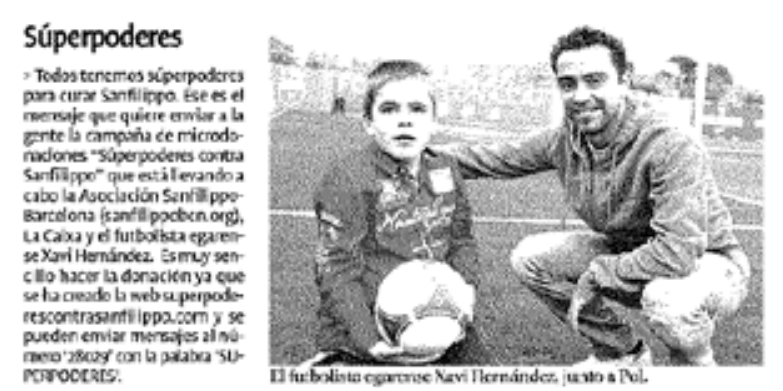

Figura 12. Fotografías del Diari de Terrassa (7 de junio de 2014)

En esa representación polifónica de la experiencia de la enfermedad, la figura del médico adquiere una especial relevancia, puesto que aporta un testimonio experto al que se le otorga mayor peso y credibilidad. En la noticia que nos ocupa, la imagen muestra a Ramón Vidal, el facultativo que trata a Pol, a una distancia íntima, lo que indica proximidad con la audiencia: el especialista se siente comprometido e involucrado en el drama de Pol y su familia. Esta representación se refuerza con el titular que acompaña a esta parte de la noticia: "El diagnóstico fue un calvario para la familia". Ramón Vidal combina, en esta declaración, la dimensión médica de la enfermedad con la dimensión humana, estableciendo una conexión emocional para la audiencia entre ambos aspectos.

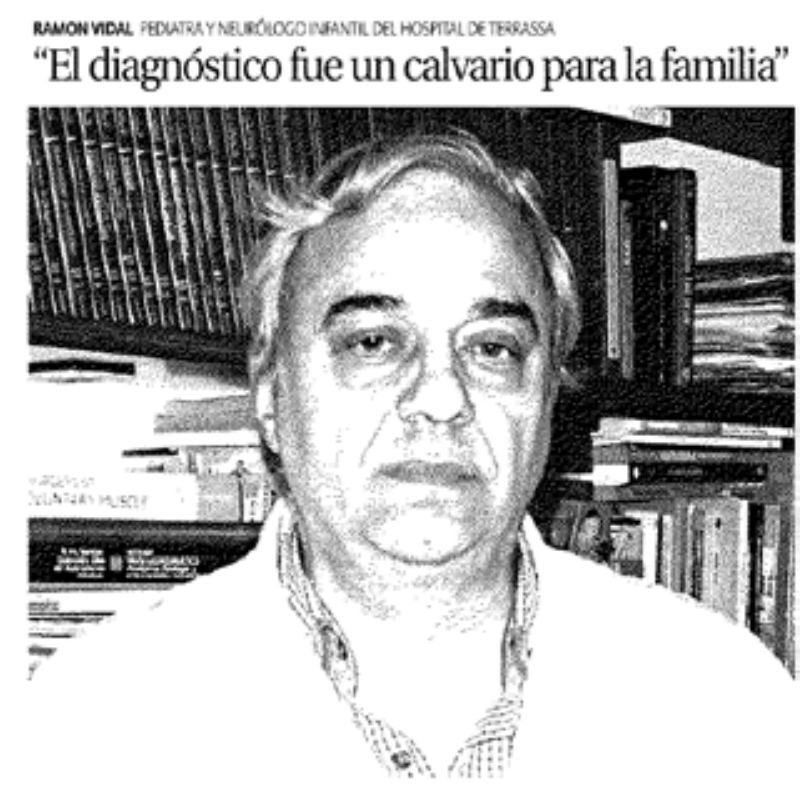

Figura 13. Dimensión médica en el Diari de Terrassa (7 de junio de 2014)

El papel fundamental del diagnóstico en la narrativa de la enfermedad es también el foco de la siguiente noticia, en la que se describe la situación de incertidumbre y desconocimiento en la que viven Ainhoa y su familia. El titular recoge la cita textual de alguno 
de los protagonistas en esta historia, aunque no se especifica quién. El lector debe suponer que probablemente se trata de una declaración de los padres. En cualquier caso, con la afirmación "Nadie sabe lo que tiene Ainhoa" se incide en el drama de una enfermedad que no puede ser adecuadamente tratada porque se ignora su causa. Con un titular así se refuerza el supuesto, comúnmente compartido, de que las enfermedades poco frecuentes son "raras" (en el sentido de 'extrañas') y “misteriosas".

\section{enfemedadesraras "Nadie sabe lo que tiene Ainhoa"}

Airlica padece una enlermeclad ara que lox rrédicos no han pocido dagresticac Sus padres, Carlos y Elisabcth, están luchando por saber lo que padece su hija monc saburom meo

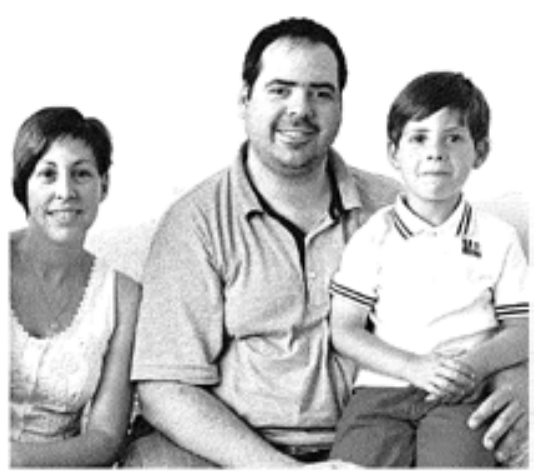

juorr cossó wocoreon

"Antes no me dejaba acercarme a ella"

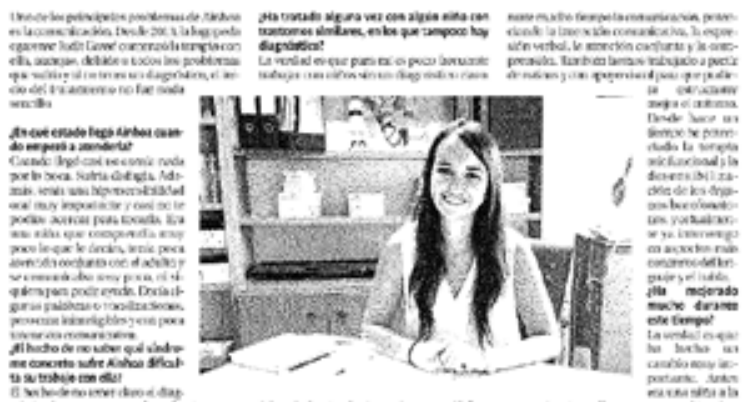

Figura 14. Notia a Pol en el Diari de Terrassa (7 de junio de 2014)

Como en la noticia dedicada a Pol, las fotografías que se incluyen en este reportaje presentan a Ainhoa y a su familia, aunque no reunidos aquí en la misma imagen. La logopeda, fotografiada con un plano horizontal y a una distancia personal lejana, aparece en el escenario 
de su despacho. El contexto le confiere un carácter de persona experta, al igual que el anuncio de su título como logopeda. En calidad de profesional, ofrece su testimonio, en el titular que acompaña a la imagen, de uno de los síntomas que padecía Ainhoa, y que, atendiendo al uso del pretérito imperfecto, cabe inferir que ahora ya no padece. La representación visual de la logopeda en la noticia, así como la transmisión del contenido de la entrevista comentando el progreso de Ainhoa, sirven para insistir en la necesidad de garantizar la terapia a Ainhoa. El espectador asiste de nuevo a una narrativa coral, con múltiples voces e imágenes de los diversos protagonistas implicados en la experiencia de la enfermedad.

En otras ocasiones, el texto de la noticia se acompaña de una galería de imágenes del niño afectado, en las que se ofrece una narrativa visual que documenta las imposiciones y estragos de la enfermedad. Se trata, en realidad, de una crónica visual de la experiencia cotidiana de vivir con una enfermedad rara. Frecuentemente, las imágenes muestran al niño enfermo asistido por algún miembro de su familia. Este es el caso de la siguiente noticia, aparecida en el Diario de León el 24 de abril de 2014.
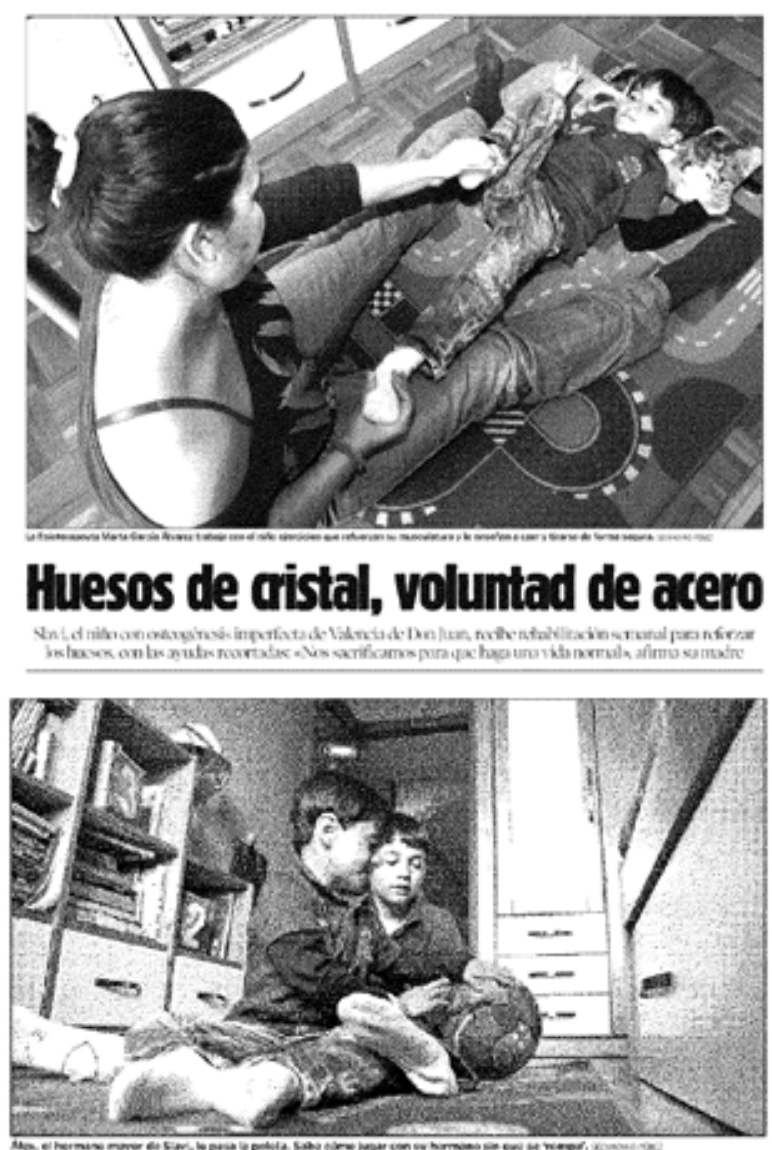

Figura 15. Titular del Diario de León (24 de abril de 2014) 


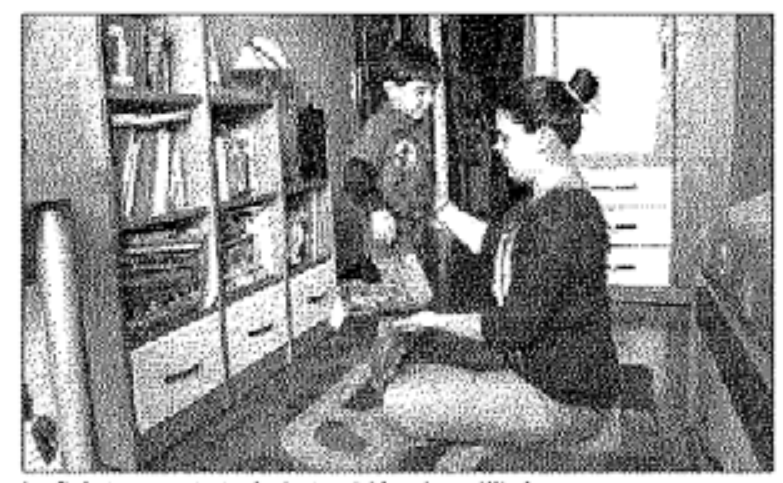

La fisioterapeuta trabaia también el equilibrio, securcesopsciz

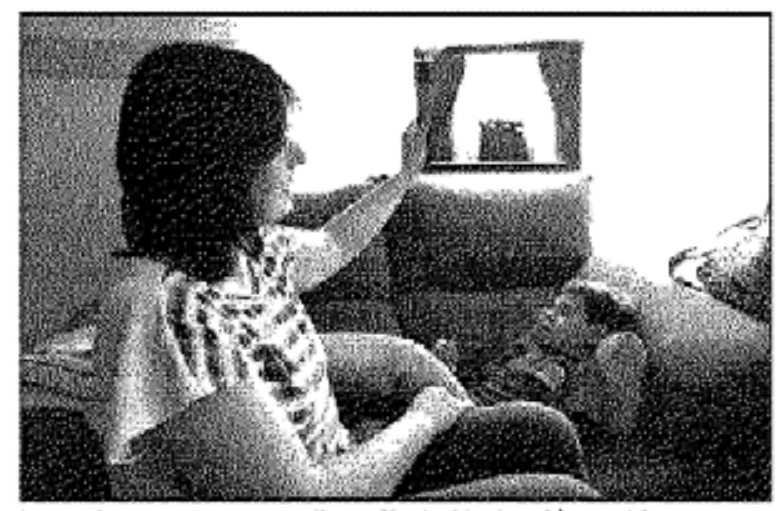

La madre nuestra una radiografia de Slavi recién nacido. 5. PŁڤ̨z

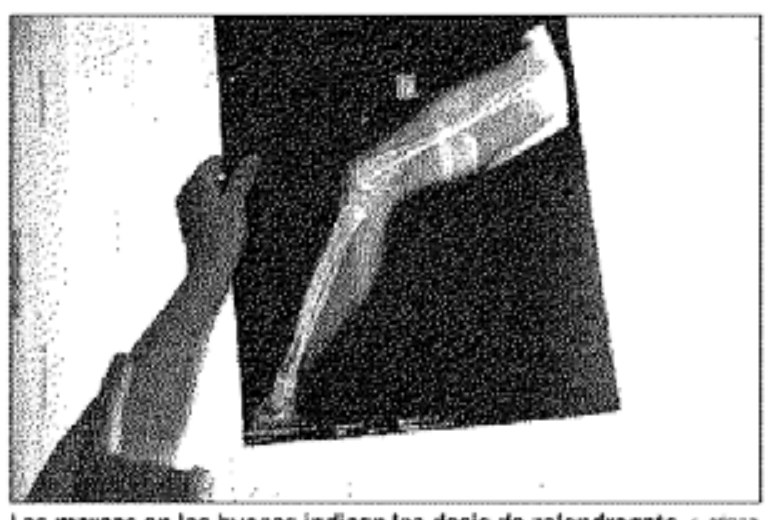

Las marcas en los huesos indican las dosis de zclendranato. 5. Peie?

Figura 16. Fotografías del Diario de León (24 de abril de 2014)

Las cuatro imágenes del reportaje reproducen diversos aspectos de la existencia diaria de Slavi. Se han tomado desde diversos ángulos y llaman la atención del observador hacia diferentes aspectos concretos de la enfermedad y del tratamiento. En la primera imagen, una toma en picado de Slavi y su fisioterapeuta, vemos a esta haciendo ejercicios para ayudar a Slavi a fortalecer su musculatura. La toma en picado sirve para presentar a Slavi como un ser indefenso, desvalido y dependiente. El espectador lo observa desde arriba, desde un ángulo de superioridad (ver Kress y van Leeuwen, 2006). Las tres fotografías que se presentan a continuación, en las que, respectivamente, aparece Slavi jugando con su hermano, haciendo ejercicios con su terapeuta, y tumbado en el sofá de su casa, con su madre en primer plano 
enseñando a la cámara un radiografía de Slavi cuando era recién nacido, se han tomado desde un ángulo oblicuo. El ángulo oblicuo indica que el fotógrafo no se ha alineado con el protagonista de la historia, Slavi. Lo muestra desde una posición marginal, y no frente a frente (Kress y van Leeuwen, 2006). En la última imagen, en la que se exhibe una radiografía de la pierna de Slavi, se recurre a la metonimia EL OBJETO POR LA PERSONA para representar la experiencia de la enfermedad. En este caso, la radiografía es el objeto. Todas estas imágenes, usadas para construir discursivamente a Slavi como un ser indefenso y necesitado de constante cuidado, constituyen testimonios gráficos (con imágenes médicas incluidas) de su enfermedad. El titular de la noticia recoge y reformula metafóricamente este contenido visual cuando anuncia "huesos de cristal", A la fragilidad física, sin embargo, inmediatamente se opone discursivamente la fortaleza moral, representada también con una metáfora: "voluntad de acero". El lector no sabe, sin embargo, si esa voluntad tan férrea es de Slavi o de aquellos que se ocupan de cuidarlo y de tratarlo.

Las noticias de niños afectados por una enfermedad rara siempre son extremadamente dramáticas. Lo que constituye generalmente noticia es la necesidad imperiosa de las familias de obtener financiación para el tratamiento o para investigar en la enfermedad. Como anunciábamos al principio de este informe, la narrativa maestra de las enfermedades raras otorga valor, cada vez en mayor medida, a la "solidaridad" de la ciudadanía, un eufemismo para hacer referencia a las donaciones individuales de los ciudadanos. En el caso particular de los niños, las llamadas a la solidaridad se presentan como más urgentes e imperiosas. La contribución, por tanto, se construye a menudo retóricamente como un imperativo ético que el lector no puede simplemente eludir. Este tipo de discurso "solidario" es el que se articula en la siguiente noticia publicada en el diario El MundoCantabria el 15 de junio de 2014:

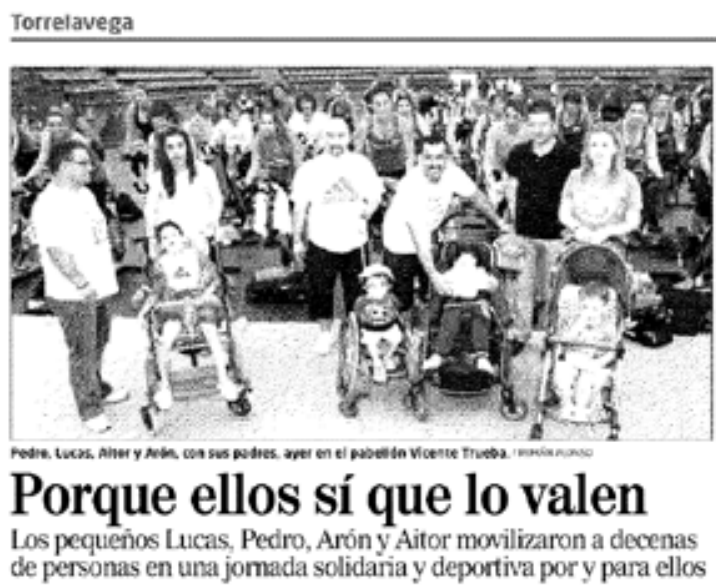

Figura 17. El Mundo-Cantabria (15 de junio de 2014) 
La imagen reproduce, a una distancia social pública, a cuatro niños afectados por una enfermedad rara, a sus padres y a una multitud de ciudadanos solidarios al fondo de la imagen. En primer plano están Pedro, Lucas, Aitor y Aarón y, tras ellos, sus padres. Hay, por tanto, tres niveles de representación en esta imagen, que icónicamente representan los grados de protagonismo y de individualización de las personas que se representan. Tanto visual como textualmente, los niños enfermos se indizan en el discurso recurriendo a mecanismos de identificación (fotografiándolos en primer plano), así como de referencia lingüística específica (proporcionando sus nombres de pila). Las sillas de ruedas en las que aparecen sentados se presentan como los objetos que definen su singularidad, la diferencia con respecto a los demás. Con el titular se apela al conocimiento del mundo del lector, puesto que el enunciado "Porque ellos sí lo valen" se hace eco de un famoso anuncio de la marca de cosméticos L'Óreal, que rezaba "Porque tú lo vales", con el que se pretendía incitar a las mujeres a consumir los productos de la firma. A la frivolidad, vanidad y egoísmo de invertir en la propia apariencia externa se opone la generosidad y el valor de ayudar a alguien necesitado. Con el titular "Porque ellos sí lo valen" se contrapone enfáticamente el "ellos" al "tú" que originariamente aparecía en el eslogan, y se insinúa que hay otros posibles sujetos que no "lo valen" tanto. El mensaje implícito transmitido con el titular alude a la falta de valor que tiene gastar el dinero en algo frívolo y superfluo, frente a la utilidad de invertirlo en una iniciativa solidaria. De este modo, el lector se ve impelido a actuar de algún modo, contribuyendo a la causa de los niños enfermos.

Tanto en la imagen como en el texto, la representación que se ofrece de los ciudadanos solidarios y de los niños que recibirán las donaciones difiere sustancialmente. En tanto que los niños afectados por una enfermedad rara son identificados con sus nombres en el titular de la noticia y, a menudo, con información acerca de su diagnóstico, el público que acude a los actos de solidaridad a menudo se introduce en el discurso con expresiones nominales inespecíficas en las que, por ejemplo, se informa del número aproximado de asistentes. Esta estrategia retórica se usa en la noticia que se acaba de analizar ("decenas de personas"), y en la que se incluye a continuación, publicada en La Opinión-El correo de Zamora el 27 de abril de 2014, cuando se anuncia en el titular "Más de 600 personas apoyaron a Daniela": 


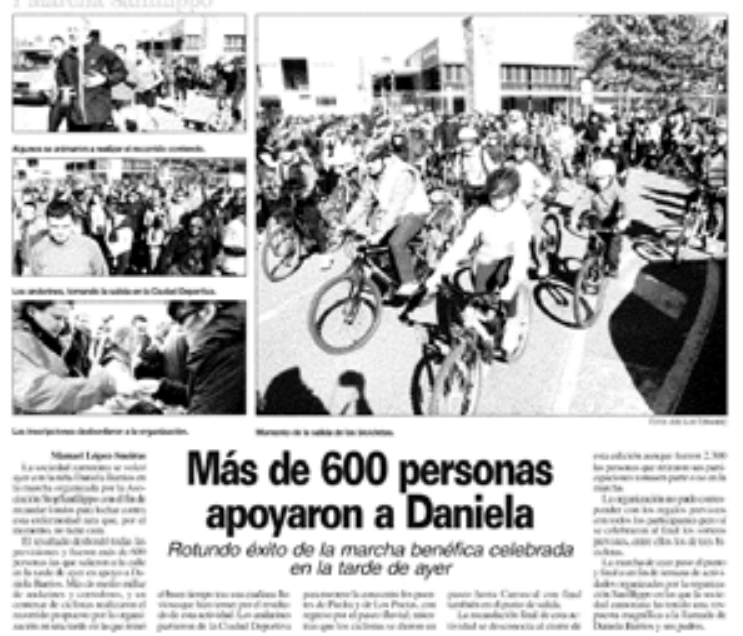

Figura 18. La Opinión-El correo de Zamora (27 de abril de 2014)

Las imágenes que se ofrecen del acto reproducen escenas del gran número de personas anónimas que asistieron a la "marcha benéfica" organizada para "apoyar" a Daniela, una niña afectada por el síndrome de Sanfilippo que solicitaba la contribución ciudadana para financiar un ensayo clínico. El fotógrafo no ha buscado identificar a los asistentes, sino solo captar la movilización popular de la iniciativa, como muestra del éxito en el seguimiento de la marcha. El público, protagonista, junto a Daniela, de la noticia, es representado como un conjunto indiferenciado de personas, del que solo se subrayan sus rasgos cuantitativos: el número de asistentes y la cantidad de dinero recaudada. También en el siguiente artículo de prensa, publicado en el Diario de Navarra el 28 de mayo de 2014, el titular recoge la cantidad precisa de dinero recaudada para el Grupo de Enfermedades Raras de Navarra (GERNA), mientras que la imagen muestra la carrera multitudinaria organizada para colectar tales fondos. El pie de foto informa del número de asistentes al acto. Claramente, pues, las referencias a la ciudadanía se construyen recurriendo a expresiones cuantificadoras.

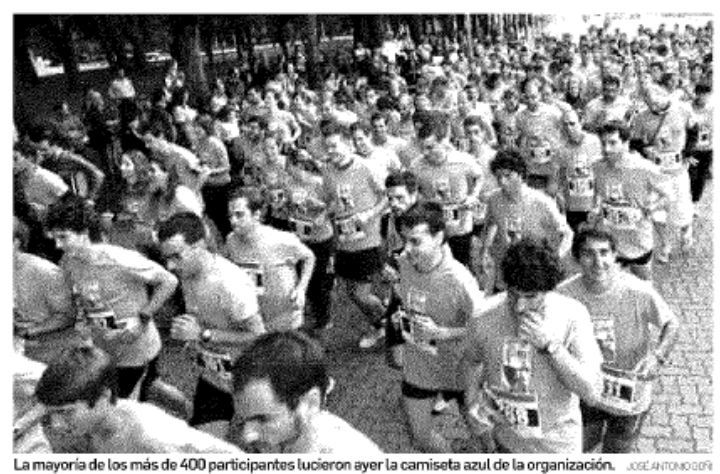

\subsection{4 euros para el GERNA}

Figura 19. Diario de Navarra (28 de mayo de 2014) 
En la narrativa mediática de las enfermedades raras, los ciudadanos, con sus contribuciones económicas, emergen como los verdaderos artífices de los cambios que están transformando la vida de las personas afectadas, tal y como se reconoce en el titular "Zamora nos ha hecho revivir", con el que se inaugura la siguiente noticia, también referida a Daniela, y que publicó La Opinión- El Correo de Zamora el 29 de octubre de 2014:

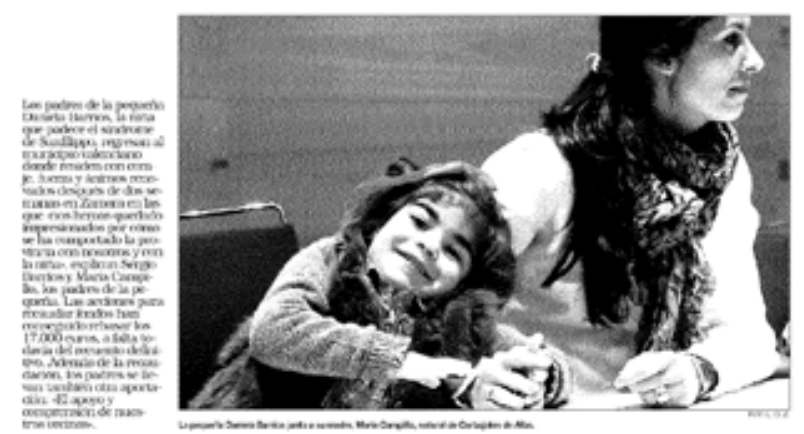

\section{"Zamora nos ha hecho revivir"}

Las acciones para recaudar fondos para Daniela Barrios, la ni ria de padres

zamoranos que padece el síndrome de Sanflippo, reúnen más de 17.000 euros

Figura 20. La Opinión- El Correo de Zamora (29 de octubre de 2014)

Los ciudadanos que han donado los 17.000 euros para el tratamiento de Daniela aparecen completamente desfocalizados, ocultos tras la expresión objetivizadora de espacialización "Zamora", en el caso del título, o simplemente mencionados implícitamente, a través de una metonimia LA ACCIÓN POR LA PERSONA, en el subtítulo, cuando, a través de una personificación, se habla de "las acciones para recaudar fondos para Daniela Barrios”. De hecho, ni siquiera aparecen visualmente representados. En la fotografía que ilustra la noticia, el espectador ve solo a Daniela inclinándose hacia su madre, con actitud sonriente y feliz, mirando directamente al observador. La causa de su felicidad se asocia a ese "revivir" del que son responsables los ciudadanos de Zamora. Los donativos de los zamoranos, por consiguiente, se definen en la narrativa como la única vía posible para salvar la vida de un niño aquejado por una grave enfermedad rara. Este contenido, integrado en la narrativa maestra de las enfermedades raras, contribuye a presentar como aceptable una situación social en la que la sanidad universal y gratuita ha pasado de ser un derecho garantizado por el estado a convertirse en un deber moral ciudadano.

Cuando la persona o personas afectadas por una enfermedad rara son adultos, es frecuente que el titular de la noticia presente a los receptores de la ayuda "solidaria" recurriendo a la metonimia LA ENFERMEDAD POR LA PERSONA, tal y como ocurre en la siguiente noticia, procedente del Faro de Vigo (26 de abril de 2014): 


\section{A Guarda responde con solidaridad a las enfermedades raras y a la crisis}
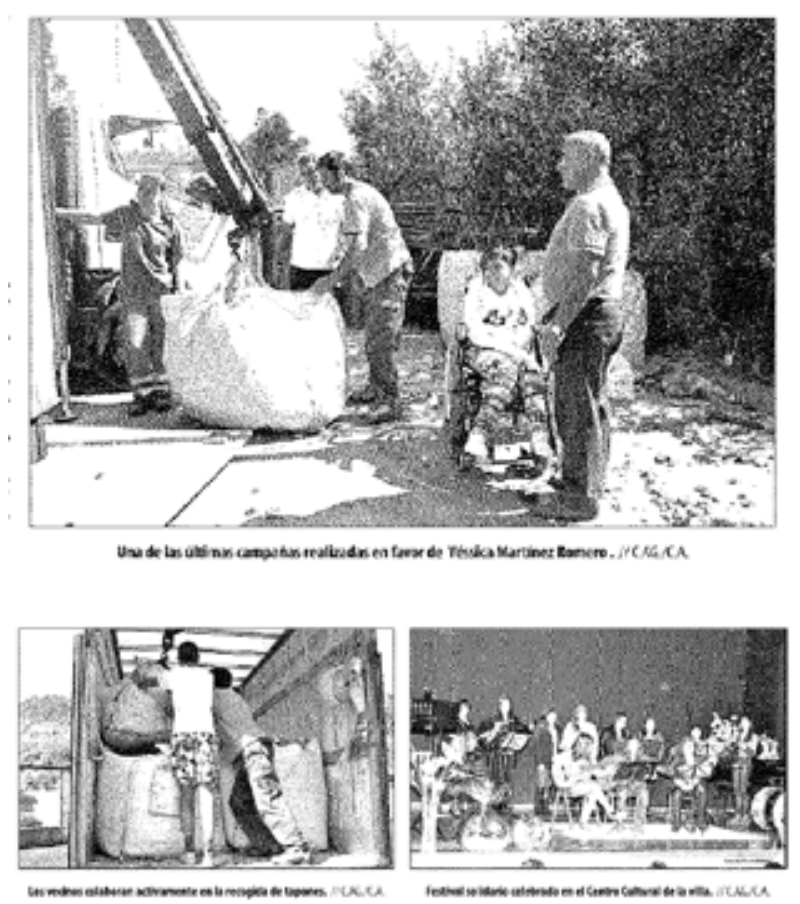

Figura 21. Faro de Vigo (26 de abril de 2014

El titular contiene, a su vez, otra metonimia: EL LUGAR POR SUS HABITANTES (A Guardia por "los vecinos de A Guardia"). Con ambas estrategias retóricas, el periodista crea una distancia con respecto a los sujetos de los que está informando. Las dos metonimias se usan para despersonalizar a los protagonistas de esa "solidaridad", inespecífica y general, a la que se alude en el titular. Como contrapunto al titular, las tres imágenes incluidas en la noticia muestran las actividades organizadas para la recaudación de fondos. Las fotografías funcionan como el testimonio gráfico de las acciones emprendidas por los habitantes de A Guardia, más que de las propias personas responsables de tales acciones. Se focaliza la atención del espectador, por consiguiente, más en la acción de voluntariado que en la identificación de los participantes en los actos.

En la misma línea de cubrir informativamente eventos multitudinarios, el Diario Palentino ofreció en su edición del 2 de junio de 2014 una crónica completa de la carrera popular organizada para colaborar con la Fundación Atrofia Muscular Espinal. Como ocurría en la noticia anterior, también en este caso el titular ("Los palentinos se vuelcan en la lucha contra la atrofia muscular espinal") presenta de modo genérico a los protagonistas del acto: los ciudadanos "solidarios" y los pacientes de atrofia muscular espinal. Las imágenes de la 
multitud participando en la carrera reafirman esta construcción despersonalizada de la ciudadanía. Con ello se pretende incidir más en el éxito de la convocatoria que en los protagonistas individuales, fomentando así el sentido de comunidad, acción colectiva y unión en una empresa conjunta.

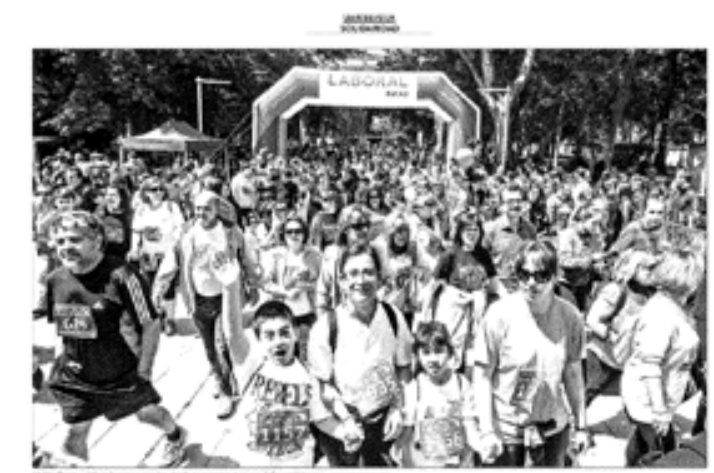

\section{Los palentinos se vuelcan en la lucha contra la atrofia muscular espinal}

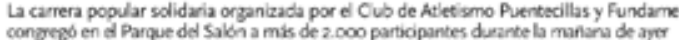

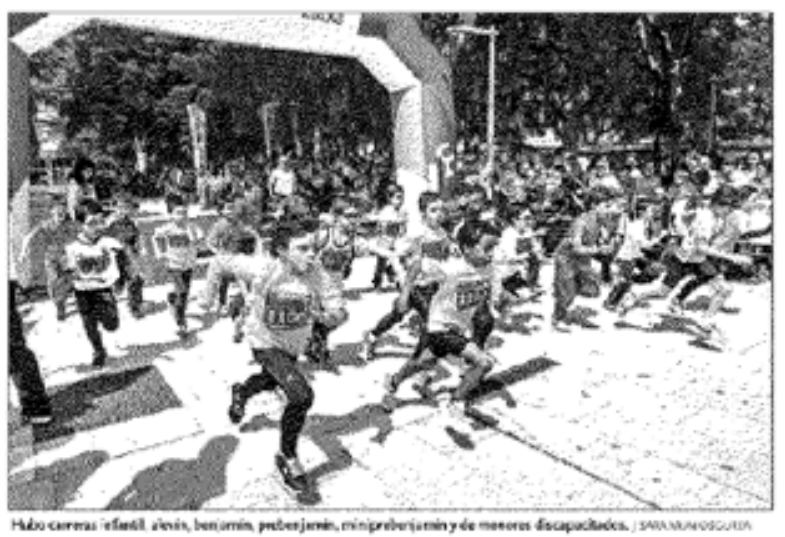

Figura 22. Diario Palentino (2 de junio de 2014)

El común denominador de todas estas noticias es la construcción positiva de la ciudadanía, a la que se califica de "solidaria", "generosa", "colaborativa", y a la que se le atribuye metafóricamente la capacidad de "combatir" ("Libros para combatir las enfermedades raras", La Opinión de Murcia, 15 de mayo de 2014) o "luchar" contra las enfermedades raras (“Tapones para luchar con Leo", El Adelantado de Segovia, 29 de mayo de 2014). En algún caso, la solidaridad ciudadana puede incluso obrar "milagros" ("El milagro de los tapones de plástico", La Opinión de Tenerife, 1 de junio de 2014). El contenido que vertebra todas las abundantes noticias dedicadas a informar sobre actos de "solidaridad" es siempre el mismo: los ciudadanos, con su generosidad y dedicación, son actores sociales críticos para salvar la vida de los niños aquejados por una enfermedad rara. 
La actividad ciudadana se inscribe siempre en "la lucha contra las enfermedades raras", lo que sugiere una construcción de este tipo de patologías como un enemigo al que hay que vencer en una acción bélica continuada. La idea de fondo es que no es suficiente con una donación esporádica, sino que el gran público ha de sentirse involucrado en una guerra a largo plazo que salvará la vida de personas inocentes. Este es, fundamentalmente, el papel que se asigna a la ciudadanía en la narrativa de las enfermedades raras en los medios.

Frente al anonimato con el que se representa a la ciudadanía solidaria, destaca el personalismo con el que se retrata a determinados personajes famosos que prestan su imagen a la causa de las enfermedades raras. En este tipo de noticias, se recurre al famoso para promover la idea de "solidaridad" entre la población, e incentivar su participación en los actos organizados para recaudar fondos. El personaje público se usa así como modelo de comportamiento social a emular, contribuyendo a reforzar el discurso retórico en favor de la solidaridad ciudadana como la acción fundamental en la lucha contra las enfermedades raras.

Un ejemplo ilustrativo de noticias dedicadas a personajes "solidarios" es el siguiente reportaje sobre el famoso bailarín y coreógrafo Víctor Ullate, que apareció publicado en Excelente el 11 de abril de 2014. Víctor Ullate suscribe y adapta, personalizándolo, el eslogan del movimiento Todos somos raros, todos somos únicos, creado por las federaciones españolas de Enfermedades Raras y de Enfermedades Neuromusculares, y la Fundación Isabel Gemio. El artículo se dedica por entero al personaje, ensalzando sus virtudes profesionales y personales, y repasando sus principales actividades y participación en causas sociales. La imagen muestra a Ullate posando de cuerpo entero, a una distancia personal lejana, en actitud muy relajada e informal (se presenta con las manos en los bolsillos, vistiendo de modo informal, sonriendo y mirando directamente a la cámara). El contacto visual expresa requerimiento/afiliación con respecto al espectador. Todos estos elementos indizan, por una parte, su identidad como personaje famoso del mundo de espectáculo; y, por otra, transmiten proximidad y empatía. A pesar de su fama, Ullate se presenta como un ser humano capaz de mostrar cercanía emocional con respecto al observador: 'Soy uno de vosotros', parece ser el mensaje transmitido con la imagen. En el ángulo inferior derecho se lee la expresión "solidario", con la que se define al personaje. La palabra "solidario" refuerza las propiedades de proximidad, humanidad y empatía transmitidas con la imagen.

El titular, por su parte, recoge una de las actividades "solidarias" a las que se hace mención en el texto de la noticia. El análisis contrastivo entre el título "bailar es raro, bailar es único" y el subtítulo "Uno de los mejores bailarines de las décadas de los años 60, 70 y 80, 
comparte su talento con los menos favorecidos" revela la contraposición entre dos construcciones discursivas de las enfermedades raras. Por una parte, con la afirmación "bailar es raro, bailar es único", Ullate suscribe implícitamente la articulación de las enfermedades poco frecuentes como condiciones que no marcan negativamente a quien las sufre como "el otro", sino como "uno más entre nosotros", gracias a la equivalencia semántica que se establece en el enunciado entre los adjetivos "raros" y "únicos". Ullate reformula el eslogan para reforzar, desde su propia condición de bailarín, ese mensaje de normalización promovido por el movimiento Todos somos raros, todos somos únicos. Bailar, al igual que padecer una enfermedad poco frecuente, es algo que no sucede a menudo y, además, nos convierte en seres singulares, especiales, irreemplazables. No obstante, el subtítulo que acompaña al artículo, "Uno de los mejores bailarines de las décadas de los años 60, 70 y 80, comparte su talento con los menos favorecidos" contradice el mensaje anterior. Víctor Ullate se construye como parte de una elite de individuos ("uno de los mejores bailarines..."), y se le reconoce un talento particular ("su talento"). Las personas que sufren una enfermedad rara se definen, en cambio, como "los menos favorecidos". Cabe preguntarse si, calificándolos como "menos favorecidos", el periodista se refería a "menos capacitados" o a "menos amparados". En cualquier caso, Víctor Ullate es "uno de los mejores", en contraste con los que son "menos".
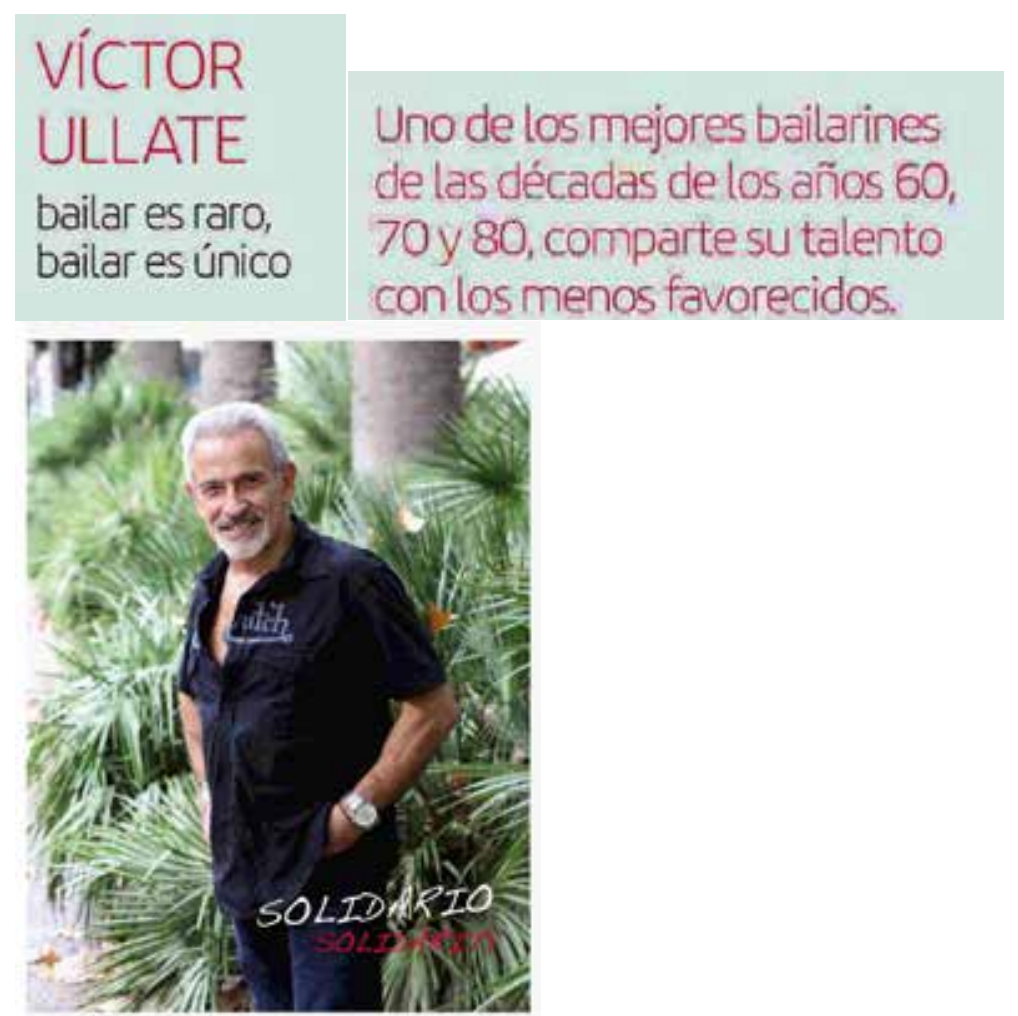

Figura 23. Excelente (11 de abril de 2014) 
En otros casos, el discurso de la solidaridad se usa como medio para promocionar ventas. Este sería el caso de la noticia siguiente, publicada en Mujer Hoy el 26 de abril de 2014. La empresaria de joyería Satya Scainetti, que está tratando de expandir su negocio en el mercado español, conecta discursivamente su actividad comercial ligada a su activismo social. Así, cuando afirma "Educamos a muchos niños con la venta de nuestras joyas" claramente articula marketing comercial y contribución social como dos actividades interdependientes. "Educamos a muchos niños" aparece en primer lugar, y como información de primer plano, mientras que "la venta de nuestras joyas", colocada a continuación en la estructura informativa del enunciado, adquiere un carácter aparentemente secundario y dependiente de lo anterior. El mensaje comunicado es claro: vender joyas es, en realidad, lo que nuestra empresa hace para ayudar a los demás. Este mensaje constituye el discurso promocional de la firma; es la estrategia de "branding" diseñada para incrementar las ventas. El uso del plural es importante en el titular porque apunta a la idea de equipo, de colaboración, de acción común. La imagen de la diseñadora, por su parte, complementa y refuerza el discurso de empatía y solidaridad anunciado en el titular. Satya aparece representada a una distancia personal lejana, estableciendo contacto visual directo con el observador. Las joyas con las que posa ante la cámara constituyen también participantes representados en la imagen, puesto que se usan intencionalmente como objetos de promoción de la firma.

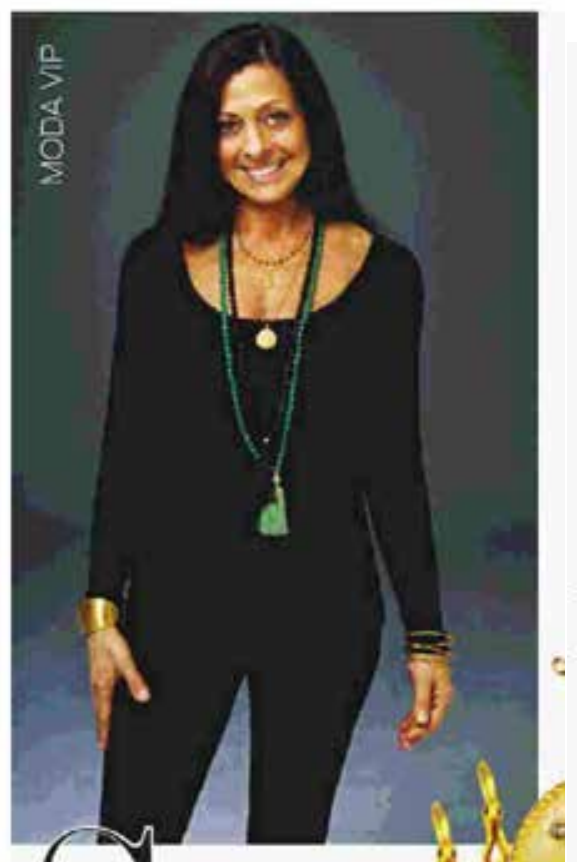

\section{Satya Scainetti EMPRESARAA DE IOYERIA}

"Educamos a muchos niños con la venta de nuestras joyas"

La fundadora de Satya Jewelry, que empieza a vender sus piezas en España, nos

Figura 24. Mujer Hoy ( 26 de abril de 2014)

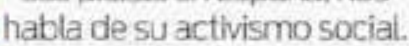


Con independencia de las motivaciones comerciales, es relevante destacar de nuevo que noticias de este tipo construyen y perpetúan una narrativa maestra en la que la solidaridad se construye como el mecanismo de intervención y de asistencia social. En este caso, la articulación discursiva de la solidaridad se lleva a cabo en el contexto del mundo empresarial.

Por último, en el campo de la investigación y el tratamiento de las enfermedades poco frecuentes, investigadores y médicos aparecen como los personajes principales, generalmente retratados con sus atributos identificativos de atuendo, objetos e instrumentos que los definen en su rol social de profesionales. Las imágenes sitúan a menudo a la persona representada en un plano medio corto, mirando al observador y en actitud relajada. El escenario que actúa de telón de fondo es frecuentemente un laboratorio, lo que permite al espectador completar la identidad del personaje con una indicación visual de su actividad. En este tipo de noticias, por tanto, la representación del sujeto convencionalmente incluye el espacio en el que desempeña su rol social de científico, tal y como puede comprobarse en el caso siguiente, extraído de la publicación Diario Médico en su edición del día 2 de abril de 2014:

\section{Hallan un factor genético de la distonía del músico}
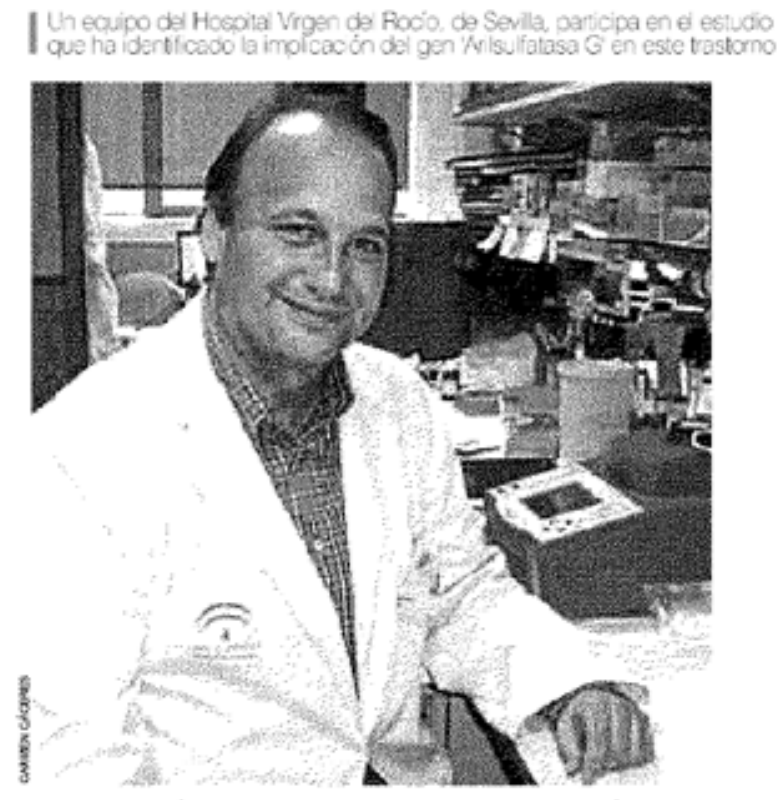

Pablo Mir, neurblogo ded Hospital Unversitario Virgen del Rocio.

Figura 25. Diario Médico (2 de abril de 2014)

En las noticias dedicadas a los investigadores, los titulares suelen estar focalizados en informar sobre alguna innovación científica relevante en relación con una determinada 
enfermedad, como ocurre en este caso, con el anuncio impersonal "Hallan un factor genético de la distonía del músico”. En general, en el titular no se construyen discursivamente ni el investigador, o equipo de investigadores, ni el conjunto de pacientes a los que va a beneficiar el descubrimiento. En todo caso, la información identificativa del equipo de científicos autor del estudio suele introducirse en el subtítulo de la noticia.

En ciertas ocasiones, sin embargo, determinados investigadores o personal médico se construyen metafóricamente en los medios como personajes míticos dedicados en cuerpo y alma a los enfermos, en el caso de los doctores, o al descubrimiento de nuevas formas de tratamiento, en el caso de los investigadores. Así, por ejemplo, en la noticia que reproducimos a continuación (Diario de Almería, 14 de abril de 2014), la Dra. Gema Esteban y las personas afectadas por Síndrome de Wolfran se introducen en el titular como las protagonistas de los hechos narrados en la noticia. Desde el punto de vista lingüístico, contrasta la pluralidad de personas denotadas por medio de la expresión de referencia inespecífica "los afectados por el Síndrome de Wolfan" con la especificidad y unicidad de la expresión nominal "su ángel protector", en referencia a Gema. Resulta significativo, asimismo, que la doctora no sea mencionada con su nombre de pila, sino recurriendo a la expresión nominal definida "su ángel protector", en una estrategia discursiva para transmitir en el lector una serie de inferencias sobre la bondad, dedicación y generosidad de Gema, por una parte, y sobre la protección, el amparo y la defensa de los intereses de los enfermos, por otra. Con la metáfora “ángel protector", se atribuye a la labor de Gema Esteban una dimensión espiritual y religiosa. En el subtítulo se especifica que el calificativo responde a su iniciativa de fundar la asociación "que se ocupa de los enfermos y familias".

El recurso a la metáfora sirve para ensalzar y premiar públicamente su dedicación altruista a los afectados y a sus familiares, pero también comunica implícitamente la soledad de Gema en el cuidado de estos enfermos y sus familias, frente a la falta de ayudas por parte del sistema sanitario (cuestión a la que se hace referencia en el cuerpo de la noticia). Las imágenes que acompañan al texto recogen varios momentos de las actividades organizadas por la Asociación fundada por Gema Esteban. La representación del público, en unas jornadas de carácter educativo para difundir información sobre la enfermedad de Wolfran, se usa retóricamente para mostrar el activismo de la asociación. En la tercera imagen aparece Gema, vestida con su bata blanca de doctora (lo que constituye un signo de identificación social), con los brazos extendidos y mirando al observador, en el contexto de un despacho o 
de un aula. El pie de foto especifica que Gema está explicando el Síndrome de Wolfran, lo que añade una faceta más a su compleja representación discursiva: la de ser una educadora.

\section{Los afectados por el Síndrome de Wolfran y su ángel protector}

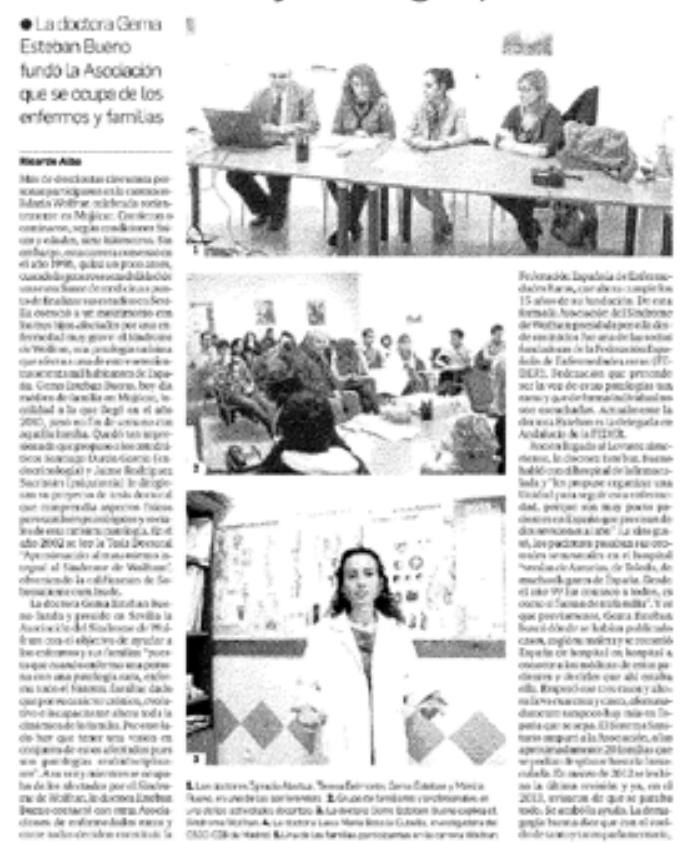

Figura 26. Diario de Almería (14 de abril de 2014)

\subsubsection{Conclusiones}

Del análisis multimodal de la prensa escrita en este segundo trimestre de 2014 se desprende que la cobertura mediática sobre las enfermedades raras y las personas que las sufren articula una narrativa maestra que retrata en primer plano y da voz a determinados actores sociales, principalmente a las personas que padecen la enfermedad y a sus familias, y a la ciudadanía, mientras silencia e invisibiliza a los representantes políticos y administrativos, responsables, en primera instancia, de asegurar y de velar por los derechos fundamentales de las personas (como es el derecho a la asistencia médica universal). El peligro de persistir en esta "invisibilidad" representativa en la prensa es consolidar un discurso social de las enfermedades raras en el que se justifique y se normalice que la financiación de tratamientos e investigación recaiga en el ciudadano medio y, en ocasiones, en ciertas iniciativas privadas, y no en los poderes públicos. Con ello se legitima una narrativa construida en el marco ideológico del liberalismo económico, en el que se prima la responsabilidad individual sobre la responsabilidad colectiva. 


\section{Segunda parte. Las enfermedades raras en la salud}

\subsection{Análisis periodístico del relato radiofónico}

(Por Àngels Álvarez. Villa, Universidad CEU Cardenal Herrera)

En el relato radiofónico sobre las Enfermedades Raras emitido durante el segundo trimestre del año 2014 han participado un total de 9 emisoras, lo que supone un descenso respecto al tratamiento desarrollado durante el primer trimestre. No aparecen en esta ocasión las emisoras Euskadi Radio, Es Radio, Canal SUR, ni la municipal Candil Radio. Desde las diferentes estaciones se han generado 33 unidades de análisis, un número de piezas informativas que suponen un descenso igualmente importante si lo comparamos con las 101 piezas registradas en el informe anterior. El total de minutos de emisión asciende a cerca de 2 horas y media. El flujo informativo emitido se encuentra muy alejado de las alrededor de seis horas de programación del trimestre pasado destinadas a la cobertura de las enfermedades minoritarias. En el mapa radiofónico analizado aparecen de nuevo tanto emisoras de titularidad pública como privada, así como radios de ámbitos y coberturas diferentes.

En la siguiente tabla se muestran los nombres de estas radios, el número de piezas informativas presentes en cada emisora así como el registro total de tiempos. La Cadena COPE es la entidad que más información ha difundido, seguida por Onda Madrid y RNE. Los resultados difieren de los pasados ya que en la anterior entrega era la Cadena SER la más volcada en esta temática, seguida por COPE y Onda Cero.

Tabla 1. Emisoras

\begin{tabular}{l|cc}
\hline & Frecuencia & Duración \\
\hline RNE & 7 & $27^{\prime} 05^{\prime \prime}$ \\
COPE & 5 & $34^{\prime} 06^{\prime \prime}$ \\
SER & 5 & $26^{\prime} 34^{\prime \prime}$ \\
ONDA CERO & 2 & $0^{\prime} 58^{\prime \prime}$ \\
ONDA MADRID & 5 & $29^{\prime} 20^{\prime \prime}$ \\
CATALUNYA RÀDIO & 1 & $2^{\prime} 00^{\prime \prime}$ \\
RAC & 2 & $2^{\prime} 38^{\prime \prime}$ \\
GESTIONA RADIO & 1 & $5^{\prime} 50^{\prime \prime}$ \\
ONDA VASCA & 5 & $24^{\prime} 32^{\prime \prime}$ \\
\hline Total & 33 & $2 \mathrm{~h} 33^{\prime} 05^{\prime \prime}$ \\
\hline
\end{tabular}

Si nos fijamos en los datos tras observar los diferentes títulos de los programas (tabla 2), se comprueba que los más activos por número de informaciones han sido Hora 14 (SER) e Informativo Mediodia y Hoy en Madrid (Onda Madrid) así como el espacio Informatiu de Migdia (Catalunya Ràdio). 
Tabla 2. Programas

\begin{tabular}{l|c}
\hline \multicolumn{1}{c}{} & Frecuencia \\
\hline HORA 14 & 4 \\
LA HORA LOCAL DE LA TARDE EN EUSKADI & 2 \\
EL MON RAC1 & 2 \\
LAS TARDES DEL CIUDADANO GARCÍA & 1 \\
INFORMATIVO DE MEDIODÍA ONDA MADRID & 3 \\
HOY EN MADRID & 3 \\
LA BRÚJULA & 1 \\
DIARIO DE LAS DOS & 2 \\
CRÓNICA DE MADRID RNE & 1 \\
24 HORAS & 1 \\
EL MATÍ COPE & 1 \\
INFORMATIU MIGDIA CATALUNYA RÀDIO & 3 \\
EUSKADI HOY ONDA VASCA & 1 \\
LA TARDE COPE & 2 \\
EUSKADI COPE EN BILBAO & 1 \\
MEDIODÍA COPE & 1 \\
RNE BESAIDE & 1 \\
ECONOMÍA A LAS DOS & 1 \\
NOTÍCIAS MEDIODÍA ONDA CERO & \\
HOY POR HOY MADRID & \\
\hline Total & 1 \\
\hline
\end{tabular}

Pero interesa igualmente fijar la atención en la relación entre los títulos y la duración de las informaciones emitidas, tal y como se muestra en la Tabla 3.

Se observa que la duración oscila entre una noticia breve de 22 segundos y el espacio de mayor duración, una entrevista de 13 minutos en Onda Vasca con el ciclista Iñaki Castañeda. Entre los espacios que más minutos han destinado a informar sobre las enfermedades de baja prevalencia se encuentran los siguientes títulos: Hoy en Madrid (Onda Madrid), La Hora Local de la Tarde (Onda Vasca) y La Tarde (COPE). El contenido informativo se ha difundido en el período analizado a través de diferentes géneros. Entre los formatos adoptados sobresalen dos, la noticia y la entrevista. El resto de géneros se emplean en escasas ocasiones, y así únicamente aparece en todo el trimestre una mesa redonda y un par de reportajes.

Tabla 3. Emisoras y programas

\begin{tabular}{|c|c|c|}
\hline Cadena & Programa & Duración \\
\hline \multirow{4}{*}{$\overline{\mathrm{COPE}}$} & LA TARDE & $20^{\prime} 52^{\prime \prime}$ \\
\hline & EL MATÍ & $6^{\prime} 50^{\prime \prime}$ \\
\hline & MEDIODÍA COPE & $4^{\prime} 46^{\prime \prime}$ \\
\hline & COPE EN BILBAO & $1^{\prime} 32^{\prime \prime}$ \\
\hline \multirow[t]{2}{*}{ SER } & HORA 14 & $10^{\prime} 33^{\prime \prime}$ \\
\hline & HOY POR HOY & $12^{\prime} 00^{\prime \prime}$ \\
\hline
\end{tabular}




\begin{tabular}{|c|c|c|}
\hline 'ONDA VASCA & \multicolumn{2}{|l|}{$\begin{array}{l}\text { LA HORA LOCAL DE LA TARDE EN } \\
\text { EUSKADI } \\
\text { EUSKADI HOY }\end{array}$} \\
\hline RAC 1 & EL MÓN & $22^{\prime \prime \prime}$ \\
\hline ONDA CERO & $\begin{array}{l}\text { LA BRÚJULA } \\
\text { NOTICIAS MEDIODÍA }\end{array}$ & $\begin{array}{l}0^{\prime} 36^{\prime \prime} \\
0^{\prime} 22^{\prime \prime}\end{array}$ \\
\hline RNE & $\begin{array}{l}\text { LAS TARDES DEL CIUDADANO GARCÍA } \\
\text { DIARIO DE LAS DOS } \\
\text { CRÓNICA DE MADRID } \\
24 \text { HORAS } \\
\text { BESAIDE }\end{array}$ & $\begin{array}{l}1^{\prime} 02^{\prime \prime} \\
3^{\prime} 56^{\prime \prime} \\
1^{\prime} 47^{\prime \prime} \\
1^{\prime} 39^{\prime \prime} \\
1^{\prime} 56^{\prime \prime}\end{array}$ \\
\hline ONDA MADRID & $\begin{array}{l}\text { HOY EN MADRID } \\
\text { SERVICIOS INFORMATIVOS } \\
\text { INFORMATIVO DEL MEDIODÍA }\end{array}$ & $\begin{array}{l}27^{\prime} 20^{\prime \prime} \\
1^{\prime} 20^{\prime \prime} \\
1^{\prime} 52^{\prime \prime}\end{array}$ \\
\hline CATALUNYA RÀDIO & INFORMATIU MIGDIA & $3^{\prime} 00^{\prime \prime}$ \\
\hline GESTIONA RADIO & ECONOMÍA A LAS DOS & $5^{\prime} 50^{\prime}$ \\
\hline \multicolumn{3}{|c|}{ Tabla 4. Género de la pieza } \\
\hline & Frecuencia & Porcentaje \\
\hline Noticia & 20 & $60^{\prime} 6 \%$ \\
\hline Entrevista & 10 & $33,3 \%$ \\
\hline Polémica & 1 & $3,03 \%$ \\
\hline Reportaje & 2 & $6 \% 6 \%$ \\
\hline Total & 33 & 100,0 \\
\hline
\end{tabular}

En cuanto a los géneros de programas, las unidades estudiadas aparecen exclusivamente en dos tipos de estructuras, el Diario Hablado, con 22 piezas, y el Magazín Generalista, de mañana y tarde, con 11 entradas. De esta manera la información se presenta mayoritariamente ligada a uno de los principales servicios informativos diarios. Si en el informe correspondiente al trimestre anterior se empleaban más géneros, en esta ocasión se produce al tiempo que una reducción en los minutos totales destinados al tema analizado, un descenso en la variedad de los formatos empleados.

Por lo que respecta al ámbito de difusión de las informaciones sobre enfermedades minoritarias domina el autonómico en un $66 \%$ frente al estatal con un 33\%. Han desaparecido las emisoras locales con relación al informe anterior pero sigue sobresaliendo la información sobre enfermedades de baja prevalencia en las estaciones autonómicas. Con relación a la tipología de la emisora, se produce un equilibrio puesto que la mitad de las piezas 
han aparecido en emisoras públicas y la otra mitad en cadenas de naturaleza privada, algo que tampoco sucedía en el trimestre ya analizado.

Tabla 5. Tipo de programa

\begin{tabular}{l|cc}
\hline & Frecuencia & Porcentaje \\
\hline Diario hablado & 22 & $66,6 \%$ \\
Magacín generalista & 11 & $33,3 \%$ \\
Magacín especializado & 0 & $0 \%$ \\
Boletín informativo & 0 & $0 \%$ \\
Total & 33 & 100,0 \\
\hline
\end{tabular}

Atendemos a continuación a la aparición de apoyos sonoros en la construcción del relato informativo. En este sentido las noticias se elaboran, en la mitad de las ocasiones, con declaraciones previamente grabadas, mientras que el uso de otros recursos como las músicas, sonidos ambientes o los efectos son escasos.

En el estudio de los protagonistas de las informaciones, tanto en las entrevistas en directo como en las declaraciones en diferido, prevalecen los afectados y familiares en primer lugar, seguidos de cerca por las Asociaciones y por los representantes de Instituciones, tal y como ya sucediera en el pasado informe. De igual modo destacan en las informaciones los representantes de FEDER con una posición intermedia en este listado. El resto de protagonistas tienen una presencia en el medio radio menor como fuentes directas. El personal médico, los voluntarios y las publicaciones científicas se convierten en las últimas referencias durante el desarrollo de la actividad periodística.

Tabla 6. Protagonistas de las intervenciones

\begin{tabular}{l|cc}
\hline & Frecuencia & Porcentaje \\
\hline Afectados y/o Familiares & 12 & $25 \%$ \\
Asociaciones y/o & 10 & $20,8 \%$ \\
Fundaciones & 9 & $18,7 \%$ \\
Institucionales & 2 & $4,1 \%$ \\
Investigadores/Científicos & 4 & $8,3 \%$ \\
Médicos/Personal Sanitario & 0 & $0 \%$ \\
Publicaciones Científicas & 1 & $2 \%$ \\
Voluntarios & 4 & $8,3 \%$ \\
Famosos & 6 & $12,5 \%$ \\
FEDER & 48 & 100,0 \\
\hline Total & & \\
\hline
\end{tabular}

En el ámbito de las temáticas a las que aluden las informaciones radiofónicas, como ya sucediera en el informe referido al trimestre anterior, son mayoritarias las vinculadas a los actos sociales, aspecto que se encuentra en sintonía con el resultado obtenido con relación a los encuadres informativos que enmarcan la actividad periodística. De igual modo emergen con fuerza aquellos aspectos ligados a las reclamaciones económicas y políticas. Dichos 
resultados ponen de relieve que este asunto resulta prioritario para los afectados y familiares de los enfermos, y que se convierte en columna vertebral de su actividad comunicativa. Sin el motor económico, y las necesarias reformas políticas, no es posible impulsar una vital actividad investigadora, ni tampoco desarrollar los tratamientos que necesitan de modo urgente los afectados. En este sentido, y nuevamente coincidiendo con la entrega pasada, los aspectos relacionados con la educación se colocan en una posición con poca visibilidad en el discurso informativo generado.

Tabla 7. Categorías temáticas

\begin{tabular}{l|cc}
\hline & Frecuencia & Porcentaje \\
\hline Actos sociales/eventos & 23 & $26,7 \%$ \\
Cuestiones económicas & 12 & $13,9 \%$ \\
Historia de vida & 9 & $10,4 \%$ \\
Investigación científica & 7 & $8,1 \%$ \\
Decisiones políticas & 15 & $18,07 \%$ \\
Medicamentos huérfanos & 8 & $9,3 \%$ \\
Sin diagnóstico & 4 & $4,6 \%$ \\
Educación & 3 & $3,4 \%$ \\
Otros & 5 & $5,8 \%$ \\
Total & 86 & 100,0 \\
\hline
\end{tabular}

Algunos ejemplos de los asuntos que acaparan los focos informativos son los siguientes: El colegio 'María Moliner' de Villa Nueva de la Cañada ha sido pionero en integrar a niños con problemas motóricos mediante el proyecto 'Federito' del que forma parte la Federación Española de las Enfermedades Raras; se ha organizado en Pamplona la primera carrera a favor de las personas con enfermedades raras; el ayuntamiento de Humanes está recolectando tapones para reciclarlos para apoyar la investigación; el ayuntamiento de Vitoria y FEDER han presentado una jornada científica y de sensibilización ciudadana sobre enfermedades raras.

Nos detenemos en los encuadres en los que se enmarcan los diferentes segmentos informativos, para descubrir que, tal y como ya sucediera anteriormente, el paradigma informativo preponderante es aquel en el que la enfermedad se inscribe en un escenario de cariz social. De este modo, las historias de vida y los actos solidarios consiguen un lugar hegemónico. El segundo marco informativo presente, aunque a una enorme distancia del descrito, es el del conflicto político. Tanto los afectados como los familiares de los enfermos, a título individual o bien a través de fundaciones y asociaciones, reclaman cambios que tienen su origen en decisiones políticas y que influirían en una mejor calidad de vida. De nuevo ocupa una tercera posición el encuadre que destaca los rasgos médicos de las diferentes enfermedades. Pese a que se dan a conocer determinados aspectos pertenecientes a los 
síntomas de algunas patologías, lo prioritario es seguir promoviendo campañas de sensibilización.

Durante el período revisado se informa sobre distintas afecciones: esclerosis lateral amiotrófica, fibrosis quística, la esclerodermia, la PKU, la esclerosis tuberosa, o la enfermedad de San Filippo. Se convocan diferentes actos solidarios: carrera en Sitges contra la PKU, la creación de un portal de subastas solidarias, la celebración del Día Internacional de la ELA, el Telemaratón de RTVE, un encuentro de campaneros recauda fondos para la investigación, etc. Y distintos personajes populares colaboran cediendo objetos personales para la celebración de una subasta: los futbolistas Xavi Hernández o Iker Casillas. Se narran historias de superación como la de Alba Vargas, se alerta de los recortes en el sistema sanitario, o se informa de la presentación a las elecciones europeas de una agrupación relacionada con la discapacidad y las enfermedades raras. Se persigue hacer visibles las enfermedades pero sobre todo a los enfermos, y conseguir fondos para iniciar o proseguir investigaciones médicas y tratamientos.

Tabla 8. Encuadres

\begin{tabular}{l|cc}
\hline & Frecuencia & Porcentaje \\
\hline Realidad social & 25 & $75,7 \%$ \\
Conflicto político & 6 & $18,1 \%$ \\
Enfermedad especializada & 2 & $6 \%$ \\
\hline Total & 33 & 100,0 \\
\hline
\end{tabular}

Por lo que respecta al impacto informativo por provincias, se advierte que son la Comunidad de Madrid, el País Vasco y Cataluña las más activas desde un punto de vista informativo, como muestran los datos de la tabla 8, y tal y como ya ocurriera en el período anterior analizado.

Tabla 9. Localización de la informacion

\begin{tabular}{l|cc}
\hline \multicolumn{2}{c}{ Frecuencia } & Porcentaje \\
\hline Comunidad de Madrid & 8 & $24,24 \%$ \\
País Vasco & 5 & $15,15 \%$ \\
Cataluña & 6 & $18,1 \%$ \\
Andalucía & 1 & $3,03 \%$ \\
España & 9 & $27,2 \%$ \\
Comunidad Foral de Navarra & & \\
Cantabria & 3 & $9,09 \%$ \\
& 1 & $3,03 \%$ \\
\hline Total & 33 & 100,0 \\
\hline
\end{tabular}

La siguiente tabla muestra los datos con relación al empleo de las fuentes para elaborar la información. Así se desprende que los periodistas acuden a las asociaciones en 
primer lugar, y a los familiares y afectados en segunda instancia. En ocasiones ambas categorías suelen coincidir. De igual modo en el estudio de los actores principales de las unidades informativas, son las asociaciones y los afectados y familiares quienes ocupan los primeros puestos, y a continuación FEDER. Les siguen de cerca las instituciones entre las que destaca la monarquía, y los famosos, en cuyo caso sobresale el nombre de la periodista Isabel Gemio relacionada con la celebración del Telemaratón en TVE.

Tabla 10. Actor principal

\begin{tabular}{l|cc}
\hline \multicolumn{1}{c}{} & Frecuencia & Porcentaje \\
\hline Instituciones & 7 & $12,5 \%$ \\
Asociaciones & 12 & $21,4 \%$ \\
Médicos & 6 & $10,7 \%$ \\
Investigadores & 3 & $5,3 \%$ \\
Afectados y familiares & 12 & $21,4 \%$ \\
FEDER & 8 & $14,2 \%$ \\
Famosos & 6 & $10,7 \%$ \\
Voluntarios & 1 & $1,7 \%$ \\
Niños & 1 & $51,7 \%$ \\
\hline Total & 56 & 100,0 \\
\hline
\end{tabular}

Ponemos el acento ahora en el modo en que se ha denominado a los afectados por las enfermedades minoritarias. La descripción que más se escucha es la de "afectado" y "enfermo". Además surge igualmente la de "niño" o "paciente". Las menos utilizadas en las piezas analizadas son la de "discapacitado" o "dependiente". En la categoría de "otros", aparecen una enorme diversidad de expresiones: "chavales", "grupos de personas", "habitantes", "hijo", “joven", "personas con enfermedades raras", "personas con limitaciones", "personas que padecen”, "personas que sufren”, "personas con patologías”, "personas con deficiencias", o bien los nombres propios para referirse a los enfermos.

Tabla 11. Denominación de la persona con er

\begin{tabular}{l|cc}
\hline \multicolumn{1}{c}{ Frecuencia } & Porcentaje \\
\hline Otras & 19 & $36,5 \%$ \\
Niño & 10 & $19,2 \%$ \\
Afectado & 13 & $25 \%$ \\
No se nombra al sujeto & 0 & $0 \%$ \\
Enfermo & 12 & $23 \%$ \\
Paciente & 6 & $11,5 \%$ \\
Dependiente & 1 & $1,9 \%$ \\
Discapacitado & 1 & $1,9 \%$ \\
Total & 52 & 100,0 \\
\hline
\end{tabular}

Finalmente abordaremos el modo en que desde los medios radiofónicos se nombra a este tipo de enfermedades. La más reiterada sigue siendo la de "enfermedad rara" aunque 
en el interior de las informaciones se hace uso, habitualmente junto a ésta, de otras expresiones. El nombre de la enfermedad posee de igual manera una enorme presencia dado que las noticias aparecen vinculadas en el período analizado a diferentes campañas solidarias relativas a distintas enfermedades. Se emplea asimismo, pero en menor medida, la expresión "enfermedad minoritaria". Desde los medios se insiste en que la expresión "enfermedad rara" obedece a un criterio cuantitativo, a su baja prevalencia, y que nunca ha de ser aplicada al enfermo.

Tabla 12. Denominación de la enfermedad

\begin{tabular}{l|cc}
\hline & Frecuencia & Porcentaje \\
\hline Enfermedad rara & 29 & $55,7 \%$ \\
Enfermedad minoritaria & 14 & $26,9 \%$ \\
Nombre propio & 19 & $36,5 \%$ \\
\hline Total & 52 & 100,0 \\
\hline
\end{tabular}

\subsection{Conclusiones}

1. 1.En el discurso radiofónico sobre las enfermedades de baja prevalencia emitido durante el segundo trimestre del año se constata una reducción en el tiempo destinado a cubrir las informaciones sobre estas patologías, así como un descenso en el número de emisoras de radio que participan. De las cerca de 6 horas de emisión se ha descendido hasta las 2 horas y media en este segundo período.

2. De nuevo los formatos elegidos para contener las unidades de información son géneros de carácter informativo como la noticia y la entrevista, difundidos a través de los diarios hablados y los magacines generalistas, tanto de mañana como de tarde. Son espacios que pertenecen a una tipología de programas destinados a ahondar en las claves de la actualidad. Se trata de espacios en los que el relato informativo prescinde de otros recursos del lenguaje radiofónico distintos a la palabra.

3. La emisora que se ha hecho eco en mayor medida de este asunto en este análisis ha sido Cadena COPE, seguida por las estaciones públicas Onda Madrid y RNE, y por las cadenas privadas Cadena SER y Onda Vasca. Por lo que respecta al impacto informativo se observa un equilibrio entre la información autonómica y la estatal, y entre los espacios que más minutos han destinado a informar sobre las enfermedades de baja prevalencia se encuentran Hoy en Madrid (Onda Madrid), La Hora Local de la Tarde (Onda Vasca) y La Tarde (COPE). 
4. En cuanto al impacto informativo por provincias, se advierte que son la Comunidad de Madrid, el País Vasco y Cataluña las más activas desde un punto de vista informativo, algo que ya ocurriera en el informe anterior.

5. El encuadre informativo dominante aplicado a las informaciones se repite nuevamente ya que es aquel en el que los periodistas enmarcan la enfermedad en un contexto de carácter social: historias de vida y actos de solidaridad. De igual modo emergen con fuerza aquellos aspectos ligados a las reclamaciones económicas y políticas.

6. En las entrevistas y declaraciones se repite la misma pauta y destacan como actores los familiares y afectados por las enfermedades, seguidos por las Asociaciones y Fundaciones. Igualmente destacan los representantes de FEDER con una posición intermedia en este listado. El resto de protagonistas tienen una presencia menor como fuentes directas. El personal médico, los voluntarios y las publicaciones científicas se convierten en las últimas referencias para los informadores durante el desarrollo de la actividad periodística.

7. La descripción que más se escucha para referirse a los pacientes es la de "afectado" y "enfermo". Además surge igualmente la de "niño" o "paciente".

8. La definición más reiterada es la de "Enfermedad Rara" aunque en el interior de las piezas informativas se hace uso habitualmente de otras expresiones tales como "enfermedad minoritaria o de baja prevalencia". El nombre de la enfermedad posee de igual manera una enorme presencia dado que las noticias aparecen vinculadas en el período analizado a diferentes campañas solidarias relativas a distintas enfermedades.

\subsection{Análisis del discurso radiofónico sobre las EPF en el mes de mayo}

(Por Samantha Requena Romero, Universidad de Almería)

\subsubsection{Análisis Cuantitativo}

Durante el mes de mayo contamos con 15 impactos radiofónicos. 
Tabla 1. Emisiones radiofónicas y enfermedades raras durante el mes de mayo de 2014

\begin{tabular}{|l|l|l|}
\hline \multicolumn{1}{|c|}{ Fecha } & \multicolumn{1}{|c|}{ Emisora } & \multicolumn{1}{c|}{ Programa } \\
\hline 4 mayo & RNE1 & Crónica de Madrid \\
\hline 6 mayo & Onda Madrid & Madrid Servicios Informativos \\
\hline 6 mayo & Onda Madrid & Hoy en Madrid \\
\hline 7 mayo & RNE1 & Diario de las 2 \\
\hline 7 mayo & RNE1 & 24 hs \\
\hline 9 mayo & Onda Madrid & Hoy en Madrid \\
\hline 13 mayo & Cadena Ser & Hoy por hoy \\
\hline 13 mayo & Cataluña radio (CatR) & L'informatiu del migdia \\
\hline 13 mayo & Onda Vasca (OV) & Informativo mediodia \\
\hline 14 mayo & Onda Vasca & Euskadi Hoy \\
\hline 16 mayo & La Cope & El Mati \\
\hline 18 mayo & Cadena Ser & Madrid Hora 14 \\
\hline 26 mayo & Onda Vasca & La hora local de la tarde en Euskadi \\
\hline 27 mayo & Onda Vasca & Euskadi Hoy \\
\hline 31 mayo & Cadena Ser & Barcelona Hora 14 \\
\hline
\end{tabular}

Como podemos observar en la Tabla 1, 12 de los programas de radio han sido emitidos en radios públicas como RNE1, Onda Madrid o Cataluña Radio. Los 3 restantes en privadas como son Cadena Ser, Onda Vasca y La Cope.

Tabla 2. Frecuencia de emisiones en radios públicas y privadas durante el mes de mayo

\begin{tabular}{|l|c|c|}
\hline Emisora radio & NOTICIAS & $\mathbf{( \% )}$ \\
\hline RNE1 & 3 & $20 \%$ \\
\hline Onda Madrid & 3 & $20 \%$ \\
\hline Onda Vasca & 4 & $26,6 \%$ \\
\hline Cataluña Radio & 1 & $6,6 \%$ \\
\hline Cadena Ser & 3 & $20 \%$ \\
\hline La COPE & 1 & $6,6 \%$ \\
\hline
\end{tabular}

Un dato también interesante que podemos discutir tras analizar la Tabla 1 es la zona geográfica en la que encontramos estos programas. Principalmente vemos que las comunidades con más frecuencia en emisión de noticias sobre enfermedades poco frecuentes (EPF) son la de Madrid, la de Cataluña y la del País Vasco. En cuanto a la fecha de emisión, lo cierto es que no se sigue un patrón determinado sino que los programas van emitiéndose regidos por las fechas de, por ejemplo y como veremos más adelante, los eventos solidarios a los que van a hacer promoción.

Si analizamos los programas en los que se emiten las piezas radiofónicas sobre EPF podemos decir que en ningún caso encontramos programas específicos de salud, sino más bien, informativos o programas generalistas que informan sobre temas poco específicos.

La enfermedades raras que son mencionadas durante el mes mayo son: el síndrome de Apert, la fibrosis quística, la fenilcetonuria (PKU), el síndrome del maullido del gato, la colitis ulcerosa, la enfermedad de Crohn, el síndrome de Behçet, la retinosis pigmentaria, la 
esclerodermia y el síndrome de Treacher Collins. Sólo son descritas la fibrosis quística, la fenilcetonuria y el síndrome del maullido del gato.

Tabla 3. Listado de patologías tratadas en programas de radio durante el mes de mayo

\begin{tabular}{|l|l|}
\hline Programa & Patología \\
\hline Crónica de Madrid & Síndrome de Apert \\
\hline Hoy por Hoy Madrid & Fibrosis Quística \\
\hline El Mati & Fenilcetonuria (UPQ) \\
\hline Madrid Hora 14 & Síndrome del Maullido del Gato \\
\hline Barcelona Hora 14 & Fenilcetonuria (PKU) \\
\hline L'informatiu del migdia & Colitis Ulcerosa. Enfermedad de Crohn \\
\hline Euskadi Hoy (14 mayo) & $\begin{array}{l}\text { Síndrome de Behçet, Retinosis Pigmentaria, } \\
\text { Esclerodermia, Síndrome de Treacher Collins }\end{array}$ \\
\hline
\end{tabular}

Como se puede observar de la Tabla 3, la fenilcetonuria es protagonista en dos programas de radio. Sin embrago, en El Mati el locutor habla de UPQ-ATM haciendo referencia a la Asociación Catalana de Trastornos Metabólicos Hereditarios. Cuando debería haber sido PKU. Seguidamente interviene el padre de una niña afectada y organizador de la carrera solidaria en Sitges, y en ningún momento vemos que se corrija ese error. Error muy común para todos aquellos que no están familiarizados con este tipo de patologías cuyos nombres son difíciles y a veces, impronunciables (Bañón y Urán, 2011: 163). También podemos comprobarlo en las cuatro veces que este locutor pronuncia "fenilcetonuria".

El resto de programas (40\%) hace referencia a las enfermedades raras en general, sobre todo hablando de la celebración de eventos solidarios (como carreras solidarias, recogida de tapones, etc.), de la recaudación del Telemaratón de TVE, de la iniciativa educativa de la Federación Española de Enfermedades Raras (FEDER) y de una denuncia a la empresa municipal de transportes de Madrid (EMT).

\subsubsection{Análisis Cualitativo}

En esta parte del análisis estudiaremos los asuntos que se tratan para hablar sobre EPF en la radio y la forma en la que se habla sobre esos asuntos. Al finalizar la parte cuantitativa presentábamos los temas que hemos identificado en nuestro corpus:

Tabla 4. Temas o asuntos tratados en el corpus de información radiofónica en el mes de mayo

\begin{tabular}{|l|l|l|l|}
\hline Tema & & Programa de radio & Fecha \\
\hline \multirow{5}{*}{$\begin{array}{l}\text { 1. Eventos } \\
\text { solidarios }\end{array}$} & Informativo Mediodía (OV) & 13 mayo \\
\cline { 3 - 4 } & Euskadi Hoy (OV) & 14 mayo \\
\cline { 3 - 4 } & El Mati (CatR) & 16 mayo \\
\cline { 3 - 4 } & & 26 mayo \\
& & $\begin{array}{l}\text { La Hora Local de la Tarde } \\
(\mathrm{OV})\end{array}$ & 27 mayo \\
\cline { 3 - 4 } & Euskadi Hoy (OV) & 31 mayo \\
\cline { 3 - 4 } & Barcelona Hora 14 (RadC) & \\
\hline
\end{tabular}




\begin{tabular}{|l|l|l|l|}
\hline & $\begin{array}{l}\text { Recogida de } \\
\text { tapones solidarios }\end{array}$ & Madrid Servicios Informativos & 6 mayo \\
\cline { 2 - 4 } & $\begin{array}{l}\text { Feria de las } \\
\text { Américas }\end{array}$ & Hoy en Madrid & 9 mayo \\
\hline \multirow{2}{*}{$\begin{array}{l}\text { 2. Día } \\
\text { Internacional }\end{array}$} & Fibrosis Quística & Hoy por Hoy Madrid & 13 mayo \\
\cline { 2 - 4 } & $\begin{array}{l}\text { Enfermedades } \\
\text { inflamatorias } \\
\text { intestinales }\end{array}$ & L'informatiu del migdia & 13 mayo \\
\hline \multirow{2}{*}{ 3. Telemaratón } & $\begin{array}{l}\text { Enfermedades } \\
\text { Raras en general }\end{array}$ & 24 horas & 7 mayo \\
\cline { 2 - 4 } 4. Educación & $\begin{array}{l}\text { Las ER van al cole de las 2 } \\
\text { con Federito }\end{array}$ & Crónica de Madrid & 7 mayo \\
\cline { 3 - 5 } & & Hoy en Madrid & 6 mayo \\
\hline 5. Denuncia & & Madrid Hora 14 & 18 mayo \\
\hline
\end{tabular}

En cuanto al tema de los eventos solidarios, si hay un elemento que caracteriza a las familias y colectivos relacionados con las EPF es la necesidad de recaudar fondos para suplir falta de material o de medicamentos de los afectados o para investigación. Las carreras solidarias a las que se alude en el corpus se celebran para recaudar fondos para la investigación de enfermedades raras en general, por un lado; y, en beneficio de un caso en particular, el de Candela, afectada por fenilcetonuria.

El Grupo de Enfermedades Raras de Navarra (GERNA) es el organismo que pone en marcha la I Carrera Solidaria en Pamplona y es objeto de todos los programas de radio emitidos por Onda Vasca. Se celebra coincidiendo con las 34 Jornadas de Economía de la Salud, otro tema muy unido al de las enfermedades raras. Con esta carrera se reivindica la creación de un registro público de ER y la presencia de un 'gestor de casos'; un médico o enfermero que se encargue de coordinar toda la atención sanitaria que necesitan los enfermos. La estructura de las noticias es siempre la misma: se informa del día, de la hora, de las inscripciones y se invita a Jose Mari Casado, secretario de GERNA a que dé más detalles sobre el evento.

La otra carrera solidaria, a favor de Candela, tiene lugar en Sitges y el tratamiento de la noticia difiere del anterior aun siendo un evento muy parecido. Llama la atención cómo el presentador de El Mati trata la gran aceptación de la carrera por parte de la gente como un elemento asociado al 'populismo', es decir, que hay muchos inscritos primero "porque (las carreras solidarias) están de moda" y segundo por el motivo real. Este es el mismo locutor que se equivoca al nombrar la enfermedad y en vez de hablar de PKU dice "UPQ". En ambos programas, El Mati y Barcelona Hora 14, intervienen los padres de la niña y la presidenta de la Asociación Catalana de Trastornos Metabólicos Hereditarios. En Barcelona Hora 14 también interviene el jefe de neurología del hospital Sant Joan de Déu. La 
recaudación se destinará al Banco de alimentos de Sant Joan de Déu y a la investigación de esta enfermedad. En ambas locuciones se hace mención a lo importante que es el cribado neonatal gracias al cual esta enfermedad puede ser diagnosticada al nacer. Además, los padres hablan del 'espanto' que causa el diagnóstico de una enfermedad rara ya que "altera la dinámica de la vida de toda la familia". La madre hace referencia a algo tan común como salir a tomar algo con los amigos y no poder por la dieta estricta de estos niños.

La recogida de tapones de plástico (Bañón y Requena, 2014: 13) es otro de las actividades solidarias a las que se hace referencia en nuestro corpus de radio. La recaudación va destinada a la investigación en enfermedades raras bajo el lema "por una nueva vida".

Por último, la Feria de Las Américas, en su 8 a edición y celebradas en Madrid donará toda su recaudación a FEDER. En la locución podemos escuchar al director de la Feria, Walter Rubio, quien hace referencia a la importancia de la creación de la Alianza Iberoamericana de las Enfermedades Raras.

El segundo tema que hemos señalado en la Tabla 4 es el del Día Internacional de la Fibrosis Quística y de las Enfermedades Inflamatorias Intestinales. Si empezamos a analizar la primera locución, la presentadora dice "se acaba de celebrar el Día internacional de la fibrosis quística, la considerada como enfermedad rara más común del país (...) en Madrid, más de 600 pacientes". Por un lado, no queda claro cuándo ha sido el día internacional, porque según la Federación Española de Fibrosis Quística, el día internacional es el 8 de septiembre y el día nacional el 23 de mayo. En esta locución interviene un médico como la neumóloga Rosa Girón, el fisioterapeuta que trabaja en la Asociación de Fibrosis Quística, una madre de dos niños afectados y un investigador de la Fundación de Investigaciones Sanitarias de Baleares y padre de afectado, Carlos Riobocos. La doctora describe la enfermedad para aquellos que no sepan de qué se trata y dice "es una enfermedad genética, hereditaria, para ello vamos a necesitar un gen alterado del padre y un gen alterado de la madre...”. Durante su intervención, la presentadora hace un inciso para continuar con la entrevista y comenta la importancia que ha tenido que en la Comunidad de Madrid hace 4 o 5 años esta enfermedad entrara en el cribado neonatal debido a la importancia de una pronta detección para una buena prevención de la fibrosis quística. Esta breve intervención de la locutora pone en situación al oyente y demuestra un cierto manejo de la información existente sobre este tipo de patologías. El fisioterapeuta habla de una de las terapias más necesarias y es la fisioterapia respiratoria por el deterioro pulmonar de esta enfermedad. La madre y miembro de la Asociación de Fibrosis Quística cuenta su experiencia y emplea el 
término "dando tumbos de médico en médico" cuando se refiere al 'peregrinaje' por el que pasan todos aquellos que viven con una EPF (Requena et al. 2014: 8). Este empleo del lenguaje coloquial acerca el testimonio a los oyentes. Este testimonio contrasta con la intervención de Carlos Riobocos que emplea un lenguaje más específico aunque también habla de "enfermedad de países ricos", "investigación muy potente" y "avances impresionantes". Con el uso de estas expresiones queda claro que el futuro de los afectados por fibrosis quística no es tan oscuro como el de otras enfermedades raras. Según este investigador existe un fármaco, "calideco" definido como "una molécula aprobada hace unos 6 años en Europa que mejora la calidad de vida de los pacientes" pero que es muy cara. La doctora Girón va más allá y habla de "tratamiento curativo que repara” y que ha sido aprobado por la FDA para 8 enfermedades más. Como podemos ver, el argumento de "como es un tratamiento caro y pocos los beneficiados no se invierte" no tiene cabida ya que como la doctora añade otras enfermedades se verán beneficiadas por esta misma molécula.

En cuanto a la segunda, se mencionan enfermedades como la colitis ulcerosa y la enfermedad de Crohn aunque no son las únicas pero sí de las que más casos existen. Interviene el presidente del grupo de especialistas de estas patologías quien habla de un aumento en los casos: de 1 a 3x100.000.

El Telemaratón ocupa dos de los programas de radio de nuestro corpus y en ambos se hace un balance de lo recaudado en el telemaratón. En 24 horas se habla de 2 millones cien mil euros y se subraya el compromiso del gobierno en "avanzar en los diagnósticos y en la ayuda de los afectados". Según la presentadora Isabel Gemio, se duplicó la cantidad de dinero con la que se cerró el telemaratón. Es interesante resaltar el hecho de que en ningún momento se mencionan los organizadores del evento: FEDER, la Federación Española de Enfermedades Neuromusculares (ASEM) y la Fundación Isabel Gemio aunque esta última vendría representada por la propia presentadora. En el Diario de las 2 se definen las EPF y se vuelve a hacer balance de lo recaudado. El 75\% de lo recaudado se destinará a proyectos de investigación, un 20\% al apoyo de asociaciones y el resto al gasto de gestión. Con respecto a estos últimos datos pensamos que sería interesante que se diera más información sobre qué proyectos y qué asociaciones son las que se beneficiarán de este dinero. De nuevo, y como pasaba en 24 horas, no se mencionan ni a FEDER ni a ASEM.

En cuarto lugar vamos a analizar la presencia del tema de la educación y las enfermedades raras. Las dos noticias que se emiten sobre este asunto están relacionadas con la iniciativa que FEDER puso en marcha en el año 2012 para fomentar la inclusión y 
normalización educativa de niños afectados por EPF. La iniciativa se conoce bajo el nombre de 'Las Enfermedades Raras van al cole con Federito'. En Crónica de Madrid cubren la noticia de la adaptación de esta actividad por el Colegio María Moliner y es Alba Ancochea, subdirectora de FEDER, quien aporta la información sobre este acontecimiento informativo. Este colegio cuenta con un fisioterapeuta y un enfermero para niños con necesidades específicas. Aunque Madrid es una ciudad que cuenta con gran aceptación de todas estas iniciativas, Ancochea deja claro que aún hay por hacer y menciona como ejemplo las diferencias entre zonas rurales y urbanas. En el programa Hoy en Madrid, es Justo Herranz, miembro de la Junta Directiva de FEDER quien interviene en el programa para hablar del proyecto educativo de FEDER. Antes de que intervenga Justo Herranz, los locutores presentan el proyecto y explican lo que se pretende con él: "la integración de los niños, el normalizar entre profesores, padres y el resto de alumnos el que nuestro compi tenga alguna de estas enfermedades que llamamos raras y que, en definitiva, podríamos empezar, tal vez, a cambiar por el poco frecuentes. Se dan en poquitas personas, no tienen que ser raros, eso sí, pueden sentirse un poco especiales...". Se puede entender que la locutora no quiere decir que "son raros" pero lo hace, esa expresión podría haberse cambiado por la idea contra la que tanto luchan los afectados por las EPF y es la de 'padeces una enfermedad rara, eres raro'.

El rol de Justo Herranz es el de reivindicar la falta de investigación, agradecer a las entidades colaboradoras con proyectos de investigación en EPF y denunciar el hecho de que los médicos digan siempre lo que no se puede hacer y nunca mencionen lo que se debe hacer y es por ello que los denomina 'defectólogos'. A esto último también hace referencia Jose Mari Casado, de GERNA, quien menciona en sus intervenciones la importancia que uno mismo sea quien establezca los límites "usted tiene una esclerodermia, usted no puede correr, hombre por favor, que sea yo quien decida, quien ponga mis propios límites" (Euskadi Hoy, 27 mayo).

El último tema que exponemos es el de denuncia. En este caso se trata de una niña afectada por el síndrome del maullido del gato que en un momento dado necesita la rampa de accesibilidad para poder subir al autobús y el conductor, al no creerse la discapacidad de la niña se niega a bajarla. La locutora presenta el síndrome como "extraño", ya vemos connotaciones negativas en el uso de este calificativo. Por intentar buscar un término alternativo a 'raro' se cae en esta llamémosle trampa que tanto intensifica el estigma contra el que estas personas luchan. Cuando interviene la madre de la niña para contar el caso, una 
de las preguntas que se le hace es si el dinero que reclaman en la denuncia contra el Ministerio de Sanidad (600 mil euros a 1 millón) es para ellos, para su asociación. La madre dice que no, que iría a la Comunidad de Madrid quien dirime el asunto en cuestión. Tras escuchar la locución nos surge la duda de si era o no necesaria esta pregunta, la que hace referencia al destino del dinero. No sería llamativo si ese dinero fuese destinado a la Asociación de la enfermedad que padece su hija, ya que estamos hablando de personas cuyas necesidades ascienden a cualquier cantidad que se pudiera recaudar del proceso judicial.

\subsubsection{Conclusión}

De los fragmentos analizados podemos decir que:

1. El tema de la solidaridad sigue siendo el que más tiempo ocupa de nuestro corpus.

2. El 10 de mayo se celebra el día mundial del Lupus y hemos echado en falta algún programa dedicado a ello.

3. Es interesante analizar de lo que se habla en los programas pero también de lo que no se habla. Por ejemplo en el caso de las noticias sobre el Telemaratón.

\section{Tercera parte. Las enfermedades raras en la televisión}

\subsection{Análisis periodístico del tratamiento televisivo}

(Por Sebastián Sánchez. Castillo, Universitat de València)

La presencia de las enfermedades poco frecuentes (EPF) durante el segundo trimestre de 2014 (abril-junio) ha resultado algo menor que en los primeros meses del año. La celebración del Día Internacional de las Enfermedades Raras en febrero ocupa un espacio muy importante en la difusión anual de estas enfermedades, aunque su eco continúa durante todo el año.

Para este segundo trimestre se han analizado un total de 59 noticias en los distintos canales de televisión, tanto nacionales, autonómicos como locales. Dicha muestra ha sido posible gracias a la cesión de los archivos audiovisuales por parte del Observatorio de las Enfermedades Raras (OBSER) y la Federación Española de Enfermedades Raras (FEDER). Respecto al trimestre anterior se ha producido y emitido el $25,76 \%$ de las noticias, un descenso considerable.

Con los datos obtenidos se ha procedido a una comparación cuantitativa respecto al trimestre anterior con la intención de ir desgranando la evolución mediática de estas informaciones en el entorno televisivo español. 
La metodología empleada tiene su continuación al periodo anterior, con técnicas estadísticas procesadas con SPSS v.21 siendo las más adecuadas para este tipo de informes relacionado con las Ciencias de la Comunicación: Análisis Bivariado, Contraste de Hipótesis y análisis de consistencia interna mediante Alfa de Cronbach $(\alpha)$.

\subsubsection{Canal de Televisión y localización de las noticias}

A la difusión de la EPF se han unido nuevos canales de televisión, tanto nacionales como locales. Se percibe un cierto aumento del interés local en casos concretos.

Los entes públicos de Televisión Española y Telemadrid son los que mayor presencia han tenido a lo largo de este trimestre. $(n=9 ; 15,2 \%)$. En este periodo han entrado en escena nuevos centros de producción de noticias que desde posiciones más locales han reforzado el discurso audiovisual, TVONO, 13TV, TVBilbao entre otros.

Tabla 1. Piezas por cadenas de TV

\begin{tabular}{lcc|cc}
\hline & \multicolumn{2}{c}{$1^{\circ}$ trimestre } & \multicolumn{2}{c}{$2^{\circ}$ trimestre } \\
\hline TVE1 & $\mathrm{n}$ & $\%$ & $\mathrm{n}$ & $\%$ \\
TVE2 & 102 & 44,5 & 9 & 15,2 \\
Tele 5 & - & - & 2 & 3,3 \\
La Sexta & 29 & 12,7 & 7 & 11,8 \\
Telemadrid & 16 & 7,0 & 6 & 10,1 \\
Canal Sur & 16 & 7,0 & 9 & 15,2 \\
ETB2 & 15 & 6,6 & 2 & 3,3 \\
Cuatro & 13 & 5,7 & 5 & 8,4 \\
Antena 3 & 12 & 5,2 & 2 & 3,3 \\
Otras & 7 & 3,1 & 2 & 3,3 \\
ETB1 & 7 & 3,1 & - & - \\
TVG & 4 & 1,7 & - & - \\
BTV & 4 & 1,7 & 1 & 1,6 \\
TV Bilbao & 2 &, 9 & 4 & 6,7 \\
8TV & - & - & 2 & 3,3 \\
RTVCM & - & - & 4 & 6,7 \\
TVONO & - & - & 1 & 1,6 \\
13TV & - & - & 2 & 3,3 \\
TV3 & - & - & 1 & 1,6 \\
\hline Total & 2 &, 9 & - & - \\
\hline & 229 & $100 \%$ & 59 & $100 \%$ \\
\hline
\end{tabular}

Han dejado de dar cobertura informativa en este periodo televisiones autonómicas de gran importancia como ETB1 y TV3.

Respecto a la localización geográfica de los informativos y programas relativos a las EPF, la comunidad de Madrid sigue siendo la que genera mayor número de impactos informativos ( $n=20 ; 33,8 \%$ ), seguida de Andalucía ( $n=12 ; 20,3 \%$ ), País Vasco (n=9;15,2\%) y Región de Murcia, referente de las EPF en España debido a la continua actividad de la Asociación de Enfermedades Raras D’Genes, localizada en Totana. 
Tabla 2. Localización de la información

\begin{tabular}{lcc|cc}
\hline & $1^{\circ}$ trimestre & \multicolumn{2}{c}{$2^{\circ}$ trimestre } \\
\hline & $\mathrm{n}$ & $\%$ & $\mathrm{n}$ & $\%$ \\
\hline Madrid & 48 & 21,0 & 20 & 33,8 \\
Andalucía & 37 & 16,2 & 12 & 20,3 \\
Cataluña & 32 & 14,0 & 5 & 8,4 \\
Región de Murcia & 28 & 12,2 & 6 & 10,1 \\
Galicia & 21 & 9,2 & 2 & 3,3 \\
País Vasco & 13 & 5,7 & 9 & 15,2 \\
C.F. de Navarra & 12 & 5,2 & 1 & 1,6 \\
Islas Baleares & 8 & 3,5 & - & - \\
Aragón & 6 & 2,6 & - & - \\
Castilla la Mancha & 5 & 2,2 & 1 & 1,6 \\
Canarias & 4 & 1,7 & - & - \\
Comunidad & & & & \\
Valenciana & 4 & 1,7 & 2 & 3,3 \\
Cantabria & 4 & 1,7 & - & - \\
Extremadura & 4 & 1,7 & - & - \\
Castilla y León & 3 & 1,3 & 1 & 1,6 \\
\hline \multirow{2}{*}{ Total } & & $100 \%$ & 59 & $100 \%$ \\
& & & & \\
\hline
\end{tabular}

\subsubsection{Medios públicos o privados}

Respecto a la naturaleza jurídica de los medios televisivos, se ha descubierto un cambio respecto al trimestre pasado. Los meses anteriores analizados marcaban una clara intencionalidad respecto al uso de los canales públicos $(n=162 ; 70,7 \%)$ frente a los privados $(n=67 ; 29,3 \%)$.

\section{Programas informativos}

- Teleberri (ETB)

- La Sexta Noticias (La Sexta)

- Telediario (TVE)

- Telenoticias (Telemadrid)

- Noticias Cuatro (Cuatro)

- Noticias 2 (Antena 3)

- Informativos Tele 5 (Tele 5)

- Diario Local (TVBilbao)

- Noticies nit (BTV)

- Deportes 1 (Canal Sur)

- Telexornal (TVGalicia)

- Informativos territoriales (TVE)

\section{Magazines}

- Comando Actualidad (TVE)

- Conexión Barcelona (BTV)

- Documental (13TV)

- Kirolak (ETB) 
- Para todos la 2 (TVE)

- Hay una cosa que te quiero decir (Tele 5)

- Al dia amb Josep Cuni (8 TV)

- La mañana (TVE)

- Audiencia abierta (TVE)

- Guipozkoa a diario ( TD ONO)

- Teknopolis (ETB)

- España directo (TVE)

En este análisis existe una paridad en el uso de medios públicos y privados, tal vez debido a la aparición de pequeños canales privados de ámbito local frente a los centros de producción públicos, Tabla 3 .

Tabla 3. Tipologia de los centros de producción

\begin{tabular}{lcc|cc}
\hline & \multicolumn{2}{c}{$1^{\circ}$ trimestre } & \multicolumn{2}{c}{$2^{\circ}$ trimestre } \\
\hline & $\mathrm{n}$ & $\%$ & $\mathrm{n}$ & $\%$ \\
\hline Pública & 162 & 70,7 & 29 & 49,1 \\
Privada & 67 & 29,3 & 30 & 50,8 \\
\hline Total & 229 & $100 \%$ & 59 & $100 \%$ \\
\hline
\end{tabular}

\subsubsection{Formato del programa televisivo}

Durante el periodo analizado se han descubierto dos tipologías de programas:

Tabla 4. Formato del programa

\begin{tabular}{lcc|cc}
\hline & \multicolumn{2}{c}{$1^{\circ}$ trimestre } & \multicolumn{2}{c}{$2^{\circ}$ trimestre } \\
\hline & $\mathrm{n}$ & $\%$ & $\mathrm{n}$ & $\%$ \\
\hline Informativo & 173 & 75,5 & 34 & 57,6 \\
Magazine & 56 & 24,5 & 25 & 42,3 \\
\hline Total & 229 & $100 \%$ & 59 & $100 \%$ \\
\hline
\end{tabular}

Según la tabla 4, los programas informativos son los que más cobertura ofrecen a las $\operatorname{EPF}(n=34 ; 57,6 \%)$, frente a los programas de infoentretenimiento o magazines $(n=25$; $42,3 \%$ ). Respecto al periodo anterior ha habido un sensible aumento de los programas de entretenimiento no informativos.

Aunque es objetivo el aumento de los programas de entretenimiento que emiten contenidos sobre EPF, se descubre una disminución de la llamada "telemendicidad". Los programas hacen uso de los contenidos sobre estas enfermedades pero con un perfil más respetuoso, más formativos y divulgativo.

“Telemendicidad: un nuevo sustantivo para definir el programa 'Entre Todos' de la 1, en el que las necesidades de las personas se convierten en espectáculo mediático. La compasión y la caridad no pueden sustituir a la justicia social. A cualquier profesional, como a cualquier persona con sensibilidad, le abochornan estos desfiles y se siente indignado ante 
una exhibición tan impúdica del sufrimiento humano. Lo primero que aprende un profesional de los servicios sociales es a preservar la dignidad de las personas. Más aún cuando esa dignidad puede estar en riesgo por su situación de grave necesidad. Justo lo contrario de lo que hace este programa: mostrar hasta el puro y duro exhibicionismo las necesidades y miserias de las personas" (El País, 23(05/14. José Manuel Ramírez Navarro es presidente de la Asociación de Directores y Gerentes de Servicios Sociales).

El programa "Entre todos" presentado por Toñi Moreno (TVE1) que en el anterior periodo había creado tendencia hacia la compasión, caridad y un exhibicionismo del dolor gratuito, no ha continuado con su línea editorial y durante los meses de abril a junio no ha presentado ningún caso sobre EPF.

Este hecho confirma que en el segundo trimestre de 2014 el discurso sobre las EPF es menos espectacular y posee un mayor grado de dignidad mediática, en definitiva unos contenidos que ayudan a la desestigmatización de este grupo social desfavorecido.

\subsubsection{Franja horaria}

Las emisiones del mediodía son las que mayor número de informaciones sobre las EPF han presentado ( $\mathrm{n}=23 ; 38,9 \%$ ), siendo las matinales y nocturnas aproximadamente las mismas $(\mathrm{n}=19 ; 32,2 \%)$ y $(\mathrm{n}=17 ; 28,8 \%)$ respectivamente.

Tabla 5. Hora de emisión

\begin{tabular}{lcc|cc}
\hline & \multicolumn{2}{c}{$1^{\circ}$ trimestre } & \multicolumn{2}{c}{$2^{\text {o }}$ trimestre } \\
\hline & $\mathrm{N}$ & $\%$ & $\mathrm{n}$ & $\%$ \\
\hline Mediodía & 122 & 53,3 & 23 & 38,9 \\
Matinal & 76 & 33,2 & 19 & 32,2 \\
Tarde/noche & 31 & $13,5,5$ & 17 & 28,8 \\
\hline Total & 229 & $100 \%$ & 59 & $100 \%$ \\
\hline
\end{tabular}

\subsubsection{Definición de paciente y de la enfermedad}

La forma en la que las entradillas o los videos definen a las personas que padecen las EPF continúa con una tendencia ya estudiada en el trimestre pasado y en los análisis del año 2013.

Tabla 6. Denominación de la persona con EPF

\begin{tabular}{lcc|cc}
\hline & $1^{\circ}$ trimestre & \multicolumn{3}{c}{$2^{\circ}$ trimestre } \\
\hline & $\mathrm{n}$ & $\%$ & $\mathrm{n}$ & $\%$ \\
\hline Afectado/a & 79 & 38,9 & 16 & 27,1 \\
Enfermo/a & 64 & 32,3 & 13 & 22,0 \\
Paciente & 24 & 14,8 & 9 & 15,2 \\
Dependiente & 17 & 7,4 & 8 & 13,5 \\
Otras & & & & \\
denominaciones & 15 & 2,2 & 6 & 10,1 \\
Niño/a & 13 & 1,3 & 4 & 6,7 \\
Paciente con EPF & - & - & 1 & 1,6 \\
No se nombra al sujeto & & & &
\end{tabular}




\begin{tabular}{lcc|cc} 
& 12 &, 9 & 2 & 3,38 \\
Discapacitado/a & 5 & 2,2 & 1 & 1,6 \\
\hline Total & 229 & $100 \%$ & 59 & $100 \%$ \\
\hline
\end{tabular}

El actor principal definido como "afectado" es la fórmula más empleada ( $n=16 ; 27,1 \%)$. En este periodo de análisis aparece en una ocasión "paciente con enfermedad poco frecuente", y por extensión "enfermedad poco frecuente" (ver tabla 7).

Tabla 7. Definición de la enfermedad

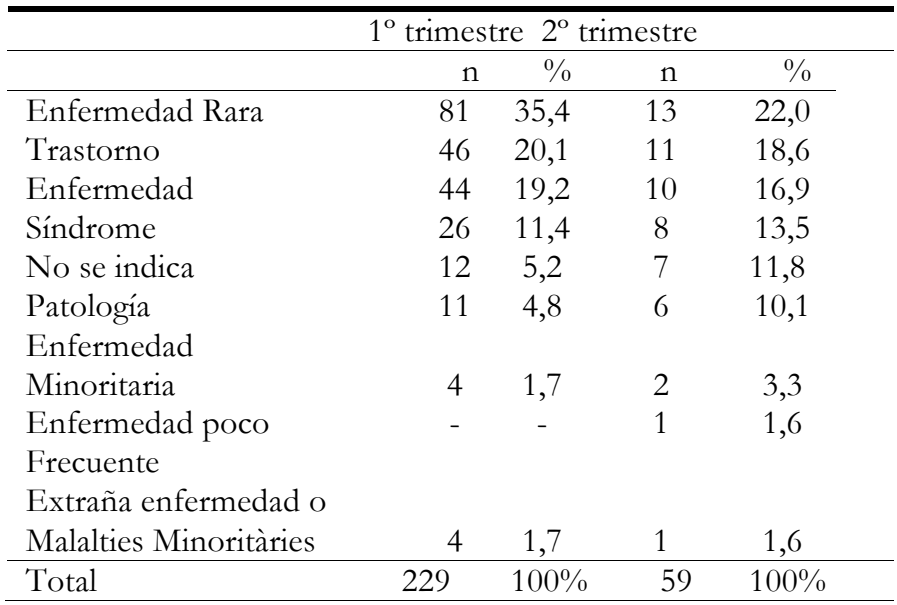

\subsubsection{Actor principal de la noticia}

Los principales protagonistas de las noticias y programas analizados siguen siendo los niños. Estos aparecen tanto en localizaciones exteriores como en sus hogares familiares.

En este periodo se percibe un sutil cambio en el tratamiento que los distintos medios otorgan a estos niños afectados. Ahora son tratados con una mayor distancia afectiva y ya no son el centro del discurso. Son la causa de la noticia pero el debate se extiende a sus familiares o a los médicos que les acompañan.

Tabla 8. Actor principal de la pieza audiovisual

\begin{tabular}{lcc|cc}
\hline & \multicolumn{2}{c}{$1^{\circ}$ trimestre } & \multicolumn{2}{c}{$2^{\circ}$ trimestre } \\
\hline & $\mathrm{n}$ & $\%$ & $\mathrm{n}$ & $\%$ \\
\hline Niño/a & 64 & 27,9 & 14 & 23,7 \\
Pacientes & 39 & 17,0 & 11 & 18,6 \\
Médicos o personal & & & & \\
sanitario & 38 & 16,6 & 9 & 15,2 \\
Familiares & 38 & 16,6 & 8 & 13,5 \\
Científicos & & & & \\
y/o investigadores & 33 & 14,4 & 6 & 10,1 \\
Político (institucional) & 10 & 4,4 & 5 & 8,4 \\
FEDER & 4 & 1,7 & 4 & 6,7 \\
Voluntarios & 3 & 1,3 & 2 & 3,3 \\
\hline \multicolumn{1}{c}{ Total } & $100 \%$ & 59 & $100 \%$ \\
\hline
\end{tabular}

\subsection{7 ¿Qué enfermedades se han visibilizado?}


Las enfermedades que con más frecuencia han aparecido en los medios audiovisuales analizados son las siguientes:

- Sanfilippo

- Esclerosis Lateral Amiotrófica (ELA)

- Síndrome de Moebius

- Albinismo

- Esclerosis Múltiple

- El síndrome de Rubinstein-Taybi

- Sensibilidad química múltiple y electrosensibilidad

- Síndrome Phelan-McDermid o delección 22q13

- Síndrome de Rett

Los eventos sociales organizados por pacientes, familiares y asociaciones han sido numerosos. La celebración de estas actividades ha tenido eco en las distintas televisiones del país tanto por razones de visibilidad de las enfermedades como por un marcado carácter de denuncia por la falta de recursos económicos a la investigación y a la atención. Son los siguientes:

- Encuentro Albinismo en Valencia (Asociación ALBA)

- Visita casa Roland McDonals

- Partido solidario ER. Osasuna-Real Madrid

- Gala Benéfica "Todos somos Yaiza"

- Todos Somos Raros, Todos Somos Únicos (TVE)

- Desfile solidario (FEDER, 05/06/2014)

- Carrera solidaria EPF. Almería. OBSER (08/06/2014)

- Exposición coches antiguos (FEDER, 15/06/2014)

- Día mundial de ELA

\subsubsection{Encuadre}

La teoría del framing o "encuadres" es muy efectiva para estudiar qué percepción tiene el público de los hechos sociales. Sostiene que esta percepción está condicionada por el proceso de reconstrucción subjetiva de la realidad que llevan a cabo los medios de comunicación. Desde este punto de vista, cada información muestra un frame; es decir, un enfoque 
determinado de la realidad, producto de una manera de seleccionar los hechos, los personajes, las imágenes o las palabras en las que enfatiza la noticia.

Tabla 9. Frames de las piezas

\begin{tabular}{lcc|cc}
\hline & \multicolumn{2}{c}{$1^{\circ}$ trimestre } & \multicolumn{2}{c}{$2^{\circ}$ trimestre } \\
\hline & $\mathrm{n}$ & $\%$ & $\mathrm{n}$ & $\%$ \\
\hline $\begin{array}{l}\text { Como realidad } \\
\text { social } \\
\text { Como } \\
\text { enfermedad } \\
\text { especializada }\end{array}$ & 169 & 73,8 & 39 & 66,1 \\
$\begin{array}{l}\text { Como conflicto } \\
\text { político }\end{array}$ & 58 & 25,3 & 16 & 27,1 \\
\hline Total & 2 &, 9 & 4 & 6,7 \\
\hline
\end{tabular}

En las noticias analizadas predomina el encuadre como "realidad social" $(\mathrm{n}=39 ; 66,1 \%)$, como "enfermedad especializada" ( $\mathrm{n}=16 ; 27,1 \%)$ y en último lugar con muy pocos ejemplos "conflicto político" ( $\mathrm{n}=4 ; 6,7 \%)$.

\subsection{8. ¿Dónde aparece el actor principal?}

Tal y como se observó en investigaciones anteriores, los actores principales, los niños en su mayoría, aparecen principalmente en la calle ( $n=22 ; 37,2 \%)$, y en último lugar en centros educativos $(\mathrm{n}=3 ; 5 \%)$.

Tabla 10. Lugar de aparición del actor principal

\begin{tabular}{lcccc}
\hline & $1^{\circ}$ trimestre & \multicolumn{2}{c}{$2^{\circ}$ trimestre } \\
\hline & $\mathrm{n}$ & $\%$ & $\mathrm{n}$ & $\%$ \\
\hline En la calle & 77 & 33,6 & 22 & 37,2 \\
Hogar familiar & 72 & 31,4 & 19 & 32,2 \\
Centro de salud & 63 & 27,5 & 11 & \\
Instalaciones de ocio & 13 & 5,7 & 18,6 & 6,7 \\
Centros educativos & 4 & 1,7 & 3 & 5,0 \\
\hline Total & 229 & $100 \%$ & 59 & $100 \%$ \\
\hline
\end{tabular}

\subsubsection{Conclusiones}

Tras el análisis de las noticias y programas de televisión durante el segundo trimestre del año 2014, es posible establecer las siguientes conclusiones:

1. Respecto al ámbito geográfico, estas son mayoritariamente de carácter nacional, seguido de autonómicas y finalmente locales.

2. En las emisiones de 2014 aunque se consolidan los informativos, son los programas de divulgación científica y social los que ocupan el segundo lugar. 
3. La franja horaria de emisión permanece inalterable, siendo los espacios vespertinos y nocturnos los más habituales.

4. Respecto al protagonismo principal de las noticias y programas sobre EFP se percibe una cierta modificación en la elección del protagonista principal. Ahora ya no es solo el niño, sino también su entorno familiar. Los menores siguen siendo la excusa de la noticia pero no se ofrece un discurso personalista en primera persona. Muchos de estos niños ponen nombre propio a las noticias, Hugo, Yaiza, Eva, Jano, etc.

5. La aparición de representantes institucionales y sociales se produce en el $52 \%$ de los videos analizados en el segundo trimestre de 2014.

6. Los medios de comunicación públicos han emitido el mismo número de noticias y programas que los privados.

7. En cuanto a la temática de las noticias, siguen prevaleciendo aquellas que aluden a la ayuda urgente a la familia, a la situación límite por motivo de los recortes y a la petición de apoyo para la compra de elementos protésicos o ayuda domiciliaria. El "dramatismo" como valor noticia sigue estando presente en la mayoría de las noticias, pero su intensidad emotiva es algo menor en el segundo trimestre de 2014.

8. El entorno familiar sigue presentándose como el más adecuado desde el punto de vista mediático para escenografiar a los afectados y sus familias.

9. En cuanto a la definición del problema, en el segundo trimestre del año 2014 comienzan a emplearse otras denominaciones como "Enfermedades poco Frecuentes" aunque apenas en el $2 \%$.

10. La campaña internacional "Cubo de agua helada" por el que se invitaba a lanzarse un cubo de agua para conseguir recursos a la investigación de la ELA, ha condicionado este periodo respecto a la visibilidad de la enfermedad aunque no han aumentado los fondos para ayudar a los enfermos. Según la presidenta de AdELA (Asociación Española de Esclerosis Lateral Amiotrófica), Adriana Guevara, “a pesar del éxito de la cadena solidaria, muchos de los famosos no sólo no han realizado el donativo, sino que ni siquiera les han pedido el número de cuenta" (Publico.es del día $11 / 10 / 2014)$.

\subsection{E1 discurso de la televisión sobre las EPF en el mes de mayo}

(Por Samantha Requena Romero, Universidad de Almería)

\subsubsection{Análisis Cuantitativo}


Durante el mes de mayo contamos con 14 impactos en televisión. Siete de ellos emitidos en canales de televisión pública como Telemadrid, TVE o ETB, y ocho emitidos en canales privados como Antena3, Tele5, 8TV o Teledonosti.

Tabla 1. Programas, canales y fecha

\begin{tabular}{|l|l|c|}
\hline Programa & Medio/Canal & Fecha \\
\hline Abierto al Amanecer & Telemadrid & 1 mayo \\
\hline Telenoticias & Telemadrid & 1 mayo \\
\hline La Mañana & TVE 1 & 2 mayo \\
\hline Audiencia Abierta & TVE 1 & 3 mayo \\
\hline Noticias 2 & Antena3 & 7 mayo \\
\hline Noticias de la Mañana & Antena3 & 8 mayo \\
\hline 8 al Día amb Josep Cuni & 8TV & 15 mayo \\
\hline Gipurkoa a Diario & Teledonosti & 16 mayo \\
\hline Teknopolis & ETB2 & 18 mayo \\
\hline Para Todos La 2 & La 2 TVE & 22 mayo \\
\hline Informativos Tele5 (21:00) & Tele 5 & 24 mayo \\
\hline Informativos Tele5 (06:00) & Tele 5 & 28 mayo \\
\hline Informativos Tele5 (08:00) & Tele 5 & 28 mayo \\
\hline Kirolak 2 & ETB2 & 28 mayo \\
\hline
\end{tabular}

En la siguiente Tabla exponemos las patologías tratadas en las emisiones televisivas que encontramos en nuestro corpus de análisis:

Tabla 2. Patologías presentes en las emisiones de mayo

\begin{tabular}{|l|l|l|}
\hline \multicolumn{1}{|c|}{ Patología } & \multicolumn{1}{|c|}{ Medio } & \multicolumn{1}{c|}{ Fecha } \\
\hline Esclerosis Lateral Amiotrófica (ELA) & 8TV & 15 mayo \\
\cline { 2 - 3 } & ETB2 & 18 mayo \\
\hline \multirow{3}{*}{ Síndrome de Sanfilippo } & Teledonosti & 16 mayo \\
\cline { 2 - 3 } & La 2 TVE & 22 mayo \\
\cline { 2 - 3 } & ETB2 & 28 mayo \\
\hline \multirow{2}{*}{ Esclerosis Múltiple } & Tele5 & 24 mayo \\
\cline { 2 - 3 } & Tele5 & 28 mayo \\
\cline { 2 - 3 } & Tele5 & 28 mayo \\
\hline
\end{tabular}

Como se puede observar, las patologías con más frecuencia en televisión son el síndrome de Sanfilippo y la esclerosis múltiple. La primera de ellas debido a la promoción de una marcha solidaria y otros eventos como unas jornadas para recaudar fondos para afectados por esta patología; y la segunda, por la celebración del Día Mundial de la esclerosis múltiple. El resto de las emisiones tratan las enfermedades raras en general, como conjunto de enfermedades poco prevalentes.

Los medios que más noticias emiten sobre EPF se muestran en la siguiente tabla:

Tabla 3. Canales de televisión que más noticias emitieron sobre epf durante el mes de mayo

\begin{tabular}{|c|c|c|}
\hline Medio & $\mathbf{N}^{\mathbf{o}}$ noticias & $\mathbf{\%}$ \\
\hline Tele 5 & 3 & $21,42 \%$ \\
\hline Telemadrid & 2 & $14,28 \%$ \\
\hline
\end{tabular}




\begin{tabular}{|c|c|c|}
\hline TVE1 & 2 & $14,28 \%$ \\
\hline Antena3 & 2 & $14,28 \%$ \\
\hline ETB2 & 2 & $14,28 \%$ \\
\hline
\end{tabular}

Como podemos ver, Tele 5 es la que más noticias emite sobre enfermedades poco frecuentes en programas informativos, como ocurre en la mayoría de canales privados. Seguida de Telemadrid, TVE1, Antena 3 y ETB2.

\subsubsection{Análisis cualitativo}

En cuanto a los temas en los que se pueden agrupar las noticias televisivas sobre EPF durante el mes de mayo distinguimos entre:

\begin{tabular}{|c|c|c|}
\hline Tema/Asunto & Programa & Fecha \\
\hline \multirow{3}{*}{ Educación } & Abierto al Amanecer & 1 mayo \\
\hline & Telenoticias & 1 mayo \\
\hline & Audiencia Abierta & 3 mayo \\
\hline \multirow{2}{*}{ Eventos solidarios } & La Mañana & 2 mayo \\
\hline & Kirolak & 28 mayo \\
\hline \multirow{2}{*}{ El Telemaratón } & Noticias 2 & 7 mayo \\
\hline & Noticias de la Mañana & 8 mayo \\
\hline \multirow{2}{*}{$\begin{array}{l}\text { Día Mundial Esclerosis } \\
\text { Múltiple }\end{array}$} & Informativos Tele 5 & 24 mayo \\
\hline & Informativos Tele 5 & 28 mayo \\
\hline $\begin{array}{l}\text { Información sobre } \\
\text { patologías }\end{array}$ & Para Todos La 2 & 22 mayo \\
\hline \multirow{3}{*}{ Testimonios } & 8 al Día amb Josep Cuni & 15 mayo \\
\hline & Gipuqkoa a Diario & 16 mayo \\
\hline & Teknopolis & 18 mayo \\
\hline
\end{tabular}

El tema de la educación sobre EPF aparece en los medios gracias a la iniciativa organizada por la Federación Española de Enfermedades Raras (FEDER) "las enfermedades raras van al cole con Federito".

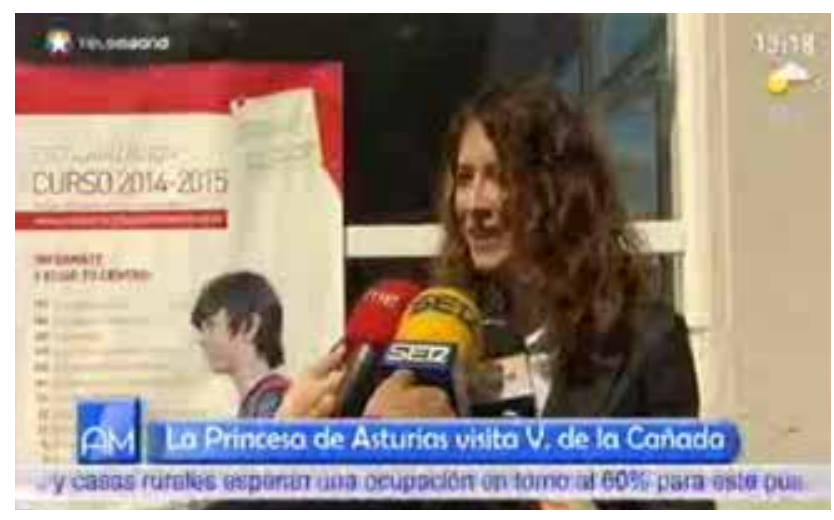

Figura 1. FEDER: "las enfermedades raras van al cole con Federito"

Lo cierto es que uno de los mayores atractivos de esta noticia es la presencia de la Princesa Letizia y del Presidente de la Comunidad de Madrid en el colegio María Moliner. En los tres programas en los que se trata se este tema, Abierto al Amanecer, Telenoticias y 
Audiencia Abierta, el contenido de la información es el mismo, tal vez proveniente de agencias y por tanto la información es ecoica, repetida, aunque la visualización de la misma difiere de un canal (Telemadrid) a otro (TVE1). Si analizamos técnicamente la información emitida por Telemadrid echamos en falta, en Abierto al Amanecer, datos que sirvan para identificar a las personas que hablan en cada momento.

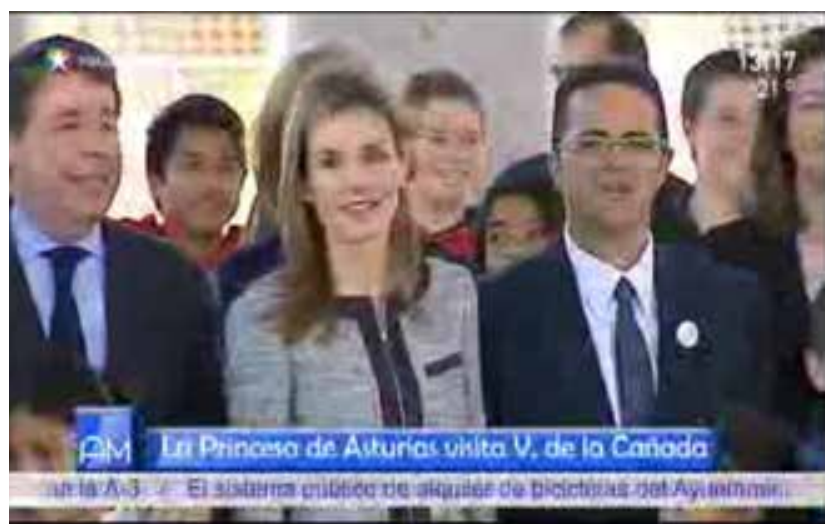

Figura 2. FEDER: "La Princesa de Asturias visita.."

Por nuestro conocimiento del tema, sabemos que interviene Alba Ancochea, subdirectora de FEDER, pero la audiencia en general no tiene por qué saberlo. Vemos a la Princesa y al Presidente de la Comunidad de Madrid, y además sabemos que son ellos porque los locutores nos lo narran, sin embargo, también aparece junto a la Princesa el Presidente de FEDER, Juan Carrión, a quien no se menciona en ningún momento. Los planos empleados son generales en los que se muestran a los escolares esperando la visita de S.A.R. La Princesa de Asturias; planos cortos para centrarse en la Princesa y demás autoridades y, planos medios o medios cortos para las personas que hablan para las cámaras.

Los eventos solidarios siguen apareciendo en los medios como vehículo principal de los familiares de personas afectadas para la consecución de fondos para investigación en este tipo de patologías.

En el programa La Mañana se hace referencia a una exposición de coches antiguos durante el mes de junio y la recaudación irá destinada a FEDER. Una de las personas que interviene para presentar este evento es Justo Herranz, portavoz de FEDER en Madrid. Pero ocurre lo mismo que en Telemadrid, sabemos que es él por nuestra experiencia investigadora y no porque haya aparecido faldón alguno identificándolo. 


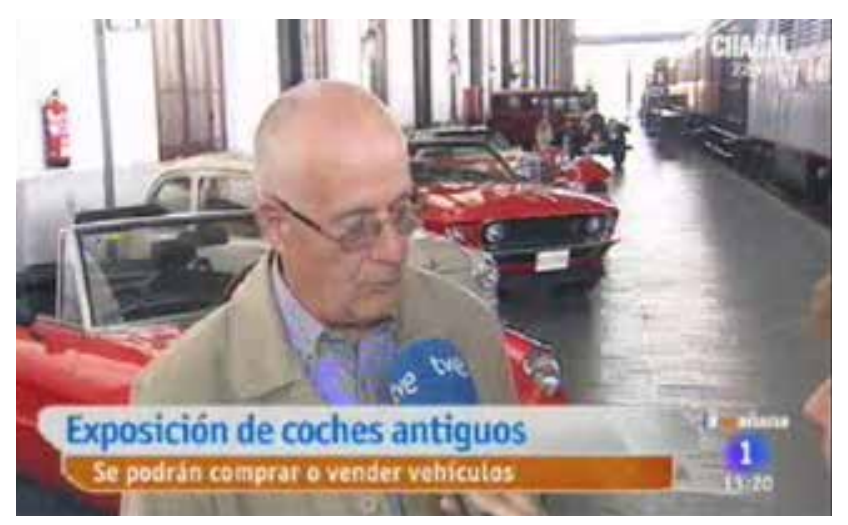

Figura 3. Programa La Mañana

Tras agradecer el hecho de que se vaya a donar lo recaudado a FEDER, Herranz habla de "57 millones de afectados en la UE (...) pero repartidas entre 7-8000 enfermedades". Justo al terminar de decir 'enfermedades' la narradora de la noticia continua diciendo "todo un reclamo en el que además se podrán encontrar piezas únicas muy difíciles de ver que salen a la calle de forma excepcional para poner el broche de oro a la ocasión". Debido a la continuidad con la que la narradora avanza en su relato, parece que en vez de estar hablando de los coches, lo estuviera haciendo de las personas que padecen una EPF. Otra de las actividades cuya recaudación irá destinada a la investigación, en este caso de una enfermedad rara en particular, síndrome de Sanfilippo, es el reto de Jose Mari Olasagasti que consiste en cortar 20 troncos de 52 centímetros. El dinero recaudado con las entradas será destinado para conseguir un tratamiento para Oier, afectado por Sanfilippo.

La cadena Antena3 se centra durante el mes de mayo en ofrecer información sobre la recaudación del Telemaratón que tuvo lugar en el mes de marzo. Aunque el Telemaratón fue organizado por FEDER, la Asociación Española de Enfermedades Neuromusculares (ASEM) y la Fundación Isabel Gemio, sólo se hace referencia a esta última: "la Fundación Isabel Gemio consigue recaudar más de dos millones de euros".

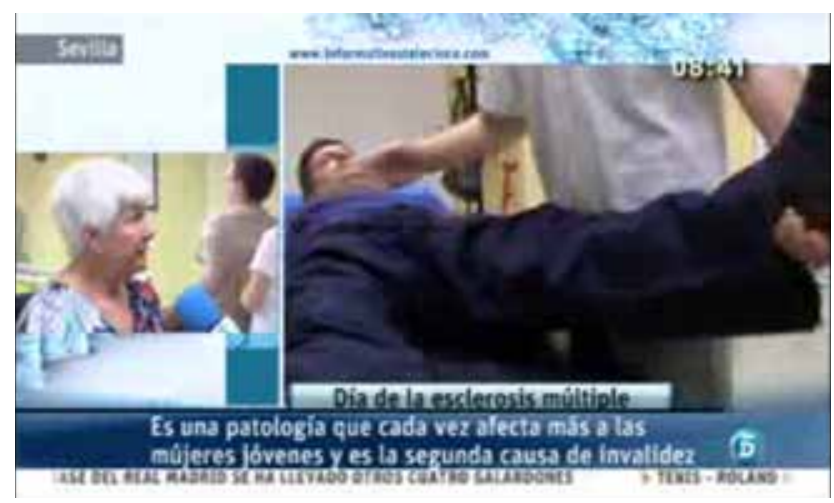

Figura 4. Cadena Antena3 
Es cierto que ella pone su imagen, pero hay que reconocer el trabajo de todos y no solo de los que se ponen cara al público. Otro dato que se ofrece es el destino de lo recaudado. Irá a investigación y a las asociaciones. Además, se habla del objetivo del telemaratón: 'dar visibilidad a los enfermos' cuando se podría decir también 'dar a conocer a la sociedad la existencia de patologías poco frecuentes'.

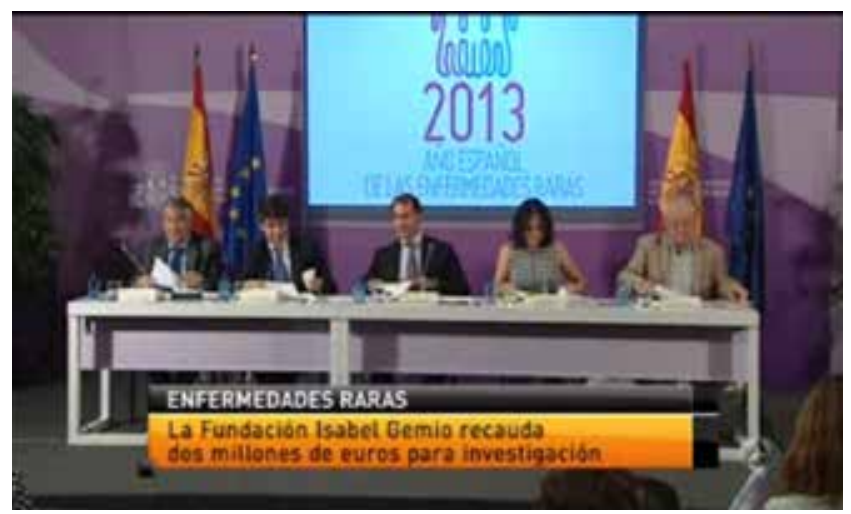

Figura 5. Día Mundial de la Esclerosis Múltiple, programa emitido en Tele5

Los impactos sobre el Día Mundial de la Esclerosis Múltiple (EM), 28 de mayo, son varios y todos emitidos en Tele5. En ninguno de ellos se habla de 'enfermedad rara o poco frecuente'. En el impacto del 24 de mayo se define como "patología que afecta al sistema nervioso central provocando inmovilidad reducida, invalidez e incluso la muerte"; en el primero del 28 de mayo como “enfermedad neurológica crónica más frecuente” y, por último, en el segundo impacto del día 28 de mayo se dice "enfermedad del sistema nervioso central que afecta a más de 2 millones de personas en el mundo". En todos los impactos televisivos se hace referencia al testimonio de la misma afectada, Carmen, quien fue diagnosticada con 30 años y lleva 14 padeciendo la enfermedad. La podemos ver con una silla de ruedas y queda claro con su testimonio todo lo que se ha dicho con anterioridad sobre los síntomas: movilidad reducida, etc. Intervienen también la Directora de la Fundación de Esclerosis Múltiple, Rosa Mirasierra, quien hace referencia a lo que supone ser diagnosticado de EM ya que suele aparecer entre los 20 y los 40 años y sobre todo en mujeres. Xavier Montalbán, Jefe de Neurología del Hospital Vall Hebrón, habla de un futuro esperanzador y un buen pronóstico aunque sigue describiendo la enfermedad como 'grave'. Es una manera de atenuar todo lo positivo que hay en sus palabras anteriores para no crear falsas expectativas a los afectados que estén escuchando esa información.

Un subtema que hemos identificado dentro de la celebración del Día Mundial de la Esclerosis Múltiple es el de los recortes en sanidad. Es durante la primera parte del segundo 
impacto del día 28 de mayo cuando se conecta con la Asociación Sevillana de esclerosis múltiple y con Águeda Alonso, Presidenta de la Federación de Asociaciones de Esclerosis Múltiples (FEDEMA).

Técnicamente hablando, los planos que se emplean son planos de detalle en los que podemos ver pacientes realizando ejercicios de fisioterapia, rehabilitación motórica, etc. que son los grandes problemas que sufren las personas afectadas por esta EPF.

El programa Para Todos La 2, es un programa como ellos mismos describen en su web "centrado en el interés social y en la participación ciudadana". El día 22 de mayo el programa trataba el tema de la educación y las nuevas tecnologías, y como ejemplo de la importancia de las TICs en nuestra vida actual escogieron una página web (www.sanfilippobcn.org) propuesta por los padres de un niño afectado por síndrome de Sanfilippo y la analizaron. La persona encargada de analizar la web define la patología de tal forma que denota poco conocimiento sobre el tema:

el síndrome de Sanfilippo C es una enfermedad degenerativa que está ocasionada o está provocada por la falta de una enzima de nuestro cuerpo que provoca trastornos, trastornos de (mira sus papeles) todo tipo entonces ellos vieron que como era una enfermad que no tiene cura, vieron que la única forma de tirar hacia adelante haciendo una asociación

Si analizamos este fragmento, tenemos que decir que no existe un síndrome llamado Sanfilippo C, sino que esta enfermedad es también conocida como Mucopolisacaridosis tipo III. Al no conocer o haber leído algo antes de grabar, habla de "trastornos de todo tipo" sin especificar nada. Y, para referirse al hecho de "tener que superar la situación de tener un hijo diagnosticado con esta enfermedad y no tener recursos" emplea la expresión "tirar hacia adelante".

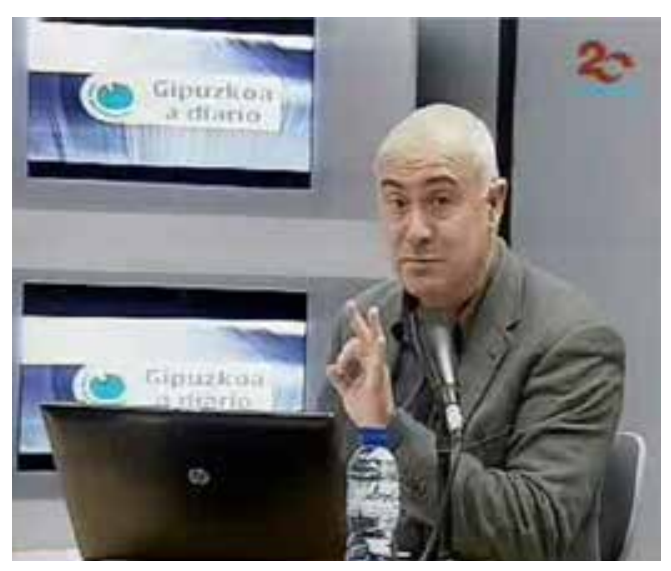

Figura 6. Programa Para Todos La 2

\footnotetext{
${ }^{1}$ http://www.rtve.es/television/20100222/para-todos-programa/319557.shtml 
Tras esta introducción se nos muestra la página web, a través de pantallazos, que han puesto en marcha los padres de Paul y se nos va describiendo el tipo de información que podemos encontrar en la misma.

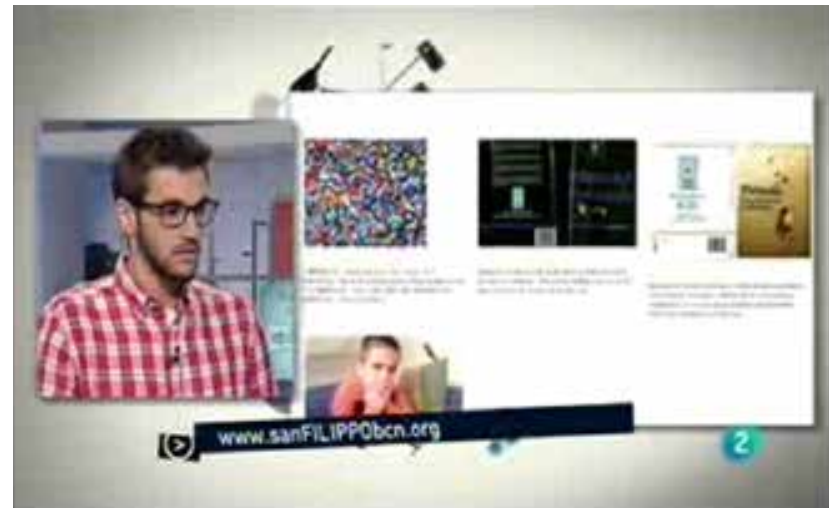

Figura 7. Programa Para Todos La 2

El último bloque temático es el de los testimonios. En 8 al Día amb Josep Cuni contamos con el testimonio de Jano, un chico afectado por esclerosis lateral amiotrófica (ELA). Él ha realizado un documental 'Yo quiero ser extraordinario y voy a ser extraordinario' y ha puesto en marcha una página web llamada Proyecto DGeneración, Conexiones con Sentido (www.dgeneracion.com). Lo cierto es que debido a que su enfermedad está algo avanzada su capacidad de habla es muy débil y cuesta un poco seguir lo que se está diciendo. Además, no podemos olvidar que se emite en 8TV, de la televisión catalana. Si lo que este chico pretendía con su participación en este programa era que la gente visualizara el documental o visitara la web, creo que lo consigue, sobre todo tras ver el pequeño fragmento que nos ofrecen en el programa.

El siguiente testimonio es el de los padres de Oier, afectado por Safilippo. El programa Gipurkoa a Diario es de una cadena local y hay que tener muy presente a la audiencia y el nivel de conocimiento que pueden tener sobre el tema. Es por ello que el presentador en lugar de ofrecer una definición técnica de la enfermedad de la que se va a hablar, prefiere dejar al padre que la defina según su conocimiento: "es un pequeño fallo que tiene el chaval en la sangre. La enzima esa no le trabaja al 100\% y la enzima es la que se encarga de echar toda la toxicidad fuera del cuerpo". También hablan de un posible tratamiento génico y pionero en EEUU pero que es “muy caro". Mencionan el precio "tres millones de euros" y al describir el tratamiento dicen que es una "simple inyección". El presentador muestra su sorpresa al escuchar el dinero y lo llega a repetir hasta tres veces e incluso mira a cámara y 
señala el tres con sus dedos como vemos en la imagen: "esa inyección es la que vale tres millones de euros...tres...tres millones de euros".

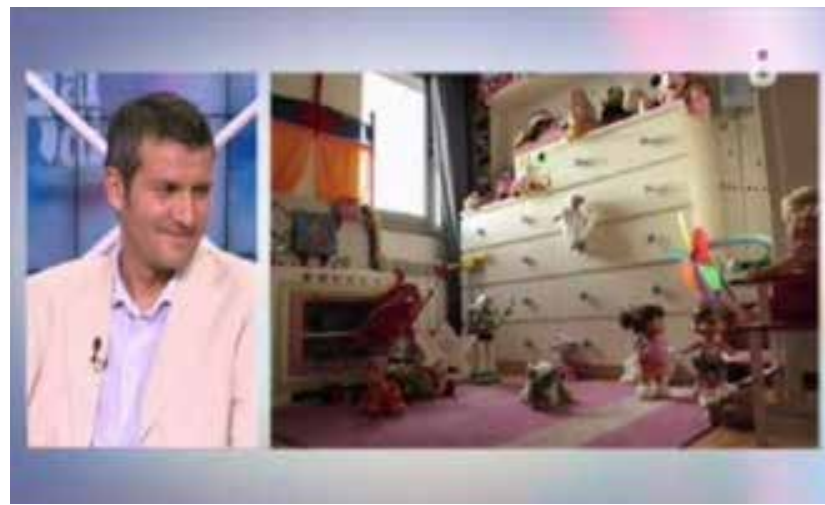

Figura 8. Programa Para Todos La 2

A esto la madre le contesta: "pero no es sólo para mi hijo, es para más niños”. Queda latente que estos padres están acostumbrados a este argumento de la rentabilidad, del 'no invertir tanto para pocos beneficiarios’ (Bañón y Fornieles, 2011: 34). También vemos cómo los padres ya tienen experiencia y dejan claro que "es un ensayo y no se sabe si va a resultar". Para que la gente que colabore no piense que después del tratamiento los niños se curan.

Tras haber hablado de para qué necesitan el dinero, pasan a presentar todos los eventos solidarios que se van a llevar a cabo para recaudar el dinero que les queda para el tratamiento ya que han recaudado hasta ahora casi un millón de euros.

El último testimonio es el emitido por la televisión vasca, ETB2, en el programa Kirolak 2. La presentadora define las enfermedades raras y dice que 'bajo ese nombre se agrupan nada más y nada menos que unas 6000 enfermedades aunque todas ellas tienen nombre propio. Son patologías identificadas y algunas muy investigadas'. Da la sensación de que sólo existen 6000 EPF y que todas ellas son conocidas, pero la realidad no es así. Luego habla de la prevalencia y se hace referencia a dos personas afectadas por dos patologías distintas. Sin embargo, sólo contamos con el testimonio de Juan José Melchisidor, afectado por ELA. A través de su testimonio conocemos cómo es el día a día de una persona afectada por una EPF como es la ELA.

\subsubsection{Conclusiones}

1. No hay emisiones en televisión en programas especializados en salud.

2. Echamos en falta la referencia a la celebración del Día Mundial del Lupus, 10 mayo.

3. La presencia de actores importantes relacionados con las EPF, como investigadores y médicos, es muy baja. 
4. Los testimonios de afectados y familiares constituyen uno de los pilares más fuertes de la presencia de las EPF en televisión durante el mes de mayo. La educación también, pero tenemos que recordar que la información ofrecida es a veces ecoica (Cruz y Requena, 2013: 210) y no original como la provista por los testimonios.

5.3. El discurso de la televisión sobre las EPF. Análisis de un ejemplo de junio de 2014 (Por Juan Manuel Arcos Urrutia, Universidad de Almería, CySOC)

\subsubsection{Corpus}

El corpus objeto de estudio está compuesto por los fragmentos audiovisuales de diferentes programas televisivos, pertenecientes a cadenas tanto públicas como privadas de ámbito nacional, regional y local, que informaron sobre las enfermedades poco frecuentes (EPF) durante el mes de junio de 2014. En total contamos con 20 impactos.

\subsubsection{Análisis cuantitativo}

En la Tabla 1 presentamos las cadenas tanto públicas como privadas de ámbito nacional, regional o local, el número de noticias y el porcentaje.

Telemadrid es la cadena que más se hace eco de noticias que tratan las EPF, en total 5 noticias, es decir un 25\% del total. El contenido de estas noticias hace referencia a la recepción que Felipe VI tuvo con los representantes de las asociaciones de nuestro país. La Federación Española de Enfermedades Raras (FEDER) estuvo presente en este acto y, además, se menciona en estas noticias.

Tabla 1. Noticias por cadenas en junio

\begin{tabular}{|c|c|c|}
\hline CADENA TV & NOTICIAS & $\mathbf{( \% )}$ \\
\hline TELEMADRID & 5 & 25 \\
\hline TVE1 & 4 & 20 \\
\hline BTV & 3 & 15 \\
\hline CANAL SUR & 2 & 10 \\
\hline LA SEXTA & 2 & 10 \\
\hline 8 TV & 1 & 5 \\
\hline CUATRO & 1 & 5 \\
\hline TBILBAO & 1 & 5 \\
\hline TV GALLEGA & 1 & 5 \\
\hline TOTAL & 20 & 100 \\
\hline
\end{tabular}

A continuación, en la Tabla 2 presentamos las patologías que se mencionan, el medio y en el programa en el que lo hacen y la fecha. Debemos comentar que las patologías sensibilidad química múltiple o electrosensibilidad y síndrome de Moebius aparecen dos veces en el corpus. 
Respecto a la primera, la noticia aparece dividida en dos partes. En primer lugar, la presentadora introduce el tema que se va a tratar $y$, seguidamente, tenemos el reportaje completo en el que se explica cómo es la sala blanca para aislar a estos pacientes de ondas provocadas por los aparatos electrónicos a los que estos pacientes tienen problemas graves en su salud provocados por las ondas electromagnéticas, como por ejemplo, zonas wifi, ciertos productos químicos.

Respecto a la enfermedad de Moebius, aunque esta noticia aparezca dos veces, es una reproducción total en los dos informativos de La Sexta. Se produce lo que Bañón y Fornieles llamaron discurso ecoico (2011b: 20), que consiste en la repetición de informaciones, sin apenas intervención del medio en la edición específica de los contenidos. Añadimos, también, que aunque el Síndrome de Wolf-Hirshhorn sólo se menciona una vez en todo el corpus, son tres las piezas informativas las que tratan esta patología.

Tabla 2. Patologías y programas

\begin{tabular}{|l|c|c|}
\hline Patología & $\begin{array}{c}\text { Medio } \\
\text { (programa) }\end{array}$ & Fecha \\
\hline $\begin{array}{l}\text { Síndrome de } \\
\text { Rubinstein Taybi }\end{array}$ & $\begin{array}{c}\text { BV } \\
\text { (Noticias Nit) }\end{array}$ & 07.06 .2014 \\
\hline $\begin{array}{l}\text { Síndrome de } \\
\text { Wolf-Hirshhorn }\end{array}$ & $\begin{array}{c}\text { TVE1 } \\
\text { (La Mañana) }\end{array}$ & 12.06 .2014 \\
\hline Síndrome de Moebius & $\begin{array}{c}\text { La Sexta } \\
\text { (La Sexta Noticias) }\end{array}$ & 14.06 .2014 \\
\hline $\begin{array}{l}\text { Sensibilidad química } \\
\text { múltiple o } \\
\text { electrosensibilidad }\end{array}$ & $\begin{array}{c}\text { BV } \\
\text { (Conexió Barcelona) }\end{array}$ & 17.06 .2014 \\
\hline $\begin{array}{l}\text { Síndrome de fatiga } \\
\text { crónica }\end{array}$ & $\begin{array}{c}\text { BV } \\
\text { (Conexió Barcelona) }\end{array}$ & 17.06 .2014 \\
\hline $\begin{array}{l}\text { Esclerosis lateral } \\
\text { amiotrófica (ELA) }\end{array}$ & $\begin{array}{c}\text { TVE1 } \\
\text { (Informativo territorial) }\end{array}$ & 20.06 .2014 \\
\hline $\begin{array}{l}\text { LAM } \\
\text { (linfangioleiomiomatosis) }\end{array}$ & $\begin{array}{c}\text { 8TV } \\
\text { (8 Al día amb Josep Cuni) }\end{array}$ & 20.06 .2014 \\
\hline
\end{tabular}

\subsubsection{Análisis cualitativo}

En cuanto a los temas que se tratan en las 20 noticias del mes de junio destacan los siguientes:

Tabla 3. Temas por programa

\begin{tabular}{|l|c|c|}
\hline Tema/Asunto & Programa & Fecha \\
\hline \multirow{3}{*}{ Estafa familias } & Telexornal (TVGAL) & 11.06 .2014 \\
\cline { 2 - 3 } & España Directo (TVE1) & 12.06 .2014 \\
\cline { 2 - 3 } & La Mañana (TVE1) & 12.06 .2014 \\
\cline { 2 - 3 } & La Mañana (TVE1) & 25.06 .2014 \\
\hline \multirow{4}{*}{ Actos solidarios } & Diario local (TBilbao) & 05.06 .2014 \\
\cline { 2 - 3 } & Noticias 1 (Canal Sur) & 08.06 .2014 \\
\cline { 2 - 3 } & Deportes 1 (Canal Sur) & 09.06 .2014 \\
\cline { 2 - 3 } & Telenoticias 2 (Telemadrid) & 12.06 .2014 \\
\hline & BV noticies nit (BTV) & 07.06 .2014 \\
\hline
\end{tabular}




\begin{tabular}{|c|c|c|}
\hline $\begin{array}{c}\text { Información sobre una EPF } \\
\text { específica }\end{array}$ & $\begin{array}{c}\text { La sexta noticias 14 horas/20 } \\
\text { horas (La Sexta) }\end{array}$ & 14.06 .2014 \\
\cline { 2 - 3 } & Connexio Barcelona (BV) & 17.06 .2014 \\
\cline { 2 - 3 } & 8 al día amb Josep Cuní (8TV) & 20.06 .2014 \\
\hline Día Internacional de la ELA & Informativo territorial (TVE1) & 20.06 .2014 \\
\hline $\begin{array}{c}\text { Reunión Rey Felipe VI con las } \\
\text { organizaciones sociales }\end{array}$ & Telenoticias 1-2 (Telemadrid) & 24.06 .2014 \\
& & 25.06 .2014 \\
\hline
\end{tabular}

La estafa que llevó a cabo una mujer de Toledo a varias familias de Galicia con niños afectados por una EPF ha sido un tema muy repetido en nuestro corpus en un total de cuatro noticias. Es una situación dramática que le sucedió a estas familias por dos motivos. En primer lugar, ya es muy duro tener a un hijo o una hija con una grave discapacidad provocada una por EPF para que, además, haya personas que se aprovechen de esta desgracia para lucrarse ella misma.

Quizás el tema más importante de todos sea el de la recaudación de fondos para poder financiar los costosos tratamientos de este tipo de patologías. Para ello, son las propias familias las que deben las que debe tomar la iniciativa para poder organizar estos eventos. Estos actos solidarios están formados, por ejemplo, por partidos de fútbol benéficos, carreras solidarias, desfiles de moda o exposiciones de coches antiguos, cuya recaudación irá destinada a la financiación de proyectos de investigación de alguna patología en cuestión. En las noticias de junio, por ejemplo, el ex futbolista Capi ha organizado un partido benéfico para recaudar fondos para un niño afectado por una patología poco frecuente. También, destaca la carrera solidaria organizada por el Observatorio de Enfermedades Raras (OBSER) junto al Colegio La Salle Virgen del Mar que se celebró en Almería el pasado 8 de junio. A continuación, hemos realizado un análisis multimodal de esta noticia en cuestión.

En cuanto a la noticia sobre el Día Internacional de la Esclerosis Lateral Amiotrófica (ELA) nos parece muy poca información. Solamente tenemos un impacto a pesar de ser una enfermedad bastante conocida.

La Federación Española de Enfermedades Raras (FEDER) ha aparecido en 5 ocasiones mencionada en las noticias de televisión. En una primera noticia del Diario local de la televisión vasca, TBilbao, se celebró un desfile de ropa y con el dinero recaudado iba destinado a FEDER. La noticia del rey Felipe VI y su recepción a las organizaciones sociales de nuestro país fue la pieza informativa que más eco se hizo de FEDER. Al tratarse de una noticia en la que apareció en el informativo de Telemadrid del mediodía y de la noche del día 24 y 25 de junio, el discurso ecoico está presente, es decir, existe una repetición total de esta información. 
Para este trabajo, como decíamos, nos pareció relevante analizar audiovisualmente la noticia de la carrera solidaria por las Enfermedades Poco Frecuentes del 8 de junio de 2014, emitida en Canal Sur, principalmente, por dos motivos. En primer lugar, era una actividad organizada por el propio OBSER y, en segundo lugar, era la primera carrera que se realizaba en Almería con este perfil.

Nuestro análisis se ha basado en un estudio multimodal en el que estudiaremos, principalmente, y nos hemos detenido en la información visual (planos), también hemos atendido a la información verbal (palabras y expresiones, por ejemplo). En definitiva, es importante analizar las relaciones de conjunto entre estas dos dimensiones. Para ello hemos seguido la metodología que Bañón y Arcos (2014) utilizaron para analizar un corpus de noticias sobre inmigración en Andalucía.

Nuestro objetivo ha sido identificar todos los planos de la noticia de la carrera solidaria por las Enfermedades Poco Frecuentes y hacer una primera selección de todos aquellos planos que tengan una función más claramente focalizadora: primeros planos (PP), primerísimos primeros planos (PPP) y planos detalle (PD).

Tabla 4. Análisis de la pieza de TV

\begin{tabular}{|c|c|c|c|c|}
\hline \multicolumn{5}{|c|}{$\begin{array}{l}\text { 08.06.2014. NOTICIAS1 (CANAL SUR) } \\
\text { Carrera solidaria EPF en Almería }\end{array}$} \\
\hline $\mathbf{N}^{\circ}$ & PLANO & MOVIMIENTO & TIEMPO & TEXTO \\
\hline 1 & $\mathrm{PP}$ & FIJO & 00:02-00:07 & $\begin{array}{l}\text { Alrededor de tres millones de personas } \\
\text { padecen en nuestro país enfermedades } \\
\text { raras o poco frecuentes. Esta mañana en... }\end{array}$ \\
\hline 2 & $\mathrm{PM}$ & FIJO & 00:08-00:09 & $\begin{array}{l}\text {..Almería se ha celebrado la primera } \\
\text { carrera... }\end{array}$ \\
\hline 3 & GPG & $\begin{array}{l}\text { Panorámica izquierda- } \\
\text { derecha }\end{array}$ & $00: 10-00: 16$ & $\begin{array}{l}\text {...solidaria por las enfermedades raras, que } \\
\text { afecta a un } 7 \% \text { de la población. } 1400 \\
\text { personas entre niños y mayores... }\end{array}$ \\
\hline 4 & PG & FIJO & $00: 17-00: 18$ & $\begin{array}{l}\text {...han participado en esta carrera para } \\
\text { hacer visibles... }\end{array}$ \\
\hline 5 & PG & $\begin{array}{l}\text { Panorámica derecha- } \\
\text { izquierda }\end{array}$ & $00: 19-00: 25$ & $\begin{array}{l}\text {...unas enfermedades que son poco } \\
\text { conocidas y que en muchos casos no } \\
\text { tienen cura. Los organizadores han } \\
\text { agradecido ... }\end{array}$ \\
\hline 6 & PG & FIJO & $00: 25-00: 28$ & $\begin{array}{l}\text {...el apoyo recibido y han destacado el } \\
\text { papel que tiene la provincia de... }\end{array}$ \\
\hline 7 & GPG & $\begin{array}{l}\text { Panorámica derecha- } \\
\text { izquierda }\end{array}$ & $00: 29-00: 35$ & $\begin{array}{l}\text {...Almería en la lucha contra estas } \\
\text { enfermedades. En la Universidad de } \\
\text { Almería se encuentra el Observatorio } \\
\text { Nacional de las Enfermedades Raras. }\end{array}$ \\
\hline
\end{tabular}

La noticia está compuesta por un total de 7 planos, distribuidos de la siguiente manera: 1 PP, 1 PM, 3 PG y 2 GPG. 
El plano general (PG) y el gran plano general (GPG) cubren más del 70\% de la información. También es cierto que este tipo de planos sirven para situar la acción principal. A continuación, destacan los planos medios (PM), 1 en total, cuya función principal podría ser la identificación de los principales actores de las noticias. En nuestra noticia, en el PM aparece la presencia del público que acudió a ver la carrera. El resto de planos quedan muy por debajo en número y porcentaje, pero son los que nos interesan especialmente, como dijimos más arriba, ya que en ellos reside, en principio, una mayor capacidad de focalización. Hay en total 1 PP y es precisamente de la presentadora del informativo.

Aunque la duración de la noticia no es muy extensa, unos 40 segundos aproximadamente, la estructura textual y temática es muy compleja. En un primer momento, la presentadora explica que son unas enfermedades que afectan a tres millones de personas. Más adelante, nos indica el porcentaje de personas afectadas por una EPF. Este dato es de un $7 \%$.

También se mencionan a estas enfermedades como 'raras' o 'poco frecuentes'. En el rótulo que aparece durante la noticia se puede leer: 'primera carrera solidaria por las enfermedades raras'. El término más extendido para este tipo de patologías es el de 'enfermedad rara', aunque cada vez más está apareciendo más en los medios la propuesta de 'enfermedades poco frecuentes', que se acuñó precisamente también en Almería con motivo del I Congreso Escolar sobre Enfermedades Poco Frecuentes en enero de 2014. A partir de esa fecha, los propios periodistas optaron por utilizar esta nueva forma en lugar de enfermedad rara, debido a la estigmatización negativa que conlleva para estos pacientes este uso. Sigue abierto, por lo tanto, el debate sobre si el adjetivo 'rara' no es el más conveniente dadas las evidentes connotaciones negativas asociadas en español.

Además de la forma utilizada por la presentadora para nombrar a estas patologías, se menciona el objetivo principal de la carrera: hacer visible a la sociedad estas enfermedades. En el cuerpo de la noticia también se presentan algunas características de estas enfermedades, como por ejemplo, la ausencia de cura o el poco conocimiento que tiene la sociedad sobre estas patologías. Finalmente, se menciona que en la Universidad de Almería se encuentra el Observatorio de las Enfermedades Raras. El mero hecho de que se nombre el OBSER en esta pieza ya es un punto muy importante.

Cabe destacar, asimismo, que en todo el discurso de la representación de las enfermedades poco frecuentes en los medios, la presencia de una metáfora muy extendida en este tema. Es aquella que hace alusión a la batalla, a partir del concepto de 'lucha'. Sus 
protagonistas, por lo tanto, son representados como luchadores incansables. Estos mensajes aparecen en el discurso de los periodistas. En la noticia de la carrera solidaria se menciona también esta lucha: 'Los organizadores han agradecido el apoyo recibido y han destacado el papel que tiene la provincia de Almería en la lucha contra estas enfermedades'.

\subsubsection{Conclusiones}

1. Durante el mes de junio de 2014 aparecieron 20 impactos en diferentes programas televisivos pertenecientes a cadenas tanto públicas como privadas de ámbito nacional, regional y local que informaron sobre enfermedades poco frecuentes.

2. El número de noticias de televisión es muy bajo en comparación con el número de impactos de prensa durante el mes de junio de 2014. En televisión hemos anotado 20 impactos de televisión, mientras que tenemos 347 noticias de prensa.

3. Telemadrid es la cadena que más se hace eco de noticias que tratan las EPF durante el mes de junio, con un total de 5 piezas informativas.

4. Las patologías poco frecuentes que se mencionan en las noticias son: Síndrome de Rubinstein Taybi, Síndrome de Wolf-Hirshhorn, Síndrome de Moebius, Sensibilidad química múltiple, electrosensibilidad, Síndrome de fatiga crónica, Esclerosis lateral amiotrófica (ELA) y linfangioleiomiomatosis (LAM).

5. Los temas que se narran en las noticias hacen mención a la estafa que una mujer de Toledo a varias familias de Galicia, distintos actos solidarios, como un partido de fútbol benéfico, carreras solidarias, desfiles de moda o exposiciones de coches antiguos, cuya recaudación irá destinada a la financiación de proyectos de investigación de alguna patología en cuestión.

6. El 21 de junio fue el Día Mundial de la ELA. Solamente tenemos un impacto. Nos parece muy poca información la que se recogió en los medios a pesar de ser una enfermedad bastante conocida.

7. En cuanto a la presencia de FEDER en las noticias de televisión, son 5 las piezas informativas en las que se menciona a la Federación Española de Enfermedades Raras.

8. Hemos realizado un análisis multimodal específico de la noticia de la carrera solidaria por la EPF organizada por el Observatorio de las Enfermedades Raras (OBSER) y por el Colegio La Salle Virgen del Mar de Almería. 
9. La noticia está compuesta por un total de 7 planos, distribuidos de la siguiente manera: 1 PP, 1 PM, 3 PG y 2 GPG.

10. Aunque la duración de la noticia no es muy extensa, unos 40 segundos aproximadamente, la estructura textual y temática es muy compleja.

11. Al hablar sobre salud y enfermedad, las metáforas siempre encuentran un lugar en las narraciones. En la noticia que hemos analizado aparece la lucha como punto importante ante la enfermedad.

\section{Referencias}

Bañón, A.M. y Fornieles, J. (2011). Communication and Rare Diseases: Contextualisation. En Bañón, A. M., Fornieles, J., Solves, J. A. y Rius, I. (coords.). Communication Strategies and Challenges for Rare Diseases: Medical Research as a Referent. CIBERER.

Bañón, A. M. y Urán, I. (2011). La representación discursiva de las enfermedades raras y de los afectados: los nombres y las cifras. En Bañón, A. M., Fornieles, J., Solves, J. A. y Rius, I. (coords.). Desafios y estrategias comunicativas de las enfermedades raras: la investigación médica como referente (pp. 151-164). CIBERER.

Bañón, A. M. y Requena, S. (2014). La representación de las enfermedades poco frecuentes en el discurso periodístico español. Propuestas para el análisis. Sociocultural Pragmatics, 2(2), pp. 1-42.

Catalano, T. y Waugh, L.R. (2013). The ideologies behind newspaper crime reports of Latinos and Wall Street/CEOs: A critical analysis of metonymy in text and image. Discourse Studies, 10(4), pp. 406-426. http://dx.doi.org/10.1080/17405904.2013.813774

Cruz, O. y Requena, S. (2013). El Día de las Enfermedades Raras en las noticias televisivas. Análisis crítico de su representación audiovisual. Discurso \& Sociedad, 7(1), pp. 200223.

Delgado, R. (1993). On telling stories in school: A reply to Farber and Sherry. V anderbilt Law Review, 46, pp. 665-676.

Erdmans, M. P. (1999). Portraits of emigration: Sour mild and honey in the promised land. Sociological Inquiry, 69(3), pp. 337-363. http://dx.doi.org/10.3102/0091732x022001195

Espino, M. M. (2008). Master narratives and counter-narratives: an analysis of Mexican American life stories of oppression and resistance along journeys to the doctorate. Tesis doctoral. University of Arizona. Recuperado de: http://arizona.openrepository.com/arizona/bitstream/10150/195733/1/azu etd 2711_sip1_m.pdf (15-05-2015).

Kress, G. R. y van Leeuwen, T. (2006). Reading Images: The Grammar of Graphic Design (2nd ed.). London: Routledge.

Tate IV, W. F. (1997). Critical race theory and education: History, theory, and implications. Review of Research in Education, 23, pp. 191-243. http://dx.doi.org/10.3102/0091732x022001195

Yosso, T. J. (2006). Critical race counterstories along the Chicana/ Chicano educational pipeline. New York: Routledge. 
Josep Solves Almela es Licenciado en Ciencias de la Información en el CEU de Valencia (Primera promoción de Periodismo: 1986-1991). Doctor en Ciencias de la Comunicación por la UAB (1999) con la tesis titulada "El pensament nacionalista valencià, una discussió sobre la identitat". Su labor docente se ha desarrollado en las asignaturas Sociología General y del área de Teoría de la Comunicación y Sociología. Por otra parte, su tarea investigadora se ha centrado en los aspectos discursivos de los medios (sobre todo en relación con el nacionalismo, la identidad cultural y la comunicación política). Ha sido miembro de la Comisión organizadora del "Seminario sobre Medios de Comunicación sin Barreras" desde 1997 y que dirige desde 2004. En los últimos años, se ha especializado en la cuestión de los medios y la discapacidad.

Josep Solves Almela holds a $\mathrm{PhD}$ in Communication Sciences from the Autonomous University of Barcelona (1999) and Bachelor of Information Science from the Polytechnic University of Valencia (1991). He is lecturer at the Faculty of Social Sciences and Communication at the University CEU Cardenal Herrera, where he teaches in the area of Communication Theory and Sociology. In 2005 he established the Research Group on Disability and Communication (GIDYC) at CEU Cardenal Herrera University where he has led research projects on the Spanish media coverage of the Paralympic Games and the study on the media coverage of disability in Valencia. He coordinated the book Tratamiento de los Juegos Paralímpicos de 2008 en los medios españoles (Madrid: CERMI, 2012).

Antonio Miguel Bañón Hernández es Doctor en Filología Hispánica por la Universidad de Murcia y, en la actualidad, es profesor de la Universidad de Almería. Dirige el grupo de investigación ECCO (Estudios Críticos sobre la Comunicación). Es coordinador científico del Centro de Investigación en Comunicación y Sociedad (CySOC). Y director técnico del Observatorio en Enfermedades Raras (OBSER). Es autor de más de un centenar de trabajos sobre sus dos líneas preferentes de investigación: el análisis del discurso oral y el análisis crítico del discurso.

Miguel Antonio Hernández Bañón holds a $\mathrm{PhD}$ in Hispanic Philology from the University of Murcia and currently teaches at the University of Almería. Directs the research group ECCO (Critical Studies in Communication). It is scientific coordinator of the Center for Research in Communication and Society (CySOC). And technical director of the Observatory on Rare Diseases (OBSER). He has authored more than one hundred works on two preferred areas of research: the analysis of oral discourse and critical discourse analysis. 